\title{
Diet and risk of stomach cancer
}

Citation for published version (APA):

Botterweck, A. A. M. (2000). Diet and risk of stomach cancer. [Doctoral Thesis, Maastricht University]. UM. https://doi.org/10.26481/dis.20001004ab

Document status and date:

Published: 01/01/2000

DOI:

10.26481/dis.20001004ab

Document Version:

Publisher's PDF, also known as Version of record

\section{Please check the document version of this publication:}

- A submitted manuscript is the version of the article upon submission and before peer-review. There can be important differences between the submitted version and the official published version of record.

People interested in the research are advised to contact the author for the final version of the publication, or visit the DOI to the publisher's website.

- The final author version and the galley proof are versions of the publication after peer review.

- The final published version features the final layout of the paper including the volume, issue and page numbers.

Link to publication

\footnotetext{
General rights rights.

- You may freely distribute the URL identifying the publication in the public portal. please follow below link for the End User Agreement:

www.umlib.nl/taverne-license

Take down policy

If you believe that this document breaches copyright please contact us at:

repository@maastrichtuniversity.nl

providing details and we will investigate your claim.
}

Copyright and moral rights for the publications made accessible in the public portal are retained by the authors and/or other copyright owners and it is a condition of accessing publications that users recognise and abide by the legal requirements associated with these

- Users may download and print one copy of any publication from the public portal for the purpose of private study or research.

- You may not further distribute the material or use it for any profit-making activity or commercial gain

If the publication is distributed under the terms of Article $25 \mathrm{fa}$ of the Dutch Copyright Act, indicated by the "Taverne" license above, 


\section{Diet and risk of stomach cancer}

Anita Botterweck 
CIP - DATA KONINKLIJKE BIBILIOTHEEK, DEN HAAG

(C) Botterweck, Anita Aldegonda Mathea

Diet and risk of stomach cancer, Anita Aldegonda Mathea Botterweck

Thesis Maastricht University - With summary in Dutch.

ISBN 90 - 5681 - 080 - 4

Subjects headings: diet - stomach cancer - epidemiology 


\section{Diet and risk of stomach cancer}

\section{PROEFSCHRIFT}

ter verkrijging van de graad van doctor

aan de Universiteit Maastricht,

op gezag van de Rector Magnificus, Prof. dr. A.C. Nieuwenhuijzen Kruseman volgens het besluit van het College van Decanen,

in het openbaar te verdedigen op woensdag 4 oktober 2000 om 14.00 uur

door

Anita Aldegonda Mathea Botterweck 


\section{Promotor}

Prof. dr. ir. P.A. van den Brandt

\section{Co-promotor}

Dr. ir. R.A. Bausch-Goldbohm (TNO Zeist)

\section{Beoordelingscommissie}

Prof. dr. ir. R.W. Stockbrügger (voorzitter)

Prof. dr. J.W. Arends

Prof. dr. A. Bast

Prof. dr. ir. F.E. van Leeuwen (Vrije Universiteit Amsterdam)

Dr. ir. P. van 't Veer (Wageningen Universiteit)

\section{piuting}

The study presented in this thesis was performed at the Nutrition and Toxicology Research Institute Maastricht (NUTRIM), which participates in the Graduate School VLAG-2 (Food Technology, Agrobiotechnology, Nutrition and Health Sciences) accredited by the Royal Netherlands Academy of Arts and Sciences. 


\section{Contents}

Chapter

page

1 Introduction

2 A prospective cohort study on vegetable and fruit consumption and stomach cancer risk in the Netherlands

3 Vitamins, carotenoids and dietary fiber and stomach cancer risk: results from a prospective study after 6.3 years of follow-up

4 Intake of nitrate and nitrite and the risk of gastric cancer: a prospective study

5 Salt intake, consumption of cured meat, use of refrigerator and stomach cancer incidence: a prospective cohort study

6 Intake of butylated hydroxyanisole and butylated hydroxytoluene and stomach 101 cancer risk: results from analyses in the Netherlands Cohort Study

7 Trends in incidence of adenocarcinoma of the oesophagus and gastric cardia in ten European countries

$8 \quad$ General discussion

Summary

Samenvatting

Dankwoord

About the author 



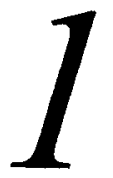

Introduction 


\section{Descriptive epidemiology}

Incidence rates of stomach cancer have been declining almost everywhere in the world in the past decades $(1,2)$ Nevertheless, stomach cancer still is the second most frequent cancer in the world with estimated 798,300 new cases per year in 1990, or $9.9 \%$ of the total incident cancer cases (3). The male-to-female sex-ratio of risk for stomach cancer is approximately two (4). Stomach cancer shows a wide geographic variation in risk. The incidence rates in high risk areas are approximately 10 times higher than in low risk areas. Standardized to the world population, the age-adjusted annual incidence rates in 1990 were highest in Japan ( 77.9 per 100,000 for men and 33.3 per 100,000 for women) but high rates were also recorded in Korea and Mongolia ( 54.3 for men, 22.8 for women), China (43.6 for men, 19.0 for women) and the former USSR and eastern Europe (36.3 for men, 16.9 for women). In western Europe, age-adjusted incidence rates were moderate (16.4 and 8.2 for men and women, respectively). Low incidence rates were recorded in other western countries such as the USA and Canada (8.4 for men and 4.0 for women) and Australia and New Zealand (10.8 for men and 4.9 for women)(3,4).

\section{Stomach cancer in the Netherlands}

In the Netherlands, the age-adjusted stomach cancer incidence rate, standardized to the world population, was 15.2 for men and 6.0 for women in 1990 (5). Stomach cancer still is a common cancer in the Netherlands. In a recent report of the Netherlands Cancer Registry, stomach cancer ranked seventh for men and ninth for women (1995) which was $4.4 \%$ and $2.7 \%$ of all registered tumors, respectively (6). In 1995, 1449 male and 812 female cases were newly diagnosed with stomach cancer and in that same year 1131 men and 740 women died of stomach cancer (6).

\section{Time trends of stomach cancer}

Characteristic for stomach cancer is the striking decline in mortality in the past decades almost everywhere in the world. The rate of decline is on average $2-4 \%$ per year. However, the rate of decline and the time of onset varies between areas (4). The decline in mortality parallels the decline in incidence because only a slight improvement in the survival rates has been reported. The overall five-year survival among American patients has been increased from 11\% (1960-1963) to $16 \%$ (1979-1984) (7). In the Netherlands, in the period 1978-1982, these numbers were $12 \%$ en $19 \%$ for men and women, respectively (IKZ/SOOZ-Cancer Registry).

\section{Pathologic classification and precursor lesions}

Neoplasms occurring in the stomach are generally classified according to the International Classification of Diseases for Oncology (ICD-O), that divides malignant neoplasms of the stomach according to histologic subtypes or anatomic subsites. Over $95 \%$ of malignant stomach neoplasms are adenocarcinomas $(7,8)$, and generally when the term stomach or gastric cancer is used, it refers 
to adenocarcinomas of the stomach. The remaining $5 \%$ consists of lymphomas, leiomyosarcomas, carcinoid tumors, carcinosarcomas and squamous cell carcinomas (8). Most tumors occur in the antral/pyloric region (about 50\%) whereas tumors of the body and cardia of the stomach are less frequently affected.

Another classification proposed by Laurén in 1965 divides adenocarcinomas of the stomach into the intestinal, diffuse, mixed and unclassified type (9). The two most common types are the intestinal and the diffuse type. This classification has both histological and prognostic relevance, but it is supposed to have epidemiological and etiological relevance too. The intestinal type is more frequent in populations with high or intermediate stomach cancer rates, in males and older age groups. The diffuse type is more common in low risk populations, is equally frequent in males and females but is more frequent in younger age- groups and has a worse prognosis than the intestinal type. The decline of stomach cancer appears to be mostly due to the decline in the intestinal type, which suggest that the intestinal type is etiologically different from the diffuse type $(10,11)$. However, evidence in favour of this hypothesis is not very convincing $(12,13)$.

Chronic atrophic gastritis and its associated lesion, intestinal metaplasia, are the precursors most closely related to the intestinal type of stomach cancer $(14,15)$. Various other pathological conditions, e.g., pernicious anaemia, gastric polyps and gastric ulcer have been linked to stomach cancer, but it is largely unknown whether these conditions are precursors of stomach cancer or premalignant conditions (7).

\section{A model for carcinogenesis}

An etiologic model of gastric carcinogenesis was first described by Correa in 1975 (16) and subsequently updated in 1992 (17). This model describes a long-term and multistage development of pathological changes in the stomach in which normal mucosa is transformed into superficial gastritis, atrophic gastritis, intestinal metaplasia, dysplasia and finally carcinoma (intestinal type of cancer) (figure 1). In each stage, several environmental factors, often acting simultaneously, are involved.

The initial stages of chronic gastritis and atrophy, have been linked to excessive salt intake and infection with Helicobacter pylori. The intermediate stages of metaplasia and dysplasia are associated with nitrate and nitrite, factors that may foster intra-gastric nitrosation. Nitrate and nitrite are precursor compounds in the endogenous formation of $\mathrm{N}$-nitroso compounds which act as gastric carcinogens in this model. The formation of $\mathrm{N}$-nitroso compounds is probably catalyzed by anarobic bacteria which frequently colonize stomachs with intestinal metaplasia. Antioxidant compounds, such as vitamin $C, \beta$-carotene and vitamin $E$ inhibit nitrosation. Once the cell is transformed into a cancer cell, other nutritional factors may further promote or inhibit metastatic tumor growth (17). 


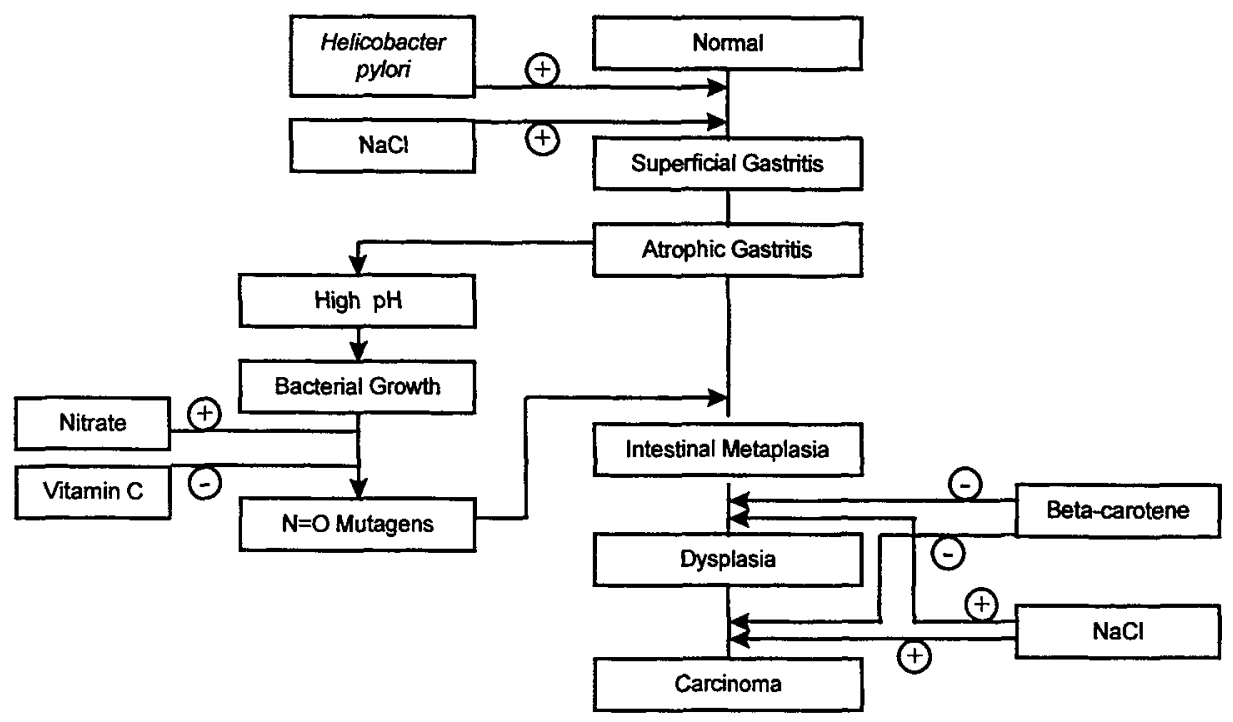

FIGURE 1: A human model of gastric carcinogenesis (intestinal type)

\section{The rise in incidence of gastric cardia cancer}

Since the $1970 \mathrm{~s}$, incidence rates for adenocarcinomas of the gastric cardia (the proximal part of the stomach) and also adenocarcinomas of the esophagus (located mainly in lower third of the esophagus) have been rising in many parts of western Europe and the United States (18-20). Meanwhile, the incidence rate for adenocarcinomas of the distal part of the stomach has been decreasing $(3,14,21)$ and the rate of squamous cell carcinoma of the esophagus (which is the dominant cell type of esophageal cancer) has remained relatively stable in western countries (22-24).

Before the increase in incidence of the adenocarcinomas of the cardia and the esophagus, $10 \%$ of the gastric cancers involved the cardia region (7) and about $17 \%$ of all esophageal cancers were adenocarcinomas (18). In countries with a rising incidence of adenocarcinomas of the gastric cardia and the esophagus, cardia cancers now constitute approximately one third of all stomach cancers (25) and adenocarcinomas constitute $30-50 \%$ of all esophageal cancers $(5,26)$.

Besides the difference in incidence trends between adenocarcinomas of the gastric cardia and the esophagus, adenocarcinomas of the distal stomach and squamous cell carcinomas of the esophagus also differences with regard to the male-to-female ratio (18), the ratio of rates among whites to blacks in the USA $(18,27)$ and geographical distribution (28) between the three types of cancer are described. This may suggest that different etiologic factors are involved in the development of these three types of cancer. Recent epidemiological studies seem to support this hypothesis (29-31). However, in the same period of the rise in incidence of adenocarcinomas of the esophagus and the gastric cardia, also improvements in diagnosis and classification of these tumors have been reported 
which may partly account for the increase (18).

\section{Etiology}

Evidence of genetic factors in the pathogenesis of stomach cancer have been reported, but probably are of minor importance. Family aggregation studies in general show that close relatives of stomach cancer patients have a 2-3 fold higher risk than controls. This could be due to genetic but also due to shared environmental factors (15). Further support for genetic influence comes from studies reporting an increased stomach cancer risk among persons with blood type $A(15,32)$.

Marked large differences in incidences within geographic areas, a sharp decline in incidence of adenocarcinomas of the distal part of the stomach, and results of migrant studies support the view that environmental and, specifically, dietary factors seem to play a dominant role in the development of stomach cancer. The association between stomach cancer and food is easy to imagine because the stomach mucosa comes in prolonged contact with food which contains a variety of carcinogens and anticarcinogens $(33,34)$.

Factors that are suggested to enhance stomach cancer risk include salt, nitrate, nitrite, smoked meat and fish, alcohol, infection with Helicobacter pylori and smoking. High intake of vegetables, fruit, vitamin C, A and E may decrease risk. Also hypothesized as risk factors are socioeconomic status and refrigerator use as indicators of lifestyle or, specifically, food habits $(14,32,34-36)$.

A number of these factors have been intensively studied in several types of studies such as animal experiments, migration, ecologic, family, case-control and cohort studies and nutritional intervention trials. Furthermore, several extensive reviews have been written $(14,32,35,37,38)$.

Overall, evidence on dietary risk factors of stomach cancer is derived from case-control studies. A disadvantage of these retrospective studies is the possibility of biased recall of dietary habits by the patients. On the other hand, cohort studies are considered to be less prone to information and selection bias than case-control studies. Eleven cohort studies have studied one or more dietary risk factors regarding stomach cancer either from assessment of food intake (eight studies) or from assessment of vitamin levels in serum or plasma (three studies). These studies were conducted in both western and non-western populations, almost all at relatively high risk for stomach cancer. Despite the high incidence of stomach cancer in the studied populations, the number of cases used in the analyses was relatively small in nearly all studies. Furthermore, most studies had a limited exposure measurement which may have resulted in an inadequate measurement of food intake and a poor control for confounding factors. Characteristics of the eleven cohort studies are described in table 1. Results of the most extensively studied dietary factors (fruit, vegetables, vitamins, salt and salted foods, nitrate, nitrite and meat products) are summarized in tables for both cohort and case-control studies (tables 2-9) and will be described. Refrigerator use, alcohol consumption, infection with Helicobacter pylori, smoking and socioeconomic status in relation to stomach cancer will be briefly addressed in this introduction. 
TABLE 1. Characteristics of prospective cohort studies on dietary factors and stomach cancer.

\begin{tabular}{|c|c|c|c|c|c|c|c|}
\hline $\begin{array}{l}\text { Author, year of } \\
\text { publication } \\
\text { (reference) }\end{array}$ & $\begin{array}{l}\text { Country } \\
\text { population }\end{array}$ & $\begin{array}{l}\text { Year } \\
\text { of } \\
\text { enroll } \\
\text { ment }\end{array}$ & $\begin{array}{l}\text { Cohort } \\
\text { size/cases } \\
\text { (age } \\
\text { range) }\end{array}$ & $\begin{array}{l}\text { Years } \\
\text { of FU }\end{array}$ & Endpoint & $\begin{array}{l}\text { Exposure } \\
\text { measurement, } \\
\text { number of food } \\
\text { items }\end{array}$ & $\begin{array}{l}\text { Measured dietary } \\
\text { factors }\end{array}$ \\
\hline $\begin{array}{l}\text { lkeda, } 1983 \\
(39)\end{array}$ & $\begin{array}{l}\text { Japan } \\
\text { men, women }\end{array}$ & $\begin{array}{l}1968- \\
1970\end{array}$ & $\begin{array}{l}7553 / 79 \\
(50,1 \pm \\
13,4)\end{array}$ & 11 & mortality & $\begin{array}{l}\text { questionnaire, } \\
\text { (6) }\end{array}$ & $\begin{array}{l}\text { broiled fish } \\
\text { dried fish }\end{array}$ \\
\hline $\begin{array}{l}\text { Hirayama, } 1990 \\
(43)\end{array}$ & $\begin{array}{l}\text { Japan } \\
\text { men, women }\end{array}$ & 1966 & $\begin{array}{l}265118 / \\
5247 \\
(\geq 40)\end{array}$ & 17 & mortality & $\begin{array}{l}\text { questionnaire, } \\
\text { (9) }\end{array}$ & $\begin{array}{l}\text { green-yellow } \\
\text { vegetables, pickles, soy } \\
\text { bean paste soup }\end{array}$ \\
\hline $\begin{array}{l}\text { Nomura, } 1990 \\
(12) \\
\text { Chyou, } \\
1990(42)^{\star}\end{array}$ & $\begin{array}{l}\text { Hawaii } \\
\text { men }\end{array}$ & $\begin{array}{l}1965- \\
1968\end{array}$ & $\begin{array}{l}7990 / 150 \\
(46-68)\end{array}$ & 19 & incidence & $\begin{array}{l}\text { diet history and } \\
\text { 24-hour dietary } \\
\text { recall, (54) }\end{array}$ & $\begin{array}{l}\text { table salt/soy sauce, } \\
\text { miso soup, pickles } \\
\text { fruit, fried vegetables, } \\
\text { ham/bacon/sausage, } \\
\text { nutrients }\end{array}$ \\
\hline $\begin{array}{l}\text { Kneller, } 1991 \\
\text { (40) }\end{array}$ & $\begin{array}{l}\text { USA } \\
\text { white men } t\end{array}$ & $\begin{array}{l}1966- \\
1967\end{array}$ & $\begin{array}{l}17633 / 75 \\
(\geq 35)\end{array}$ & 20 & mortality & $\begin{array}{l}\text { questionnaire } \\
\text { (35) }\end{array}$ & $\begin{array}{l}\text { meals, fish, fruits, } \\
\text { vegetables, cruciferous } \\
\text { vegetables }\end{array}$ \\
\hline Kato, $1992(46)$ & $\begin{array}{l}\text { Japan } \\
\text { men, women }\end{array}$ & 1985 & $\begin{array}{l}9753 / 57 \\
(55-69)\end{array}$ & 6 & mortality & $\begin{array}{l}\text { mailed self- } \\
\text { administered } \\
\text { questionnaire, } \\
\text { (25) }\end{array}$ & $\begin{array}{l}\text { green-yellow } \\
\text { vegetables, other } \\
\text { vegetables, fruit, miso } \\
\text { soup, pickles }\end{array}$ \\
\hline $\begin{array}{l}\text { Zheng, } 1995 \\
\text { (41) }\end{array}$ & $\begin{array}{l}\text { USA } \\
\text { women }\end{array}$ & 1986 & $\begin{array}{l}34691 / 26 \\
(45-59)\end{array}$ & 7 & $\begin{array}{l}\text { incidence } \\
\text { mortality }\end{array}$ & $\begin{array}{l}\text { self- } \\
\text { administered } \\
\text { questionnaire } \\
\text { (127) }\end{array}$ & $\begin{array}{l}\text { processed meat and } \\
\text { fish, vegetables, fruit, } \\
\text { vitamins }\end{array}$ \\
\hline $\begin{array}{l}\text { Galanis, } \\
1998(44)\end{array}$ & $\begin{array}{l}\text { Hawaii } \\
\text { men, women }\end{array}$ & $\begin{array}{l}1975- \\
1980\end{array}$ & $\begin{array}{l}40575 / 108 \\
(\geq 18)\end{array}$ & 14.8 & incidence & $\begin{array}{l}\text { questionnaire } \\
\text { (13 food } \\
\text { groups) }\end{array}$ & $\begin{array}{l}\text { fruit, vegetables, high- } \\
\text { salt foods, processed } \\
\text { meats }\end{array}$ \\
\hline $\begin{array}{l}\text { Terry, } 1998 \\
(45),\end{array}$ & $\begin{array}{l}\text { Sweden } \\
\text { men,women } \\
\text { twin pairs }\end{array}$ & 1967 & $\begin{array}{l}11546 / \\
116 \\
(42-81)\end{array}$ & 21 & incidence & $\begin{array}{l}\text { questionnaire } \\
\text { (23) }\end{array}$ & fruit, vegetables \\
\hline $\begin{array}{l}\text { Stähelin, } 1984 \\
\text { (48) }\end{array}$ & $\begin{array}{l}\text { Switserland, } \\
\text { men }\end{array}$ & $\begin{array}{l}1960- \\
1962\end{array}$ & $\begin{array}{l}4224 / 19 \\
(15-60)\end{array}$ & 9 & mortality & $\begin{array}{l}\text { plasma levels of } \\
\text { vitamins }\end{array}$ & $\begin{array}{l}\text { vitamins } A, C, E, \beta \text { - } \\
\text { carotene }\end{array}$ \\
\hline $\begin{array}{l}\text { Nomura, } 1985 \\
\text { (49) }\end{array}$ & Hawaii, men & $\begin{array}{l}1971- \\
1975\end{array}$ & $\begin{array}{l}6800 / 70 \\
(46-65)\end{array}$ & 10 & incidence & $\begin{array}{l}\text { plasma levels of } \\
\text { vitamins }\end{array}$ & $\begin{array}{l}\text { vitamin } E \text {, retinol, } \beta \\
\text { carotene }\end{array}$ \\
\hline $\begin{array}{l}\text { Knekt, } 1988 \\
(47)\end{array}$ & Finland, men & $\begin{array}{l}1968- \\
1972\end{array}$ & $\begin{array}{l}21172 / 48 \\
(15-99)\end{array}$ & 10 & incidence & $\begin{array}{l}\text { plasma levels of } \\
\text { vitamins }\end{array}$ & vitamin $E$ \\
\hline
\end{tabular}

" same study population as Nomura, 1990: data were reanalyzed in case-cohort approach $\dagger$ of Norwegian, Swedish or German descent 


\section{Dietary factors: evidence from cohort and case-control studies}

All cohort studies on dietary intake and stomach cancer risk and serum studies with more than 15 cases are tabulated. For cohort studies, relative risks are given. With regard to the case-control studies, the number of studies with a positive, inverse or no association are counted and presented for each dietary factor.

\section{Cohort studies}

Overall, cohort studies did not show a clear association with sodium intake or salted foods, except that in some studies high consumption of specific salted foods (broiled fish, salted fish) was associated with a significantly increased stomach cancer risk (table 2) $(39,40$ ). Three of four studies showed a (slightly) positive association between consumption of cured meat or processed meat and stomach cancer risk (table 2$)(12,40,41)$.

Cohort studies on consumption of fruit and vegetables did not yield consistent findings (table 3 ). Five studies showed an inverse association between fruit or vegetable consumption and stomach cancer $(12,41-45)$, whereas two others found that consumption of fruit or vegetables was positively associated with stomach cancer risk $(40,46)$.

A strong inverse association was found in three studies for vegetables $(41)$, fruit $(41,44)$ and fruit and vegetables combined (45), with RRs varying from 0.2 to 0.6 for the highest intake level compared with the lowest intake level. A high consumption of 'all vegetables' (42) and green-yellow vegetables (43) was associated with a lower risk, with a significant trend of decreasing risk with increasing vegetable consumption. Also, an inverse association between stomach cancer and consumption of fried vegetables (12), cruciferous and green vegetables $(42)$ and fruit $(12,42)$ was found, but the association was not statistically significant. In two other studies, there was an increase in risk for consumption of cruciferous vegetables (40) or green-yellow vegetables (46). Kato (1992) even reported a significant positive association between daily fruit consumption and stomach cancer compared to less than two times per week consumption of fruit (46).

A cohort study among Japanese men in Hawaii reported that the cases consumed somewhat smaller amounts of $\beta$-carotene, other carotenoids and vitamin $C$ than the non-cases but the differences were not statistically significant (42) (table 4). In the Iowa Women's Health Study high intake of vitamin $\mathrm{C}$ and $\mathrm{E}$, carotenoids and retinol was associated with a decreased stomach cancer risk; the association was only significantly inverse for the carotenoids (41). In three serum studies, the results showed a protective effect of plasma levels of vitamins $A, C$ and $E$, and $\beta$-carotene (47-49). However, these associations were not statistically significant decreased.

\section{Case-control studies}

At least 28 different studies have examined the relation between fruit consumption and stomach cancer (table 5). Total fruit consumption was inversely associated with stomach cancer risk in 11 studies reporting on this association, except two studies that did not show an association $(50,51)$. The majority of studies reported also a protective effect of citrus, non-citrus, raw or fresh fruit consumption and 
TABLE 2. Results of prospective studies regarding salt intake and cured meat and stomach cancer.

\begin{tabular}{|c|c|c|c|}
\hline $\begin{array}{l}\text { Author, year of } \\
\text { publication } \\
\text { (reference) }\end{array}$ & Exposure (highest vs. lowest intake category) & $\begin{array}{l}\text { RR highest vs. lowest exposure } \\
\text { category }(95 \% \mathrm{Cl}) \text {, trend-test } p\end{array}$ & $\begin{array}{l}\text { Adjustment } \\
\text { variables }\end{array}$ \\
\hline $\begin{array}{l}\text { lkeda, } 1983 \\
\text { (39) }\end{array}$ & $\begin{array}{l}\text { broiled fish ( } 22 x \text { vs. }<2 x \text { per week) } \\
\text { dried fish ( } \geq 2 x \text { vs. }<2 x \text { per week) }\end{array}$ & $\begin{array}{l}\mathrm{RR}=1.7 \text { (sign) } \\
\mathrm{RR}=0.95 \text { (ns) }\end{array}$ & age, sex \\
\hline $\begin{array}{l}\text { Hirayama, } 1990 \\
(43)\end{array}$ & soy bean paste soup (daily vs. non-daily) & $\mathrm{RR}=0.86(0.82-0.90)^{*}$ & age, sex \\
\hline $\begin{array}{l}\text { Nomura, } 1990 \\
\text { (12)/ Chyou, } 1990 \\
(42)\end{array}$ & $\begin{array}{l}\text { table salt/soy sauce (always vs. never) } \\
\text { miso soup ( } \geq 5 / w k \text { vs. } \leq 1 / w k) \\
\text { pickles }(\geq 5 / w k \text { vs. } \leq 1 / w k) \\
\text { ham/bacon/sausage ( } \geq 5 / w k \text { vs. } \leq 1 / w k) \\
\text { sodium } \dagger \\
\text { processed meats } \dagger\end{array}$ & $\begin{array}{l}R R=1.0(0.6-1.6) \\
R R=0.9(0.5-1.3) \\
R R=1.2(0.8-1.7) \\
R R=1.3(0.9-2.0) \\
\Uparrow, n s\end{array}$ & age \\
\hline $\begin{array}{l}\text { Kneller, } 1991 \\
(40)\end{array}$ & $\begin{array}{l}\text { salted fish ( } \geq 1 \text { times/month vs. never) } \\
\text { bacon or side pork }(\geq 14 \text { vs. }<3 \text { times/month) }\end{array}$ & $\begin{array}{l}\mathrm{RR}=1.9(1.0-3.6), n s \\
\mathrm{RR}=1.4(0.6-3.1), n s\end{array}$ & $\begin{array}{l}\text { year of birth, } \\
\text { current smoking }\end{array}$ \\
\hline Kato, $1992(46)$ & $\begin{array}{l}\text { miso soup ( } \geq 2 \text { cups vs. }<1 \text { cup/day) } \\
\text { pickles (daily vs. } \leq 1-2 \text { week) }\end{array}$ & $\begin{array}{l}\mathrm{RR}=1.0(0.5-2.3), 0.8 \\
\mathrm{RR}=0.8(0.4-1.5), 0.6\end{array}$ & age, sex \\
\hline $\begin{array}{l}\text { Zheng, } 1995 \\
\text { (41) }\end{array}$ & $\begin{array}{l}\text { processed meat and fish ( } \geq 13 \text { vs. } 4.4 \\
\text { times/month) }\end{array}$ & $\mathrm{RR}=2.2(0.8-6.0)$ & $\begin{array}{l}\text { age, education, } \\
\text { smoking status, } \\
\text { packyears of } \\
\text { smoking }\end{array}$ \\
\hline $\begin{array}{l}\text { Galanis, } 1998 \\
\text { (44) }\end{array}$ & $\begin{array}{l}\text { high salt foods ( } \geq 4 \text { times/week vs. none) } \\
\text { processed meats }(\geq 3 \text { times/week vs. none) }\end{array}$ & $\begin{array}{l}R R=1.1(0.7-1.8), 0.65 \\
R R=1.0(0.6-1.7), 0.37\end{array}$ & $\begin{array}{l}\text { age, sex, } \\
\text { education, place } \\
\text { of birth, }\end{array}$ \\
\hline
\end{tabular}

* $90 \%$ confidence intervals; $†$ Comparison of mean values between cases and noncases sign = significant; $n s$ = non-significant; - = no association; $\Uparrow=$ direction of the association (no RRs were given); cases had a higher intake than the non-cases.

stomach cancer. A few studies did not find an association for citrus fruit $(52,53)$ or raw or fresh fruit $(54,55)$. One study reported that fruit consumption was positively associated with stomach cancer risk (52). For total vegetable consumption, raw or cooked vegetables and several vegetables groups (green-yellow vegetables, cruciferous vegetables), an inverse relationship has been observed for stomach cancer in the majority of 27 different studies that investigated this association (table 5). Legumes tended to be not associated with stomach cancer risk.

In general, these studies showed that persons in the upper ranges compared to the lower ranges of intake of vegetables and fruit tended to have a $50 \%$ reduction in risk (14,56-58). There are many plausible biologically reasons why vegetables and fruit reduce cancer risk. These include the presence of potentially anticarcinogenic substances such as vitamins $\mathrm{C}$ and $\mathrm{E}$, carotenoids, flavonoids, phenols, hydrolysis products of glucosinolates (59).

Twelve case-control studies examined the effect of vitamin A, retinol, carotenoids, vitamins $\mathrm{C}$ and 
TABLE 3. Results of prospective studies regarding fruit and vegetable consumption and stomach cancer.

\begin{tabular}{|c|c|c|c|}
\hline $\begin{array}{l}\text { Author, year of } \\
\text { publication } \\
\text { (reference) }\end{array}$ & Exposure (highest vs. lowest intake category) & $\begin{array}{l}\text { RR highest vs lowest exposure } \\
\text { category }(95 \% \text { CI), trend-testp }\end{array}$ & Adjustment factors \\
\hline $\begin{array}{l}\text { Hirayama, } 1990 \\
\text { (43) }\end{array}$ & green-yellow vegetables (daily vs. non-daily) & $R R=0.92(0.87-0.96)^{*}$ & age, sex \\
\hline $\begin{array}{l}\text { Nomura, } 1990 \\
\text { (12) }\end{array}$ & $\begin{array}{l}\text { fruit }(\geq 5 / w k \text { vs. } \leq 1 / w k) \\
\text { fried vegetables }(\geq 2 / w k \text { vs. } \leq 1 / w k)\end{array}$ & $\begin{array}{l}\mathrm{RR}=0.8(0.5-1.3) \\
\mathrm{RR}=0.8(0.4-1.6)\end{array}$ & age \\
\hline Chyou, 1990 (42) & $\begin{array}{l}\text { all vegetables (high vs. none) } \\
\text { green vegetables (high vs. none) } \\
\text { cruciferous vegetables (consumer vs. none) } \\
\text { yellow vegetables } \dagger \\
\text { all fruits (high vs. none) } \\
\text { yellow fruits } \dagger \\
\text { citrus fruits } \dagger\end{array}$ & $\begin{array}{l}R R=0.7(0.4-1.1), 0.001 \\
R R=0.7(0.4-1.2), 0.06 \\
R R=0.7(0.4-1.2), 0.07 \\
\Downarrow, \text { ns } \\
R R=0.8(0.4-1.3), 0.20 \\
\Downarrow, \text { ns } \\
\Downarrow, \text { ns }\end{array}$ & age, smoking \\
\hline $\begin{array}{l}\text { Kneller, } 1991 \\
(40)\end{array}$ & $\begin{array}{l}\text { fruits (highest vs. lowest quartile) } \\
\text { vegetables (highest vs. lowest quartile) } \\
\text { cruciferous vegetables (highest vs. lowest } \\
\text { quartile) } \\
\text { apples ( } \geq 14 \text { vs }<1 \text { times/month) }\end{array}$ & $\begin{array}{l}\mathrm{RR}=1.5(0.8-2.9), n s \\
\mathrm{RR}=0.9(0.5-1.8), n s \\
\mathrm{RR}=1.3(0.7-2.7), n s \\
\mathrm{RR}=3.2(1.1-9.2), p<0.05\end{array}$ & $\begin{array}{l}\text { year of birth, } \\
\text { current smoking }\end{array}$ \\
\hline Kato, 1992 (46) & $\begin{array}{l}\text { green-yellow vegetables } \\
\text { (daily vs. } \geq 1-2 / \text { week) } \\
\text { other vegetable pickles } \\
\text { (daily vs. } \geq 1-2 / \text { week) } \\
\text { fruits (daily vs. } \geq 1-2 \text { week) }\end{array}$ & $\begin{array}{l}R R=1.5(0.8-3.1), 0.2 \\
R R=1.2(0.6-2.3), 0.6 \\
R R=1.9(1.0-3.6) .0 .03\end{array}$ & age, sex \\
\hline $\begin{array}{l}\text { Zheng, } 1995 \\
\text { (41) }\end{array}$ & $\begin{array}{l}\text { vegetables (highest vs. lowest intake) } \\
\text { fruil (highest vs. lowest intake) }\end{array}$ & $\begin{array}{l}\mathrm{RR}=\text { approximately } 0.5 \\
\mathrm{RR}=\text { approximately } 0.5\end{array}$ & $\begin{array}{l}\text { unknown } \\
\text { unknown }\end{array}$ \\
\hline $\begin{array}{l}\text { Galanis, } 1998 \\
(44)\end{array}$ & $\begin{array}{l}\text { fresh fruit ( } \geq 7 \text { vs. } 0-6 / \text { times/week) } \\
\text { raw vegetables ( } \geq 7 \text { vs. } 0-6 / \text { times/week) }\end{array}$ & $\begin{array}{l}R R=0.6(0.4-0.9) \\
R R=0.8(0.5-1.2)\end{array}$ & $\begin{array}{l}\text { age, sex, } \\
\text { education, place of } \\
\text { birth }\end{array}$ \\
\hline $\begin{array}{l}\text { Terry, } 1998 \\
(45)\end{array}$ & fruit and vegetables (high vs. very little/none) & $\mathrm{RR}=0.2(0.1-0.6), p<0.05$ & $\begin{array}{l}\text { age, sex, alcohol, } \\
\text { smoking status, } \\
\text { BMl at age } 25 \\
\text { years, childhood } \\
\text { socio-economic } \\
\text { status }\end{array}$ \\
\hline
\end{tabular}

* $90 \%$ confidence intervals; $\uparrow$ Comparison of mean values between cases and noncases ns = non-significant; $\Downarrow=$ direction of the association (no RRs were given); the cases had a lower intake than the non-cases.

$\mathrm{E}$ and stomach cancer (table 6). Vitamin A intake was inversely associated with stomach cancer risk in two studies $(60,61)$, whereas no association was found in another study (62). Of the nine studies that investigated the effect of retinol on stomach cancer, four found no association and two a nonsignificantly inverse association (odds ratios for highest vs. lowest intake was 0.8$)(63,64)$. However, in two other studies high intake of retinol was associated with an increased stomach cancer risk 
TABLE 4. Results of prospective studies regarding dietary intake or plasma levels of vitamins and stomach cancer.

\begin{tabular}{|c|c|c|c|}
\hline $\begin{array}{l}\text { Author, year of } \\
\text { publication } \\
\text { (reference) }\end{array}$ & $\begin{array}{l}\text { Exposure (highest vs. lowest intake } \\
\text { category) }\end{array}$ & $\begin{array}{l}\text { RR highest vs lowest exposure } \\
\text { category ( } 95 \% \mathrm{Cl}) \text {, trend-test } p\end{array}$ & $\begin{array}{l}\text { Adjustment } \\
\text { factors }\end{array}$ \\
\hline $\begin{array}{l}\text { Chyou, } 1990 \\
(42)\end{array}$ & $\begin{array}{l}\text { vitamin } A \dagger \\
\text { retinol } \dagger \\
\beta \text {-carotene } \dagger \\
\text { other carotenes } \dagger \\
\text { vitamin } C \dagger \\
\text { vitamin } E \dagger\end{array}$ & $\begin{array}{l}\Downarrow, \text { ns } \\
\pi_{, n s} \\
\Downarrow, n s \\
\Downarrow, n s \\
\Downarrow, n s \\
-\end{array}$ & age \\
\hline $\begin{array}{l}\text { Zheng, } 1995 \\
\text { (41) }\end{array}$ & $\begin{array}{l}\text { retinol (>5672 vs. }<2098 \mathrm{IU} / \mathrm{day}) \\
\text { carotene }(>9.27 \text { vs. }<8.62 \mathrm{U} / \mathrm{day}) \\
\text { vitamin } \mathrm{C}(>5.56 \mathrm{vs} .<4.97 \mathrm{mg} / \mathrm{day}) \\
\text { vitamin } \mathrm{E}(>2.93 \mathrm{vs.}<2.01 \mathrm{mg} / \mathrm{day})\end{array}$ & $\begin{array}{l}R R=0.6(0.2-1.7), 0.36 \\
R R=0.3(0.1-1.0),<0.05 \\
R R=0.5(0.2-1.3), 0.16 \\
R R=0.6(0.2-1.5), 0.26\end{array}$ & $\begin{array}{l}\text { age, smoking } \\
\text { status, } \\
\text { packyears of } \\
\text { smoking, total } \\
\text { energy intake }\end{array}$ \\
\hline $\begin{array}{l}\text { Stähelin, } 1984 \\
\text { (48) }\end{array}$ & $\begin{array}{l}\text { plasma vitamin } C \\
\text { plasma vitamin } A \\
\text { plasma } \beta \text {-carotene } \\
\text { plasma vitamin } E\end{array}$ & $\begin{array}{l}\Downarrow, \text { ns } \\
\Downarrow, \text { ns } \\
\Downarrow_{1, n s} \\
-\end{array}$ & age, sex \\
\hline $\begin{array}{l}\text { Nomura, } 1985 \\
(49)\end{array}$ & $\begin{array}{l}\text { plasma retinol } \\
\text { plasma } \beta \text {-carotene } \\
\text { plasma vitamin } E\end{array}$ & $\dot{\Downarrow}, \mathrm{ns}$ & age \\
\hline Knekt, 1988 (47) & $\begin{array}{l}\text { plasma } \alpha \text {-tocopherol (highest vs. lowest } \\
\text { plasma levels) }\end{array}$ & $\mathrm{RR}=0.63(0.23-1.75) \ddagger$ & $\begin{array}{l}\text { age, smoking, } \\
\text { cholesterol }\end{array}$ \\
\hline
\end{tabular}

† Comparison of mean values between cases and noncases; $\ddagger$ cases diagnosed during the first two year of follow-up were excluded $-=$ no association; ns $=$ non-significant difference between cases and non-cases; $\Downarrow=$ direction of the association (no RRs were given); cases had a lower intake or plasma level than the non-cases; $\hat{i}=$ cases had a higher intake than the non-cases.

$(65,66)$. All 11 studies reporting on vitamin $\mathrm{C}$ found that a high intake was significantly associated with a decreased stomach cancer risk with odds ratios varying between 0.2 to 0.6 for highest intake level compared to the lowest level. Most of the studies showed that a high intake of carotenoids or beta-carotene was associated with a reduced risk of stomach cancer. The odds ratios observed for high vs low intake varied between 0.2 and 0.7 . A protective effect of vitamin $E$ against stomach cancer was reported in four of seven studies. No clear associations were reported in the other three studies (6668). Nitrate and nitrite have been implicated in stomach carcinogenesis. In the stomach, nitrate can be converted into nitrite which can react with amines and amides in food to produce carcinogenic $\mathrm{N}$ nitroso compounds $(17,69)$. The formation of $\mathrm{N}$-nitroso compounds can be inhibited by vitamins $\mathrm{C}$ and $E(70)$. Nitrates are naturally found in foods especially in vegetables, potatoes and drinking water (71). Concentrations in foods vary depending on agricultural practices (use of artificial fertilizers), soil and storage conditions (14). Nitrite is present in cheese and cured or smoked meat because it is used as preservative or can be formed out of nitrate in poorly stored foods.

High intake of nitrate from foods was associated with a decreased risk in seven studies; one study reported a non-significant positive association (72) (table 7). The inverse association may be 
TABLE 5. Summary of results of case-control studies regarding fruit and vegetable consumption.

\begin{tabular}{|c|c|c|c|c|c|}
\hline \multirow[b]{2}{*}{ Exposure } & \multicolumn{4}{|c|}{ Number of studies } & \multirow[t]{2}{*}{ References } \\
\hline & $\begin{array}{l}\text { Total } \\
\text { number of } \\
\text { studies }\end{array}$ & $\begin{array}{l}\text { Positive } \\
\text { association* }\end{array}$ & $\begin{array}{l}\text { Inverse } \\
\text { association }\end{array}$ & $\begin{array}{l}\text { No } \\
\text { association }\end{array}$ & \\
\hline Total fruit & 13 & & $\begin{array}{l}9 \\
(2)\end{array}$ & 2 & $(50,51,60,62,75,78,80-86)$ \\
\hline Citrus fruit & 12 & & $\begin{array}{l}7 \\
(3)\end{array}$ & 2 & $(50-53,60,62,64,67,72,76,77,87)$ \\
\hline Non-citrus fruit & 5 & (1) & $\begin{array}{l}3 \\
(1)\end{array}$ & & $(52,60,62,77,87)$ \\
\hline Raw or fresh fruits & 9 & & 7 & 2 & $(54,55,60,64,76,79,88-90)$ \\
\hline Total vegetables & 15 & $(1)$ & $\begin{array}{l}8 \\
(4)\end{array}$ & 2 & $(50-52,60,62,67,75,77,82,84,85,89,91-93)$ \\
\hline Raw vegetables & 11 & & $\begin{array}{l}7 \\
(4)\end{array}$ & & $(50,53,55,60,62,72,76,79,80,87,94)$ \\
\hline Cooked vegetables & 4 & & 3 & 1 & $(53,76,79,88)$ \\
\hline $\begin{array}{l}\text { Green-yellow/ } \\
\text { green vegetables }\end{array}$ & 10 & 1 & $\begin{array}{l}6 \\
(2)\end{array}$ & 1 & $(51,54,60,64,67,80,84,87,88,95)$ \\
\hline $\begin{array}{l}\text { Cruciferous } \\
\text { vegetables }\end{array}$ & 4 & & $\begin{array}{l}2 \\
(2)\end{array}$ & & $(60,62,67,91)$ \\
\hline Legumes & 3 & & (1) & 2 & $(50,60,67)$ \\
\hline
\end{tabular}

* number in parentheses: non-significant positive or inverse association

explained by the fact that the most important source for nitrates are vegetables, which are also rich in protective compounds such as vitamins, flavonoids, glucosinolates and indoles (59). The association between nitrate from drinking water and stomach cancer was investigated in only two studies, which both reported a positive association with risk. Most studies found an increased risk of stomach cancer associated with high intake of nitrite, but not all $(63,73)$.

Studies investigating the association between stomach cancer and consumption of processed meat, cured meat as a whole or several types of cured meat found that a high consumption was associated with an twofold increased risk, but the association was not always significantly increased (table 8)(56). There were also studies that reported no effect (74-79). Several compounds of these meat products have been supposed to enhance stomach cancer risk including nitrite and nitrosamines (in sausage, ham and bacon) or polycyclic aromatic hydrocarbons (smoked meat) $(56,77)$. Most of these meat products also contain high concentrations of sodium chloride.

It is not clear whether sodium or the combination of sodium and chloride is associated with stomach 
TABLE 6. Summary of results of case-control studies regarding vitamin intake.

\begin{tabular}{|c|c|c|c|c|c|}
\hline \multirow[b]{2}{*}{ Exposure } & \multicolumn{4}{|c|}{ Number of studies } & \multirow[t]{2}{*}{ References } \\
\hline & $\begin{array}{l}\text { Total } \\
\text { number of } \\
\text { studies }\end{array}$ & $\begin{array}{l}\text { Positive } \\
\text { association } \\
*\end{array}$ & $\begin{array}{l}\text { Inverse } \\
\text { association } \\
\star\end{array}$ & $\begin{array}{l}\text { No } \\
\text { association }\end{array}$ & \\
\hline Vitamin A & 3 & & (2) & 1 & $(60-62)$ \\
\hline Retinol & 9 & $\begin{array}{l}1 \\
(1)\end{array}$ & (3) & 4 & $(60,63-68,89,96)$ \\
\hline Beta-carotene & 6 & & $\begin{array}{l}5 \\
(1)\end{array}$ & & $(60,63,64,67,68,96)$ \\
\hline (Other) carotenes & 7 & (1) & $\begin{array}{l}2 \\
(4)\end{array}$ & & $(60,62,65-67,72,89)$ \\
\hline Vitamin C & 11 & & 11 & & $(60-64,66-68,72,89,96)$ \\
\hline Vitamin $E$ & 7 & & $\begin{array}{l}2 \\
(2)\end{array}$ & 3 & $(60,61,63,66-68,96)$ \\
\hline
\end{tabular}

* number in parentheses: non-significant positive or inverse association

cancer risk, but excessive salt intake causes mucosal damage and excessive cell replication which may make the mucosa more susceptible for the action of carcinogens (17). Thirty-five studies investigated salt intake, salt added to food, use of salt, preference of salty foods or consumption of highly salted foods (table 9). Nearly all studies reported a positive association between total salt intake, use of salt, preference of (highly) salted foods as a marker of high salt intake and salted foods and stomach cancer risk, with a few exceptions. High intake of salt was associated on average with a $50 \%$ increase in risk in these studies (56). The results seem to be less consistent for salted fish and pickled vegetables.

\section{Refrigerator use}

The introduction of the refrigerator in households decades ago has been associated with improved storing conditions of foods. Bacterial conversion of nitrates and nitrites to N-nitroso compounds or production of other carcinogenic metabolites by bacteria and fungi in stored food probably also decreased. Furthermore, refrigeration reduced the need for traditionally preserved foods (salted, smoked foods) and increased the availability of fresh fruit and vegetables (34).

A number of case-control studies performed in Europe or the USA rather consistently reported a decreased stomach cancer risk with long-term use of a refrigerator $(65,67,72,76,88,94,105)$, but not all $(53,62,84)$. A number of studies showed that people who used a refrigerator for more than $30-40$ years had a $50 \%$ reduction in risk $(65,76,94,105)$. 
TABLE 7. Summary of results of case-control studies regarding nitrate and nitrite intake.

\begin{tabular}{|c|c|c|c|c|c|}
\hline \multirow[b]{2}{*}{ Exposure } & \multicolumn{4}{|c|}{ Number of studies } & \multirow[t]{2}{*}{ References } \\
\hline & $\begin{array}{l}\text { Total } \\
\text { number } \\
\text { of } \\
\text { studies }\end{array}$ & $\begin{array}{l}\text { Positive } \\
\text { association* }\end{array}$ & $\begin{array}{l}\text { Inverse } \\
\text { association* }\end{array}$ & $\begin{array}{l}\text { No } \\
\text { association }\end{array}$ & \\
\hline Nitrate from foods & 8 & (1) & $\begin{array}{l}5 \\
(2)\end{array}$ & & $(63,66-68,72,73,96,97)$ \\
\hline Nitrate from water & 2 & $\begin{array}{l}\text { (1) } \\
1\end{array}$ & & & $(98,99)$ \\
\hline Nitrite & 8 & $\begin{array}{l}5 \\
\text { (1) }\end{array}$ & & 2 & $(63,66-68,73,96,97,100)$ \\
\hline
\end{tabular}

* number in parentheses: non-significant positive or inverse association

\section{Alcohol consumption}

Alcohol or alcoholic beverages have been moderately positively associated with stomach cancer risk in a number of case-control studies. However, in many other studies including large cohort studies no relationship was observed (57). There is no evidence that ethanol itself is carcinogenic. Besides ethanol, alcoholic beverages contain nitrosamines and other contaminants that may have carcinogenic properties (106).

\section{Non-dietary factors}

\section{Smoking}

Smokers have approximately a twofold higher stomach cancer risk compared with nonsmokers (56). This has been observed in both cohort and case-control studies. The risk increases with intensity and/or duration of smoking.

\section{Socioeconomic status and occupation}

In the USA and Western Europe, stomach cancer is twice as frequent in the lower as in the highest socioeconomic groups. Increased stomach cancer rates have been observed with a number of occupations, including coal mining, farming (in Japan) and nickel refining (former USSR). Asbest workers and rubber workers have been reported to have an increased risk of stomach cancer. Whether these occupations are truly associated with increased stomach cancer risk or reflect the socioeconomic characteristics of the employees is not clear $(8,107)$.

\section{Helicobacter pylori}

More recently a new factor has been associated with a increased stomach cancer risk: infection 
TABLE 8. Summary of results of case-control studies regarding meat products.

\begin{tabular}{|c|c|c|c|c|c|}
\hline \multirow[b]{2}{*}{ Exposure } & \multicolumn{4}{|c|}{ Number of studies } & \multirow{2}{*}{ References } \\
\hline & $\begin{array}{l}\text { Total } \\
\text { number } \\
\text { of } \\
\text { studies }\end{array}$ & $\begin{array}{l}\text { Positive } \\
\text { association }\end{array}$ & $\begin{array}{l}\text { Inverse } \\
\text { association" }\end{array}$ & $\begin{array}{l}\text { No } \\
\text { association }\end{array}$ & \\
\hline Processed meat & 5 & $\begin{array}{l}3 \\
\text { (1) }\end{array}$ & & 1 & $(51,60,72,74,101)$ \\
\hline Cured meat & 4 & (2) & & 2 & $(53,54,76,77)$ \\
\hline Smoked meat & 4 & $\begin{array}{l}3 \\
\text { (1) }\end{array}$ & & & $(67,78,80,90)$ \\
\hline Bacon & 3 & (2) & & 1 & $(55,77,78)$ \\
\hline Ham, raw ham & 2 & (1) & & 1 & $(52,64)$ \\
\hline Sausage & 5 & 2 & & 3 & $(74,75,77,79)$ \\
\hline
\end{tabular}

* number in parentheses: non-significant positive or inverse association

with Helicobacter pylori (H.pylori). A large number of reviews have been published about this subject $(34,36,108-115)$.

H. pylori infection is highly common throughout the world (108). In developed countries it is uncommon for children to be colonized, whereas approximately $50 \%$ of the adults are colonized by the age of 60 year. In developing countries colonizing may occur during childhood and around $90 \%$ of adults may be infected (116). Infection is equally common in men and woman (108).

Because H.pylori is not eradicated spontaneously, infection persists for years, decades or possibly a lifetime (108). Type B gastritis caused by H.pylori may be either symptomatic or asymptomatic and becomes chronic. Chronic gastritis is a precursor lesion to intestinal-type of gastric carcinoma. H.pylori is thought to increase cell replication which increases the risk for mutagenesis, alters the mucus barrier or produces carcinogens such as reactive oxygen species and nitrite oxide (111). The best evidence of an association between H.pylori infection and stomach cancer has come from four prospective serological studies (all analyzed on nested case-control studies), in the UK (117), in the US (118) and China (119) and among Japanese Americans (120). In these studies, H.pylori antibody levels were measured in sera collected years prior to the cancer diagnosis. The odds ratio from a combined analysis of three of four studies was 3.8 (95\% CI, 2.3-6.2) (119). The Chinese study found a lower odds ratio of $1.6(95 \% \mathrm{CI}, 0.68-2.6)(119)$. It has been estimated that $35 \%$ to $60 \%$ of stomach cancers can be attributed to $H$. pylori infection $(113,117,118)$. 
TABLE 9. Summary of results of case-control studies regarding salt/sodium intake, salt preference, salted foods.

\begin{tabular}{|c|c|c|c|c|c|}
\hline \multirow[b]{2}{*}{$\begin{array}{l}\text { Exposure (high vs. } \\
\text { low intake/use) }\end{array}$} & \multicolumn{4}{|c|}{ Number of studies } & \multirow[t]{2}{*}{ References } \\
\hline & $\begin{array}{l}\text { Total } \\
\text { number } \\
\text { of } \\
\text { studies }\end{array}$ & $\begin{array}{l}\text { Positive } \\
\text { association }^{*}\end{array}$ & $\begin{array}{l}\text { Inverse } \\
\text { association* }\end{array}$ & $\begin{array}{l}\text { No } \\
\text { association }\end{array}$ & \\
\hline Total salt intake & 7 & $\begin{array}{l}4 \\
(2)\end{array}$ & & 1 & $(13,50,60,62,64,65,100)$ \\
\hline $\begin{array}{l}\text { Add salt to foods/ } \\
\text { use of (table) salt }\end{array}$ & 6 & 5 & 1 & & $(75,76,78,81,102,103)$ \\
\hline $\begin{array}{l}\text { Salt preference } \\
\text { (prefer salty food or } \\
\text { taste v. not) }\end{array}$ & 6 & 5 & & 1 & $(52,76,89,91,94,104)$ \\
\hline $\begin{array}{l}\text { Salted foods (in } \\
\text { general) }\end{array}$ & 4 & 4 & & & $(54,80,87,88,91,95)$ \\
\hline Salted fish & 9 & 5 & (1) & 3 & $(52,53,74,76,77,81,87,89,92)$ \\
\hline Pickled vegetables & 10 & $\begin{array}{l}2 \\
(2)\end{array}$ & 1 & 5 & $(52,54,55,74,80,81,87,89,91,92)$ \\
\hline Salty snacks & 3 & $\begin{array}{l}2 \\
\text { (1) }\end{array}$ & & & $(51,72,91)$ \\
\hline
\end{tabular}

* number in parentheses: non-significant positive or inverse association

\section{Aim of the current study}

The aim of this study is to investigate the association between several dietary factors (fruit and vegetables, vitamins $\mathrm{A}, \mathrm{C}$ and $\mathrm{E}$, folate, carotenoids, dietary fiber, salt, cured meat, the use of a refrigerator and freezer, butylated hydroxyanisole (BHA) and butylated hydroxytoluene (BHT) and stomach cancer in a prospective cohort study. The associations are investigated in the Netherlands Cohort Study on diet and cancer (NLCS)(121).

\section{The Netherlands Cohort Study}

The NLCS is a large population-based prospective study that has begun in September 1986 among 58,279 men and 62,573 women ages 55-69 at the beginning of the study (121). This older age group was chosen because dietary habits were thought be relatively stable and a sufficient number of cancer cases was expected to occur within a relatively short period of follow-up. Respondents orginated from the general population sampled from 204 municipalities in the Netherlands. They completed a selfadministered mailed questionnaire on usual dietary intake and other important lifestyle characteristics. Food consumption was measured by means of a semi-quantitative food frequency questionnaire with 150 items and the food frequency questionnaire was validated against a 9-day dietary record (122). 
For some foods participants were asked to specify type and brand. For products with brand names it was possible to obtain specific information, for example, on BHA and BHT content.

Follow-up for cancer in the entire cohort consisted of record linkage with nine regional cancer registries (covering the whole country) and with PALGA, a national pathology register (123). A casecohort approach was used to analyse the data. The cases are derived from the entire cohort, while the person-years at risk of the entire cohort are estimated from a random sample of 3500 people (subcohort) (124). After the baseline measurement, the subcohort was randomly sampled from the cohort and was followed for vital status information. For analyses, information was used from the period between September 1986 and December 1992 (6.3 years of follow-up). Within these 6.3 years of follow-up, 310 incident cases of stomach carcinoma were detected.

\section{Choice of factors}

The choice of the factors is based on the proposed importance of the factors in stomach cancer etiology, that is, factors that have been studied intensively in mainly case-control studies (fruit and vegetables, vitamins, salt) and/or have been hypothesized to play an important role in the hypothetic model of gastric carcinogenesis (salt, nitrate and nitrite). Futhermore, the availability of comprehensive and unique exposure data in the NLCS created the possibility for studying folate, dietary fiber and BHA and BHT in relation with stomach cancer. Cured meat and use of refigerator have been studied together with salt, because curing, refrigeration and salting are all methods of food preservation.

The hypotheses can be formulated as follows:

- The consumption of fruit vegetables and specific compounds of fruit and vegetables, such as vitamins $\mathrm{A}, \mathrm{C}$ and $\mathrm{E}$, folate, several carotenoids and dietary fiber is inversely associated with the risk of stomach cancer.

- Nitrate from food intake and drinking water and dietary nitrite intake are positively associated with stomach cancer risk.

- A high consumption of salt and cured meat is positively associated with stomach cancer risk.

- Long-term use of a refrigerator is inversely association with stomach cancer risk.

- The consumption of the synthetic antioxidants butylated hydroxyanisole and butylated hydroxytoluene is inversely associated with the risk of stomach cancer

\section{Time-trend study}

Time-trends studies suggests that the incidence of adenocarcinomas of the gastric cardia and also the lower third of the esophagus is rising in several countries of Europe and in the US in contrast to the decreasing incidence of adenocarcinomas of the distal stomach. The increasing incidence of both tumors of the gastric cardia and the esophagus suggests that they are etiologically related but distinct from tumors in the distal part of the stomach. However, before investigating risk factors involved in the development of adenocarcinomas of the gastric cardia and the esophagus, the time trend of these tumors should be monitored more closely to confirm the trend. 
We had the opportunity to study the time-trend in incidence of adenocarcinomas of the gastric cardia and the esophagus in several European countries simultaneously with EUROCIM data. The Eurocim database is a computerized cancer incidence and mortality database developed by the European Network of Cancer Registries (ENCR). Cancer registries that are members of the ENCR are asked to make regular submissions of incidence, mortality and population data to a central Eurocim databank held at the International Agency for Research on Cancer in Lyon. The Eurocim database comprises detailed cancer data by topography and morphology from 95 European cancer registries over various years in the period 1960-1995 (125).

\section{Outline of the thesis}

In chapter 2, the association between vegetable and fruit consumption and stomach cancer is described. Several compounds of fruit and vegetables (vitamins A, C and E, folate, carotenoids, dietary fiber) are investigated in relation to stomach cancer risk in chapter 3 . In chapter 4 , results on nitrate and nitrite intake and stomach cancer risk are described. The association with salt intake, cured meat consumption, the use of a refrigerator and freezer and stomach cancer risk are presented in chapter 5. The synthetic food antioxidants BHA and BHT as are related to stomach cancer risk (chapter 6). In chapter 7, Eurocim data are used to describe and compare trends in incidence of adenocarcinomas of the gastric cardia and the esophagus in ten European countries, 1968-1995.

Finally, in chapter 8, a general discussion is given. The results of our study are compared with results of other cohort and case-control studies on diet and stomach cancer. Methodological aspects and other etiologic factors relevant for stomach cancer are discussed.

\section{REFERENCES}

1. Parkin DM, Laara E, Muir CS. Estimates of the worldwide frequency of sixteen major cancers in 1980. Int J Cancer 1988;41:184-97.

2. Parkin DM, Pisani P, Ferlay J. Estimates of the worldwide incidence of eighteen major cancers in 1985. Int J Cancer 1993;54:594-606.

3. Parkin DM, Pisani P, Ferlay J. Estimates of the worldwide incidence of 25 major cancers in 1990. Int J Cancer 1999;80:827-41.

4. Tomatis L. Cancer: Causes, Occurrence and Control. IARC Scientific Publications No. 100, World Health Organization, Lyon: 1990

5. Visser O, Coebergh JWW, Schouten LJ. Incidence of cancer in the Netherlands. Second report of the Netherlands Cancer Registry, Netherlands Cancer Registry (NeCaRe), Utrecht: 1990

6. Visser O, Coebergh JWW, Schouten LJ, Dijck JAAM. Incidence of cancer in the Netherlands, 1995. Netherlands Cancer Registry (NeCaRe), Utrecht: 1998

7. Thompson GB, van HJA, Sarr MG. Adenocarcinoma of the stomach: are we making progress? Lancet 1993;342:713-8.

8. Devita VT, Hellman S, Rosenberg SA. Principles \& Practice of Oncology. Philadelphia: J.B. Lippincott Company, 1989.

9. Lauren $P$. The two histological main types of gastric carcinoma: diffuse and so-called intestinal-type carcinoma. Acta Path Microbiol Scandinav 1965;64:31-49. 
10. Munoz N, Asvall J. Time trends of intestinal and diffuse types of gastric cancer in Norway. Int J Cancer 1971;8:144-57.

11. Cipriani F, Buiatti E, Palli D. gastric cancer in Italy. Ital J Gastroenterol 1991;23:429-35.

12. Nomura A, Grove JS, Stemmermann GN, Severson RK. A prospective study of stomach cancer and its relation to diet, cigarettes, and alcohol consumption. Cancer Res 1990;50:627-31.

13. Nazario CM, Szklo M, Diamond E, et al. Salt and gastric cancer: a case-control study in Puerto Rico. Int J Epidemiol 1993;22:790-7.

14. Howson CP, Hiyama T, Wynder EL. The decline in gastric cancer: epidemiology of an unplanned triumph. Epidemiol Rev 1986;8:1-27.

15. Fuchs CS, Mayer RJ. Gastric carcinoma. N Engl J Med 1995;333:32-41.

16. Correa P, Haenszel W, Cuello C, Tannenbaum S, Archer M. A model for gastric cancer epidemiology. Lancet 1975;2:58-60.

17. Correa P. Human gastric carcinogenesis: a multistep and multifactorial process--First American Cancer Society Award Lecture on Cancer Epidemiology and Prevention. Cancer Res 1992;52:6735-40.

18. Blot WJ, Devesa SS, Kneller RW, Fraumeni JF, Jr. Rising incidence of adenocarcinoma of the esophagus and gastric cardia. Jama 1991;265:1287-9.

19. Powell J, McConkey CC. Increasing incidence of adenocarcinoma of the gastric cardia and adjacent sites. $\mathrm{Br}$ J Cancer 1990;62:440-3.

20. Harrison SL, Goldacre MJ, Seagroatt V. Trends in registered incidence of oesophageal and stomach cancer in the Oxford region, 1974-88. Eur J Cancer Prev 1992;1:271-4.

21. Zheng T, Mayne ST, Holford TR, et al. The time trend and age-period-cohort effects on incidence of adenocarcinoma of the stomach in Connecticut from 1955-1989. Cancer 1993;72:330-40.

22. Blot WJ, Fraumeni JF, Jr. Trends in esophageal cancer mortality among US blacks and whites. Am J Public Health 1987;77:296-8.

23. Hansen S, Wiig JN, Giercksky KE, Tretli S. Esophageal and gastric carcinoma in Norway 1958-1992: incidence time trend variability according to morphological subtypes and organ subsites. Int J Cancer 1997;71:340-4.

24. Liabeuf A, Faivre J. Time trends in oesophageal cancer incidence in Cote d'Or (France), 1976-93. Eur J Cancer Prev 1997;6:24-30.

25. Antonioli DA, Cady B. Changing aspects of gastric adenocarcinoma. N Engl J Med 1984;310:1538.

26. Reed PI. Changing pattern of oesophageal cancer [conference]. Lancet 1991;338:178.

27. Blot WJ, Devesa SS, Fraumeni JF, Jr. Continuing climb in rates of esophageal adenocarcinoma: an update. Jama 1993;270:1320.

28. Hansson LE, Sparen P, Nyren O. Increasing incidence of carcinoma of the gastric cardia in Sweden from 1970 to 1985. Br J Surg 1993;80:374-7.

29. Kabat GC, Ng SK, Wynder EL. Tobacco, alcohol intake, and diet in relation to adenocarcinoma of the esophagus and gastric cardia. Cancer Causes Control 1993;4:123-32.

30. Brown LM, Swanson CA, Gridley G, et al. Adenocarcinoma of the esophagus: role of obesity and diet. J Natl Cancer Inst 1995;87:104-9.

31. Vaughan TL, Davis S, Kristal A, Thomas DB. Obesity, alcohol, and tobacco as risk factors for cancers of the esophagus and gastric cardia: adenocarcinoma versus squamous cell carcinoma. Cancer Epidemiol Biomarkers Prev 1995; 4:85-92.

32. Nomura A. Stomach. In: Schottenfeld D FJJR, ed. Cancer epidemiology and prevention. Philadelphia: W. B. Saunders Company, 1982:624-637.

33. Mirvish SS. The etiology of gastric cancer. Intragastric nitrosamide formation and other theories. J Natl Cancer Inst 1983;71:629-47.

34. Hwang H, Dwyer J, Russell RM. Diet, Helicobacter pylori infection, food preservation and gastric cancer risk: are there new roles for preventative factors? Nutr Rev 1994;52:75-83.

35. Correa P, Haenszel W. Epidemiology of Gastric Cancer. In: Correa P, Haenszel, W. (eds), Epidemiology of cancer of the digestive tract. The Hague, Boston, London: Martinus Nijhoff Publishers, 1982:59-83.

36. De Koster E, Buset M, Fernandes E, Deltenre M. Helicobacter pylori: the link with gastric cancer. Eur J Cancer Prev 1994;3:247-57.

37. Steinmetz KA, Potter JD. Vegetables, fruit, and cancer. I. Epidemiology. Cancer Causes Control 1991;2:325-57.

38. Steinmetz KA, Potter JD. Vegetables, fruit, and cancer prevention: a review. J Am Diet Assoc 1996;96:1027-39. 
39. Ikeda M, Yoshimoto K, Yoshimura T, Kono S, Kato H, Kuratsune M. A cohort study on the possible association between broiled fish intake and cancer. Gann 1983;74:640-8.

40. Kneller RW, McLaughlin JK, Bjelke E, et al. A cohort study of stomach cancer in a high-risk American population. Cancer 1991;68:672-8.

41. Zheng W, Sellers TA, Doyle TJ, Kushi LH, Potter JD, Folsom AR. Retinol, antioxidant vitamins, and cancers of the upper digestive tract in a prospective cohort study of postmenopausal women. Am J Epidemiol 1995; 142:955-60.

42. Chyou PH, Nomura AM, Hankin JH, Stemmermann GN. A case-cohort study of diet and stomach cancer. Cancer Res 1990;50:7501-4.

43. Hirayama T. Life-style and mortality. A large-scale census-based Cohort Study in Japan. Basel: Karger, 1990.

44. Galanis DJ, Kolonel LN, Lee J, Nomura A. Intakes of selected foods and beverages and the incidence of gastric cancer among the Japanese residents of Hawaii: a prospective study. Int J Epidemiol 1998;27:173-80.

45. Terry P, Nyren O, Yuen J. Protective effect of fruits and vegetables on stomach cancer in a cohort of Swedish twins. Int J Cancer 1998;76:35-7.

46. Kato I, Tominaga S, Matsumoto K. A prospective study of stomach cancer among a rural Japanese population: a 6-year survey. Jpn J Cancer Res 1992;83:568-75.

47. Knekt P, Aromaa A, Maatela J, et al. Serum vitamin E and risk of cancer among Finnish men during a 10-year follow-up. Am J Epidemiol 1988;127:28-41.

48. Stahelin HB, Rosel F, Buess E, Brubacher G. Cancer, vitamins, and plasma lipids: prospective Basel study. J Natl Cancer Inst 1984;73(6):1463-8.

49. Nomura AM, Stemmermann GN, Heilbrun LK, Salkeld RM, Vuilleumier JP. Serum vitamin levels and the risk of cancer of specific sites in men of Japanese ancestry in Hawaii. Cancer Res 1985;45:2369-72.

50. Ramon JM, Serra L, Cerdo C, Oromi J. Dietary factors and gastric cancer risk. A case-control study in Spain. Cancer 1993;71:1731-5.

51. Ward MH, Lopez Carrillo L. Dietary factors and the risk of gastric cancer in Mexico City. Am J Epidemiol 1999;149:925-32.

52. Tajima K, Tominaga S. Dietary habits and gastro-intestinal cancers: a comparative case-control study of stomach and large intestinal cancers in Nagoya, Japan. Jpn J Cancer Res 1985;76:705-16.

53. Gonzalez CA, Sanz JM, Marcos G, et al. Dietary factors and stomach cancer in Spain: a multi-centre case-control study. Int J Cancer 1991;49:513-9.

54. Lee $\mathrm{HH}$, Wu HY, Chuang YC, et al. Epidemiologic characteristics and multiple risk factors of stomach cancer in Taiwan. Anticancer Res 1990;10:875-81.

55. Graham S, Schotz W, Martino P. Alimentary factors in the epidemiology of gastric cancer. Cancer 1972;30:92738.

56. Forman D. The etiology of gastric cancer. IARC Scientific Publications 1991;105:22-32.

57. Boeing H. Epidemiological research in stomach cancer: progress over the last ten years. J Cancer Res Clin Oncol $1991 ; 117: 133-43$.

58. Negri E, La VC, Franceschi S, D'Avanzo B, Parazzini F. Vegetable and fruit consumption and cancer risk. Int J Cancer 1991;48:350-4.

59. Steinmetz KA, Potter JD. Vegetables, fruit, and cancer. II. Mechanisms. Cancer Causes Control 1991;2:427-42.

60. Harrison LE, Zhang ZF, Karpeh MS, Sun M, Kurtz RC. The role of dietary factors in the intestinal and diffuse histologic subtypes of gastric adenocarcinoma: a case-control study in the U.S. Cancer 1997;80:1021-8.

61. Ramon JM, Serra ML, Cerdo C, Oromi J. Nutrient intake and gastric cancer risk: a case-control study in Spain. Int J Epidemiol 1993;22:983-8.

62. Correa P, Fontham E, Pickle LW, Chen V, Lin YP, Haenszel W. Dietary determinants of gastric cancer in south Louisiana inhabitants. J Natl Cancer Inst 1985;75:645-54.

63. Hansson LE, Nyren O, Bergstrom R, et al. Nutrients and gastric cancer risk. A population-based case-control study in Sweden. Int $\mathrm{J}$ Cancer 1994;57:638-44.

64. La Vecchia C, Negri E, Decarli A, D'Avanzo B, Franceschi S. A case-control study of diet and gastric cancer in northern Italy. Int $\mathrm{J}$ Cancer 1987;40:484-9.

65. Graham S, Haughey B, Marshall J, et al. Diet in the epidemiology of gastric cancer. Nutr Cancer 1990;13:19-34. 66. Gonzalez CA, Riboli E, Badosa J, et al. Nutritional factors and gastric cancer in Spain. Am J Epidemiol 1994;139:466-73. 
67. Risch HA, Jain M, Choi NW, et al. Dietary factors and the incidence of cancer of the stomach. Am J Epidemiol 1985;122:947-59.

68. La Vecchia C, Ferraroni M, D'Avanzo B, Decarli A, Franceschi S. Selected micronutrient intake and the risk of gastric cancer. Cancer Epidemiol Biomarkers Prev 1994;3:393-8.

69. Forman D. Dietary exposure to N-nitroso compounds and the risk of human cancer. Cancer Surv 1987;6:719-38.

70. Mirvish SS. Effects of vitamins $\mathrm{C}$ and $\mathrm{E}$ on $\mathrm{N}$-nitroso compound formation, carcinogenesis, and cancer. Cancer 1986;58(8 Suppl):1842-50.

71. van Loon AJM, Klaveren v, J. D. Nitraatinname van de Nederlandse bevolking. Voeding 1991;52:96-100.

72. Boeing $\mathrm{H}$, Frentzel BR, Berger $\mathbf{M}$, et al. Case-control study on stomach cancer in Germany. Int $\mathbf{J}$ Cancer 1991;47:858-64.

73. Pobel D, Riboli E, Cornee J, Hemon B, Guyader M. Nitrosamine, nitrate and nitrite in relation to gastric cancer: a case-control study in Marseille, France. Eur J Epidemiol 1995;11:67-73.

74. Acheson ED, Doll R. Dietary factors in carcinoma of the stomach: A study of 110 cases and 200 controls. Gut 1964;5:126-31.

75. Boeing $H$, Jedrychowski W, Wahrendorf J, Popiela T, Tobiasz AB, Kulig A. Dietary risk factors in intestinal and diffuse types of stomach cancer: a multicenter case-control study in Poland. Cancer Causes Control $1991 ; 2: 227-33$.

76. Buiatti E, Palli D, Decarli A, et al. A case-control study of gastric cancer and diet in Italy. Int $\mathbf{J}$ Cancer 1989;44:611-6.

77. Hansson LE, Nyren O, Bergstrom R, et al. Diet and risk of gastric cancer. A population-based case-control study in Sweden. Int J Cancer 1993;55:181-9.

78. Wu-Williams AH, Yu MC, Mack TM. Life-style, workplace, and stomach cancer by subsite in young men of Los Angeles County. Cancer Res 1990;50:2569-76.

79. Tuyns AJ, Kaaks R, Haelterman M, Riboli E. Diet and gastric cancer. A case-control study in Belgium. Int J Cancer 1992;51:1-6.

80. Hoshiyama Y, Sasaba T. A case-control study of stomach cancer and its relation to diet, cigarettes, and alcohol consumption in Saitama Prefecture, Japan. Cancer Causes Control 1992;3:441-8.

81. Haenszel W, Kurihara M, Locke FB, Shimuzu K, Segi M. Stomach cancer in Japan. J Natl Cancer Inst 1976;56:265-74.

82. Trichopoulos D, Ouranos G, Day NE, et al. Diet and cancer of the stomach: a case-control study in Greece. Int J Cancer 1985;36:291-7.

83. Yu GP, Hsieh CC. Risk factors for stomach cancer: a population-based case-control study in Shanghai. Cancer Causes Control 1991;2:169-74.

84. Jedrychowski W, Boeing H, Popiela T, Wahrendorf J, Tobiasz AB, Kulig J. Dietary practices in households as risk factors for stomach cancer: a familial study in Poland. Eur J Cancer Prev 1992;1:297-304.

85. Jedrychowski W, Wahrendorf J, Popiela T, Rachtan J. A case-control study of dietary factors and stomach cancer risk in Poland. Int J Cancer 1986;37:837-42.

86. Burr ML, Holliday RM. Fruit and stomach cancer. J Human Nutr Dietetics 1989;2:273-7.

87. Kono S, Ikeda M, Tokudome S, Kuratsune M. A case-control study of gastric cancer and diet in northern Kyushu, Japan. Jpn J Cancer Res 1988;79:1067-74.

88. Demirer T, Icli F, Uzunalimoglu $O$, Kucuk $O$. Diet and stomach cancer incidence. A case-control study in Turkey. Cancer 1990;65:2344-8.

89. You WC, Blot WJ, Chang YS, et al. Diet and high risk of stomach cancer in Shandong, China. Cancer Res 1988;48:3518-23.

90. Sanchez-Diez A, Hernandez MR, Cueto EA. Study of the relation between diet and gastric cancer in a rural area of the Province of Leon, Spain. Eur J Epidemiol 1992;8:233-7.

91. Lee JK, Park BJ, Yoo KY, Ahn YO. Dietary factors and stomach cancer: a case-control study in Korea. Int J Epidemiol 1995;24:33-41.

92. Haenszel W, Kurihara M, Segi M, Lee RK. Stomach cancer among Japanese in Hawaii. J Natl Cancer Inst 1972;49:969-88.

93. Bjelke E. Epidemiologic studies of cancer of the stomach, colon, and rectum; with special emphasis on the role of diet. Scand J Gastroenterol Suppl 1974;31:1-235. 
94. Coggon D, Barker DJ, Cole RB, Nelson M. Stomach cancer and food storage. J Natl Cancer Inst 1989;81:117882.

95. Hu JF, Zhang SF, Jia EM, et al. Diet and cancer of the stomach: a case-control study in China. Int J Cancer 1988;41:331-5.

96. Buiatti E, Palli D, Bianchi S, et al. A case-control study of gastric cancer and diet in Italy. III. Risk patterns by histologic type. Int J Cancer 1991;48:369-74.

97. Palli D, Bianchi S, Decarli A, et al. A case-control study of cancers of the gastric cardia in Italy. Br J Cancer 1992;65:263-6.

98. Rademacher JI, Young TB, Kanarek MS. Gastric cancer mortality and nitrate levels in Wisconsin drinking water. Arch Environ Health 1992;47:292-4.

99. Xu G, Song $\mathrm{P}$, Reed PI. The relationship between gastric mucosal changes and nitrate intake via drinking water in a high-risk population for gastric cancer in Moping county, China. Eur J Cancer Prev 1992;1:437-43.

100. La Vecchia C, Negri E, Franceschi S, Decarli A. Case-control study on influence of methionine, nitrite, and salt on gastric carcinogenesis in northern Italy. Nutr Cancer 1997;27:65-8.

101. Ward $\mathrm{MH}$, Sinha R, Heineman EF, et al. Risk of adenocarcinoma of the stomach and esophagus with meat cooking method and doneness preference. Int J Cancer 1997;71:14-9.

102. Tuyns AJ. Salt and gastrointestinal cancer. Nutr Cancer 1988;11:229-32.

103. Friedman GD, Parsonnet J. Salt intake and stomach cancer: some contrary evidence. Cancer Epidemiol Biomarkers Prev 1992;1:607-8.

104. Negri E, La VC, D'Avanzo B, Gentile A, Boyle P, Franceschi S. Salt preference and the risk of gastrointestinal cancers. Nutr Cancer 1990;14:227-32.

105. La Vecchia C, Negri E, D'Avanzo B, Franceschi S. Electric refrigerator use and gastric cancer risk. Br J Cancer 1990;62:136-7.

106. Kato I, Nomura AM. Alcohol in the aetiology of upper aerodigestive tract cancer. Eur J Cancer B Oral Oncol 1994;30b:75-81.

107. Cocco P, Ward MH, Buiatti E. Occupational risk factors for gastric cancer: an overview. Epidemiol Rev 1996;18:218-34.

108. Taylor DN, Blaser MJ. The epidemiology of Helicobacter pylori infection. Epidemiol Rev 1991;13:42-59.

109. Marshall BJ. Helicobacter pylori: A primer for 1994. The Gastroenterologist 1993;1:241-7.

110. Nomura A, Stemmermann GN. Helicobacter pylori and gastric cancer. J Gastroenterol Hepatol 1993;8:294-303.

111. Parsonnet J. Helicobacter pylori and gastric cancer. Gastroenterol Clin North Am 1993;22:89-104.

112. Munoz N. Is Helicobacter pylori a cause of gastric cancer? An appraisal of the seroepidemiological evidence. Cancer Epidemiol Biomarkers Prev 1994;3:445-51.

113. Veldhuyzen van ZSJ, Sherman PM. Helicobacter pylori infection as a cause of gastritis, duodenal ulcer, gastric cancer and nonulcer dyspepsia: a systematic overview. Can Med Assoc J 1994;150:177-85.

114. Danesh J. Helicobacter pylori infection and gastric cancer: systematic review of the epidemiological studies. Aliment Pharmacol Ther 1999;13:851-6.

115. Kuipers EJ. Review article: exploring the link between Helicobacter pylori and gastric cancer. Aliment Pharmacol Ther 1999;13 Suppl 1:3-11.

116. Megraud F. Epidemiology of Helicobacter pylori infection. Gastroenterol Clin North Am 1993;22:73-88.

117. Forman D, Newell DG, Fullerton F, et al. Association between infection with Helicobacter pylori and risk of gastric cancer: evidence from a prospective investigation. Bmj 1991;302:1302-5.

118. Parsonnet J, Friedman GD, Vandersteen DP, et al. Helicobacter pylori infection and the risk of gastric carcinoma. N Engl J Med 1991;325:1127-31.

119. Schistosomes, liver flukes and Helicobacter pylori. In: IARC monographs on the evaluation of carcinogenic risk of chemicals to humans. International Agency for Research on Cancer, Lyon: 1994, volume 61.

120. Nomura A, Stemmermann GN, Chyou PH, Kato I, Perez PGI, Blaser MJ. Helicobacter pylori infection and gastric carcinoma among Japanese Americans in Hawaii [see comments]. N Engl J Med 1991;325:1132-6.

121. van den Brandt PA, Goldbohm RA, van 't Veer P, Volovics A, Hermus RJ, Sturmans F. A large-scale prospective cohort study on diet and cancer in The Netherlands. J Clin Epidemiol 1990;43:285-95.

122. Goldbohm RA, van den Brandt PA, Brants HA, et al. Validation of a dietary questionnaire used in a large-scale prospective cohort study on diet and cancer. Eur J Clin Nutr 1994;48:253-65.

123. van den Brandt PA, Schouten LJ, Goldbohm RA, Dorant E, Hunen PM. Development of a record linkage protocol for use in the Dutch Cancer Registry for Epidemiological Research. Int I Epidemiol 1990;19:553-8. 


\section{Chapter 1}

124. Self SG, Prentice RL. Asymptotic distribution theory and efficiency results for case-cohort studies. Ann Stat 1988;16:64-81.

125. European Network of Cancer Registries Eurocim database. 2.I ed. International Agency for Research on Cancer, Lyon: 1997. 


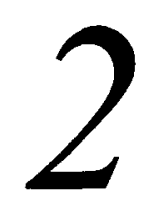

\section{A prospective cohort study on vegetable and fruit consumption and stomach cancer risk in the Netherlands}

Anita A.M. Botterweck ${ }^{1}$

Piet A. van den Brandt ${ }^{1}$

R. Alexandra Goldbohm ${ }^{2}$

1 Department of Epidemiology, University Maastricht, Maastricht, The Netherlands

2 Department of Consumer Research and Epidemiology, TNO Nutrition and Food Research Institute, Zeist, The Netherlands

Published in the American Journal of Epidemiology 1998; 148:842-853. 


\begin{abstract}
The association between vegetables and fruit consumption and stomach cancer risk was investigated in the Netherlands Cohort Study among 120,852 men and women aged 55-69 years at the start in September 1986. Analyses were based on 282 incident stomach cancer cases after 6.3 years of followup. Age- and sex-adjusted rate ratios (RRs) of stomach cancer in increasing quintiles of combined vegetable and fruit consumption were $1.00,0.70,0.65,0.76$ and 0.64 ( $p$ trend $=0.04$ ). Multivariate analysis resulted in RRs that were somewhat closer to one $(p$ trend $=0.14$ ). Furthermore, inverse associations for total vegetables, pulses, raw leafy vegetables, total fruit, citrus fruit and apples and pears that were observed in crude analyses became weaker or disappeared in multivariate analyses. Total vegetable, but not fruit consumption was significantly lower in cases diagnosed in the first follow-up year. In analyses limited to first year cases (resembling a case-control study), RRs for increasing tertiles of total vegetable consumption were $1.00,0.17,0.18$ ( $p$ trend $=0.0001$ ), which may indicate presence of information-bias in case-control studies. This prospective study suggests that vegetable and fruit consumption was not clearly associated with stomach cancer risk in the Dutch population. Our findings are comparable to findings of other cohort studies, but do not support findings of case-control studies.
\end{abstract}




\section{INTRODUCTION}

In recent reviews of the epidemiological literature it was concluded that a high consumption of vegetables and fruit is rather strongly and consistently associated with a reduced stomach cancer risk (1-3). Persons with a high intake compared to a low intake on average tended to have a 50 percent reduction in stomach cancer risk (4). However, this epidemiological evidence is mainly based on studies with a case-control design which may be hampered by information bias. The results of the few prospective studies that have been conducted so far, were less consistent (5-11). The associations with stomach cancer risk, if any, tended to be less strong than the ones reported in case-control studies. Generally, information on consumption of vegetables and fruit in the prospective studies was not very detailed and adjustment for confounding was poor. In addition, none of these studies assessed the independent effect of specific types of vegetables or fruit by adjusting for total vegetables or fruit. The prospective studies were conducted in both Western and non-Western populations, that is Japanese, Chinese, American men of Scandinavian and German descent, and American women. These populations were almost all at relatively high risk for stomach cancer. Here, we report results of the association between various types of vegetables and fruit and stomach cancer risk in a largescale prospective cohort study in the Netherlands (a relatively low risk population) after 6.3 years of follow-up.

\section{MATERIALS AND METHODS}

\section{The cohort study}

The Netherlands Cohort Study on diet and cancer is a prospective cohort study which started in September 1986 among the general population. A detailed description of the study design has been reported elsewhere (12). Briefly, the cohort included 62,573 women and 58,279 men aged 55 to 69 years at the beginning of the study. At baseline, the cohort members completed a mailed, selfadministered questionnaire on dietary habits, smoking, occupation, medical history, personal and family history of cancer, and demographic data. For data analysis the case-cohort approach was used in which cases are derived from the entire cohort, while the person-years at risk of the entire cohort are estimated from a random sample of 3500 subjects (subcohort) (13). This subcohort (1688 men, 1812 women) has been followed up biennially for vital status information in order to estimate the accumulated person time in the cohort. No subcohort members were lost to follow-up. Follow-up for incident cancer has been established by record linkage with cancer registries and a pathology register (14). The present analysis is restricted to cancer incidence in the first 6.3 years of follow-up from September 1986 until December 1992. After excluding subjects reporting prevalent stomach cancer at baseline, cases with in situ stomach carcinoma, stomach cancer other than carcinoma or without microscopically confirmed stomach cancer, there were 310 ( $242 \mathrm{men}, 68$ women) incident stomach carcinoma cases remaining. In the subcohort, 1630 men and 1716 women remained after excluding prevalent cancer cases other than skin cancer. In the subcohort, eight stomach cancer cases were 
detected.

\section{The dietary questionnaire}

The dietary section of the questionnaire was a 150 -item semi-quantitative food frequency questionnaire concentrating on usual consumption of food and beverages during the year preceding the start of the study. The questionnaire was validated against a 9-day diet record (15). The Spearman correlation coefficients between the dietary record and the questionnaire were 0.38 and 0.60 for total vegetable and total fruit consumption, respectively (15). Regarding vegetable consumption, participants were asked to report their consumption frequency of 12 prepared and five raw vegetables, separately for summer and winter. They could choose one of six categories, ranging from "never or less than once per month" to "3-7 times per week". Portion sizes were asked for string/French beans and prepared endive. As for tomatoes and onions participants were asked how many pieces they usually ate per week; for sweet peppers per month and for mushrooms how many $250 \mathrm{~g}$ boxes per month. For tomatoes and sweet peppers these questions were asked for summer and winter specifically. For fruit, participants were asked to report their consumption frequency of eight different types of fruit and the number of pieces they ate each time. For fruit juices, the frequency of consumption and the number of glasses were asked. The seven frequency categories ranged from "never or less than once per month" to "6-7 times per week". Finally, participants could mention other types of fruit used once a week or more in an open-ended question.

\section{Data analysis}

Subjects with incomplete or inconsistent dietary data were excluded, leaving 282 stomach cancer cases and 3123 subcohort members for fruit analyses (15). In order to check the consistency of the responses on vegetable questions, we computed a vegetable error index for each subject based on a count of inconsistencies. If a score of a subject exceeded a preset value, i.e. more than three errors, the subject was excluded, leaving 265 stomach cancer cases and 2953 subcohort members for vegetable analyses.

The variables of major interest were intake of total vegetables and fruit combined, total vegetables, total fruit, several vegetable and fruit groups and specific types of vegetables and fruit (see table 1). The Allium vegetables onion and leek were not included in the analyses because they have been examined in the Netherlands Cohort Study previously (16). For vegetables, cases and subcohort members were categorized according to a combined summer and winter consumption frequency. Because individual portion sizes of prepared vegetables correlated in the pilot study data, the individual portion sizes of string/French beans and prepared endive were used to derive the individual portion size of other prepared vegetables for each person. Mean daily vegetable consumption (g/day) was calculated by multiplying frequency and portion size. For the calculation of mean daily fruit consumption ( $\mathrm{g} /$ day), frequency and standard weights were used. The intake values of vegetables and fruit were categorized into quintiles, tertiles, or categories, depending on the distribution in the subcohort.

Analyses were conducted for men and women together. Age, sex, level of education (17), stomach 
disorders, family history of stomach cancer, smoking status, fruit consumption (in the case of vegetable analyses) and vegetable consumption (in the case of fruit analyses) were considered as potential confounders. Participants who reported having an ulcer, a stomach bleeding or a stomach operation because of a bleeding in the past and/or reported having previously taken medication for stomach complaints longer than half a year were defined as having stomach disorders. On average they reported to have the first complaints 20 years ago before baseline. Nitrate, nitrite consumption and energy intake were not included in multivariate analyses because they were not associated with stomach cancer risk in our study (18). Furthermore, inclusion of these three factors in the model did not change the risk estimates. The GLIM statistical package was used to compute rate ratios (RRs) of stomach cancer and their 95 percent confidence intervals $(95 \% \mathrm{CD})(19)$ ). Exponentially distributed survival times were assumed in the follow-up period. Specific macros were developed to account for the additional variance introduced by using the subcohort instead of the entire cohort (20). Tests for trend in the RRs were based on likelihood ratio tests. Two-sided $p$-values were used throughout this article.

For each category of vegetable and fruit consumption combined, total vegetables, total fruit and vegetable and fruit groups, both age- and sex-adjusted rate ratios and multivariate RRs were computed. Furthermore, multivariate RRs for continuous estimates of total vegetables and fruit and specific vegetables and fruit were calculated per increment of $25 \mathrm{~g} /$ day. The independent contribution of specific vegetables and fruit was assessed by analyses in which total vegetable or fruit consumption was included in the model, respectively. To evaluate the potential influence of prediagnostic symptoms of stomach cancer on vegetable and fruit consumption, we first calculated the mean intake of vegetables and fruit comsumption combined, of total vegetables and of fruit for cases grouped according to the year of follow-up. Thereafter, analyses were conducted after excluding cases diagnosed in the first year of follow-up and analyses limited to cases diagnosed in the first year of follow-up for vegetable and fruit consumption combined (21). Furthermore, analyses for vegetable and fruit consumption combined were conducted for subjects with and without stomach disorders to evaluate whether results are different because of changes in dietary habits related to stomach disorders.

\section{RESULTS}

Differences in the mean daily vegetable consumption between men and women in the subcohort were small (table 1). Women in the subcohort consumed more fruit than did men (196.1 versus 154.9 $\mathrm{g} /$ day) which was due to a difference in consumption of nearly all types of fruit and fruit juices. Cases consumed less vegetables than did subcohort members. This was true for both men and especially women. Both male and female cases also consumed less fruit and fruit juices than did subcohort members, except that female cases consumed more citrus fruit than did female subcohort members. Fruit consumption in the subcohort was positively associated with age $(p<0.01)$ (table 2). Current smokers and subjects with stomach complaints consumed less vegetables and fruit than did ex- 
TABLE 1. Mean (standard deviation (SD)) daily vegetable and fruit consumption (in grams) in stomach cancer cases and subcohort members by sex: Netherlands Cohort Study 1986-1992.

\begin{tabular}{|c|c|c|c|c|}
\hline \multirow[b]{2}{*}{ Vegetable/fruit consumption } & \multicolumn{2}{|l|}{ Men } & \multicolumn{2}{|l|}{ Women } \\
\hline & Cases $(n=208)$ & Subcohort $(n=1456)$ & Cases $(n=57)$ & Subcohort $(n=1497)$ \\
\hline \multicolumn{5}{|l|}{ Vegetable consumption } \\
\hline Total vegetables & $182.0(80.6)$ & $187.1(76.3)$ & $176.2(79.2)$ & $191.0(74.5)$ \\
\hline Prepared vegetables & $148.5(68.5)$ & $150.8(63.1)$ & $134.8(59.1)$ & $149.5(59.3)$ \\
\hline Raw vegetables * & $33.5(25.4)$ & $36.2(29.0)$ & $41.4(31.3)$ & $41.5(29.8)$ \\
\hline Brassicas & $33.3(21.9)$ & $32.7(20.3)$ & $28.4(20.1)$ & $31.6(20.0)$ \\
\hline Brussels sprouts & $8.0(7.3)$ & $7.7(6.7)$ & $6.5(5.9)$ & $7.7(7.4)$ \\
\hline Cauliflower & $14.6(11.4)$ & $14.6(11.1)$ & $12.8(10.3)$ & $13.9(10.5)$ \\
\hline Cabbage (white/green) & $6.9(8.3)$ & $7.2(8.2)$ & $6.2(7.7)$ & $6.9(8.0)$ \\
\hline Kale & $3.7(3.9)$ & $3.3(3.4)$ & $2.9(3.6)$ & $3.2(3.4)$ \\
\hline Pulses *t & $32.9(23.3)$ & $34.7(23.0)$ & $26.4(18.3)$ & $30.7(20.7)$ \\
\hline String/French beans * & $19.9(17.4)$ & $20.5(15.3)$ & $15.2(10.7)$ & $19.5(14.7)$ \\
\hline Broad beans & $5.0(7.1)$ & $4.7(7.2)$ & $3.6(6.0)$ & $4.3(6.6)$ \\
\hline Leafy vegetables, prepared & $23.4(17.7)$ & $21.6(16.0)$ & $19.2(18.2)$ & $21.3(14.9)$ \\
\hline Spinach & $11.0(10.5)$ & $9.6(8.9)$ & $8.6(8.4)$ & $9.4(8.3)$ \\
\hline Endive & $12.4(10.4)$ & $12.0(10.8)$ & $10.6(12.9)$ & $11.9(10.2)$ \\
\hline Leafy vegetables, raw & $8.4(7.1)$ & $9.9(9.2)$ & $9.1(8.6)$ & $10.1(8.4)$ \\
\hline Endive & $1.5(2.9)$ & $2.4(4.9)$ & $2.2(4.2)$ & $2.5(4.3)$ \\
\hline Lettuce & $6.9(6.1)$ & $7.6(6.7)$ & $6.9(6.5)$ & $7.6(6.6)$ \\
\hline \multicolumn{5}{|l|}{ Other vegetables } \\
\hline Carrots, prepared & $8.4(7.4)$ & $9.0(8.9)$ & $7.1(6.5)$ & $8.9(8.6)$ \\
\hline Carrots, raw * & $1.4(4.6)$ & $2.1(7.8)$ & $5.1(13.8)$ & $3.5(9.4)$ \\
\hline Sweet peppers * & $2.1(3.5)$ & $2.5(4.0)$ & $2.8(3.8)$ & $3.3(4.9)$ \\
\hline Tomatoes * & $19.8(20.1)$ & $19.5(20.1)$ & $24.4(21.1)$ & $23.5(20.3)$ \\
\hline Red beets * & $7.3(7.4)$ & $7.7(8.7)$ & $7.0(7.2)$ & $8.1(7.7)$ \\
\hline Sauerkraut & $6.2(6.0)$ & $5.9(5.5)$ & $4.4(3.8)$ & $5.7(4.9)$ \\
\hline Mushrooms * & $2.8(3.6)$ & $3.2(3.9)$ & $3.0(4.6)$ & $3.7(4.4)$ \\
\hline Gherkins & $1.0(2.1)$ & $1.9(8.1)$ & $0.8(2.5)$ & $1.8(6.6)$ \\
\hline Rhubarb & $1.9(5.0)$ & $2.2(5.7)$ & $2.4(5.9)$ & $2.4(5.4)$ \\
\hline Fruit consumption & Cases $(n=219)$ & Subcohort $(n=1525)$ & Cases $(n=63)$ & Subcohort $(n=1598)$ \\
\hline Total fruit * & $144.9(103.2)$ & $154.9(111.8)$ & $186.6(111.0)$ & $196.1(118.9)$ \\
\hline Citrus fruit * & $56.0(63.3)$ & $64.8(69.8)$ & $90.5(79.2)$ & $88.2(73.2)$ \\
\hline Oranges * & $39.6(50.8)$ & $40.6(51.1)$ & $57.1(58.0)$ & $55.9(55.8)$ \\
\hline Mandarins * & $3.5(5.8)$ & $3.8(7.2)$ & $4.3(9.7)$ & $5.5(8.9)$ \\
\hline Grapefruit* & $4.4(15.0)$ & $6.6(21.7)$ & $14.7(35.7)$ & $11.4(26.3)$ \\
\hline \multicolumn{5}{|l|}{ Processed orangel } \\
\hline grapefruit juice * & $8.4(32.1)$ & $13.8(38.2)$ & $14.3(29.2)$ & $15.3(35.4)$ \\
\hline Apples, pears * & $62.1(71.7)$ & $67.4(74.6)$ & $72.9(69.7)$ & $84.2(82.0)$ \\
\hline Bananas & $12.2(23.7)$ & $12.9(25.0)$ & $12.7(23.2)$ & $12.9(26.8)$ \\
\hline Strawberries * & $6.5(7.6)$ & $6.8(7.8)$ & $7.4(6.6)$ & $8.1(8.6)$ \\
\hline Grapes* & $4.0(8.5)$ & $3.9(8.5)$ & $5.0(7.6)$ & $5.0(9.7)$ \\
\hline Dried fruit * & $0.4(1.3)$ & $0.7(3.2)$ & $1.2(2.6)$ & $0.9(2.8)$ \\
\hline Other fruit * & $6.7(25.7)$ & $8.0(29.0)$ & $10.6(25.6)$ & $13.5(36.0)$ \\
\hline Other fruit juices * & $6.7(25.6)$ & $7.8(28.7)$ & $10.3(25.3)$ & $12.8(34.2)$ \\
\hline
\end{tabular}

* $\rho$ value (Mann-Whitney $\cup$ test comparing subcohort means between men and women) $<0.05$ $\dagger$ In this group dried seeds also were included 
TABLE 2. Mean intake of total vegetables and fruit ( $g$ /day) in the subcohort for several characteristics for men and women together: Netherlands Cohort Study 1986-1992.

\begin{tabular}{|c|c|c|c|c|}
\hline \multirow[b]{2}{*}{ Characteristics } & \multicolumn{2}{|c|}{ Vegetable consumption } & \multicolumn{2}{|c|}{ Fruit consumption } \\
\hline & $n=2953$ & g/day & $n=3123$ & g/day \\
\hline \multicolumn{5}{|l|}{ Age (years) } \\
\hline $55-59$ & 1132 & 187 & 1198 & 149 \\
\hline $60-64$ & 1025 & 189 & 1082 & 155 \\
\hline $65-69$ & 796 & 185 & 843 & 161 \\
\hline \multicolumn{5}{|l|}{ Cigarette smoking status } \\
\hline never & 1026 & 210 & 1090 & 132 \\
\hline ex-smoker & 1016 & 212 & 1061 & 120 \\
\hline current smoker & 911 & 206 & 972 & 94 \\
\hline \multicolumn{5}{|l|}{ Education level } \\
\hline primary school /ower vocational & 1501 & 204 & 1616 & 87 \\
\hline secondary school/medium vocational & 1034 & 210 & 1080 & 95 \\
\hline university/higher vocational & 398 & 209 & 406 & 92 \\
\hline \multicolumn{5}{|l|}{ Stomach disorders } \\
\hline no & 2676 & 208 & 2832 & 92 \\
\hline yes & 277 & 196 & 291 & 66 \\
\hline \multicolumn{5}{|l|}{ Family history of stomach cancer } \\
\hline no & 2754 & 207 & 2913 & 92 \\
\hline yes & 199 & 202 & 210 & 97 \\
\hline \multicolumn{5}{|l|}{ Fruit consumption } \\
\hline quintile 1 & 606 & 200 & & \\
\hline quintile 2 & 593 & 219 & & \\
\hline quintile 3 & 605 & 220 & & \\
\hline quintile 4 & 584 & 233 & & \\
\hline quintile 5 & 565 & 247 & & \\
\hline \multicolumn{5}{|l|}{ Vegetable consumption } \\
\hline quintile 1 & & & 624 & 50 \\
\hline quintile 2 & & & 629 & 73 \\
\hline quintile 3 & & & 629 & 80 \\
\hline quintile 4 & & & 626 & 90 \\
\hline quintile 5 & & & 615 & 127 \\
\hline
\end{tabular}

" $p$ value (analysis of variance comparing means adjusted for age and sex) $<0.05$; " $p$ value $<0.01$; ** $p$ value $<0.001$ $\dagger p$ value (analysis of variance comparing means adjusted for sex) $<0.01$

$\ddagger$ Due to missing values the numbers do not add up to 2953 or 3123

smokers, non-smokers and subjects without stomach disorders. Both vegetable and fruit consumption differed between subjects with a different level of education. Neither vegetable nor fruit consumption differed between subjects with and without stomach cancer in the family. As expected, a positive association existed between vegetable and fruit consumption $(p<0.001)$. 


\section{Chapter 2}

Table 3 shows categorical analyses of vegetable and fruit consumption. For vegetable and fruit consumption combined, a significant inverse association with stomach cancer risk was observed in the age- and sex-adjusted analysis (trend $p=0.04$ ), with RRs of $0.70,0.65,0.76$ and 0.64 for the second to fifth quintile. After multivariate adjustment, the test for trend was not longer statistically significant. After adjustment for age and sex, a nonsignificant inverse association between total vegetables and stomach cancer was shown. The RRs for increasing quintiles were 1.00, 0.76, 0.47, 0.64 and 0.79 (trend $p=0.10$ ). This U-shaped association was also found for prepared vegetables and pulses (trend $p=0.18$ and 0.09 , respectively). The associations became weaker after multivariate adjustment in all three vegetable groups. There was a weak nonsignificant inverse association between stomach cancer risk and raw vegetables and raw leafy vegetables. The test for trend was not significant either. After multivariate adjustment, these weak associations disappeared completely. For Brassicas and prepared leafy vegetables there was no association with stomach cancer risk in both age- and sex-adjusted and multivariate analysis.

The age- and sex-adjusted RRs for total fruit were all lower than one (RRs for increasing quintiles were $1.00,0.92,0.88,0.74,0.83$, respectively) but the trend test was not statistically significant (trend $p=0.14$ ). After multivariate adjustment the RRs became closer to unity. The consumption of citrus fruit and apples and pears was significantly inversely associated with stomach cancer risk in age- and sex-adjusted analyses (trend $p=0.03$ and 0.05 , respectively). However, after multivariate adjustment these associations were no longer statistically significant.

Separate analyses in men only revealed similar findings as compared to the entire group (data not shown).

The RR for both total vegetables and fruit consumption, as continuous variables, for an increment of 25 g/day was 0.98 with a $95 \%$ CI just including one (table 4 ). For raw endive and gherkins a statistically significantly negative association and, for spinach, a statistically significant positive association with stomach cancer risk was observed in models with all confounders and excluding or including total vegetables. RRs ratios for other specific vegetables were close to one (e.g., cauliflower, grapefruit), below one (e.g., cabbage, mandarins) or higher than one (e.g., raw carrots, grapes), but the $95 \%$ Cls never excluded one. When total vegetables or fruit was included in the model, apparent inverse associations disappeared and rate ratios that were higher than one moved farther away from one.

There was an increase in the mean consumption of vegetable and fruit consumption combined and total vegetables in stomach cancer cases diagnosed in later years of follow-up (table 5). The mean fruit consumption in each of the case groups fluctuated but showed no clear trend. Cases diagnosed in the first year of follow-up and those diagnosed in the first 2 years of follow-up consumed significantly less total vegetables than did cases diagnosed in later years of follow-up $(p<0.001)$. For vegetable and fruit consumption combined, table 6 shows that, after exclusion of stomach cancer cases diagnosed in the first year of follow-up, the RRs for the second to the fifth quintile were closer to the null value $(0.84,0.79,0.95$ and 0.81 , respectively; trend $p=0.51)$ than those for the entire group (table 3). If we limited our analyses to the cases diagnosed in first year of follow-up, a strongly reduced stomach cancer risk with increasing tertile of intake was observed (RR of the 
TABLE 3. Rate ratios (RRs) and 95 percent confidence interval ( $95 \% \mathrm{Cl}$ ) of stomach cancer according to intake of vegetables and fruit (categorical analyses): Nethertands Cohort Study 1986-1992.

\begin{tabular}{|c|c|c|c|c|c|c|}
\hline \multirow[b]{2}{*}{ Vegetableffruit group } & \multicolumn{4}{|c|}{ Quintile/calegory of intake } & \multirow[b]{2}{*}{5 (high) } & \multirow[b]{2}{*}{$\begin{array}{l}\text { Test for } \\
\text { trend } \\
\text { pvalue }\end{array}$} \\
\hline & $1(\text { low })^{*}$ & 2 & 3 & 4 & & \\
\hline \multicolumn{7}{|c|}{ Total vegetables and fruit combined } \\
\hline median intake ( $g /$ day) & 190.0 & 276.0 & 345.0 & 418.0 & 544.0 & \\
\hline cases of stomach cancer & 75 & 51 & 47 & 51 & 40 & \\
\hline person years & 3503 & 3567 & 3577 & 3599 & 3620 & \\
\hline RR, age- and sex-adjusted & 1.00 & 0.70 & 0.65 & 0.76 & 0.64 & \\
\hline $95 \% \mathrm{Cl}$ & $\cdot$ & $0.48-1.02$ & $0.45-0.96$ & $0.52-1.11$ & $0.43-0.97$ & 0.04 \\
\hline multivariate RR $†$ & 1.00 & 0.74 & 0.69 & 0.81 & 0.72 & \\
\hline $95 \% \mathrm{Cl}$ & - & $0.50-1.09$ & $0.47-1.03$ & $0.55-1.20$ & $0.48-1.10$ & 0.14 \\
\hline \multicolumn{7}{|l|}{ Total vegetables } \\
\hline median intake (g/day) & 103.0 & 145.0 & 178.0 & 217.0 & 286.0 & \\
\hline cases of stomach cancer & 72 & 57 & 33 & 44 & 58 & \\
\hline person years & 3511 & 3593 & 3573 & 3546 & 3643 & \\
\hline RR, age and sex-adjusted & 1.00 & 0.76 & 0.47 & 0.64 & 0.79 & \\
\hline $95 \% \mathrm{Cl}$ & $\cdot$ & $0.52-1.09$ & $0.31-0.72$ & $0.43-0.95$ & $0.55-1.14$ & 0.10 \\
\hline multivariate RR $\ddagger$ & 1.00 & 0.81 & 0.51 & 0.71 & 0.86 & \\
\hline $95 \% \mathrm{Cl}$ & $\cdot$ & $0.55-1.18$ & $0.33-0.80$ & $0.47-1.07$ & $0.58-1.26$ & 0.25 \\
\hline \multicolumn{7}{|l|}{ Prepared vegetables } \\
\hline median intake (g/day) & 79.0 & 114.0 & 142.0 & 174.0 & 231.0 & \\
\hline cases of stomach cancer & 70 & 51 & 36 & 47 & 60 & \\
\hline person years & 3490 & 3568 & 3577 & 3573 & 3657 & \\
\hline RR, age- and sex-adjusted & 1.00 & 0.70 & 0.49 & 0.68 & 0.79 & \\
\hline $95 \% \mathrm{Cl}$ & $\cdot$ & $0.48-1.03$ & $0.32-0.75$ & $0.46-1.00$ & $0.55-1.14$ & 0.18 \\
\hline multivariate RR $\ddagger$ & 1.00 & 0.73 & 0.52 & 0.72 & 0.81 & \\
\hline $95 \% \mathrm{Cl}$ & - & $0.49-1.08$ & $0.34-0.81$ & $0.48-1.08$ & $0.56-1.19$ & 0.26 \\
\hline \multicolumn{7}{|l|}{ Raw vegetables } \\
\hline median intake (g/day) & 8.0 & 22.0 & 33.0 & 47.0 & 74.0 & \\
\hline cases of stomach cancer & 68 & 49 & 54 & 45 & 48 & \\
\hline person years & 3547 & 3567 & 3520 & 3602 & 3630 & \\
\hline RR, age- and sex-adjusted & 1.00 & 0.69 & 0.89 & 0.73 & 0.81 & \\
\hline $95 \% \mathrm{Cl}$ & - & $0.47-1.02$ & $0.61-1.30$ & $0.49-1.09$ & $0.55-1.19$ & 0.33 \\
\hline multivariate RR $\ddagger$ & 1.00 & 0.78 & 1.02 & 0.84 & 0.97 & \\
\hline $95 \% \mathrm{Cl}$ & - & $0.52-1.16$ & $0.69-1.51$ & $0.56-1.27$ & $0.64-1.46$ & 0.96 \\
\hline \multicolumn{7}{|l|}{ Pulses } \\
\hline median intake (g/day) & 10.0 & 19.0 & 28.0 & 39.0 & 60.0 & \\
\hline cases of stomach cancer & 59 & 54 & 39 & 59 & 53 & \\
\hline person years & 3254 & 3645 & 3620 & 3771 & 3575 & \\
\hline RR, age- and sex-adjusted & 1.00 & 0.82 & 0.52 & 0.78 & 0.71 & \\
\hline $95 \% \mathrm{Cl}$ & - & $0.56-1.21$ & $0.34-0.80$ & $0.53-1.14$ & $0.48-1.05$ & 0.09 \\
\hline multivariate RR $\ddagger$ & 1.00 & 0.82 & 0.54 & 0.81 & 0.70 & \\
\hline $95 \% \mathrm{Cl}$ & - & $0.55-1.22$ & $0.35-0.84$ & $0.54-1.20$ & $0.47-1.06$ & 0.10 \\
\hline
\end{tabular}


TABLE 3. Continued

\begin{tabular}{|c|c|c|c|c|c|c|}
\hline \multirow[b]{2}{*}{ Vegetable/fruit group } & \multicolumn{4}{|c|}{ Quintile/category of intake } & \multirow[b]{2}{*}{5 (high) } & \multirow[b]{2}{*}{$\begin{array}{l}\text { Test for } \\
\text { trend } \\
\rho \text { pvalue }\end{array}$} \\
\hline & $1\left(\right.$ low) ${ }^{*}$ & 2 & 3 & 4 & & \\
\hline \multicolumn{7}{|l|}{ Brassicas } \\
\hline median intake ( $\mathrm{g} / \mathrm{day}$ ) & 10.0 & 20.0 & 27.0 & 38.0 & 58.0 & \\
\hline cases of stomach cancer & 48 & 62 & 51 & 53 & 50 & \\
\hline person years & 3342 & 3447 & 3633 & 3808 & 3636 & \\
\hline RR, age-and sex-adjusted & 1.00 & 1.28 & 0.92 & 0.94 & 0.91 & \\
\hline $95 \% \mathrm{Cl}$ & - & $0.86-1.90$ & $0.61 \cdot 1.39$ & $0.63-1.42$ & $0.60-1.37$ & 0.24 \\
\hline multivariate RR $\ddagger$ & 1.00 & 1.32 & 0.95 & 0.98 & 0.93 & \\
\hline $95 \% \mathrm{Cl}$ & - & $0.88-1.99$ & $0.62-1.45$ & $0.64-1.49$ & $0.61-1.43$ & 0.29 \\
\hline \multicolumn{7}{|l|}{ Leafy vegetables, prepared } \\
\hline median intake (g/day) & 4.0 & 12.0 & 19.0 & 26.0 & 41.0 & \\
\hline cases of stomach cancer & 53 & 52 & 50 & 57 & 52 & \\
\hline person years & 3592 & 3512 & 3229 & 3918 & 3615 & \\
\hline RR, age- and sex-adjusted & 1.00 & 0.91 & 1.00 & 1.01 & 0.93 & \\
\hline $95 \% \mathrm{Cl}$ & - & $0.61-1.36$ & $0.67-1.51$ & $0.68-1.49$ & $0.62-1.39$ & 0.94 \\
\hline multivariate RR $\ddagger$ & 1.00 & 0.94 & 1.05 & 1.02 & 0.96 & \\
\hline $95 \% \mathrm{Cl}$ & - & $0.63-1.43$ & $0.69-1.59$ & $0.68-1.53$ & $0.63-1.44$ & 0.98 \\
\hline \multicolumn{7}{|l|}{ Leafy vegetables, raw } \\
\hline median intake (g/day) & 3.0 & 8.0 & 18.0 & & & \\
\hline cases of stomach cancer & 106 & 90 & 86 & & & \\
\hline person years & 6399 & 5926 & 5539 & & & \\
\hline $\mathrm{RR}$, age- and sex-adjusted & 1.00 & 0.98 & 0.78 & & & \\
\hline $95 \% \mathrm{Cl}$ & . & $0.73-1.32$ & $0.57-1.07$ & & & 0.12 \\
\hline multivariate $R R \ddagger$ & 1.00 & 1.08 & 0.90 & & & \\
\hline $95 \% \mathrm{Cl}$ & - & $0.79-1.47$ & $0.64-1.25$ & & & 0.76 \\
\hline \multicolumn{7}{|l|}{ Total fruit } \\
\hline median intake (g/day) & 46.0 & 109.0 & 157.0 & 216.0 & 325.0 & \\
\hline cases of stomach cancer & 74 & 59 & 57 & 46 & 45 & \\
\hline person years & 3803 & 3707 & 3837 & 3743 & 3797 & \\
\hline $\mathrm{RR}_{\text {, age- and sex-adjusted }}$ & 1.00 & 0.92 & 0.88 & 0.74 & 0.83 & \\
\hline $95 \% \mathrm{Cl}$ & - & $0.64-1.32$ & $0.61-1.27$ & $0.50-1.09$ & $0.56-1.23$ & 0.14 \\
\hline multivariate RR § & 1.00 & 0.98 & 0.94 & 0.80 & 0.97 & \\
\hline $95 \% \mathrm{Cl}$ & - & $0.68-1.43$ & $0.65-1.38$ & $0.54-1.20$ & $0.64-1.48$ & 0.51 \\
\hline \multicolumn{7}{|l|}{ Citrus fruit } \\
\hline median intake (g/day) & 3.0 & 28.0 & 64.0 & 100.0 & 175.0 & \\
\hline cases of stomach cancer & 78 & 63 & 64 & 31 & 45 & \\
\hline person years & 3800 & 3809 & 4255 & 3235 & 3738 & \\
\hline RR, age- and sex-adjusted & 1.00 & 0.87 & 0.84 & 0.60 & 0.75 & \\
\hline $95 \% \mathrm{Cl}$ & - & $0.61-1.23$ & $0.59-1.19$ & $0.39-0.93$ & $0.51-1.11$ & 0.03 \\
\hline multivariate RR § & 1.00 & 0.95 & 0.92 & 0.70 & 0.86 & \\
\hline $95 \% \mathrm{Cl}$ & - & $0.66-1.36$ & $0.64-1.33$ & $0.44-1.10$ & $0.57-1.29$ & 0.20 \\
\hline
\end{tabular}


TABLE 3. Continued

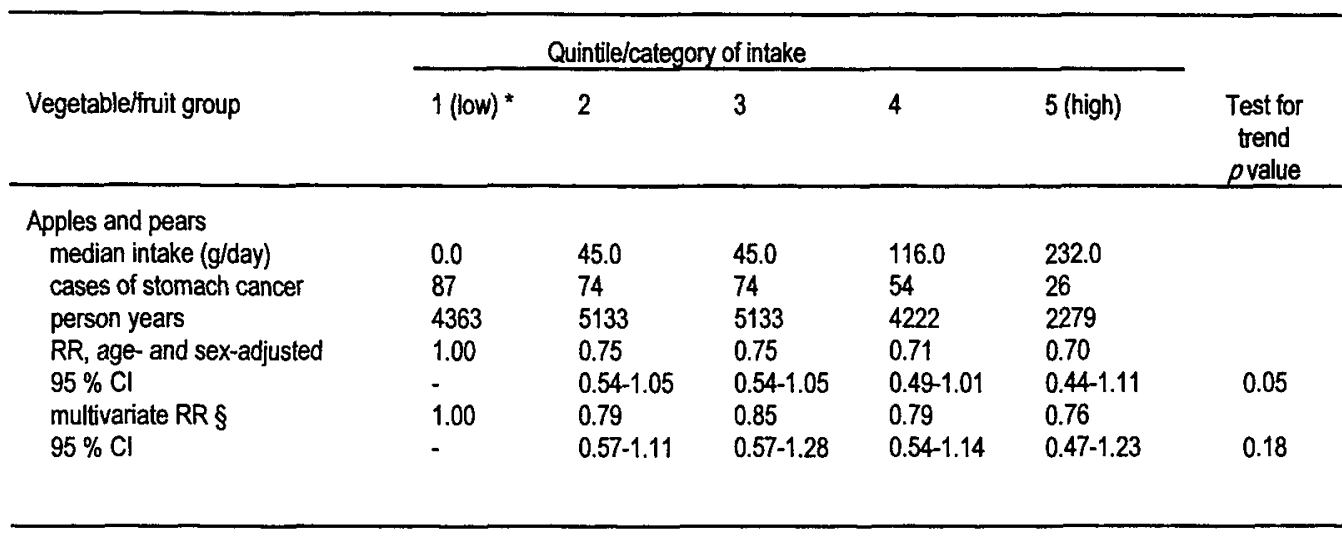

* Reference category

† The model included age, sex, smoking, eduction, stomach disorders and family history of stomach cancer

$¥$ The model included age, sex, smoking, eduction, stomach disorders, family history of stomach cancer and total fruit consumption (g/day)

$\S$ The model included age, sex, smoking, eduction, stomach disorders, family history of stomach cancer and total vegetable consumption (g/day)

highest to lowest tertile $=0.49,95 \% \mathrm{CI} 0.20-1.18$, trend $p=0.06$ ). This inverse association could be attributed exclusively to the lower vegetable consumption of the first year cases: the RRs and $95 \% \mathrm{CI}$ for increasing tertiles of total vegetable consumption were $1.00,0.17(0.06-0.50), 0.18(0.06-$ $0.54)$, trend $p=0.0001$, while these were $1.00,0.84(0.34-1.90), 1.01(0.42-2.41)$, trend $p=0.96$ for total fruit consumption. When cases diagnosed in the first or second year of follow-up were combined ( $n=70$ cases), similar associations were found (data not shown). For subjects without stomach disorders, RRs were almost all similar to those found in the entire group. In contrast, for subjects with stomach disorders a reduced stomach cancer risk with increasing tertile of intake was observed (rate ratio of the highest to lowest tertile $=0.48,95 \%$ CI $0.19-1.19$, trend $p=0.09$ ).

\section{DISCUSSION}

We found evidence for an inverse association between stomach cancer risk and the consumption of vegetable and fruit consumption combined, total vegetables, pulses, raw leafy vegetables, total fruit, citrus fruit and apples and pears in age- and sex-adjusted analyses, which became weaker and nonsignificant in multivariate analyses. In 30 analyses of specific vegetables and fruit, we found statistically significant inverse associations for raw endive and gherkins and a statistically significant positive association for spinach, which all must be regarded cautiously because of multiple testing. Analyses limited to cases occurring in the first year of follow-up revealed a strong reduced stomach cancer risk with increasing vegetable and fruit consumption combined. For subjects with stomach 
TABLE 4. Rate ratios (RRs) and 95 percent confidence intervals $(95 \% \mathrm{Cl})$ for continuous estimates of vegetables and fruit intake (total and specific types): Netherlands Cohort Study 1986-1992.

\begin{tabular}{|c|c|c|c|c|}
\hline Vegetables or fruit variables & 25 gram $R^{*}$ * & $95 \% \mathrm{Cl}$ & 25 gram RR † & $95 \% \mathrm{Cl}$ \\
\hline Total vegetables $\ddagger$ & 0.98 & $0.94-1.02$ & - & - \\
\hline Brussels sprouts & 1.03 & $0.65-1.65$ & 1.18 & $0.70-1.98$ \\
\hline Cauliflower & 0.97 & $0.72-1.31$ & 1.05 & $0.75-1.47$ \\
\hline Cabbage (white/green) & 0.87 & $0.57-1.31$ & 0.93 & $0.59-1.48$ \\
\hline Kale & 1.70 & $0.70-4.14$ & 2.13 & $0.83-5.47$ \\
\hline String/French beans & 0.85 & $0.67-1.07$ & 0.86 & $0.66-1.12$ \\
\hline Broad beans & 1.00 & $0.63-1.58$ & 1.07 & $0.67-1.73$ \\
\hline Spinach & 1.40 & $0.99-1.97$ & 1.66 & $1.12-2.45$ \\
\hline Endive, prepared & 1.03 & $0.76-1.39$ & 1.05 & $0.75-1.47$ \\
\hline Endive, raw & 0.33 & $0.12-0.89$ & 0.34 & $0.12-0.94$ \\
\hline Lettuce & 0.88 & $0.52-1.48$ & 0.94 & $0.55-1.62$ \\
\hline Carrots, prepared & 0.79 & $0.52-1.21$ & 0.83 & $0.52-1.32$ \\
\hline Carrots, raw & 1.12 & $0.75-1.67$ & 1.18 & $0.78-1.78$ \\
\hline Sweet peppers & 0.82 & $0.34-1.95$ & 0.94 & $0.37-2.37$ \\
\hline Tomatoes & 1.07 & $0.91-1.26$ & 1.16 & $0.96-1.40$ \\
\hline Red beets & 0.76 & $0.50-1.16$ & 0.79 & $0.50-1.25$ \\
\hline Sauerkraut & 0.92 & $0.51-1.67$ & 1.04 & $0.54-2.00$ \\
\hline Mushrooms & 0.80 & $0.33-1.97$ & 0.89 & $0.35-2.25$ \\
\hline Gherkins & 0.29 & $0.09-0.91$ & 0.30 & $0.09-0.95$ \\
\hline Rhubarb & 0.82 & $0.43-1.57$ & 0.84 & $0.44-1.61$ \\
\hline Total fruit $\S$ & 0.98 & $0.96-1.01$ & - & - \\
\hline Oranges & 1.00 & $0.94-1.06$ & 1.02 & $0.95-1.10$ \\
\hline Mandarins & 0.83 & $0.53-1.32$ & 0.87 & $0.55-1.39$ \\
\hline Grapefruit & 0.98 & $0.85-1.13$ & 1.00 & $0.86-1.17$ \\
\hline Apples, pears & 0.97 & $0.93-1.02$ & 0.98 & $0.92-1.05$ \\
\hline Bananas & 0.97 & $0.85-1.10$ & 0.98 & $0.86-1.12$ \\
\hline Strawberries & 0.87 & $0.58-1.32$ & 0.91 & $0.60-1.39$ \\
\hline Grapes & 1.06 & $0.75-1.48$ & 1.12 & $0.79-1.59$ \\
\hline Orange/grapefruit juice & 0.92 & $0.82-1.03$ & 0.92 & $0.82-1.03$ \\
\hline Other fruit juice & 0.95 & $0.84-1.07$ & 0.95 & $0.84-1.08$ \\
\hline Dried fruit & 0.54 & $0.13-2.23$ & 0.57 & $0.14-2.37$ \\
\hline Other fruit & 0.95 & $0.84-1.07$ & 0.95 & $0.84-1.07$ \\
\hline
\end{tabular}

* Adjusted for age, sex, smoking, education, stomach disorders, family history of stomach cancer and total fruit consumption (for vegetables variables) or total vegetable consumption (for fruit variables)

$\dagger$ Adjusted for age, sex, smoking, education, stomach disorders, family history of stomach cancer, total fruit consumption (g/day) and total vegetable consumption ( $\mathrm{g} /$ day)

$\ddagger$ Adjusted for age, sex, smoking, education, stomach disorders, family history of stomach cancer and total fruit consumption (g/day) $\S$ Adjusted for age, sex, smoking, education, stomach disorders, family history of stomach cancer and total vegetable consumption (g/day)

disorders, a reduced risk with increasing vegetable and fruit consumption combined was also found. This cohort study was conducted in a large sample of men and women from the general Dutch population. After 6.3 years of follow-up, the number of stomach cancer cases identified $(n=282)$ should be sufficient to detect a large effect if present. One of the strengths of our study is the high 
TABLE 5. Mean (standard deviation (SD)) daily consumption of total vegetables and fruit combined (N\&F), total vegetables and fruit in stomach cancer cases according to year of follow-up: Netherlands Cohort Study, 1986-1992.

\begin{tabular}{|c|c|c|c|c|c|c|}
\hline \multirow[b]{2}{*}{ Group * } & \multicolumn{2}{|c|}{ V\&F } & \multicolumn{2}{|c|}{ Total vegetables } & \multicolumn{2}{|c|}{ Total fruit } \\
\hline & $\begin{array}{c}\text { Number of } \\
\text { cases }\end{array}$ & $\begin{array}{c}\text { Mean (SD) } \\
\text { g/day }\end{array}$ & $\begin{array}{c}\text { Number of } \\
\text { cases }\end{array}$ & Mean (SD) & $\begin{array}{c}\text { Number of } \\
\text { cases }\end{array}$ & $\begin{array}{c}\text { Mean (SD) } \\
\text { glday }\end{array}$ \\
\hline All cases & 265 & $335.7(146.7)$ & 265 & $180.8(80.2)$ & 282 & $154.2(106.2)$ \\
\hline \multicolumn{7}{|l|}{$\begin{array}{l}\text { Year of } \\
\text { follow-up } \dagger\end{array}$} \\
\hline 1 & 31 & $293.6(142.5)$ & 31 & $138.6(75.0)$ & 34 & $155.0(103.7)$ \\
\hline 2 & 39 & $307.8(138.3)$ & 39 & $166.5(78.9)$ & 40 & $143.1(90.3)$ \\
\hline 3 & 36 & $348.6(139.8)$ & 36 & $176.6(63.0)$ & 41 & $162.6(125.8)$ \\
\hline 4 & 47 & $340.6(132.4)$ & 47 & $182.8(8.0)$ & 48 & $156.1(97.2)$ \\
\hline 5 & 50 & $379.5(163.7)$ & 50 & $208.8(90.6)$ & 51 & $170.0(109.1)$ \\
\hline $6+7$ & 62 & $327.7(148.9)$ & 62 & $189.1(77.3)$ & 68 & $142.1(108.9)$ \\
\hline
\end{tabular}

* Mean (SD) of consumption in the subcohort was 362.3 (148.5) $\mathrm{g} /$ day $(n=2953), 189.1$ (75.4) $\mathrm{g} / \mathrm{day}(\mathrm{n}=2953), 175.7$ (117.3) g/day $(\mathrm{n}=3123)$ for $\mathrm{V} \& \mathrm{~F}$, total vegetable consumption and fruit consumption, respectively

$\dagger \rho$ value of Mann-Whitney $U$ test between the mean intake of the first and following years of follow-up was $0.06,0.0005$ and 0.89 for V\&F, total vegetables, and fruit total, respectively

degree of completeness of follow-up of both person-years and cancer cases, indicating that selection bias due to loss to follow-up is unlikely. Another strength with the prospective design is that the diet is measured before the disease is diagnosed thus avoiding the problem of biased recall of dietary habits. A fact that could have influenced the results is that people with preclinical symptoms of stomach carcinoma or stomach disorders might have changed their dietary habits months or years before the baseline measurement. Therefore, we compared results of analyses in which we excluded cases diagnosed during the first year of follow-up or subjects with stomach disorders with analyses with the total group. In multivariate analyses, adjustment was made for all measured variables which were associated with stomach cancer risk. However, it is possible that unmeasured or unidentified risk factors may have affected the study results. We could not adjust for Helicobacter pylori infection because this was not measured in 1986. The prevalence of antibodies against Helicobacter pylori is about $50 \%$ in healthy Dutch people aged $50-70$ years (22). We can only speculate that a certain proportion of our study subjects with stomach disorders (e.g., peptic ulcer, gastritis) may be infected with Helicobacter pylori and as a consequence have lowered their vegetable and fruit consumption. However, subjects without severe stomach disorders may also be infected but did not change their dietary habits. Stratified analyses (on stomach cancer and vegetable and fruit consumption combined consumption) by subjects with and without stomach disorders revealed a stronger association in subjects with stomach disorders. Thus, subjects with and without stomach disorders should be regarded as separate groups in analyses.

A potential limitation of our study is the possibility of misclassification of exposure. Particularly, the estimation of the frequency of consumption of a wide range of vegetables in both summer and winter as well as the estimation of the portion size is rather difficult. It is therefore possible that participants 
TABLE 6. Multivariate rale ratios (RRs) and 95 percent confidence interval ( $95 \% \mathrm{Cl}$ ) of stomach cancer according to quintiles or tertiles of combined vegetable and fruit intake (N\&F, g/day): Netherlands Cohort Study 1986-1992.

\begin{tabular}{|c|c|c|c|c|c|}
\hline \multicolumn{2}{|c|}{$\begin{array}{l}\text { V\&F } \\
\text { (median intake in g/day) }\end{array}$} & Number of cases & Person-years & $\operatorname{RR}(95 \% \mathrm{Cl})$ & $\begin{array}{c}\text { Test for trend } \\
\text { pvalue }\end{array}$ \\
\hline \multicolumn{6}{|c|}{ Exclusion of cases diagnosed in first year of follow-up $\dagger$} \\
\hline Quintile $1^{*}$ & $(190.0)$ & 60 & 2,916 & 1.00 & \\
\hline Quintile 2 & $(276.0)$ & 46 & 2,979 & $0.84(0.55-1.26)$ & \\
\hline Quintile 3 & $(345.0)$ & 43 & 2,985 & $0.79(0.52-1.19)$ & \\
\hline Quintile 4 & $(418.0)$ & 48 & 3,009 & $0.95(0.63-1.43)$ & \\
\hline Quintile 5 & $(554.0)$ & 36 & 3,018 & $0.81(0.52-1.26)$ & 0.51 \\
\hline \multicolumn{6}{|c|}{ Analysis restricted to cases detected in the first year of follow-up $\dagger$} \\
\hline Tertile $1^{*}$ & $(226.0)$ & 18 & 962 & 1.00 & \\
\hline Tertile 2 & $(345.0)$ & 6 & 995 & $0.37(0.15-0.94)$ & \\
\hline Tertile 3 & $(493.0)$ & 7 & 967 & $0.49(0.20-1.18)$ & 0.06 \\
\hline \multicolumn{6}{|c|}{ Subjects without stomach disorders $\ddagger$} \\
\hline Quintile 1* & $(192.0)$ & 57 & 3,035 & 1.00 & \\
\hline Quintile 2 & $(275.0)$ & 40 & 3,181 & $0.75(0.49-1.15)$ & \\
\hline Quintile 3 & $(346.0)$ & 38 & 3,291 & $0.67(0.44-1.04)$ & \\
\hline Quintile 4 & $(418.0)$ & 44 & 3,323 & $0.88(0.58-1.35)$ & \\
\hline Quintile 5 & $(555.0)$ & 36 & 3,387 & $0.76(0.48-1.18$ & 0.35 \\
\hline \multicolumn{6}{|c|}{ Subjects with stomach disorders $\ddagger$} \\
\hline Tertile 1* & $(213.0)$ & 26 & 703 & 1.00 & \\
\hline Tertile 2 & $(328.0)$ & 16 & 524 & $0.87(0.43-1.73)$ & \\
\hline Tertile 3 & $(487.0)$ & 7 & 421 & $0.48(0.19-1.19)$ & 0.09 \\
\hline
\end{tabular}

\footnotetext{
* Reference category

† Adjusted for age, sex, family history of stomach cancer, stomach disorders, education and smoking status $¥$ Adjusted for age, sex, family history of stomach cancer, education, smoking status
}

to some degree have under- or overestimated their actual intake. This possible non-differential misclassification would have resulted in bias towards the null value, and consequently the actual risk estimates may have been stronger than those we have observed. We have, however, intended to minimize the amount of uninformative data. Subjects with incomplete or inconsistent dietary data and, specifically, those subjects who appeared not to have understood how to answer the questions on vegetable consumption were excluded. The correlation coefficient for total vegetable consumption is rather low but comparable to the figures reported for other prospective studies (23-25). A reason 
for the low correlation may be the relative lack of contrast in the frequency of total vegetable consumption (as indicated by a coeffient of variation of approximately $40 \%$ ). In the Dutch population, people are accustomed to a diet including one hot meal per day, which almost always includes vegetables. However, because of personal preferences, the contrast is much higher for specific vegetables (coeffient of variation is approximately $100 \%$ ) and, therefore, a smaller measurement error is to be expected. Fruit consumption is easier to estimate, and the contrast in the fruit consumption was high (about a 6-fold difference between the highest and lowest quintile) (coeffient of variation is approximately $70 \%$ ) and large enough to detect an effect. Moreover, in this study population, an inverse association between vegetables and fruit and lung cancer risk has been found, which shows that it is possible to detect associations using our semi-quantative food questionnaire (26).

Our findings are quite comparable to findings of other prospective studies, but they do not support findings of case-control studies which showed a more consistent and a strong protective effect of vegetable and fruit consumption. The six prospective studies that have investigated the effect of vegetable and fruit consumption on stomach cancer did not yield consistent results. A large Japanese study (5247 stomach cancer cases) reported a significant negative association for green-yellow vegetables and stomach cancer (rate ratio daily consumption vs. never $=0.67$ ) (trend $p=0.0008)(5)$, whereas a smaller Japanese study ( 57 cases) reported nonsignificant positive associations for both green-yellow vegetables and other vegetables (rate ratio daily vs. 1-2/week were 1.54 and 1.15, respectively) (9). In the Iowa Women's Health study (26 cases) a nonsignificant inverse association was found for nearly all vegetables and fruit groups (11). In the groups with the highest intake, an approximate halving of the risk was observed. A study among Hawaiians of Japanese descent (150 cases) found a nonsignificant reduction in risk for total vegetables, green vegetables and cruciferous vegetables $(6,7)$. The rate ratios (high consumption vs. never) were 0.7 for all three vegetable groups. Two other studies conducted in the USA ( 75 cases) and China ( 539 cases) reported no association for total vegetables $(8,10)$. For fruit consumption, positive as well as inverse and no associations with stomach cancer risk have been reported in prospective studies (6-11). The relative risks reported for subjects with the highest versus lowest consumption varied from $0.6(6)$ to 1.9 (9), while the contrast in fruit consumption varied from large ( $>301$ g/day vs. 0) (6) to small (daily vs. 1-2 times/week) (9). In these studies adjustment was made for age and sex $(5-7,9)$, age and smoking $(8)$ or age, education and smoking (11). None of these studies assessed the independent effect of specific vegetable or fruit groups by adjusting for total vegetables or fruit. When in the Netherlands Cohort Study both dietary and non-dietary potential confounders were added in the multivariate model some of the weak nonsignificant inverse associations (e.g. raw vegetables) disappeared completely. Thus, insufficient adjustment for potential confounders could have led to a seemingly stronger protective effect in some other studies. In the Netherlands Cohort Study quite detailed information was gathered on vegetable and fruit consumption. In some of the other prospective studies rather short questionnaires with few items on vegetables and fruit consumption were used $(5,9)$.

Specific methodological shortcomings of case-control studies may explain the discrepancies between results of prospective studies and case-control studies. One of the major problems of case-control studies is the possibility of recall bias due to knowledge of the disease status. It has been shown that recall of past dietary intake can be influenced by current dietary habits (27-29). Furthermore, cases 
might have changed their dietary habits as a consequence of their disease or its precursors (e.g. gastritis). Many case-control studies obtained information about food habits of cases (less than) one year before the time of diagnosis of cancer or the onset of symptoms. In our study, we showed that, in the last (two) year(s) before diagnosing stomach cancer, subjects consumed less vegetables than those who were diagnosed in later years. When we included only these cases in analyses, as is done in case-control studies, we found a strong inverse association between vegetable consumption and stomach cancer risk similar to the findings in many case-control studies.

A reason for a reduced consumption of vegetables, but not fruit consumption may be that people with preclinical symptoms of stomach cancer have an aversion to hot meals in which vegetables are usually eaten. We could confirm this because these cases had also a reduced intake of meat, fish, and potatoes mostly eaten with vegetables in a hot meal (data not shown).

The finding of only a weak effect of vegetable and fruit consumption on stomach cancer risk could also be explained by a relatively high intake of vegetables and fruit in the Dutch population. In the Dutch National Food Consumption Survey of 1987-1988, the mean daily vegetable consumption in men and women aged 50-64 years was 165.8 and $163.5 \mathrm{~g}$ and for fruit 129.4 and $162.3 \mathrm{~g}$, respectively (30). In a recently published cohort study in Wales, mean daily intake of vegetables and fruit was 4050 percent lower (118 and $83 \mathrm{~g}$, respectively) than in our study (31). In this study a significant protective effect against digestive tract cancer (of which 30 percent were stomach cancer cases) for

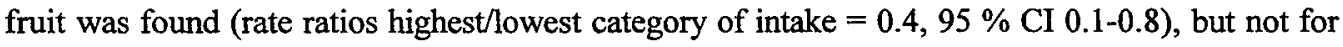
vegetables (rate ratios highest/lowest category of intake $=0.7,95 \% \mathrm{CI} 0.3-1.5$ ). In another study, total vegetable intake was significantly inversely associated (mean vegetable intake was $76.8 \mathrm{~g} /$ day) and fruit intake was nonsignificantly associated with stomach cancer risk (mean fruit intake was 218.4 $\mathrm{g} /$ day)(6). This may imply that when the intake is lower than a certain threshold level, a risk reducing effect may be expected.

In conclusion, a clear protective effect of vegetable consumption against stomach cancer was not found in the Dutch population. The Netherlands Cohort Study was more in line with the findings of other prospective studies than case-controls studies. Methodological limitations of case-control studies, particularly information bias, may have resulted in an observed strong protective effect of vegetable and fruit consumption against stomach cancer in these studies.

Using the present data we were not able to study sex differences in the associations, but it may be worthwhile to repeat the analyses after more years of follow-up because of differences in amount and types of vegetables and fruit consumed between men and women.

\section{ACKNOWLEDGEMENTS}

The Netherlands Cohort Study was supported by the Dutch Cancer Society. This investigation was partly supported by the Commodity Board for Vegetables and Fruits and Unilever Research Laboratorium, Vlaardingen, The Netherlands.

We thank the regional cancer registries, the Dutch national database of Pathology (PALGA), and the National Health Care Information Center for providing incidence data; A. Volovics for statistical 
advice; E. Dorant, S. Van de Crommert, H. Brants, W. Van Dijk, P. Florax, M. Moll, J. Nelissen, and A. Pisters for assistance; H. van Monfort, R. Schmeitz, T. van Monfort, and M. de Leeuw for programming and statistical assistance.

\section{REFERENCES}

1. Steinmetz KA, Potter JD. Vegetables, fruit, and cancer. I. Epidemiology. Cancer Causes Control 1991;2:325-57.

2. Boeing H. Epidemiological research in stomach cancer: progress over the last ten years. J Cancer Res Clin Oncol 1991;117:133-43.

3. Block G, Patterson B, Subar A. Fruit, vegetables, and cancer prevention: a review of the epidemiological evidence. Nutr Cancer 1992;18:1-29.

4. Steinmetz KA, Potter JD. Vegetables, fruit, and cancer prevention: a review. J Am Diet Assoc 1996;96:1027-39.

5. Hirayama T. Life-style and mortality. A large-scale census-based Cohort Srudy in Japan. Basel: Karger, 1990.

6. Chyou PH, Nomura AM, Hankin JH, Stemmermann GN. A case-cohort study of diet and stomach cancer. Cancer Res 1990;50:7501-4.

7. Nomura A, Grove JS, Stemmermann GN, et al. A prospective study of stomach cancer and its relation to diet, cigarettes, and alcohol consumption. Cancer Res 1990;50:627-31.

8. Kneller RW, McLaughlin JK, Bjelke E, et al. A cohort study of stomach cancer in a high-risk American population. Cancer 1991;68:672-8.

9. Kato I, Tominaga S, Matsumoto K. A prospective study of stomach cancer among a rural Japanese population: a 6-year survey. Jpn J Cancer Res 1992;83:568-75.

10. Guo W, Blot WJ, Li $J Y$, et al. A nested case-control study of oesophageal and stomach cancers in the Linxian nutrition intervention trial. Int $J$ Epidemiol 1994;23:444-50.

11. Zheng W, Sellers TA, Doyle TJ, et al. Retinol, antioxidant vitamins, and cancers of the upper digestive tract in a prospective cohort study of postmenopausal women. Am J Epidemiol 1995;142:955-60.

12. van den Brandt PA, Goldbohm RA, van ' $t$ Veer P, et al. A large-scale prospective cohort study on diet and cancer in The Netherlands. J Clin Epidemiol 1990;43:285-95.

13. Self SG, Prentice RL. Asymptotic distribution theory and efficiency results for case-cohort studies. Ann Stat 1988;16:64-81.

14. van den Brandt PA, Schouten LJ, Goldbohm RA, et al. Development of a record linkage protocol for use in the Dutch Cancer Registry for Epidemiological Research. Int J Epidemiol 1990;19:553-8.

15. Goldbohm RA, van den Brandt PA, Brants HA, et al. Validation of a dietary questionnaire used in a large-scale prospective cohort study on diet and cancer. Eur J Clin Nutr 1994;48:253-65.

16. Dorant $\mathrm{E}$, van den Brandt PA, Goldbohm RA, et al. Consumption of onions and a reduced risk of stomach carcinoma. Gastroenterology $\overline{1} 996 ; 110: 12-20$.

17. van Loon AJM, Goldbohm RA, van den Brandt PA. Socioeconomic status and stomach cancer incidence in men: Results from the Netherlands Cohort Study. J. Epidemiol Comm. Health 1998; 52:166-71.

18. van Loon AJM, Botterweck AAM, Goldbohm RA, et al. Intake of nitrate and nitrite and the risk of gastric cancer: a prospective cohort study. Br J Cancer 1998; 78:129-35.

19. Baker R. Glim 3.77 Reference manual. Oxford: Numerical Algorithms Group, 1985.

20. Volovics A, van den Brandt PA. Methods for the analyses of case-cohort studies. Biom J 1997;39:195-214.

21. van den Brandt PA, Goldbohm RA, van't Veer P, et al. Toenail selenium levels and the risk of breast cancer. Am J Epidemiol 1994;140:20-6.

22. Loffeld RJ, Stobberingh E, van Spreeuwel JP, et al. The prevalence of anti-Helicobacter (Campylobacter) pylori antibodies in patients and healthy blood donors. J Med Microbiol 1990;32:105-9.

23. Ocké $\mathrm{MC}$, Bueno-de-Mesquita $\mathrm{HB}$, Goddijn $\mathrm{HE}$, et al. The Dutch EPIC food frequency questionnaire.I. Description of the questionnaire, and relative validity and reproducibility for food groups. Int J Epidemiol 1997;26:S37-S48.

24. Hankin JH, Wilkens LR, Kolonel LN, et al. Validation of a quantitative diet history method in Hawaii. Am J Epidemiol 1991;133:616-28. 


\section{Chapter 2}

25. Nes M, Frost Andersen L, Solvoll K, et al. Accuracy of a quantitative food frequency questionnaire applied in elderly Norwegian women. Eur J Clin Nutr 1992;46:809-21.

26. Goldbohm RA, Verhoeven DTH, Voorrips LE, et al. A prospective cohort study on vegetable consumption and lung cancer risk. Zeist: TNO Nutrition and Food Research Institute, 1997.

27. Jensen $\mathrm{OM}$, Wahrendorf $\mathbf{J}$, Rosenqvist $\mathrm{A}$, et al. The reliability of questionnaire-derived historical dietary information and temporal stability of food habits in individuals. Am J Epidemiol 1984;120:281-90.

28. Thompson FE, Lamphiear DE, Metzner HL, et al. Reproducibility of reports of frequency of food use in the Tecumseh Diet Methodology Study. Am J Epidemiol 1987;125:658-71.

29. Wu ML, Whittemore AS, Jung DL. Errors in reported dietary intakes. II. Long-term recall. Am J Epidemiol 1988;128:1137-45.

30. Ministerie van Welzijn Volksgezondheid en Cultuur en Ministerie van Landbouw en Visserij. Wat eet Nederland; resultaten van de voedselconsumptiepeiling 1987-1988 (In Dutch). Rijswijk: Distributiecentrum DOP, 1988.

31. Hertog MG, Bueno de Mesquita HB, Fehily AM, et al. Fruit and vegetable consumption and cancer mortality in the Caerphilly Study. Cancer Epidemiol Biomarkers Prev 1996;5:673-7. 


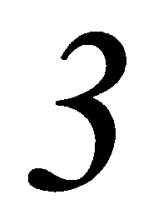

Vitamins, carotenoids, dietary fiber, and the risk of gastric carcinoma: results from a prospective study after 6.3 years of follow-up

Anita A.M. Botterweck ${ }^{1}$

Piet A. van den Brandt ${ }^{1}$

R. Alexandra Goldbohm ${ }^{2}$

1 Department of Epidemiology, University Mastricht, The Netherlands

2 Department of Consumer Research and Epidemiology, TNO Nutrition and Food Research Institute, Zeist, The Netherlands

Published in Cancer 2000; 88:737-48. 


\section{ABSTRACT}

Background: Numerous components of fruit and vegetables are considered to decrease the risk of gastric carcinoma. In the current prospective study, the authors examined the association between the intake of vitamins, carotenoids, dietary fiber and vitamin supplement use and the incidence rate of gastric carcinoma.

Methods: The Netherlands Cohort Study began in 1986 with 120,852 men and women ages 55-69 years. Data regarding diet and other covariates were collected by means of a self-administered questionnaire. After 6.3 years of follow-up, data regarding 282 incident cases of gastric carcinoma and 3123 subcohort members were available for case-cohort analyses.

Results: In analyses adjusted for age, gender, smoking history, education, stomach disorders and family history of gastric carcinoma, an inverse association with vitamin $C$ intake (rate ratio (RR) for highest versus lowest intake category, $0.7,95 \%$ confidence interval ( $95 \% \mathrm{Cl}) 0.5-1.0)$ was observed, with a borderline significant trend across three intake categories $(p=0.06)$. After the exclusion of cases diagnosed in the first and second follow-up years, the RR was 0.9 (95\% CI 0.6-1.2; trend $p=$ 0.44). Intake of retinol and $\beta$-carotene were positively associated with gastric carcinoma risk with highest versus lowest quintile RRs of $1.6(95 \% \mathrm{CI} 1.0-2.5$; trend $p=0.02)$ and $1.6(95 \% \mathrm{CI} 1.0-2.6$; trend $p=0.13$ ), respectively, after the exclusion of first-year and second-year cases. Intake of folate, vitamin $E, \alpha$-carotene, lutein plus zeaxanthin, $\beta$-cryptoxanthin, lycopene and dietary fiber was not associated with gastric carcinoma. Patients who used of vitamin A-containing supplements had a lower risk of gastric carcinoma than nonusers $(\mathrm{RR}=0.4,95 \% \mathrm{CI} 0.2-0.9)$.

Conclusions: No clear inverse associations were found between intake of vitamins, carotenoids and dietary fiber and the risk of gastric carcinoma after adjustment for confounding variables and the exclusion of first-year and second-year cases. 


\section{INTRODUCTION}

Case-control studies have shown a rather consistent inverse association between fruit and vegetable consumption and the risk of gastric carcinoma (1-3). The results of prospective studies, however, are more variable (4-12). Numerous components of fruit and vegetables, e.g., vitamins $\mathrm{C}$ and $\mathrm{E}$, carotenoids, dietary fiber, flavonoids, phenols, hydrolysis products of glucosinolates, may be responsible for the protective effect against gastric carcinoma. The mechanisms of action by which these components may act include antioxidant effects (vitamins C, E, carotenoids, and flavonoids), inhibition of nitrosamine formation (vitamins $\mathrm{C}$ and $\mathrm{E}$ ), dilution or binding of carcinogens (fiber) (1315).

With regard to the risk of gastric carcinoma, dietary intake of vitamins $C$ and $E, \beta$-carotene and retinol (or vitamin $A$ ) have been most extensively studied in case-control studies. For vitamin $C$ and $\beta$-carotene, a consistent inverse association was found, but none was found for vitamin $\mathrm{E}$ (16). Retinol is found only in foods derived from animal sources but is studied in relation to the risk of gastric carcinoma because of its vitamin A activity. Retinol is supposed to reduce risk because it is involved in the regulation of cell differentiation (1). However, the intake of retinol was not associated clearly with the risk of gastric carcinoma (16). Furthermore, two prospective studies $(6,11)$ and two randomized nutrition intervention trials $(17,18)$ have been conducted on the dietary intake of vitamins $\mathrm{C}$ and $\mathrm{E}, \beta$-carotene, and retinol, all with conflicting results.

The association between other components of fruit and vegetables (e.g., folate, dietary fiber, carotenoids) (19-22) and the use of vitamin-containing supplements $(11,21)$ and the risk of gastric carcinoma stomach have been investigated only in a few studies.

In the Netherlands Cohort Study on diet and cancer, we studied the association between the intake of vitamins $\mathrm{C}$ and $\mathrm{E}$, folate, retinol and dietary fiber, and the use of vitamin-containing supplements and the risk of gastric carcinoma after 6.3 years of follow-up. Furthermore, with the use of a recently developed carotenoid food composition table (23), analyses were performed with $\alpha$-carotene, $\beta$ carotene, lutein plus zeaxanthin, $\beta$-cryptoxanthin, and lycopene.

\section{MATERIALS AND METHODS}

\section{The Netherlands Cohort Study}

The Netherlands Cohort Study is a prospective cohort study that began in September 1986 among the general population. The study design has been described previously (24). Briefly, the cohort included 62,573 women and 58,279 men ages 55-69 years at the beginning of the study. At baseline, the cohort members completed a mailed, self-administered questionnaire on dietary habits and other risk factors for cancer. For data analysis, the case-cohort approach was used in which cases were derived from the entire cohort, while the person-years at risk of the entire cohort were estimated from a random sample of 3500 subjects (subcohort) (25). This subcohort (1688 men, 1812 women) was sampled from the cohort after the baseline measurement and was followed for vital status over 6.3 years. No 


\section{Chapter 3}

subcohort members were lost to follow-up.

Follow-up to determine the incidence rate of cancer was established by record linkage with cancer registries and a pathology register (26). The current analyses were restricted to cancer incidence in the first 6.3 years of follow-up from September 1986 until December 1992. After excluding subjects who reported prevalent stomach cancer at baseline, patients with in situ gastric carcinoma, and those with gastric carcinoma other than carcinoma or without microscopically confirmed gastric carcinoma, there were 310 (242 men, 68 women) incident gastric carcinoma cases remaining. In the subcohort, 1630 men and 1716 women remained on the study after excluding prevalent cancer cases other than skin carcinoma.

\section{The dietary questionnaire}

The dietary section of the questionnaire was a 150-item semiquantitative food frequency questionnaire concentrating on habitual consumption of food and beverages during the year preceding the beginning of the study. The questionnaire was validated against a 9-day diet record (27). In this study, variables of principal interest were vitamins $\mathrm{C}$ and $\mathrm{E}$, folate, retinol, carotenoids, dietary fiber, and the use of vitamin-containing supplements. The mean daily intake of vitamins $\mathrm{C}$ and $\mathrm{E}$, retinol and dietary fiber were calculated using the computerized Dutch Food Composition Table (28). For folate, most information was derived from the McCance and Widderson food composition table (29). For calculating the intake of specific carotenoids, an additional food composition table has been constructed recently (23). With this carotenoid table, we were able to evaluate six of the most important types of carotenoids: $\alpha$-carotene, $\beta$-carotene, lutein, zeaxanthin, $\beta$-cryptoxanthin, and lycopene. Briefly, foods that are the main sources of carotenoids (e.g., vegetables) were sampled and analyzed for $\alpha$-carotene, $\beta$-carotene, lutein, zeaxanthin, and lycopene. Some other foods, such as margarines, also were analyzed to check data supplied by manufacturers. For all other foods, data were derived from recent studies based on similar methods of analysis. In the carotenoid food composition table, lutein and zeaxanthin were combined, because most literature sources had not distinguished these two carotenoids. Most vegetables, however, contain primarily lutein and only minor amounts of zeaxanthin.

In the Dutch Food Composition Table dietary fiber is a collective noun for lignin, cellulose, hemicellulose and pectins (in this study, fiber was regarded collectively as total dietary fiber). Dietary fiber can also be regarded as nonstarch polysaccharides (NSP). Data of the NSP content of foods were used to calculate the intake of soluble, insoluble, and total NSPs in this study. The NSP content of foods was calculated using the Englyst method (30). Lignin is not a component of NSPs.

Information of dietary supplement use was collected at baseline using an open-ended question with space for adding four different supplements. Subjects were asked whether they used vitamin tablets, drops or other preparations during the 5-year period before baseline. We did not have information on the vitamin content of the supplements or how often a supplement was used.

Other factors relevant to the association between vitamins, dietary fiber, and use of vitamincontaining supplements and the risk of gastric carcinoma included age, gender, level of education (low, medium, and high) (31), gastric disorders (yes or no), family history of gastric carcinoma (yes or no), smoking history (never, exsmoker, and current smoker), packyears of smoking, coffee and 
alcohol consumption (grams per day), and energy intake (kjoules per day). In this study, gastric disorders were defined as the presence of any gastric disease in the past that required medical attention (e.g. peptic ulcer, gastritis).

\section{Data analysis}

Subjects with incomplete or inconsistent dietary data were excluded (27), leaving 282 (219 men, 63 women) patients with gastric carcinoma and 3123 subcohort members (1525 men, 1598 women) for the analyses. Subjects were classified by quintile of intake of the vitamins, carotenoids, and dietary fiber or were classified by their use of vitamin-containing supplements (yes or no), depending on the distribution in the subcohort. For vitamin C, quintile 2 and 3, and quintile 4 and 5 were combined, because the validation study demonstrated that these quintiles could not be distinguished (27).

All analyses were conducted for men and women together. Because of potential influence of prediagnostic symptoms of stomach cancer on food consumption, all analyses were also conducted after excluding cases diagnosed in the first and second years of follow-up $(4,32)$.

The mean daily intake of vitamins, carotenoids, dietary fiber, or, in the case of vitamin supplements the number and percentage were presented for all cases, all cases with the exception of those patients who were diagnosed in the first or second years of follow-up and subcohort members. Pearson correlation coeffients were calculated for vitamins, carotenoids and dietary fiber and for energy intake in the subcohort.

Data were analysed using the case-cohort approach (25). Age-adjusted and gender-adjusted rate ratios (RRs) for gastric carcinoma and their 95 percent confidence intervals (95\% CD) were computed for all variables, using the GLIM statistical package (33). Exponentially distributed survival times were assumed in the follow-up period. Specific macros were developed to account for the additional variance introduced by using the subcohort instead of using the entire cohort (34). Tests for trend in the rate ratios were based on likelihood ratio tests. The basic multivariate model included age, gender, level of education, gastric disorders, family history of gastric carcinoma, and smoking history. Energy intake, nitrite intake, and sodium intake were not included in multivariate analyses because these variables were not associated with the risk of gastric carcinoma in our study (35). This was supported by the fact that additional inclusion of energy, nitrite, or sodium intake in the model did not change the risk estimates. Coffee, alcohol consumption and packyears of smoking were positively associated with the risk of gastric carcinoma; however, adding these variables to the multivariate model did not essentially change the results. More elaborate models were build in order to identify the unique contribution of specific vitamins or carotenoids to the risk of gastric carcinoma. Furthermore, we studied the interaction between vitamins $C$ and $E$ (both antioxidant vitamins) and vitamin $C$ and folate (both compounds in vegetables), by calculating multivariate rate ratios for combinations of vitamin $\mathrm{C}$ intake (3 categories) and vitamin $\mathrm{E}$ or folate intake (tertiles). 


\section{RESULTS}

The mean baseline intake of vitamins, carotenoids and dietary fiber in all patients with gastric carcinoma, in the case-group without patients who were diagnosed in the first or second follow-up years and in the group of subcohort members are presented in table 1. All cases and the restricted case-group had a slightly higher intake of retinol and vitamin $\mathrm{E}$ than subcohort members. The two case groups had a lower intake of vitamin $\mathrm{C}$ and lycopene than the subcohort members. For folate and lutein plus zeaxanthin, there were no differences in intake levels between all cases and subcohort members; the intake of the restricted case group was higher than that of subcohort members. Intake levels of $\alpha$-carotene, $\beta$-carotene and $\beta$-cryptoxanthin in the two case groups were comparable to the levels in the subcohort members. Intakes of the four fiber variables were similar in the two case groups and subcohort members. A higher percentage of subcohort members used vitamin-containing supplements (vitamin $\mathrm{A}, \mathrm{C}$ or $\mathrm{E}$ ) compared to the two case groups. There were minor differences in percentage of users between the two case groups.

Pearson correlation coefficients ( $\mathrm{r}$ ) were high between vitamin $\mathrm{C}$ intake and $\beta$-cryptoxanthin intake ( $r=0.77)$, between folate and either vitamin $C(r=0.65), \beta$-carotene $(r=0.60)$, or lutein plus zeaxanthin $(\mathrm{r}=0.66)$ and between $\alpha$-carotene and $\beta$-carotene $(\mathrm{r}=0.93)$ and $\beta$-carotene and lutein plus zeaxanthin $(r=0.68)$. Highly correlated with energy intake were folate $(r=0.58)$, vitamin $E(r=0.53)$, total dietary fiber $(r=0.58)$ and total NSP $(r=0.57)$ (data not shown).

In the subcohort, mean intake of vitamins, carotenoids and dietary fiber was compared across categories of potential confounders (data not shown). With increasing age (three age categories: 55-59 years, $60-64$ years, $65-69$ years), the intake of retinol, folate, vitamin $E, \alpha$-carotene, $\beta$-carotene, lutein plus zeaxanthin, and all fiber variables was decreased; the intake of vitamin $C$ and $\beta$-cryptoxanthin was increased. Men had a higher intake of retinol, vitamin $E$, folate, lutein plus zeaxanthin and dietary fiber and a lower intake of vitamin $C, \beta$-cryptoxanthin and lycopene compared with women. There was no difference in the intake of $\alpha$ - and $\beta$-carotene between men and women. Subjects with gastric disorders had a lower intake of vitamins, carotenoids (except lycopene) and dietary fiber compared with subjects without gastric disorders. The intake of vitamins and carotenoids was lower in subjects with a positive family history of gastric carcinoma, but the intake of dietary fiber did not differ between subjects with and without a positive family history. A positive association was found between the three levels of education (low, medium, and high) and the intake of vitamins and lycopene. The intake of $\beta$-carotene and dietary fiber did not differ between the levels of education. For the other variables, no clear pattern was shown. Smokers had a higher intake of retinol and lutein plus zeaxanthin but a lower intake of vitamins $\mathrm{C}$ and $\mathrm{E}$, folate, and the other carotenoids compared with exsmokers and never smokers. There was no difference in dietary fiber intake between never smokers, exsmokers and smokers.

A higher percentage of vitamin-containing supplement users were women, had a higher level of education, had no history of gastric carcinoma in the family, and were never smokers. Those who used supplement users consumed less coffee and more fruit and vitamins (vitamin $C$, folate, retinol and $\alpha$-carotene and $\beta$-carotene, $\beta$-cryptoxanthin, and lycopene) in this study (data not shown). The RRs of vitamins, carotenoids, supplement use, and dietary fiber are shown in tables 2-5. The 
TABLE 1. Vitamin, carotenoids and dietary fiber intake and vitamin supplement use in all stomach cancer cases, in case-group with first-year and second-year cases excluded, and subcohort members: Netherlands Cohort Study 1986-1992.

\begin{tabular}{|c|c|c|c|}
\hline \multirow{3}{*}{ Nutrient variable } & \multicolumn{3}{|c|}{ Vitamin, carotenoids and dietary fiber intake } \\
\hline & \multicolumn{2}{|c|}{ Cases } & \multirow{2}{*}{$\begin{array}{c}\text { Subcohort } \\
n=3123 \\
\text { Mean (SD) }\end{array}$} \\
\hline & $\begin{array}{c}\text { All } \\
n=282 \\
\text { Mean (SD) }\end{array}$ & $\begin{array}{c}\text { first and second year cases } \\
\text { excluded, } n=208 \\
\text { Mean (SD) }\end{array}$ & \\
\hline $\begin{array}{l}\text { Vitamins (mg/day) } \\
\text { retinol } \\
\text { vitamin C } \\
\text { vitamin E } \\
\text { folate }\end{array}$ & $\begin{array}{r}0.60(0.32) \\
96.59(43.85) \\
13.53(6.35) \\
289.76(74.14)\end{array}$ & $\begin{array}{r}0.61(0.31) \\
98.94(44.02) \\
13.88(6.53) \\
295.54(73.04)\end{array}$ & $\begin{array}{r}0.54(0.31) \\
103.42(43.03) \\
13.36(6.24) \\
289.71(77.33)\end{array}$ \\
\hline $\begin{array}{l}\text { Carotenoids (mg/day) } \\
\alpha \text {-carotene } \\
\beta \text {-carotene } \\
\text { lutein + zeaxanthin } \\
\beta \text {-cryptoxanthin } \\
\text { lycopene }\end{array}$ & $\begin{array}{l}0.66(0.48) \\
2.92(1.43) \\
2.54(1.18) \\
0.16(0.17) \\
1.09(1.65)\end{array}$ & $\begin{array}{l}0.68(0.48) \\
3.01(1.42) \\
2.64(1.21) \\
0.16(0.16) \\
1.01(0.97)\end{array}$ & $\begin{array}{l}0.70(0.58) \\
2.97(1.58) \\
2.52(1.11) \\
0.18(0.17) \\
1.19(1.74)\end{array}$ \\
\hline $\begin{array}{l}\text { Dietary fiber ( } g / \text { day) } \\
\text { total dietary fiber } \\
\text { total non-starch poly-saccharides } \\
\text { soluble non-starch poly-saccharides } \\
\text { insoluble non-starch poly-saccharides }\end{array}$ & $\begin{array}{r}26.98(7.48) \\
19.09(5.69) \\
8.40(2.49) \\
10.72(3.40)\end{array}$ & $\begin{array}{r}27.34(7.26) \\
19.35(5.56) \\
8.52(2.43) \\
10.86(3.35)\end{array}$ & $\begin{array}{r}27.03(8.20) \\
19.06(5.90) \\
8.34(2.50) \\
10.74(3.57)\end{array}$ \\
\hline & & amin supplement use ( $(\%))$ & \\
\hline $\begin{array}{l}\text { Vitamin } A \text { containing supplement } \\
\text { Vitamin } C \text { containing supplement } \\
\text { Vitamin } E \text { containing supplement }\end{array}$ & $\begin{array}{r}8(2.8) \\
19(6.7) \\
11(3.9)\end{array}$ & $\begin{array}{r}5(2.4) \\
16(7.7) \\
8(3.8)\end{array}$ & $\begin{array}{r}226(7.2) \\
325(10.4) \\
204(6.5)\end{array}$ \\
\hline
\end{tabular}

three types of analyses included age-adjusted and gender-adjusted, and multivariate analyses of all patients with gastric carcinoma and multivariate analyses after the exclusion of patients who were diagnosed in the first and second follow-up years. For retinol, no clear association was found with the risk of gastric carcinoma in age-adjusted and gender-adjusted, and multivariate adjusted analyses. However, the after exclusion of first-year and second-year cases, a positive association was observed (RR highest vs. lowest quintile 1.6, 95\% CI 1.0-2.5, trend $p=0.02$ ) (table 2). Vitamin C showed a significant inverse association with risk of gastric carcinoma in the age-adjusted and gender-adjusted analyses, with RRs of 0.6 and 0.7 for the second and third intake categories, respectively (trend $p=$ 0.01 ). This association became weaker and was of borderline significance in the multivariate analysis (trend $p=0.06$ ). The RRs moved close to one after the exclusion of first-year and second-year cases: the RRs for increasing intake categories were 1.0, 0.8 and 0.9 (trend $p=0.44$ ) (table 2). Additional adjustment for other vitamins did not change appreciably the observed associations for retinol and vitamin $C$ (data not shown). No clear associations were found between the intake of vitamin $E$, folate, $\alpha$-carotene, lutein and zeaxanthin, and lycopene and the risk of gastric carcinoma in the age-adjusted 
and gender-adjusted, and multivariate analyses. For folate and $\alpha$-carotene, RRs became higher than 1.0 after the exclusion of first-year and second-year cases but without an apparent trend (trend $p=$ 0.40 and trend $p=0.48$, respectively) (table 2 and 3 ). Also, no association was observed with the intake of $\beta$-carotene in the age-adjusted and gender-adjusted analyses and the multivariate analysis. Exclusion of first-year and second-year cases resulted in a nonsignificant, positive association with the risk of gastric carcinoma; the RRs for increasing quintiles were 1.0, 1.5, 1.2, 1.3 and 1.6 (trend $p=0.13$ ) (table 3). Inclusion of the other vitamins in the models did not alter the rate ratios (data not shown). The non-significant, inverse association between $\beta$-cryptoxanthin and gastric carcinoma that was observed in the age-adjusted and gender-adjusted analyses became weaker after multivariate adjustment and disappeared totally after the exclusion of first-year and second-year cases (table 3). Those who used vitamins A, C, or E containing supplements had a lower risk of gastric carcinoma compared with nonusers in all types of analyses, but only those who used vitamin A-containing supplements had a significantly decreased RR (table 4). The additional inclusion of vitamin variables and the use of vitamins $\mathrm{C}$ and $\mathrm{E}$ containing supplements in the model did not change the RRs substantially for users of vitamin A-containing supplements (data not shown). However, the nonsignificant association between the use of vitamins $\mathrm{C}$ or $\mathrm{E}$ containing supplements and the risk of gastric carcinoma disappeared completely after additional adjustment for vitamins and use of supplements containing vitamins $\mathrm{A}$ and $\mathrm{E}$, and $\mathrm{C}$ and $\mathrm{A}$, respectively.

No association was found for total dietary fiber, total NSP, soluble and insoluble NSP in either ageadjusted and gender-adjusted analyses, or multivariate analyses, or in the analyses that excluded firstyear and second-years cases (table 5).

The rate ratios for combined exposure to vitamins $\mathrm{C}$ and $\mathrm{E}$, and to vitamin $\mathrm{C}$ and folate are presented in table 6. In each tertile of vitamin $\mathrm{E}$, increasing intake of vitamin $\mathrm{C}$ was associated with a lower risk of gastric carcinoma. The pattern was less clear for vitamin E. After exclusion of first-year and second-year cases, the rate ratios were all closer to 1.0. For combined exposure of vitamin $\mathrm{C}$ and folate, no consistent pattern was observed in any of the analyses.

\section{DISCUSSION}

In this study, an inverse association of vitamin $\mathrm{C}$ with the risk of gastric carcinoma was found in ageadjusted and gender-adjusted analyses that became less apparent after controlling for several confounders and after the exclusion of patients who were diagnosed in the first and second follow-up years. The intake of retinol and $\beta$-carotene were associated positively with the risk of gastric carcinoma. No clear associations were observed for vitamin $\mathrm{E}$, folate, $\alpha$-carotene, lutein plus zeaxanthin, $\beta$-cryptoxanthin, lycopene, or dietary fiber. The use of vitamin A-containing supplements was associated with a reduced risk of gastric carcinoma.

The Netherlands Cohort Study was carried out in a large sample of the general population of men and women ages 55-69 years at baseline. After 6.3 years of follow-up, 310 gastric carcinoma cases were detected, substantially greater than any other prospective study that investigated the association between vitamins and the risk of gastric carcinoma stomach $(6,11)$. 
TABLE 2. Age- and gender- adjusted rate ratios (RRs), multivariate RRs, and 95 percent confidence interval $(95 \% \mathrm{Cl})$ of stomach carcinoma according to quintiles of vitamins: Netherlands Cohort Study 1986-1992.

\begin{tabular}{|c|c|c|c|c|c|c|}
\hline \multirow[b]{2}{*}{ Vitamins } & \multicolumn{5}{|c|}{ Intake in quintiles/category } & \multirow{2}{*}{$\begin{array}{l}\text { Test for } \\
\text { trend } \\
\rho \text { value }\end{array}$} \\
\hline & 1 (low) ${ }^{*}$ & 2 & 3 & 4 & 5 (high) & \\
\hline \multicolumn{7}{|l|}{ Retinol } \\
\hline median intake (mg/day) & 0.26 & 0.38 & 0.48 & 0.61 & 0.86 & \\
\hline cases/person years & $50 / 3807$ & $32 / 3812$ & $63 / 3807$ & $56 / 3820$ & $81 / 3769$ & \\
\hline RRt & 1.0 & 0.6 & 1.0 & 0.8 & 1.1 & \\
\hline $95 \% \mathrm{Cl}$ & & $0.4-0.9$ & $0.7-1.5$ & $0.6-1.2$ & $0.8-1.7$ & 0.13 \\
\hline cases/person years & $50 / 3763$ & $32 / 3780$ & $63 / 3788$ & $55 / 3814$ & $81 / 3741$ & \\
\hline multivariate RR $\ddagger$ & 1.0 & 0.6 & 1.0 & 0.8 & 1.2 & \\
\hline $95 \% \mathrm{Cl}$ & - & $0.4-0.9$ & $0.7-1.5$ & $0.5-1.2$ & $0.8-1.7$ & 0.12 \\
\hline cases/person years§ & $30 / 2534$ & $27 / 2519$ & $47 / 2543$ & $39 / 2569$ & $64 / 2480$ & \\
\hline multivariate RR & 1.0 & 0.8 & 1.3 & 0.9 & 1.6 & \\
\hline $95 \% \mathrm{Cl}$ & - & $0.5-1.4$ & $0.8-2.0$ & $0.6-1.5$ & $1.0-2.5$ & 0.02 \\
\hline \multicolumn{7}{|l|}{ Vitamin C } \\
\hline median intake (mg/day) & 55.00 & 86.65 & 134.80 & & & \\
\hline cases/person years & $84 / 3771$ & $101 / / 600$ & $97 / 7644$ & & & \\
\hline $\mathrm{RRT}$ & 1.0 & 0.6 & 0.7 & & & \\
\hline $95 \% \mathrm{Cl}$ & & $0.5-0.9$ & $0.5-0.9$ & & & 0.01 \\
\hline cases/person years & $83 / 3737$ & $101 / 7537$ & $97 \Pi 7613$ & & & \\
\hline multivariate RR $\ddagger$ & 1.0 & 0.7 & 0.7 & & & \\
\hline $95 \% \mathrm{Cl}$ & & $0.5-1.0$ & $0.5-1.0$ & & & 0.06 \\
\hline cases/person years $\S$ & $56 / 2506$ & $75 / 5049$ & $76 / 5090$ & & & \\
\hline multivariate RR & 1.0 & 0.8 & 0.9 & & & \\
\hline $95 \% \mathrm{Cl}$ & - & $0.5-1.1$ & $0.6-1.2$ & & & 0.44 \\
\hline \multicolumn{7}{|l|}{ Vitamin $E$} \\
\hline median intake (mg/day) & 6.59 & 9.26 & 12.26 & 15.82 & 21.70 & \\
\hline cases/person years & $54 / 3765$ & $46 / 3842$ & $62 / 3807$ & $62 / 3818$ & $58 / 3783$ & \\
\hline RRt & 1.0 & 0.8 & 1.0 & 1.0 & 0.8 & \\
\hline $95 \% \mathrm{Cl}$ & - & $0.5-1.2$ & $0.7-1.5$ & $0.7-1.4$ & $0.5-1.2$ & 0.46 \\
\hline cases/person years & $53 / 3724$ & $46 / 3817$ & $62 / 3789$ & $62 / 3812$ & $58 / 3745$ & \\
\hline multivariate RR $\ddagger$ & 1.0 & 0.8 & 1.1 & 1.0 & 0.8 & \\
\hline $95 \% \mathrm{Cl}$ & - & $0.5-1.2$ & $0.7-1.6$ & $0.7-1.5$ & $0.5-1.2$ & 0.62 \\
\hline cases/person years§ & $38 / 2481$ & $29 / 2552$ & $46 / 2539$ & $50 / 2565$ & $44 / 2508$ & \\
\hline multivariate RR & 1.0 & 0.7 & 1.1 & 1.1 & 0.9 & \\
\hline $95 \% \mathrm{Cl}$ & - & $0.4-1.2$ & $0.7-1.7$ & $0.7-1.7$ & $0.6-1.4$ & 0.83 \\
\hline \multicolumn{7}{|l|}{ Folate } \\
\hline median intake (mg/day) & 201.96 & 245.93 & 282.06 & 321.34 & 384.16 & \\
\hline cases/person years & $53 / 3762$ & $56 / 3840$ & $59 / 3662$ & $54 / 3749$ & $60 / 3803$ & \\
\hline $\mathrm{RR} \dagger$ & & 0.9 & 0.9 & 0.9 & 0.9 & \\
\hline $95 \% \mathrm{Cl}$ & & $0.6-1.4$ & $0.6-1.4$ & $0.6-1.3$ & $0.6-1.3$ & 0.39 \\
\hline cases/person years & $53 / 3715$ & $55 / 3827$ & $59 / 3830$ & $54 / 3718$ & $60 / 3797$ & \\
\hline multivariate RR $\ddagger$ & 1.0 & 1.0 & 1.0 & 0.9 & 1.0 & \\
\hline $95 \% \mathrm{Cl}$ & & $0.7-1.5$ & $0.7-1.5$ & $0.6-1.4$ & $0.6-1.4$ & 0.71 \\
\hline cases/person years§ & $32 / 2485$ & $41 / 2570$ & $45 / 2564$ & $40 / 2486$ & $49 / 2539$ & \\
\hline multivariate RR & 1.0 & 1.2 & 1.3 & 1.1 & 1.3 & \\
\hline $95 \% \mathrm{Cl}$ & $\cdot$ & $0.8-1.9$ & $0.8-2.1$ & $0.9-1.8$ & $0.8-2.1$ & 0.40 \\
\hline
\end{tabular}

* Reference category; $†$ Adjusted for age and gender, $¥$ Adjusted for age, gender, smoking status, education, stomach disorders, family history of stomach carcinoma; $§$ Analyses with first-year and second-year cases excluded and adjusted for age, gender, smoking status, education, stomach disorders, family history of stomach carcinoma. 
TABLE 3. Age- and gender- adjusted rate ratios (RR) and multivariate rate ratios and 95 percent confidence interval (95\% $\mathrm{Cl}$ ) of stomach carcinoma according to quintiles of carotenoids: Netherlands Cohort Study 1986-1992.

\begin{tabular}{|c|c|c|c|c|c|c|}
\hline \multirow[b]{2}{*}{ Carotenoids } & \multicolumn{5}{|c|}{ Intake in quintiles } & \multirow{2}{*}{$\begin{array}{l}\text { Test for } \\
\text { trend } \\
\text { P-value }\end{array}$} \\
\hline & $1\left(\right.$ low) ${ }^{*}$ & 2 & 3 & 4 & 5 (high) & \\
\hline \multicolumn{7}{|l|}{$\alpha$-carotene } \\
\hline median intake (mg/day) & 0.19 & 0.38 & 0.57 & 0.82 & 1.32 & \\
\hline cases/person years & $61 / 3769$ & $55 / 3824$ & $58 / 3808$ & $51 / 3802$ & $57 / 3813$ & \\
\hline RRt & 1.0 & 0.9 & 0.9 & 0.8 & 1.0 & \\
\hline $95 \% \mathrm{Cl}$ & - & $0.6-1.3$ & $0.7-1.4$ & $0.6-1.2$ & $0.7-1.4$ & 0.79 \\
\hline cases/person years & $61 / 3709$ & $55 / 3792$ & $57 / 3789$ & $51 / 3796$ & $57 / 3800$ & \\
\hline multivariate RR $\ddagger$ & 1.0 & 0.9 & 1.0 & 0.9 & 1.0 & \\
\hline $95 \% \mathrm{Cl}$ & - & $0.6-1.3$ & $0.7-1.4$ & $0.6-1.3$ & $0.7-1.5$ & 1.00 \\
\hline cases/person years§ & $39 / 2465$ & $41 / 2546$ & $44 / 2545$ & $40 / 2545$ & $43 / 2545$ & \\
\hline multivariate $R R$ & 1.0 & 1.0 & 1.1 & 1.0 & 1.2 & \\
\hline $95 \% \mathrm{Cl}$ & - & $0.6-1.6$ & $0.7-1.8$ & $0.7-1.6$ & $0.8-1.9$ & 0.45 \\
\hline \multicolumn{7}{|l|}{$\beta$-carotene } \\
\hline median intake (mg/day) & 1.43 & 2.11 & 2.66 & 3.36 & 4.77 & \\
\hline cases/person years & $54 / 3775$ & $63 / 3818$ & $52 / 3813$ & $52 / 3785$ & $61 / 3824$ & \\
\hline RRt & 1.0 & 1.1 & 0.9 & 0.9 & 1.2 & \\
\hline $95 \% \mathrm{Cl}$ & - & $0.8-1.6$ & $0.6-1.9$ & $0.6-1.4$ & $0.8-1.7$ & 0.83 \\
\hline cases/person years & $54 / 3722$ & $63 / 3805$ & $51 / 3782$ & $52 / 3766$ & $61 / 3812$ & \\
\hline multivariate RR $\ddagger$ & & 1.2 & 1.0 & 1.0 & 1.2 & \\
\hline $95 \% \mathrm{Cl}$ & - & $0.8-1.7$ & $0.6-1.5$ & $0.6-1.5$ & $0.8-1.8$ & 0.61 \\
\hline cases/person years $\S$ & $32 / 2484$ & $49 / 2547$ & $37 / 2542$ & $41 / 2522$ & $48 / 2550$ & \\
\hline multivariate $F . R$ & 1.0 & 1.5 & 1.2 & 1.3 & 1.6 & \\
\hline $95 \% \mathrm{Cl}$ & - & $1.0-2.4$ & $0.7-1.9$ & $0.7-2.1$ & $1.0-2.6$ & 0.13 \\
\hline \multicolumn{7}{|l|}{ Lutein + zeaxanthin } \\
\hline median intake (mg/day) & 1.35 & 1.87 & 2.34 & 2.83 & 3.81 & \\
\hline cases/person years & $68 / 3794$ & $47 / 3787$ & $53 / 3817$ & $47 / 3802$ & $67 / 3816$ & \\
\hline RRT & 1.0 & 0.7 & 0.7 & 0.7 & 1.0 & \\
\hline $95 \% \mathrm{Cl}$ & - & $0.5-1.0$ & $0.5-1.1$ & $0.5-1.0$ & $0.7-1.4$ & 0.86 \\
\hline cases/person years & $68 / 3766$ & $46 / 3768$ & $53 / 3785$ & $47 / 3770$ & $67 / 3797$ & \\
\hline multivariate RR $\ddagger$ & 1.0 & 0.7 & 0.8 & 0.7 & 1.0 & \\
\hline $95 \% \mathrm{C}$ & - & $0.5-1.1$ & $0.5-1.2$ & $0.5-1.0$ & $0.7-1.5$ & 0.94 \\
\hline cases/person years§ & $43 / 2513$ & $34 / 2520$ & $41 / 2550$ & $36 / 2530$ & $53 / 2532$ & \\
\hline multivariate $R R$ & 1.0 & 0.8 & 0.9 & 0.8 & 1.3 & \\
\hline $95 \% \mathrm{Cl}$ & - & $0.5-1.3$ & $0.6-1.5$ & $0.5-1.3$ & $0.8-2.0$ & 0.25 \\
\hline
\end{tabular}

Biased recall of diet was unlikely in this study, because the dietary intake data were collected before gastric carcinoma cancer was diagnosed. Selection bias also was unlikely because of the high completeness of follow-up of the patients and subcohort members (36). In the multivariate analyses, we controlled for all measured risk factors of gastric carcinoma. However, unmeasured or unknown factors may have caused residual confounding. We had no information about the prevalence of Helicobacter pylori infection among the cohort members. Infection with Helicobacter pylori is regarded as an important risk factor for gastric carcinoma (37). In the healthy Dutch population aged 50-70 years, the prevalence of infection was estimated to be 50\% in 1990 (38).

Another fact that may have influenced the results is the nondifferential misclassification of exposure, 
TABLE 3. Continued

\begin{tabular}{|c|c|c|c|c|c|c|}
\hline \multirow[b]{2}{*}{ Carotenoids } & \multicolumn{5}{|c|}{ Intake in quintiles } & \multirow{2}{*}{$\begin{array}{l}\text { Test for } \\
\text { trend } \\
\rho \text { value }\end{array}$} \\
\hline & $1(\text { low })^{*}$ & 2 & 3 & 4 & 5 (high) & \\
\hline \multicolumn{7}{|l|}{ B-cryptoxanthin } \\
\hline median intake (mg/day) & 0.02 & 0.06 & 0.13 & 0.25 & 0.39 & \\
\hline cases/person years & $82 / 3783$ & $54 / 3823$ & $52 / 3791$ & $42 / 3806$ & $52 / 3812$ & \\
\hline RRt & 1.0 & 0.7 & 0.7 & 0.6 & 0.8 & \\
\hline $95 \% \mathrm{Cl}$ & - & $0.5-1.0$ & $0.5-1.1$ & $0.4-0.9$ & $0.6-1.2$ & 0.14 \\
\hline cases/person years & $81 / 3752$ & $54 / 3798$ & $52 / 3775$ & $42 / 3775$ & $52 / 3787$ & \\
\hline multivariate RR $\ddagger$ & & 0.8 & 0.8 & 0.7 & 0.9 & \\
\hline $95 \% \mathrm{Cl}$ & - & $0.6-1.2$ & $0.6-1.2$ & $0.5-1.0$ & $0.6-1.4$ & 0.36 \\
\hline cases/person yearsई & $54 / 2500$ & $42 / 2553$ & $38 / 2532$ & $36 / 2527$ & $37 / 2533$ & \\
\hline multivariate RR & 1.0 & 1.0 & 0.9 & 0.9 & 1.0 & \\
\hline $95 \% \mathrm{Cl}$ & - & $0.6-1.5$ & $0.6-1.4$ & $0.6-1.4$ & $0.6-1.5$ & 0.77 \\
\hline \multicolumn{7}{|l|}{ Lycopene } \\
\hline median intake (mg/day) & 0.15 & 0.48 & 0.81 & 1.21 & 2.20 & \\
\hline cases/person years & $70 / 3790$ & $49 / 3834$ & $55 / 3789$ & $55 / 3810$ & $53 / 3792$ & \\
\hline RRt & 1.0 & 0.7 & 0.9 & 1.0 & 0.9 & \\
\hline $95 \% \mathrm{Cl}$ & & $0.5-1.1$ & $0.6-1.3$ & $0.7-1.4$ & $0.6-1.3$ & 0.87 \\
\hline cases/person years & $70 / 3765$ & $48 / 3821$ & $55 / 3776$ & $55 / 3769$ & $53 / 3755$ & \\
\hline multivariate RR & & 0.7 & 0.9 & 1.1 & 1.0 & \\
\hline $95 \% \mathrm{Cl}$ & & $0.5-1.1$ & $0.6-1.4$ & $0.7-1.5$ & $0.7-1.5$ & 0.50 \\
\hline cases/person years $\S$ & $50 / 2525$ & $30 / 2567$ & $42 / 2532$ & $45 / 2521$ & $40 / 2500$ & \\
\hline multivariate RR & 1.0 & 0.6 & 1.0 & 1.2 & 1.1 & \\
\hline $95 \% \mathrm{Cl}$ & - & $0.4-1.0$ & $0.6-1.5$ & $0.8-1.9$ & $0.7-1.7$ & 0.16 \\
\hline
\end{tabular}

* Reference category, $\uparrow$ Adjusted for age and gender, $\ddagger$ Adjusted for age, gender, smoking status, education, stomach disorders, family history of stomach carcinoma; $\S$ Analyses with first-year and second-year cases excluded and adjusted for age, gender, smoking status, education, stomach disorders, family history of stomach cancer.

which may have resulted in underestimation of the strength of the association. When information about consumption of foods is converted into nutrient intake, this conversion adds further inaccuracy to the data, due to variability in nutrient density of foods, e.g., seasonal influences and methods of preparation or consumption of foods (raw or cooked). However, the results of the validation study show that the questionnaire was able to rank subjects adequately according to their intake of nutrients. The crude Pearson correlation coeffients and the energy-adjusted and gender-adjusted (in parentheses) between the dietary record and the questionnaire for vitamin $\mathrm{A}$ and $\mathrm{C}$ and dietary fiber intake were $r=0.52(r=0.48), r=0.58(r=0.55)$ and $r=0.74(r=0.74)$, respectively (27). Nevertheless, the reference instrument (9-day diet record) used in the validation study may be subject to error; therefore, the possibility of measurement error cannot be excluded.

Furthermore, people with preclinical symptoms of stomach carcinoma may have changed their dietary habits 1-2 years before the diagnosis of gastric carcinoma. We found in an earlier analysis that patients who were diagnosed in the first or second years of follow-up had a significant lower consumption of vegetables (4) and, consequently, a lower intake of certain vitamins, carotenoids and dietary fiber. Therefore, all analyses also were conducted with the exclusion of patients who were 
TABLE 4. Age- and gender- adjusted rate ratios (RR), multivariate rate ratios, and 95 percent confidence interval (95\% CI) of stomach cancer according to users and non-users of vitamin supplements: Netherlands Cohort Study 1986-1992.

\begin{tabular}{|c|c|c|}
\hline Use of vitamin supplements & Non-users * & User \\
\hline $\begin{array}{l}\text { Supplement with vitamin A } \\
\text { cases/person years } \\
\text { RR† } \\
95 \% \mathrm{Cl} \\
\text { cases/person years } \\
\text { multivariate RR } \ddagger \\
95 \% \mathrm{Cl} \\
\text { cases/person years } \S \\
\text { multivariate RR } \\
95 \% \mathrm{Cl}\end{array}$ & $\begin{array}{l}274 / 17636 \\
1.0 \\
- \\
273 / 17520 \\
1.0 \\
- \\
202 / 11720 \\
1.0 \\
-\end{array}$ & $\begin{array}{l}8 / 1380 \\
0.4 \\
0.2-0.9 \\
8 / 1367 \\
0.5 \\
0.2-1.0 \\
5 / 925 \\
0.4 \\
0.2-0.9\end{array}$ \\
\hline $\begin{array}{l}\text { Supplement with vitamin } \mathrm{C} \\
\text { cases/person years } \\
\text { RR† } \\
95 \% \mathrm{Cl} \\
\text { cases/person years } \\
\text { multivariate RR } \\
95 \% \mathrm{Cl} \\
\text { cases/person years§ } \\
\text { multivariate RR } \\
95 \% \mathrm{Cl}\end{array}$ & $\begin{array}{l}263 / 17043 \\
1.0 \\
- \\
262 / 16940 \\
1.0 \\
- \\
191 / 11339 \\
1.0 \\
-\end{array}$ & $\begin{array}{l}19 / 1972 \\
0.7 \\
0.4-1.1 \\
19 / 1947 \\
0.8 \\
0.5-1.2 \\
16 / 1306 \\
0.9 \\
0.5-1.5\end{array}$ \\
\hline $\begin{array}{l}\text { Supplement with vitamin } \mathrm{E} \\
\text { cases/person years } \\
\mathrm{RR \dagger} \\
95 \% \mathrm{Cl} \\
\text { cases/person years } \\
\text { multivariate RR } \\
95 \% \mathrm{Cl} \\
\text { cases/person years } \\
\text { multivariate RR } \\
95 \% \mathrm{Cl}\end{array}$ & $\begin{array}{l}271 / 17772 \\
1.0 \\
- \\
270 / 17669 \\
1.0 \\
- \\
199 / 11828 \\
1.0 \\
-\end{array}$ & $\begin{array}{l}11 / 1243 \\
0.7 \\
0.4-1.2 \\
11 / 1218 \\
0.7 \\
0.4-1.4 \\
8 / 817 \\
0.7 \\
0.4-1.5\end{array}$ \\
\hline
\end{tabular}

${ }^{\star}$ Reference category

† Adjusted for age and gender

$\ddagger$ Adjusted for age, gender, smoking status, education, stomach disorders, family history of stomach carcinoma.

$\S$ Analyses with first and second year cases excluded and adjusted for age, gender, smoking status, eduction, stomach disorders, family history of stomach carcinoma

diagnosed in the first or second follow-up years, resulting overall in different RRs compared with RRs from the analyses in which all cases were included. Only two prospective studies have reported previously on the association between vitamin intake and gastric carcinoma. The Iowa Women's Health Study, in contrast with the current findings, reported an inverse association with vitamins $C$ and $E$, carotenoids and retinol and gastric carcinoma (11). A cohort study among Japanese men in Hawaii reported no statistically significant difference between cases and noncases in mean intake of vitamins $\mathrm{C}$ and $\mathrm{E}$, retinol, and carotenoids (6). Limitations of these studies included a poor control for confounders (6) and a small number of gastric carcinoma cases (11). Furthermore, nutrient intake 
TABLE 5. Age- and gender- adjusted rate ratios (RR), multivariate rate ratios and 95 percent confidence interval $(95 \% \mathrm{Cl})$ of stomach carcinoma according to quintiles of dielary fiber. Netherlands Cohort Study 1986-1992.

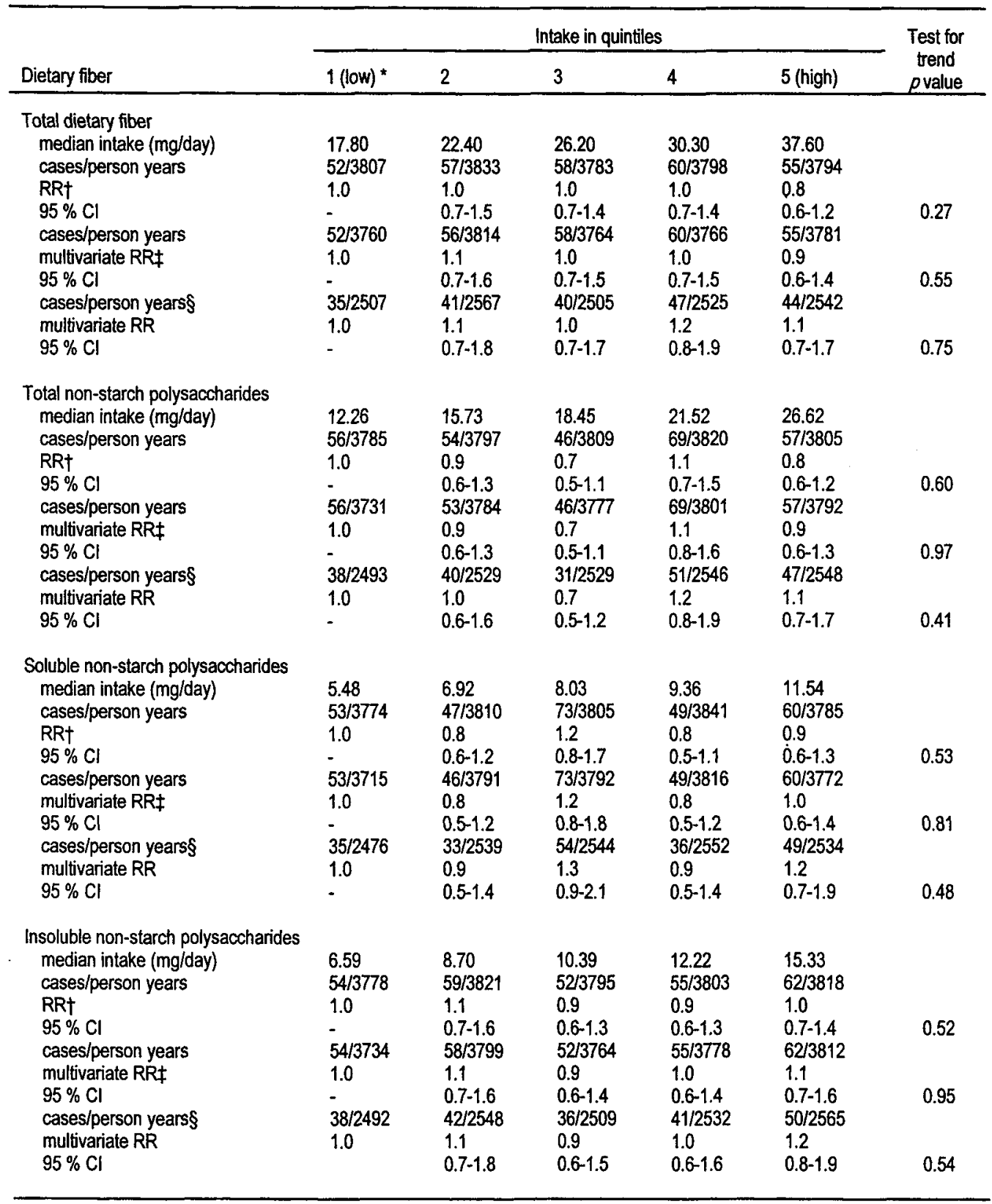

* Reference category; † Adjusted for age and gender, $¥$ Adjusted for age, gender, smoking status, education, stomach disorders, family history of stomach carcinoma; $§$ Analyses with first and second year cases excluded and adjusted for age, gender, smoking status, eduction, stomach disorders, family history of stomach carcinoma. 
TABLE 6: Rate ratios for combinations of vitamin $C$ intake categories and tertiles of vitamin $E$ intake, and vitamin $C$ intake categories and tertiles of folate intake: Netherlands Cohort Study 1986-1992.

\begin{tabular}{|c|c|c|c|c|c|c|}
\hline \multirow{2}{*}{$\begin{array}{l}\text { Vitamin C } \\
\text { categories }\end{array}$} & \multicolumn{3}{|c|}{ RR for Tertiles of vitamin E (no. of cases) } & \multicolumn{3}{|c|}{ RR for Tertiles of folate (no. of cases) } \\
\hline & 1 & 2 & 3 & 1 & 2 & 3 \\
\hline & & & Anal. & all cases * & & \\
\hline \multirow[t]{2}{*}{$\begin{array}{l}1 \\
2 \\
3\end{array}$} & $\begin{array}{l}1.00(38) \dagger \\
0.54(27) \ddagger \\
0.70(23)\end{array}$ & $\begin{array}{l}0.83(27) \\
0.66(38) \\
0.63(30)\end{array}$ & $\begin{array}{l}0.73(18) \\
0.61(36) \ddagger \\
0.62(44) \ddagger\end{array}$ & $\begin{array}{l}1.00(57) \dagger \\
0.50(23) \ddagger \\
0.51(6)\end{array}$ & $\begin{array}{l}0.96(21) \\
0.79(49) \\
0.90(33)\end{array}$ & $\begin{array}{l}0.99(5) \\
0.73(29) \\
0.68(58)\end{array}$ \\
\hline & \multicolumn{6}{|c|}{ Analyses with first and second year cases excluded * } \\
\hline $\begin{array}{l}1 \\
2 \\
3\end{array}$ & $\begin{array}{l}1.00(25) \dagger \\
0.64(21) \\
0.75(16)\end{array}$ & $\begin{array}{l}0.85(18) \\
0.72(27) \\
0.73(23)\end{array}$ & $\begin{array}{l}0.80(13) \\
0.69(27) \\
0.78(37)\end{array}$ & $\begin{array}{l}1.00(35) \dagger \\
0.56(16) \\
0.41(3)\end{array}$ & $\begin{array}{l}1.26(17) \\
1.11(41) \\
0.92(21)\end{array}$ & $\begin{array}{l}1.37(4) \\
0.74(18) \\
0.99(52)\end{array}$ \\
\hline
\end{tabular}

*Adjusted for age, gender, smoking status, education, stomach disorders, family history of stomach carcinoma
$\dagger$ reference category
$\ddagger$ Cl excludes one

was based on a limited number of food items (6), and no results of analyses were reported that excluded first-year and second-year cases. Two randomized nutrition intervention trials on the effects of vitamin/mineral supplementation on the occurrence of gastric carcinoma showed conflicting results. The General Population Trial in Linxian, China, showed that supplements containing $\beta$ carotene, vitamin $\mathrm{E}$, and selenium reduced the incidence of gastric carcinoma with $16 \%$ and the mortality with $21 \%$ after 5.25 -year intervention (17), whereas, in the ATBC trial in Finland, more cases of gastric carcinoma were diagnosed among those who received $\beta$-carotene or $\alpha$-tocopherol compared with those who did not after 7.5 years of follow-up (18). These latter observations may have been due to chance because of the small number of cancer cases. In addition, the intervention period was relatively short, and supplementation was given relatively late in life in both trials. In the General Population Trial, it is not clear whether a specific component or a combination of components of the supplement were responsible for the reduction in gastric carcinoma incidence. We did not observe an inverse association between vitamin $\mathrm{E}$, folate, $\alpha$-carotene, lutein plus zeaxanthin, $\beta$-cryptoxanthin, and dietary fiber and the risk of gastric carcinoma. Several case-control studies, however, found a decrease in the risk of gastric carcinoma associated with vitamin $\mathrm{E}(21,39)$, folate intake $(20,22,40,41)$, and dietary fiber $(19,21)$. One case-control study reported protective effects for lutein and lycopene, but not for $\alpha$-carotene (22).

Only vitamin $\mathrm{C}$ was associated with a decreased risk of gastric carcinoma; however, after adjustment for several confounders and the exclusion of first-year and second-year cases, this association weakened and became nonsignificant. However, the RRs did not change after adjustment for other vitamins. For vitamin $\mathrm{C}$, several different mechanisms of action were described, such as antioxidant effects, free radical scavenger, and the inhibition of nitrosamine formation (13,15). Another biologic explanation for an inverse association is a direct action of vitamin $\mathrm{C}$ on the growth of Helicobacter 
pylori (42). However, a mechanism for this anti-Helicobacter pylori activity is not known.

For retinol, subjects with the highest intake had a significantly increased risk of gastric carcinoma. This was also found in several case-control studies $(20,43,44)$. Retinol is derived from animal food sources. It has been suggested that other components than retinol in these foods, such as toxicants in liver, may be responsible for the observed effect $(44,45)$.

The finding of a positive association between $\beta$-carotene and the risk of gastric carcinoma seems to be in line with the finding of the ATBC trial, in which more cases were detected in the $\beta$-carotene supplement group. It has been hypothesized that $\beta$-carotene may be involved in potentially harmful nutrient interactions and that $\beta$-carotene may inhibit the apoptosis of preneoplastic or neoplastic cells, thus enhancing the survival of such cells (46).

The results of this study indicated that use of vitamin supplements, particular vitamin A-containing supplements, was associated with a reduced risk of gastric carcinoma. In a Swedish case-control study, the regular use of vitamin supplementation was found to be protective (21). In the Iowa Women's Health Study, vitamin supplement use also seemed to be associated with a reduced cancer risk; however, due to the small number of patients, no specific or stable risk estimates could be calculated (11). In the current analysis, the small number of patients were a limitation as well; therefore, this result may have been a chance finding. At the beginning of the study in 1986, use of vitamin supplements was not a common habit in the Dutch population. In the Dutch national Food Consumption Survey 1987-1988, the use of vitamin supplements in the group ages 50-65 years was estimated to be about $6 \%$ (47). In addition, the use of supplements was related positively to adherence to alternative diets (e.g., vegetarian diet) (47). Supplements users, in our study, tended to eat more servings of fruit and vegetables and had a higher level of education; in other studies, they were more likely to exercise and follow a low-fat diet pattern, that is, they had a generally more health-oriented life style (48).This may indicate that this small group of users probably are different in many ways compared with people who do not use vitamin-containing supplements.

There probably is not one specific component in fruit and vegetables that acts on gastric carcinogenesis, but several potentially anticarcinogenic agents may all act together (15). This may explain why we found no effect for several specific components in fruit and vegetables and only a slight protective effect against gastric carcinoma from fruit and vegetables (4). It is also possible that other components in fruit and vegetables than those studied are involved in the development of gastric carcinoma or that factors early in life may be important in its development. The results of migrant studies suggest that this may be the case $(49,50)$. In the current study, it was found that food habits in our study population (ages 55-69 years) were relatively stable (51). This may be more an indicator of food consumption in adult life than in childhood or adolescence.

In this study, there was no indication of a protective effect of vitamin $E$, folate, $\alpha$-carotene, lutein plus zeaxanthin, $\beta$-cryptoxanthin, lycopene and dietary fiber intake against stomach cancer. A weak inverse association was found between vitamin $C$ and the risk of gastric carcinoma. The positive association between intake of retinol and $\beta$-carotene and stomach cancer deserves further investigation. 


\section{ACKNOWLEDGEMENTS}

We gratefully acknowledge the regional cancer registries, the Dutch national database of Pathology (PALGA), and the National Health Care Information Center for providing incidence data; $\mathbf{A}$. Volovics for statistical advice; E. Dorant, S. Van de Crommert, H. Brants, W. Van Dijk, P. Florax, M. Moll, J. Nelissen, A. Pisters and C. de Zwart for assistance; H. van Montfort, R. Schmeitz, T. van Monfort, and M. de Leeuw for programming and statistical assistance.

\section{REFERENCES}

1. Steinmetz KA, Potter JD. Vegetables, fruit, and cancer prevention: a review. J Am Diet Assoc 1996;96:1027-39.

2. Boeing H. Epidemiological research in stomach cancer: progress over the last ten years. J Cancer Res Clin Oncol $1991 ; 117: 133-43$.

3. Block G, Patterson B, Subar A. Fruit, vegetables, and cancer prevention: a review of the epidemiological evidence. Nutr Cancer 1992;18:1-29.

4. Botterweck AAM, van den Brandt PA, Goldbohm RA. A prospective cohort study on vegetable and fruit consumption and stomach cancer risk in the Netherlands. Am J Epidemiol 1998;148:842-53.

5. Hirayama T. Life-style and mortality. A large-scale census-based Cohort Study in Japan. Basel: Karger, 1990.

6. Chyou PH, Nomura AM, Hankin JH, Stemmermann GN. A case-cohort study of diet and stomach cancer. Cancer Res 1990;50:7501-4.

7. Nomura A, Grove JS, Stemmermann GN, Severson RK. A prospective study of stomach cancer and its relation to diet, cigarettes, and alcohol consumption. Cancer Res 1990;50:627-31.

8. Kneller RW, McLaughlin JK, Bjelke E, Schuman LM, Blot WJ, Wacholder S, et al. A cohort study of stomach cancer in a high-risk American population. Cancer 1991;68:672-8.

9. Kato I, Tominaga S, Matsumoto K. A prospective study of stomach cancer among a rural Japanese population: a 6-year survey. Jpn J Cancer Res 1992;83:568-75.

10. Guo W, Blot WJ, Li JY, Taylor PR, Liu BQ, Wang W, et al. A nested case-control study of oesophageal and stomach cancers in the Linxian nutrition intervention trial. Int J Epidemiol 1994;23:444-50.

11. Zheng W, Sellers TA, Doyle TJ, Kushi LH, Potter JD, Folsom AR. Retinol, antioxidant vitamins, and cancers of the upper digestive tract in a prospective cohort study of postmenopausal women. Am $\mathrm{J}$ Epidemiol $1995 ; 142: 955-60$.

12. Galanis DJ, Kolonel LN, Lee J, Nomura A. Intakes of selected foods and beverages and the incidence of gastric cancer among the Japanese residents of Hawaii: a prospective study. Int J Epidemiol 1998;27:173-80.

13. Mirvish SS. Effects of vitamins $\mathrm{C}$ and $\mathrm{E}$ on $\mathrm{N}$-nitroso compound formation, carcinogenesis, and cancer. Cancer 1986;58(8 Suppl):1842-50.

14. Moller ME, Dahl R, Bockman OC. A possible role of the dietary fibre product, wheat bran, as a nitrite scavenger. Food Chem Toxicol 1988;26:841-5.

15. Steinmetz KA, Potter JD. Vegetables, fruit, and cancer. II. Mechanisms. Cancer Causes Control 1991;2:427-42.

16. Kono S, Hirohata T. Nutrition and stomach cancer. Cancer Causes Control 1996;7:41-55.

17. Blot WJ, Li JY, Taylor PR, Guo W, Dawsey S, Wang GQ, et al. Nutrition intervention trials in Linxian, China: supplementation with specific vitamin/mineral combinations, cancer incidence, and disease-specific mortality in the general population. J Natl Cancer Inst 1993;85:1483-92.

18. The Alpha-Tocopherol, Beta Carotene Cancer Prevention Study Group. The effect of vitamin $\mathrm{E}$ and beta carotene on the incidence of lung cancer and other cancers in male smokers. N Engl J Med 1994;330:1029-35.

19. Risch HA, Jain M, Choi NW, Fodor JG, Pfeiffer CJ, Howe GR, et al. Dietary factors and the incidence of cancer of the stomach. Am J Epidemiol 1985;122:947-59.

20. Gonzalez CA, Riboli E, Badosa J, Batiste E, Cardona T, Pita S, et al. Nutritional factors and gastric cancer in Spain. Am J Epidemiol 1994;139:466-73. 
21. Hansson LE, Nyren O, Bergstrom R, Wolk A, Lindgren A, Baron J, et al. Nutrients and gastric cancer risk. A population-based case-control study in Sweden. Int J Cancer 1994;57:638-44.

22. Harrison LE, Zhang ZF, Karpeh MS, Sun M, Kurtz RC. The role of dietary factors in the intestinal and diffuse histologic subtypes of gastric adenocarcinoma: a case-control study in the U.S. Cancer 1997;80:1021-8.

23. Goldbohm RA, Brants HAM, Hulshof KFAM, van den Brandt PA. The contribution of various foods to intake of vitamin $A$ and carotenoids in the Netherlands. Int J Vit Res 1998;68:378-83.

24. Van den Brandt PA, Goldbohm RA, van 't Veer P, Volovics A, Hermus RJ, Sturmans F. A large-scale prospective cohort study on diet and cancer in The Netherlands. J Clin Epidemiol 1990;43:285-95.

25. Self SG, Prentice RL. Asymptotic distribution theory and efficiency results for case-cohort studies. Ann Stat 1988;16:64-81.

26. van den Brandt PA, Schouten LJ, Goldbohm RA, Dorant E, Hunen PM. Development of a record linkage protocol for use in the Dutch Cancer Registry for Epidemiological Research. Int J Epidemiol 1990;19:553-8.

27. Goldbohm RA, van den Brandt PA, Brants HA, van 't Veer P, Al M, Sturmans F, et al. Validation of a dietary questionnaire used in a large-scale prospective cohort study on diet and cancer. Eur J Clin Nutr 1994;48:253-65.

28. Nevo tabel. Dutch Food Composition table 1986-1987; Nederlands voedingsstoffenbestand 1986-1987. The Hague: Voorlichtingsbureau voor de Voeding, 1986.

29. Holland B, Welch AA, Unwin ID, Buss DH, Paul AA, Southgate DAT. McCance \& Widderson's The composition of foods. $5^{\text {th }}$ ed. Cambridge: Royal Society of Chemistry, 1991.

30. Englyst H. Determination of carbohydrate and its composition in plant materials. In: James WPT, Theander O. The analysis of dietary fibre in food. New York: Marcel Dekker, 1981.

31. van Loon AJM, Goldbohm RA, van den Brandt PA. Socioeconomic status and stomach cancer incidence in men: results from the Netherlands Cohort Study. J Epidemiol Community Health 1998;52:166-71.

32. van den Brandt PA, Goldbohm RA, van 't Veer P, Bode P, Dorant E, Hermus RJ, et al. Toenail selenium levels and the risk of breast cancer. Am J Epidemiol 1994;140:20-6.

33. Baker R. Glim 3.77 Reference manual. Oxford: Numerical Algorithms Group, 1985.

34. Volovics A, van den Brandt PA. Methods for the analyses of case-cohort studies. Biom J 1997;39:195-214.

35. van Loon AJM, Botterweck AAM, Goldbohm RA, Brants HAM, van Klaveren JD, van den Brandt PA. Intake of nitrate and nitrite and the risk of gastric cancer: a prospective cohort study. Br J Cancer 1998;78:129-35.

36. Goldbohm RA, van den Brandt PA, Dorant E. Estimation of the coverage of Dutch municipalities by cancer registries and PALGA based on hospital discharge data. Tijdschr Soc Gezondheidsz 1994;72:80-4.

37. Munoz N. Is Helicobacter pylori a cause of gastric cancer? An appraisal of the seroepidemiological evidence. Cancer Epidemiol Biomarkers Prev 1994;3:445-51.

38. Loffeld RJ, Stobberingh E, van Spreeuwel JP, Flendrig JA, Arends JW. The prevalence of anti-Helicobacter (Campylobacter) pylori antibodies in patients and healthy blood donors. J Med Microbiol 1990;32:105-9.

39. Buiatti E, Palli D, Bianchi S, Decarli A, Amadori D, Avellini C, et al. A case-control study of gastric cancer and diet in Italy. III. Risk patterns by histologic type. Int J Cancer 1991;48:369-74.

40. La Vecchia C, Ferraroni M, D'Avanzo B, Decarli A, Franceschi S. Selected micronutrient intake and the risk of gastric cancer. Cancer Epidemiol Biomarkers Prev 1994;3:393-8.

41. Munoz SE, Ferraroni M, La Vecchia C, Decarli A. Gastric cancer risk factors in subjects with family history. Cancer Epidemiol Biomarkers Prev 1997;6:137-40.

42. Zhang HM, Wakisaka N, Maeda O, Yamamoto T. Vitamin C inhibits the growth of a bacterial risk factor for gastric carcinoma: Helicobacter pylori. Cancer 1997;80:1897-903.

43. Palli D, Bianchi S, Decarli A, Cipriani F, Avellini C, Cocco P, et al. A case-control study of cancers of the gastric cardia in Italy. Br $\mathrm{J}$ Cancer 1992;65:263-6.

44. Graham S, Haughey B, Marshall J, Brasure J, Zielezny M, Freudenheim J, et al. Diet in the epidemiology of gastric cancer. Nutr Cancer 1990;13:19-34.

45. Brown LM, Blot WJ, Schuman SH, Smith VM, Ershow AG, Marks RD, et al. Environmental factors and high risk of esophageal cancer among men in coastal South Carolina. J Natl Cancer Inst 1988;80:1620-5.

46. World Health Organization, International Agency for Research on Cancer. Carotenoids. IARC Handbooks of Cancer Prevention, volume 2. Lyon: International Agency for Research on Cancer, 1998: 262-3.

47. Dorant E, van den Brandt PA, Hamstra AM, Feenstra MH, Goldbohm RA, Hermus RJJ, et al. The use of vitamins, minerals and other dietary supplements in the Netherlands. Int J Vitam Nutr Res 1993;63:4-10. 


\section{Chapter 3}

48. Patterson RE, Neuhouser ML, White E, Hunt JR, Kristal AR. Cancer-related behaviour of vitamin supplement users. Cancer Epidemiology, Biomarkers \& Prevention 1998;7:79-81.

49. Kmet J. The role of migrant population in studies of selected cancer sites: a review. J Chronic Dis 1970;23:30524.

50. Howson CP, Hiyama T, Wynder EL. The decline in gastric cancer: epidemiology of an unplanned triumph. Epidemiol Rev 1986;8:1-27.

51. Goldbohm RA, van 't Veer P, van den Brandt PA, van 't Hof MA, Brants HA, Sturmans F, et al. Reproducibility of a food frequency questionnaire and stability of dietary habits determined from five annually repeated measurements. Eur J Clin Nutr 1995;49:420-9. 


\section{4}

\section{Intake of nitrate and nitrite and the risk of gastric cancer: a prospective cohort study}

A. Jeanne M. van Loon ${ }^{1,4}$

Anita A.M. Botterweck ${ }^{1}$

R. Alexandra Goldbohm ${ }^{2}$

Henny A.M. Brants ${ }^{2}$

Jacob D. van Klaveren ${ }^{3}$

Piet A. van den Brandt ${ }^{1}$

1 Department of Epidemiology, University Maastricht, Maastricht, The Netherlands

2 Department of Consumer Research and Epidemiology, TNO Nutrition and Food Research Institute, Zeist, The Netherlands

3 State Institute for Quality Control of Agricultural Products, Wageningen, The Netherlands

4 Present Address: Department of Chronic Disease and Environmental Epidemilology, National Institute of Public Health and Environmental Protection, Bilthoven, The Netherlands

Published in the British Journal of Cancer 1998; 78: 129-135. 


\begin{abstract}
The association between the intake of nitrate or nitrite and gastric cancer risk was investigated in a prospective cohort study started in 1986 in the Netherlands of 120,852 men and women aged 55-69 years. At baseline, data on dietary intake, smoking habits and other covariates were collected by means of a self-administered questionnaire. For data-analysis, a case-cohort approach was used, in which the person-years at risk were estimated from a randomly selected subcohort (1688 men and 1812 women). After 6.3 years of follow-up, 282 microscopically confirmed incident cases of stomach cancer were detected: 219 men and 63 women. We did not find a higher risk for gastric cancer for people with a higher nitrate intake from food (rate ratio (RR) highest/lowest quintile $=0.80 ; 95 \%$ confidence interval (CI) $0.47-1.37 ; p$ trend $=0.18$ ), a higher nitrate intake from drinking water (RR highest/lowest quintile $=0.88 ; 95 \% \mathrm{CI} 0.59-1.32 p$ trend $=0.39$ ) or a higher intake of nitrite $(\mathrm{RR}$ highest/lowest quintile $=1.44 ; 95 \% \mathrm{CI} 0.95-2.18 ; p$ trend $=0.24$ ). $\mathrm{RRs}$ for gastric cancer were also computed for each tertile of nitrate intake from foods within tertiles of vitamin $\mathrm{C}$ intake and intake of beta-carotene, but no consistent pattern was found. Therefore, our study does not support a positive association between the intake of nitrate or nitrite and gastric cancer risk.
\end{abstract}




\section{INTRODUCTION}

Over the past 20 years there has been an accumulation of nitrate in vegetables due to the methods of cultivation. Moreover, nitrate content in drinking water has been increasing as a consequence of the extensive use of artificial fertilizers. This accumulation of nitrate has again raised the question whether high intake of nitrate leads to specific health risks, especially gastric cancer (1). In the Netherlands, the main sources of nitrate are leafy vegetables and other vegetables, potatoes and drinking water (2). In addition, both nitrite and nitrate are used as food additive in cheese and cured meats. It is not nitrate per se, but metabolites of nitrate, which are known carcinogens. Nitrate can be converted into nitrite, which can react with secondary amines or amides to produce carcinogenic $\mathrm{N}$-nitroso compounds. In the Netherlands estimations of the nitrate intake vary between $52 \mathrm{mg}$ nitrate ion/day (3) and $131 \mathrm{mg}$ nitrate ion/day (4). The intake of nitrite is estimated as between $0.1 \mu \mathrm{g}$ nitrite ion/day (3) and $5.2 \mathrm{mg}$ nitrite ion/day (4). As about $5 \%$ of all ingested nitrate is converted to nitrite (5) there is usually a greater exposure to nitrite from the reduction of nitrate than from exogenous intake. Approximately $20 \%$ of the nitrite that enters the stomach arises directly from nitrite in the diet and $80 \%$ from the reduction of salivary nitrate (6). Nevertheless, dietary nitrite increases gastric nitrite levels when nitrosatable compounds are ingested, whereas this situation is only partly true for salivary nitrite (6). Therefore, it is relevant to study the intake of both nitrate and nitrite in relation to gastric cancer risk.

Several factors can influence the conversion of nitrate to nitrite and N-nitroso compounds. Ascorbic acid can inhibit nitrosation by acting as a competitive substrate for nitrite (7). Both ascorbic acid and beta-carotene may act as scavengers for free radicals, thus preventing oxidative damage in gastric mucosa and mutations in DNA (8). Furthermore, the conversion of nitrate to nitrite may be inhibited by storage of foods in refrigerator or freezer (9). Other aspects such as smoking habits, socioeconomic status, family history of stomach cancer and prevalence of stomach disorders may confound the association between nitrate or nitrite intake and gastric cancer risk (10-13). Numerous epidemiological studies which have been undertaken on the association between nitrate intake and gastric cancer risk show a lack of consistency (10,14-27). However, in most of these studies high nitrate consumption via ingested food showed no association with gastric cancer risk or even an inverse association. This finding might result from the fact that vegetables - the main source of nitrate - also contain vitamin $\mathrm{C}$ and beta-carotene, which appear to be protective factors for gastric cancer. Therefore, intake of nitrate from foods must be studied separately from intake of nitrate from drinking water, which does not contain protective substances.

So far, epidemiological studies on nitrate intake and gastric cancer risk have been ecological or casecontrol in design, in which problems arise with control for confounding, the long latency period and the accurate recall of information on food intakes. Some of these problems can be overcome in prospective cohort studies. The Netherlands Cohort Study is a prospective study on diet and cancer in which most relevant information was available to study the association between the intake of nitrate (from foods and drinking water) and the intake of nitrite and gastric cancer risk, with control for potential confounders. 


\section{MATERIALS AND METHODS}

\section{The cohort study}

The NLCS on diet, other lifestyle characteristics and cancer risk started in September 1986. The cohort included 58,279 men and 62,573 women aged 55-69 years at the beginning of the study. Data were collected by means of a self-administered questionnaire. A detailed description of the cohort study design has been reported elsewhere (28). For data analysis, the case-cohort approach was used in which gastric cancer cases were derived from the entire cohort, whereas the person-years at risk are estimated from a random sample of 3500 subjects (subcohort). After the baseline exposure measurement, the subcohort was randomly sampled (1688 men and 1812 women) and was followed up biennially for vital status information. Follow-up for incident cancer has been established by record linkage with all regional cancer registries in the Netherlands and with a national pathology register (PALGA). The method of record linkage has been described previously (29). The analysis is restricted to gastric cancer incidence in the period from September 1986 to December 1992. During these 6.3 years of follow-up, 347 stomach cancer cases were detected. We excluded self-reported prevalent cancer cases other than skin cancer $(n=33)$, cases with in situ carcinoma $(n=2)$ and cases without microscopically confirmed diagnosis $(n=2)$. Therefore 310 incident cases $(242$ males and 68 females) were available for analysis. Self-reported prevalent cancer cases other than skin cancer were also excluded from the subcohort, with the result that 3346 subjects (1630 men and 1716 women) remained in this group. Finally, subjects with incomplete or inconsistent dietary data were excluded, leaving 282 cases (219 men and 63 women) and 3123 subcohort members (1525 men and 1598 women) available for the analyses.

\section{Intake of nitrate and nitrite}

The participants, usual consumption of food and beverages during the year preceding the start of the study was assessed at baseline with a 150 -item semi-quantitative food frequency questionnaire. This questionnaire has been validated against a nine-day diet record (30) and it covered the main sources of nitrate (vegetables, drinking water) and nitrite (cured meat). Food composition values for nitrate were derived from the databank on contaminants in food from the State Institute for Quality Control of Agricultural Products (RIKILT, Wageningen). Estimations were based on the mean nitrate contents between 1985 and 1989, in which, for some vegetables (e.g., endive, lettuce) distinction was made between summer and winter. Furthermore, information on nitrate losses during preparation (washing, cutting and cooking) were considered. For several vegetables (endive, spinach, cabbage) and for potatoes, experimental data were available regarding nitrate losses during preparation $(31,32)$. For other vegetables nitrate losses were estimated to be $40 \%$. Regarding nitrate intake from drinking water, we have combined information about nitrate contents in drinking water for each pumping station in the Netherlands in 1986 (databank on contaminants in food) with information about the distribution of drinking water (collected from all waterworks in the Netherlands). In this way, we could determine the nitrate content in drinking water for each home address by postal code. To calculate the nitrate intake from water, we also used information about the amount of water, coffee, 
tea and soup consumed (derived from the questionnaire). Food composition values for nitrite were obtained from TNO Nutrition and Food Research Institute (Zeist). Nitrite contents in vegetables and cheese were considered to be too low to include in the analyses. Therefore, nitrite intake was assessed solely on the intake of cured meat.

\section{Other relevant aspects}

Other factors relevant to the association between nitrate or nitrite intake and gastric cancer risk that were measured were smoking status (never/ex/current), level of education (primary school, lower vocational school, junior high school, senior high school, higher vocational school or university), family history of stomach cancer (yes or no), prevalence of stomach disorders (any stomach disease in the past that required medical attention), the use of refrigerator (number of years) or freezer (yes or no) and the intake of coffee (categorical), vitamin C (mg/day) and beta-carotene (mg/day). Mean individual nutrient intakes per day were computed using the Dutch food table of 1986 (33). Although high salt intake is linked with increased risk for gastric cancer in many aetiological studies (9), preliminary results from the Netherlands Cohort Study showed no association between salt intake and gastric cancer risk (34). Salt intake was, therefore, omitted from the analyses.

\section{Data analysis}

The intake of nitrate from different sources, the intake of nitrite and the distribution of potential confounders possibly associated with nitrate or nitrite intake and gastric cancer risk were compared between the cases and subcohort group. Intake of nitrate and nitrite was categorized into quintiles according to the distribution in the subcohort. The associations between nitrate intake or nitrite intake and covariates were studied in the subcohort by comparing the distribution of several covariates among the quintiles of nitrate intake from foods, nitrate intake from drinking water and intake of nitrite. To study the association between intake of nitrate and nitrite and gastric cancer risk and the role of possible confounders, data were analysed according to the case-cohort approach $(35,36)$, using the GLIM statistical package (37). First, age- and sex- adjusted rate ratios (RRs) and $95 \%$ confidence intervals (CI) for gastric cancer were determined for nitrate intake from foods, nitrate intake from drinking water, total intake of nitrate and intake of nitrite. In the multivariate analyses, $R R s$ for gastric cancer were computed for the different exposures after adjustment for age, sex, smoking status, highest level of education, intake of vitamin $\mathrm{C}$ and beta-carotene, family history of stomach cancer, prevalence of stomach disorders and use of refrigerator or freezer. To distinguish possible positive associations between nitrate intake from foods and gastric cancer risk from possible effects of the intake of vitamin $\mathrm{C}$ or beta-carotene on gastric cancer risk, we have computed RRs for gastric cancer for each tertile of nitrate intake from foods within tertiles of vitamin $C$ intake and intake of betacarotene. Moreover, the association between nitrate intake from foods or drinking water and gastric cancer risk was studied after exclusion of people with self-reported stomach disorders, because the conversion of nitrate to nitrite could be influenced by the prevalence of stomach disorders (38). Finally, analyses were also conducted after excluding cases that occurred in the first year of follow-up to consider the potential influence of preclinical gastric cancer on the intake of nitrate or nitrite. 


\section{RESULTS}

The mean intake of nitrate and nitrite and the distribution of relevant covariates in the group of cases and the subcohort is presented in table 1. Among the cases there were proportionally more men compared with the subcohort members and cases were on average older than members of the subcohort (mean age for cases 63.0 and for subcohort members 61.4 years). A higher percentage of the cases had primary school as highest level of education compared with the subcohort. Stomach disorders were more prevalent among cases compared with members of the subcohort. The same was found with regard to family history of stomach cancer. The mean number of years of refrigerator use was only slightly higher among cases, although proportionally fewer cases used a freezer, compared with the use of refrigerator and freezer by the subcohort members. There were fewer non-smokers among cases and more current smokers compared with smoking habits of the subcohort members and proportionally more cases consumed large amounts of coffee ( $>4$ cups per day) than subcohort members.

The mean intake of beta-carotene did not differ substantially between cases and subcohort members and the intake of vitamin $\mathrm{C}$ was somewhat lower among cases. The intake of nitrate from foods,

TABLE 1: Distribution of nitrate and nitrite intake in gastric cancer cases and subcohort.

\begin{tabular}{|c|c|c|}
\hline \multirow[b]{2}{*}{ Total } & Subcohort members * & Gastric cancer cases * \\
\hline & 3123 & 282 \\
\hline Sex (\% male) & 48.8 & 77.7 \\
\hline Age (mean \pm s.d.) & $61.4 \pm 4.2$ & $63.0 \pm 4.1$ \\
\hline Level of education (\% primary school only) & 30.1 & 37.4 \\
\hline Stomach disorders (\% ever) & 9.3 & 19.1 \\
\hline Family history stomach cancer (\% yes) & 6.7 & 11.3 \\
\hline Refrigerator (mean number of years \pm s.d.) & $24.8 \pm 8.9$ & $25.5 \pm 8.9$ \\
\hline Freezer (\% never) & 36.0 & 34.9 \\
\hline Smoking (\% never) & 34.9 & 15.6 \\
\hline Smoking (\% current) & 31.3 & 44.7 \\
\hline Coffee intake ( $\%>4$ cups/day) & 10.2 & 16.0 \\
\hline Betacarotene (mean $\mathrm{mg}$ eq vit A/day \pm s.d.) & $0.42 \pm 0.24$ & $0.40 \pm 0.22$ \\
\hline Vitamin C (mean mg/day \pm s.d.) & $103 \pm 43$ & $97 \pm 44$ \\
\hline \multicolumn{3}{|l|}{ mean mg/day \pm s.d. } \\
\hline Dietary nitrate & $105 \pm 44$ & $102 \pm 43$ \\
\hline Nitrate from drinking water & $5.8 \pm 6.5$ & $6.1 \pm 7.2$ \\
\hline Total nitrate & $111 \pm 45$ & $108 \pm 44$ \\
\hline Nitrite & $0.13 \pm 0.14$ & $0.15 \pm 0.16$ \\
\hline
\end{tabular}

* Only subjects with complete dietary data 
nitrate from drinking water and nitrite did not substantially differ between cases and subcohort members; cases had a somewhat higher intake of nitrate from drinking water and a slightly higher intake of nitrite, while the intake of nitrate from foods and the total nitrate intake was somewhat lower among cases compared with members of the subcohort.

The association between covariates and nitrate intake from foods, nitrate intake from drinking water or nitrite intake was studied in the subcohort (table 2). Proportionally, more men were found in the higher quintiles of nitrate intake and proportionally more people with only primary school were found in the lowest quintile of nitrate intake from foods. Also, a correlation was found between the prevalence of stomach disorders and nitrate intake from foods. Moreover, nitrate intake from foods was positively correlated with the intake of beta-carotene and vitamin C. Nitrate intake from drinking water was positively correlated with use of freezer (\% never), coffee consumption ( $\%>4$ cups per day) and intake of vitamin $C$. Regarding nitrite intake, proportionally more men were found in the higher quintiles and the percentage never smokers was higher within the lower quintiles of nitrite intake. Furthermore, nitrite intake was inversely correlated with family history of stomach cancer (\% ever) and use of freezer (\% never).

The results of the age- and sex-adjusted analyses are presented in table 3 . There was a non-significant inverse association between nitrate intake from foods and gastric cancer risk (RR highest/lowest quintile $=0.83,95 \% \mathrm{CI} 0.58-1.20 ; p$ trend $=0.11$ ) and also between the total nitrate intake and gastric cancer risk (RR highest/lowest quintile $=0.88,95 \% \mathrm{CI} 0.60-1.28 ; p$ trend $=0.17$ ). No association was found between nitrate intake from drinking water and gastric cancer risk (RR highest/lowest quintile $=0.94,95 \%$ CI $0.64-1.38 ; p$ trend $=0.66$ ). The association between nitrite intake and gastric cancer risk was not clear. The significantly higher risk for gastric cancer was found in the highest quintile of nitrite intake ( $\mathrm{RR}=1.49,95 \% \mathrm{CI} 1.01-2.20)$, but the gastric cancer risk in the second highest quintile was below one $(\mathrm{RR}=0.87,95 \% \mathrm{CI} 0.57-1.33)$. In the multivariate analyses, adjustment was made for age, sex, smoking status, highest level of education, coffee consumption, intake of vitamin $\mathrm{C}$ and beta-carotene, family history of stomach cancer, prevalence of stomach disorders, use of refrigerator and use of freezer (table 3). After adjustment, there was still a non-significant inverse association between nitrate intake from foods and gastric cancer risk (RR highest/lowest quintile = $0.80 ; 95 \% \mathrm{CI} 0.47-1.37 ; p$ trend $=0.18$ ). Nor did the association between total nitrate intake and gastric cancer risk change after additional adjustment (RR highest/lowest quintile $=0.90,95 \% \mathrm{CI}$ $0.53-1.55 ; p$ trend $=0.30$ ). Regarding nitrate intake from drinking water and gastric cancer risk, the $\mathrm{RR}$ in the highest quintile changed marginally to $0.88(95 \% \mathrm{CI} 0.59-1.32 ; p$ trend $=0.39)$. The association between nitrite intake and gastric cancer risk was still ambiguous.

The non-significant inverse association between nitrate intake from foods and gastric cancer risk was thought to be due to a protective effect of vegetables like vitamin $\mathrm{C}$ and beta-carotene. Therefore, we have studied the association between nitrate intake from foods and gastric cancer risk within tertiles of vitamin $\mathrm{C}$ intake and within tertiles of beta-carotene intake, based on the distribution in the subcohort (table 4). For these analyses adjustment was made for age and sex. Within each tertile of vitamin $C$ intake or intake of beta-carotene we expected a positive association between nitrate intake and gastric cancer risk, but no consistent pattern was found. We have also studied the association 
TABLE 2: Association between possible confounders and nitrate or nitite intake in the subcohort *

$\operatorname{Sex}(\%$ male)

Age (mean)

Level of education (\% primary school only)

Stomach disorders (\% ever)

Family history stomach cancer (\% yes)

Refrigerator (mean number of years)

Freezer (\% never)

Smoking (\% never)

Coffee intake (\% $>4$ cups/day)

Beta-carotene (mean $\mathrm{mg}$ eq vit $A$ )

VitaminC (mean mg/day)
Sex (\% male)

Age (mean)

Level of education (\% primary school only)

Stomach disorders (\% ever)

Family history stomach cancer (\% yes)

Refrigerator (mean number of years)

Freezer (\% never)

Smoking (\% never)

Coffee intake ( $\%>4$ cups/day)

Beta-carotene (mean $\mathrm{mg}$ eq vil $\mathrm{A}$ )

Vitamin C (mean mg/day)
Sex (\% male)

Age (mean)

Level of education (\% primary school only)

Stomach disorders (\% ever)

Family history stomach cancer (\% yes)

Refrigerator (mean number of years)

Freezer (\% never)

Smoking (\% never)

Coffee intake (\% > 4 cups $/$ day)

Beta-carotene (mean $\mathrm{mg}$ eq vit $\mathrm{A}$ )

Vitamin C (mean mg/day)

\begin{tabular}{ccccc}
\multicolumn{5}{c}{ Nitrate (dietary): quintiles } \\
\hline 1 (low) & 2 & 3 & 4 & 5 (high) \\
\hline 47.4 & 47.5 & 49.8 & 49.5 & 49.9 \\
61.6 & 61.2 & 61.4 & 61.3 & 61.4 \\
36.2 & 32.5 & 27.4 & 25.6 & 28.1 \\
12.3 & 8.5 & 10.1 & 7.0 & 8.7 \\
7.9 & 6.9 & 5.6 & 7.5 & 5.8 \\
24.0 & 24.2 & 24.8 & 25.0 & 25.8 \\
36.6 & 35.2 & 34.8 & 38.0 & 35.4 \\
33.5 & 36.0 & 35.4 & 35.3 & 34.3 \\
12.8 & 8.6 & 9.0 & 10.1 & 10.3 \\
0.23 & 0.32 & 0.38 & 0.47 & 0.70 \\
75.9 & 90.0 & 100.6 & 114.4 & 136.2 \\
& & & & \\
\hline
\end{tabular}

\begin{tabular}{ccccc}
\hline \multicolumn{5}{c}{ Nitrate (drinking water): quintiles } \\
\hline 1 (low) & 2 & 3 & 4 & 5 (high) \\
\hline 47.0 & 48.1 & 49.9 & 52.3 & 46.8 \\
61.5 & 61.3 & 61.1 & 61.6 & 61.5 \\
33.7 & 31.1 & 28.0 & 26.1 & 31.5 \\
8.3 & 9.2 & 9.5 & 10.4 & 9.1 \\
6.3 & 6.3 & 6.2 & 6.2 & 8.7 \\
24.2 & 24.2 & 25.5 & 24.9 & 24.9 \\
29.5 & 33.7 & 38.3 & 38.1 & 40.6 \\
37.0 & 39.0 & 34.3 & 31.5 & 32.7 \\
11.5 & 6.1 & 7.3 & 10.6 & 15.2 \\
0.42 & 0.42 & 0.41 & 0.43 & 0.43 \\
99.0 & 101.2 & 103.0 & 105.1 & 108.9 \\
& & & & \\
\hline
\end{tabular}

\begin{tabular}{ccccc}
\hline \multicolumn{5}{c}{ Nitrite: quintiles } \\
\hline 1 (low) & 2 & 3 & 4 & 5 (high) \\
\hline 39.3 & 40.4 & 47.5 & 54.3 & 62.8 \\
61.9 & 61.5 & 61.3 & 61.2 & 61.1 \\
33.1 & 29.7 & 26.2 & 29.0 & 32.4 \\
8.8 & 7.3 & 8.8 & 11.3 & 10.4 \\
9.4 & 7.2 & 5.9 & 6.1 & 5.0 \\
24.0 & 25.1 & 24.6 & 25.2 & 24.9 \\
40.7 & 35.8 & 35.0 & 35.2 & 33.2 \\
40.1 & 39.6 & 32.9 & 32.2 & 29.8 \\
10.1 & 8.1 & 8.9 & 8.8 & 14.9 \\
0.43 & 0.41 & 0.40 & 0.42 & 0.44 \\
102.5 & 104.1 & 100.4 & 105.1 & 105.1 \\
& & & & \\
\end{tabular}

* Only subjects with complete dietary data

between nitrate intake from foods or drinking water and gastric cancer risk after excluding people 
TABLE 3: Rate ratios (RRs) and $95 \%$ confidence intervals (Cl) for gastric cancer according to nitrate and nitrite intake (quintiles).

\begin{tabular}{|c|c|c|c|c|}
\hline & $\begin{array}{c}\text { No. of cases in } \\
\text { cohort }\end{array}$ & $\begin{array}{c}\text { Person-years in } \\
\text { subcohort }\end{array}$ & $\operatorname{RR}(95 \% \mathrm{Cl}) \dagger$ & $\operatorname{RR}(95 \% \mathrm{Cl}) \ddagger$ \\
\hline \multicolumn{5}{|c|}{ Dietary nitrate (mean, $\mathrm{mg} /$ day) } \\
\hline $1(55.8)$ & 69 & 3784 & $1^{*}$ & $1^{*}$ \\
\hline $2(79.4)$ & 61 & 3813 & $0.93(0.64-1.33)$ & $1.02(0.69-1.51)$ \\
\hline $3(98.7)$ & 45 & 3814 & $0.65(0.44-0.96)$ & $0.71(0.46-1.09)$ \\
\hline $4(120.7)$ & 49 & 3813 & $0.71(0.48-1.04)$ & $0.80(0.51-1.25)$ \\
\hline $5(172.2)$ & 58 & 3796 & $0.83(0.58-1.20)$ & $0.80(0.47-1.37)$ \\
\hline$X^{2}$ trend test (-value) & & & $2.55(0.11)$ & $1.82(0.18)$ \\
\hline \multicolumn{5}{|c|}{ Nitrate from drinking water (mean, mg/day) } \\
\hline $1(0.02)$ & 61 & 3836 & $1^{*}$ & $1^{*}$ \\
\hline $2(1.65)$ & 54 & 3790 & $0.91(0.62-1.34)$ & $0.93(0.62-1.39)$ \\
\hline $3(3.85)$ & 53 & 3829 & $0.87(0.59-1.28)$ & $0.87(0.58-1.31)$ \\
\hline $4(6.91)$ & 57 & 3812 & $0.86(0.59-1.27)$ & $0.83(0.55-1.24)$ \\
\hline $5(16.5)$ & 57 & 3750 & $0.94(0.64-1.38)$ & $0.88(0.59-1.32)$ \\
\hline $\mathrm{X}^{2}$ trend test (-value) & & & $0.20(0.66)$ & $0.73(0.39)$ \\
\hline \multicolumn{5}{|c|}{ Total nitrate (mean, mg/day) } \\
\hline $1(59.8)$ & 63 & 3771 & $1^{*}$ & $1^{*}$ \\
\hline $2(84.7)$ & 67 & 3844 & $1.11(0.77-1.60)$ & $1.25(0.84-1.86)$ \\
\hline $3(104.4)$ & 42 & 3805 & $0.65(0.43-0.98)$ & $0.74(0.47-1.15)$ \\
\hline $4(127.3)$ & 54 & 3820 & $0.83(0.57-1.22)$ & $0.92(0.59-1.44)$ \\
\hline $5(179.8)$ & 56 & 3779 & $0.88(0.60-1.28)$ & $0.90(0.53-1.55)$ \\
\hline $\mathrm{X}^{2}$ trend test (-value) & & & $1.85(0.17)$ & $1.08(0.30)$ \\
\hline \multicolumn{5}{|l|}{ Nitrite (mean, mg/day) } \\
\hline $1(0.01)$ & 47 & 3873 & $1^{*}$ & $1^{*}$ \\
\hline $2(0.04)$ & 51 & 3706 & $1.15(0.76-1.74)$ & $1.20(0.78-1.86)$ \\
\hline $3(0.09)$ & 58 & 3829 & $1.21(0.81-1.83)$ & $1.18(0.77-1.82)$ \\
\hline $4(0.16)$ & 46 & 3844 & $0.87(0.57-1.33)$ & $0.88(0.56-1.37)$ \\
\hline $5(0.35)$ & 80 & 3760 & $1.49(1.01-2.20)$ & $1.44(0.95-2.18)$ \\
\hline$X^{2}$ trend test (-value) & & & $2.20(0.14)$ & $1.38(0.24)$ \\
\hline
\end{tabular}

\footnotetext{
* Reference category; $\uparrow$ Adjustment for age and sex; $¥$ Multivarate analyses with adjustment for age, sex, smoking (never/ex/current), highest level of education, coffee consumption, intake of vitamin $C$ and beta-carotene, family history of stomach cancer (yes or no), prevalence of stomach disorders (ever or never), use of refrigerator (number of years) and use of freezer (ever or never).
}

with stomach disorders, because the conversion of nitrate to nitrite could be affected due to the prevalence of stomach disorders (38). Regarding nitrate intake, this did not change the point estimates substantially, whereas the rate ratio for gastric cancer in the highest quintile of nitrite intake decreased after exclusion of people with stomach disorders ( $R R$ highest/lowest quintile $1.26,95 \% \mathrm{CI} 0.82-1.92$, $p$ trend $=0.53$ ). Moreover, we have considered the potential influence of preclinical cancer on the intake of nitrate and nitrite by excluding all cases that occurred in the first year of follow-up. The 
TABLE 4: Rate ratios for gastric cancer according to nitrate intake from foods (tertiles), within tertiles of vitamin $~ v$ intake and tertiles of beta-carotene intake $(1=$ low, $3=$ high $)$.

\begin{tabular}{|c|c|c|c|c|}
\hline & \multicolumn{4}{|c|}{ Tertiles of vitamin C } \\
\hline & & $\begin{array}{l}1 \\
(n=1150)\end{array}$ & $\begin{array}{l}2 \\
\text { (n=11445) }\end{array}$ & $\begin{array}{l}3 \\
(n=1101) \\
\end{array}$ \\
\hline \multirow[t]{6}{*}{ Nitrate from foods } & 1 & 1 & 1 & 1 \\
\hline & 2 & $0.94(0.58-1.52)$ & $0.78(0.46-1.34)$ & $0.87(0.48-1.58)$ \\
\hline & 3 & $0.81(0.49-1.31)$ & $1.02(0.62-1.67)$ & $0.92(0.51-1.67)$ \\
\hline & $\begin{array}{l}\mathrm{X}^{2} \text { trend } \\
\text { (p-value) }\end{array}$ & $0.86(0.35)$ & $0.02(0.90)$ & $0.07(0.79)$ \\
\hline & \multicolumn{4}{|c|}{ Intake of beta-carotene } \\
\hline & & $\begin{array}{c}1 \\
(n=1137) \\
\end{array}$ & $\begin{array}{c}2 \\
(=1130)\end{array}$ & $(n=1129)$ \\
\hline \multicolumn{5}{|l|}{ Nitrate from foods } \\
\hline & 1 & 1 & 1 & 1 \\
\hline & 2 & $1.11(0.69-1.77)$ & $0.70(0.39-1.25)$ & $0.87(0.51-1.49)$ \\
\hline & 3 & $0.62(0.36-1.05)$ & $0.99(0.58-1.70)$ & $0.84(0.49-1.43)$ \\
\hline & $\begin{array}{l}\mathrm{X}^{2} \text { trend } \\
\text { (p-value) }\end{array}$ & $3.26(0.07)$ & $0.01(0.96)$ & $0.49(0.48)$ \\
\hline
\end{tabular}

* Reference category

relative RRs of gastric cancer in the multivariate analysis were $1.00,1.09,0.64,0.92$ and 0.91 for increasing quintiles of nitrate intake from foods $(p$ trend $=0.44$ ). The multivariately adjusted RRs for quintiles of nitrite intake were $1.00,1.21,1.05,0.76$ and $1.34(p$ trend $=0.56)$ for those diagnosed after the first year.

\section{DISCUSSION}

We did not find a higher risk for gastric cancer for people with a higher intake of nitrate from foods or drinking water or a higher intake of nitrite. Adjustment for potential confounders did not change the association between nitrate or nitrite intake and gastric cancer risk substantially. Finally, when we analysed the association between nitrate intake from foods and gastric cancer risk within tertiles of vitamin $\mathrm{C}$ intake or intake of beta-carotene, no clear pattern emerged.

As mentioned already, most studies on nitrate or nitrite intake and gastric cancer risk have been ecological studies or case-control studies. As far as we know, no cohort study has been conducted on nitrate or nitrite intake and gastric cancer risk. The ecological studies investigated the association 
between nitrate in drinking water and gastric cancer risk in several European countries. In studies in Denmark (14) and Italy (16), a positive association was reported between nitrate intake from drinking water and gastric cancer incidence. Ecological studies in the UK (15) and France (20) showed no clear associations, whereas another study in the UK (17) showed an inverse association between nitrate intake from drinking water and gastric cancer mortality. In all studies adjustment was made for age and sex and in the study of Beresford (1985) adjustment was also made for socioeconomic status. There were only small differences in median nitrate levels in drinking water in the different countries. Therefore, this could not explain these inconsistent findings. In two studies a latency period between exposure to nitrate and gastric cancer risk was taken into account $(14,15)$. This too could not explain the inconsistent results.

Case-control studies have mainly investigated the association between nitrate or nitrite from foods and gastric cancer risk $(10,18,19,21,24-27)$. In most studies a statistically significant inverse association was reported between nitrate intake from foods and gastric cancer risk $(10,18,19,24-26)$, which disappeared after additional adjustment for potential confounders (mainly intake of vitamin $C$ and beta-carotene). In all case-control studies on nitrite and gastric cancer risk, a positive association was reported $(18,19,24-27)$, which reduced after adjustment for intake of other nutrients.

Nitrate intake from drinking water was studied only in three case-control studies. Boeing et al. (1991) used the source of drinking water (private vs central) as a proxy for nitrate levels in drinking water (10). They reported a significantly elevated risk for users of well water compared with users of central water supplies. (22) Rademacher et al. found no association between central or private water sources and gastric cancer risk (22). However, the mean nitrate contents in drinking water were apparently low (average in private wells: $2.42 \mathrm{mg} \mathrm{NO}_{3}^{-}-\mathrm{N} / \mathrm{L}, \mathrm{SD}=3.80$; average in public sources $0.95 \mathrm{mg} \mathrm{NO}_{3}^{-}$ - N/L, SD =1.10). Another case-control study on gastric mucosal changes and nitrate intake from drinking water also used information on nitrate levels in drinking water (23). In this study, the nitrate content in the drinking water was generally high with a mean of $109.6 \mathrm{mg} / \mathrm{L}$ (range $4.4-497.2 \mathrm{mg} / \mathrm{L}$ ) and it was closely related to histological changes. However, the histological changes were also closely related to the microbiological quality of the drinking water. Therefore, it is not clear whether these histological changes were due to nitrate or due to microbiological quality.

Our results are partly in line with the findings mentioned above. Most studies on nitrate or nitrite intake from foods reported an effect of adjustment by potential confounders, mainly other dietary constituents. However, in our study adjustment for potential confounders did not change the association between nitrate or nitrite intake and gastric cancer risk substantially. The final conclusions are similar, however: no association is found between nitrate or nitrite intake from foods and gastric cancer risk after adjustment for covariates. Although the results from other studies on nitrate intake from drinking water and gastric cancer risk are ambiguous, several studies have suggested that nitrate intake from drinking water is positively associated with gastric cancer risk. Nevertheless, this seems only the case at high nitrate concentrations. Since the nitrate levels in drinking water in the Netherlands are rather low (only $5 \%$ of the pumping stations supply drinking water with a nitrate concentration between 25 and $50 \mathrm{mg} \mathrm{NO} / \mathrm{L}$ (39)), this can explain why we found no association between nitrate intake from drinking water and gastric cancer risk. Moreover, neither an ecological 
study that used salivary nitrate and nitrite concentrations as an indicator of nitrate intake nor a cohort study of nitrate fertiliser workers supported the hypothesis that nitrate exposure is associated with a higher gastric cancer risk either $(40,41)$.

The cohort study has been performed in a large sample of the general population aged 55-69 years at baseline. Follow-up period of 6.3 years resulted in the identification of 219 male and 63 female gastric cancer cases, indicating that the study had reasonable but not very large power. The follow-up of subjects in the subcohort was $100 \%$ complete and the completeness of cancer ascertainment is of a high standard, and thus selection bias due to loss to follow-up is unlikely. Although several known risk factors for gastric cancer were measured and controlled for in the multivariate analyses, residual confounding could still have existed. Besides, we had no information about the prevalence of Helicobacter pylori infection, which may be an important risk factor for stomach cancer, probably through athropic gastritis or chronic inflammation (42). The only indication we had for altered stomach conditions was self-reported prevalence of stomach disorders. We have studied the association between nitrate and gastric cancer risk after excluding those who reported any stomach disease that required medical attention (mainly ulcera), with no change in results. However, the association between nitrite intake and gastric cancer risk seems to be weaker after excluding people with stomach disorders.

Another fact that could have influenced the results is misclassification of exposure. The intake of nitrate and nitrite is assessed by combining information on food intake with nitrate and nitrite contents in foods. Food intake is estimated with a semi-quantitative food frequency questionnaire. This questionnaire is able to rank subjects adequately according to the intake of food groups like vegetables, potatoes, fruits, meat products and cheese (30), which constitute the main sources of nitrate and nitrite. Food composition values for nitrate and nitrite were derived from the Dutch databank on contaminants in foods. To avoid incidental peaks in nitrate contents due to weather conditions, we have calculated mean nitrate contents in summer and winter. However, a questionnaire may not be a reliable method to ascertain nitrate exposure because of the large amount of variation in nitrate levels that occurs in vegetables (43). Besides, very high nitrate and nitrite contents can occur in foods that are stored, preserved or prepared in a specific way (9). We have used information about the use of refrigerator and freezer as indicators for storing conditions. Unfortunately, we have no direct information about storing, preservation or preparation. This may result in misclassification of exposure. Although recall bias is no issue in prospective cohort studies, dietary habits might have been changed by symptoms prior to the diagnosis of cancer. We have examined the potential influence of preclinical gastric cancer on nitrate and nitrite intake by excluding cases that occurred in the first year of follow-up. The rate ratios after exclusion were largely similar to those observed for the entire follow-up period.

Given that the latency period of gastric cancer may be decades (44), one would ideally consider the intake of nitrate and nitrite 20 years before follow-up. Regarding nitrate contents in foods, mainly vegetables, information was only available for the period between 1985 and 1995. During this period nitrate contents were largely similar (45). We do not have exact information about nitrite contents in cured meats 20 years ago. In the United States the content of nitrate and nitrite in cured meats 
decreased by $75 \%$ between 1925 and 1981 (46). Therefore, the intake of nitrite 20 years before follow-up is likely to be greater than our estimation of the nitrite intake, using data from 1985 to 1989. However, there are no reasons to assume that the categorization of individuals in quintiles of nitrite intake should be different and, therefore, the association between nitrite intake and gastric cancer risk should also be comparable with our current results.

In summary, we found a non-significant inverse association between nitrate intake from foods and gastric cancer risk and no association between nitrate intake from drinking water. Adjustment for potential confounding factors did not substantially change these associations. We did not find a clear association between nitrite intake from foods and gastric cancer risk. Our study, therefore, does not support a positive association between the intake of nitrate or nitrite and gastric cancer risk.

\section{ACKNOWLEDGEMENTS}

We want to thank the participants in this study, the regional cancer registries (IKA, IKL, IKMN, IKN, IKO, IKR, IKST, IKW, IKZ), and PALGA for providing incidence data; E. Dorant, S. van de Crommert, P. Florax, J. Nelissen, M. Moll and W. van Dijk for assistance in the cohort study. The Netherlands Cohort Study is financially supported by the Dutch Cancer Society.

\section{REFERENCES}

1. Gangolli SD, van den Brandt PA, Feron VJ, et al. Nitrate, nitrite and N-nitroso compounds. Eur J Pharmacol 1994;292:1-38.

2. van Loon AJM, van Klaveren JD. Nitraatinname van de Nederlandse bevolking. Voeding 1991;52:96-100.

3. Ellen G, Egmond E, Van Loon JW, et al. Dietary intakes of some essential and non-essential trace elements, nitrate, nitrite and $\mathrm{N}$-nitrosamines, by Dutch adults: estimated via a 24-hour duplicate portion study. Food Addit Contam 1990;7:207-21.

4. Stephany RW, Schuller PL. The intake of nitrate, nitrite and volatile N-nitrosamines and the occurrence of volatile N-nitrosamines in human urine and veal calves. IARC Sci Publ 1978;19:443-60.

5. Forman D. Dietary exposure to N-nitroso compounds and the risk of human cancer. Cancer Surv 1987;6:719-38.

6. Mirvish SS. The etiology of gastric cancer. Intragastric nitrosamide formation and other theories. J Natl Cancer Inst 1983;71:629-47.

7. Mirvish SS, Wallcave L, Eagen M, et al. Ascorbate-nitrite reaction: possible means of blocking the formation of carcinogenic N-nitroso compounds. Science 1972;177:65-8.

8. Kyrtopoulos SA. Ascorbic acid and the formation of $\mathrm{N}$-nitroso compounds: possible role of ascorbic acid in cancer prevention. Am J Clin Nutr 1987;45(5 Suppl): 1344-50.

9. Boeing H. Epidemiological research in stomach cancer: progress over the last ten years. J Cancer Res Clin Oncol 1991;117:133-43.

10. Boeing $H$, Frentzel BR, Berger $M$, et al. Case-control study on stomach cancer in Germany. Int J Cancer 1991;47:858-64.

11. Palli D, Galli M, Caporaso NE, et al. Family history and risk of stomach cancer in Italy. Cancer Epidemiol Biomarkers Prev 1994;3:15-8.

12. Kono $S$, Hirohata T. Nutrition and stomach cancer. Cancer Causes Control 1996;7:41-55.

13. van Loon AJM, Goldbohm RA, van den Brandt PA. Socioeconomic status and stomach cancer incidence in men: results from the Netherlands Cohort Study. J Epidemiol Community Health 1998;52:166-71. 
14. Jensen OM. Nitrate in drinking water and cancer in northern Jutland, Denmark, with special reference to stomach cancer. Ecotoxicol Environ Safety 1982;6:258-67.

15. Clough PWL. Nitrates and gastric carcinogenesis. Minerals Environment 1983;5:91-5.

16. Gilli G, Corrao G, Favilli S. Concentrations of nitrates in drinking water and incidence of gastric carcinomas: first descriptive study of the Piemonte Region, Italy. Sci Total Environ 1984;34:35-48.

17. Beresford SA. Is nitrate in the drinking water associated with the risk of cancer in the urban UK? Int J Epidemiol 1985;14:57-63.

18. Risch HA, Jain M, Choi NW, et al. Dietary factors and the incidence of cancer of the stomach. Am J Epidemiol 1985;122:947-59.

19. Buiatti E, Palli D, Decarli A, et al. A case-control study of gastric cancer and diet in Italy: II. Association with nutrients. Int J Cancer 1990;45:896-901.

20. Leclerc $H$, Vincent $P$, Vandevenne $P$. [Nitrates in drinking water and cancer] Nitrates de l'eau de boisson et cancer. Bull Acad Natl Med 1991;175:651-66.

21. Palli D, Bianchi S, Decarli A, et al. A case-control study of cancers of the gastric cardia in Italy. Br J Cancer 1992;65:263-6.

22. Rademacher JJ, Young TB, Kanarek MS. Gastric cancer mortality and nitrate levels in Wisconsin drinking water. Arch Environ Health 1992;47:292-4.

23. $\mathrm{Xu} \mathrm{G}$, Song $\mathrm{P}$, Reed PI. The relationship between gastric mucosal changes and nitrate intake via drinking water in a high-risk population for gastric cancer in Moping county, China. Eur J Cancer Prev 1992;1:437-43.

24. Gonzalez CA, Riboli E, Badosa J, et al. Nutritional factors and gastric cancer in Spain. Am J Epidemiol 1994;139:466-73.

25. Hansson LE, Nyren O, Bergstrom R, et al. Nutrients and gastric cancer risk. A population-based case-control study in Sweden. Int J Cancer 1994;57:638-44.

26. La Vecchia C, Ferraroni M, D'Avanzo B, et al. Selected micronutrient intake and the risk of gastric cancer. Cancer Epidemiol Biomarkers Prev 1994;3:393-8.

27. Pobel D, Riboli E, Cornee J, et al. Nitrosamine, nitrate and nitrite in relation to gastric cancer: a case-control study in Marseille, France. Eur J Epidemiol 1995;11:67-73.

28. van den Brandt PA, Goldbohm RA, van ' $t$ Veer $P$, et al. A large-scale prospective cohort study on diet and cancer in The Netherlands. J Clin Epidemiol 1990;43:285-95.

29. van den Brandt PA, Schouten LJ, Goldbohm RA, et al. Development of a record linkage protocol for use in the Dutch Cancer Registry for Epidemiological Research. Int J Epidemiol 1990;19:553-8.

30. Goldbohm RA, van den Brandt PA, Brants HA, et al. Validation of a dietary questionnaire used in a large-scale prospective cohort study on diet and cancer. Eur J Clin Nutr 1994;48:253-65.

31. van de Worp HHM. Onderzoek naar de gehalte aan nitraat en nitriet in een aantal wintergroenten. RIKILT: Wageningen, 1987.

32. Driessen JJM. Nitraat- en nitrietgehalte van een aantal rauwe en toebereide groenten. Wageningen: RIKILT: Wageningen, 1989.

33. Nevo tabel. Dutch Food Composition table 1986-1987 (Nederlands voedingsstoffenbestand 1986-1987) Voorlichtingsbureau voor de Voeding: The Hague, 1986.

34. Botterweck AAM. Zoutgebruik en het risico op maagkanker. Universiteit Maastricht, TNO Voeding: Maastricht/Zeist, 1994.

35. Prentice RL. A case-cohort design for epidemiologic cohort studies and disease prevention trials. Biometrika 1986;73:1-11.

Volovics A, van den Brandt PA. Methods for the analyses of case-cohort studies. Biom J 1997;39:195-214.

Baker R. Glim 3.77 Reference manual. Numerical Algorithms Group: Oxford, 1985.

Correa P. A human model of gastric carcinogenesis. Cancer Res 1988;48:3554-60.

van Duyvenbooden W, Matthysen AJCM. Integrated Criteria document nitrate. RIVM: Bilthoven, 1989.

Forman D, Al DS, Doll R. Nitrates, nitrites and gastric cancer in Great Britain. Nature 1985;313:620-5.

Al Dabbagh S, Forman D, Bryson D, et al. Mortality of nitrate fertiliser workers. Br J Ind Med 1986;43:507-15. Forman D, Newell DG, Fullerton F, et al. Association between infection with Helicobacter pylori and risk of gastric cancer: evidence from a prospective investigation. BMJ 1991;302:1302-5.

43. Bruning-Fann CS, Kaneene JB. The effects of nitrate, nitrite and N-nitroso compounds on human health: a review. Vet Hum Toxicol 1993;35:521-38. 
44. Forman D. Are nitrates a significant risk factor in human cancer? Cancer Surv 1989;8:443-58.

45. KAP, Kwaliteitsprogramma Agrarische Produkten verslag 1997; Resultaten residubewaking in Nederland, RIKILT : Wageningen, 1995.

46. Howson CP, Hiyama T, Wynder EL. The decline in gastric cancer: epidemiology of an unplanned triumph. Epidemiol Rev 1986;8:1-27. 
Chapter 4 
Salt intake, cured meat consumption, refrigerator use and stomach cancer incidence: a prospective cohort study

Anita A.M. Botterweck ${ }^{1}$

Piet A. van den Brandt ${ }^{1}$

R. Alexandra Goldbohm ${ }^{2}$

${ }^{1}$ Department of Epidemiology, Maastricht University, Maastricht, The Netherlands

${ }^{2}$ Department of Consumer Research and Epidemiology, TNO Voeding, Zeist, The Netherlands

Submitted for publication 


\section{ABSTRACT}

Background: Many case-control studies have reported that salt and cured meat intake are positively and refrigerator use is inversely associated with stomach cancer risk. In the current prospective study these associations were evaluated.

Methods: The Netherlands Cohort Study consisted of 120,852 men and women ages 55-69 years at baseline in 1986. After 6.3 years of follow-up, 282 incident stomach cancer cases were registered. Salt exposure was measured by calculating mean daily sodium intake (dietary salt) from 150 food items and by specific salt questions.

Results: In multivariate analyses adjusted for age, sex, smoking, education, stomach disorders, history of stomach cancer in the family, rate ratios (RR) for increasing quintiles of energyadjusted intake of dietary salt were $1.00,1.49,1.03,1.54$ and 1.18 , respectively (trend $p=0.43$ ). An inverse association was found between stomach cancer and salt added at the hot meal (trend $p$ $=0.04$ ). For salt added to home-made soup, use of salt at the table, salt preference and duration of refrigerator use, no associations were observed. Positive associations were found for bacon (RR highest/lowest intake $=1.3395 \% \mathrm{CI}, 1.03-1.71)$ and other sliced cold meat (RR highest/lowest intake $=1.2995 \% \mathrm{CI}, 0.96-1.72$ ), but not for smoked sausage, total cold meats, rashers/bacon, boiled ham and smoked beef/pork loin roll.

Separate analyses among subjects with self-reported stomach disorders revealed higher rate ratios of stomach cancer for dietary salt and several types of cured meat.

Conclusion: The present findings suggest that intake of dietary salt and several types of cured meat were weakly positively associated with stomach cancer risk. 


\section{INTRODUCTION}

Salt has been traditionally used as food preservative and to improve the taste of food. For decades, salt has been hypothesized to play a role in the aetiology of stomach cancer. Salt acts as an irritant that leads to mucosal damage in the stomach, excessive cell replication and it makes the mucosa cells more susceptible to carcinogens from foods (1).

Numerous epidemiological studies have investigated the association between stomach cancer risk and salt or sodium intake (e.g., (2-4)), salted foods (e.g., (5-7)), salt added during cooking or at table (e.g., (8-10)) and preference of salty taste (e.g., (11-13)). In many case-control studies a positive association was reported between an indicator of high salt intake and stomach cancer risk, but in some studies including nearly all of the cohort studies no association was observed (14). Increased risks have also been found for a high consumption of meat products (e.g., (15-17)). Meat products like bacon, sausage, ham, salami often contain, besides much salt, also nitrite, nitrosamines, and may contain polycyclic aromatic hydrocarbons (in smoked meats) or heterocyclic amines (in cooked foods) (17). It is not clear whether excessive salt or the other compounds are responsible for an increased stomach cancer risk.

In contrast, (long-term) use of a refrigerator, as an alternative method of food preservation, has been hypothesized to decrease stomach cancer risk (e.g., $(9,18,19)$ ). There is no direct relation with stomach cancer, but refrigerator use may reflect a change in dietary habits such as increased fruit and vegetable consumption and a decreased consumption of salted and smoked foods.

Evidence on salt and cured meat consumption has been mostly derived from case-control studies, where information bias may be present. Particularly for stomach cancer, people might have changed their dietary habits months or years prior to the diagnosis due to preclinical symptoms of stomach cancer or even precursors of stomach cancer.

In the Netherlands Cohort Study on diet and cancer, the association between salt intake, several types of cured meat and use of refrigerator and stomach cancer risk was investigated after 6.3 years of follow-up. In this prospective study, we were able to conduct analyses in which cases diagnosed relatively short after the start of the study and which are most likely to have changed their dietary habits were excluded. Moreover, the association between salt intake and cured meat and stomach cancer risk was studied separately for people with and without self-reported stomach disorders. 


\section{METHODS}

\section{The Netherlands Cohort Study}

The Netherlands Cohort Study started in September 1986 (20). The cohort included 62,573 women and 58,279 men aged 55 to 69 years at the start of the study. The participants originated from 204 municipalities in the Netherlands. Data on dietary habits and other risk factors for cancer were collected by means of a self-administered questionniare. For data analysis the casecohort approach was used in which cases are derived from the entire cohort, while the personyears at risk of the entire cohort are estimated from a random sample of 3500 subjects (subcohort) (21). After the baseline measurement, the subcohort (1688 men, 1812 women) was randomly sampled from the cohort and was followed up for vital status information. No subcohort members were lost to follow-up. Follow-up for incident cancer has been established by record linkage with cancer registries and a pathology register (22). The present analyses are restricted to cancer incidence in the first 6.3 years of follow-up from September 1986 until December 1992.

\section{Exposure assessment}

Habitual consumption of food and beverages during the year preceding the study was assessed using a 150-item semi-quantitative food frequency questionnaire (23).

Sodium intake was calculated from the 150 food items using the computerized Dutch food composition table (24). In this study, the variable sodium intake represents sodium naturally present in foods together with sodium added in food processing by food manufacturers. Sodium is recalculated as salt (sodium-chloride) and denoted as dietary salt throughout this article. In the questionnaire several questions specifically focused on the use of table salt, salt added when preparing a hot meal or home-made soup, and salt preference. Two questions concentrated on the use of a refrigerator and freezer (see appendix).

Foods that have a major contribution to the total salt intake are bread, cheese and cured meat. In the Netherlands, cured meat contains a mixture of salt, nitrate and nitrite, and was therefore interesting to study with regard to methods of food preparation.

Participants were asked to report their frequency of consumption of six types of cured meat: bacon and smoked sausage eaten at the hot meal; boiled ham, rashers/bacon, smoked beef/pork loin roll and other sliced cold meat eaten at the cold meal. The seven answer categories ranged from 'never or less than once per month' to '6-7 times per week'. Participants had to indicate the consumption amount in grams or household units (slices).

The questionnaire was validated against a 9-day diet record. The Spearman correlation coefficient between the questionnaire and the dietary record for sodium and meat products was 0.64 and 0.54 , respectively (23).

\section{Data analysis}

After excluding subjects reporting prevalent stomach cancer at baseline, cases with in situ stomach carcinoma, cases with stomach cancer other than carcinoma or without microscopically 
confirmed stomach cancer, there were 310 (242 men, 68 women) incident stomach carcinoma cases remaining. In the subcohort, 1630 men and 1716 women remained after excluding prevalent cancer cases other than skin cancer. Furthermore, subjects with incomplete or inconsistent dietary data were also excluded (23), leaving 282 (219 men, 63 women) stomach cancer cases and 3123 subcohort members (1525 men, 1598 women) for the analyses.

Dietary salt intake was energy-adjusted by using the residual method in order to asses the independent contribution of salt (25). Daily mean intake of cured meat ( $\mathrm{g} / \mathrm{day}$ ) was calculated by multiplying frequency and consumption amount. The variables boiled ham, rashers/bacon, smoked beef/pork loin roll and other sliced cold meat were combined into the variable total sliced cold meats. The variables were categorized into quintiles (dietary salt intake) or categories (other salt variables, all cured meat variables and use of refrigerator and freezer) depending on the distribution in the subcohort. The answering categories 'often' and 'very often' from the table salt question and 'not salty enough' and 'far from salty enough' from the salt preference questions were combined due to few cases in the separate answer categories.

Intake of salt and cured meat differed between men and women. However, results of analyses by sex were very similar. Therefore, results were presented for men and women together. Mean daily intake of dietary salt, salt added to a hot meal or home-made soup, cured meat and mean years of refrigerator use were presented for all stomach cancer cases, all cases except those diagnosed in the first or second year of follow-up and subcohort members. Mean values of salt intake, salt added to the hot meal and home-made soup, total cured meat (a combination of all cured meat variables) and years of refrigerator use were compared across the various categories of the potential confounders. Variables that were considered as potential confounders were age (55-59, 60-64, 65-69 years), sex, level of education (low, medium and high)(26), self-reported stomach disorders (yes or no), family history of stomach cancer (yes or no), smoking status (never, exsmoker and current smoker). In this study, stomach disorders were defined as having any stomach disease in the past which required medical attention (e.g. peptic ulcer, gastritis).

Data were analysed using the case-cohort approach (21). Rate ratios (RRs) of stomach cancer and their 95 percent confidence intervals (CI) were computed for the variables, using the GLIM statistical package (27). Exponentially distributed survival times were assumed in the follow-up period. Specific macros were developed to account for the additional variance introduced by using the subcohort instead of using the entire cohort (28). Tests for trend in the rate ratios were based on likelihood ratio tests and two-sided p-values were used throughout this article. Age- and sexadjusted as well as multivariate analyses were done for all variables. The multivariate model included the above mentioned potential confounders. Additional adjustment was made for fruit and vegetable consumption for all variables. For cured meat, also dietary salt intake was added in the multivariate model. Because in previous analyses no associations were observed between total energy intake, nitrate and nitrite intake (29) and stomach cancer risk, these factors were not considered as confounders.

To evaluate a potential influence of prediagnostic symptoms of stomach cancer on salt intake and cured meat consumption, the mean intake of these variables for cases diagnosed in the first and 
second year of follow-up was compared with the mean intake of cases diagnosed in the third to seventh year of follow-up. Differences in intake was tested with Mann-Whitney $U$ tests because of skewed frequency distributions of the variables. Thereafter, analyses were done after excluding cases diagnosed in the first and second follow-up year $(30,31)$. Furthermore, analyses for salt intake and cured meat were conducted for subjects with and without stomach disorders to evaluate whether results are different due to changes in dietary habits related to stomach disorders.

\section{RESULTS}

Nearly all participants answered the question about use of table salt (99.1\%), salt added to the hot meal $(98.0 \%)$, use of refrigerator $(96.6 \%)$ and freezer $(97.7 \%)$. The questions about salt added to home-made soup, taste of soup from a pack or can or taste of restaurant food were answered by $86.5 \%, 89.7 \%$ and $85.3 \%$ of the participants, respectively.

In table 1 the mean intake of salt and cured meat in all stomach cancer cases, the case-group without cases diagnosed in the first or second follow-up year and subcohort members are shown. The two case-groups had a higher dietary salt intake and consumed more bacon (as component of the hot meal), total sliced cold meats, rashers/bacon and other sliced cold meat but less smoked beef/pork loin roll than the subcohort members. There were no difference between the two case groups and subcohort members with respect to salt added to the hot meal or home-made soup and smoked sausage. For boiled ham, the intake of the restricted case group was lower than that of all cases and the subcohort members. There was no difference in years of refrigerator use and percentage of freezer users between cases and subcohort members. A higher percentage of the two case groups often used table salt compared to the subcohort members. Also a higher percentage of cases indicated that the taste of soup from a pack or can or restaurant food was much too salty compared to the subcohort members.

First and second year cases added less salt to the hot meal, but consumed more total sliced cold meats, boiled ham and smoked beef/pork loin roll than cases diagnosed in the third to the seventh year of follow-up. Differences in dietary salt intake, salt added to home-made soup and consumption of other types of cured meat between the two case groups were small and the MannWhitney $U$ test was not statistically significant for any of the variables (data not shown).

The association between potential confounders and energy-adjusted dietary salt, salt added to the hot meal and home-made soup, consumption of total cured meat and use of the refrigerator was studied in the subcohort (table 2). There was no association between energy-adjusted dietary salt intake, salt added to home-made soup and age. The amount of salt added to the hot meal and the consumption of total cured meat decreased with increasing age. Men had a higher intake of dietary salt, salt added to the hot meal and home-made soup and consumption of total cured meat compared to women. Current smokers used more salt when preparing the hot meal and consumed more total cured meat. Subjects in the lowest educational level added more salt to the hot meal and consumed more total cured meat. Subjects that reported to have stomach disorders consumed 
TABLE 1. Salt intake, consumption of cured meat, use of refrigerator and freezer, use of table salt, salt preference in all stomach cancer cases, case-group with first and second year cases excluded and subcohort members: Netherlands Cohort Study 1986-1992.

\begin{tabular}{|c|c|c|c|}
\hline \multirow[t]{3}{*}{ Variables } & \multicolumn{2}{|c|}{ Cases } & \multirow{2}{*}{$\begin{array}{l}\text { Subcohort } \\
n=3123\end{array}$} \\
\hline & $\begin{array}{c}\text { All } \\
n=282\end{array}$ & $\begin{array}{l}\text { First and second year } \\
\text { cases excluded, } n=208\end{array}$ & \\
\hline & mean (SDH) & mean (SD+) & mean (SDt) \\
\hline \multicolumn{4}{|l|}{ Salt intake (g/day) } \\
\hline salt in foods (dietary salt) & $6.4(1.5)$ & $6.4(1.5)$ & $5.8(1.5)$ \\
\hline salt added to the hot meal during cooking* & $4.0(4.5)$ & $4.1(4.6)$ & $4.0(4.0)$ \\
\hline salt added to home-made soup during cooking* & $0.6(0.8)$ & $0.6(0.7)$ & $0.6(0.9)$ \\
\hline \multicolumn{4}{|l|}{ Cured meat (g/day) } \\
\hline bacon as component of the hot meal & $2.5(4.2)$ & $2.6(4.7)$ & $2.1(3.7)$ \\
\hline smoked sausage as component of the hot meal & $2.4(2.3)$ & $2.4(2.3)$ & $2.5(2.6)$ \\
\hline total sliced cold meats & $15.1(17.3)$ & $14.6(17.4)$ & $12.9(15.0)$ \\
\hline boiled ham & $4.5(6.9)$ & $4.0(6.2)$ & $4.4(7.1)$ \\
\hline rashers, bacon & $1.6(4.1)$ & $1.7(4.2)$ & $1.4(4.0)$ \\
\hline smoked beef, pork loin roll & $2.0(4.3)$ & $1.7(3.4)$ & $2.5(5.5)$ \\
\hline other sliced cold meat & $7.2(12.5)$ & $7.2(12.5)$ & $4.6(8.5)$ \\
\hline \multirow[t]{2}{*}{ Use of refrigerator (years) } & $26.1(7.9)$ & & $25.6(7.6)$ \\
\hline & $n(\%)$ & $\mathrm{n}(\%)$ & $n(\%)$ \\
\hline \multicolumn{4}{|l|}{ Use of freezer* } \\
\hline yes & $181(64.2)$ & $134(64.4)$ & $1952(62.5)$ \\
\hline no & $97(34.4)$ & $70(33.7)$ & $1099(35.2)$ \\
\hline \multicolumn{4}{|l|}{ Use of salt at the table* } \\
\hline never & $113(40.2)$ & $88(42.5)$ & $1270(40.7)$ \\
\hline seldom & $87(31.0)$ & $62(30.0)$ & $875(28.0)$ \\
\hline sometimes & $55(19.6)$ & $38(18.4)$ & $746(23.9)$ \\
\hline often/very often & $26(9.3)$ & $19(9.2)$ & $204(6.6)$ \\
\hline \multicolumn{4}{|l|}{ Taste of soup from a pack or can * } \\
\hline not salty enough & $7(2.8)$ & $4(2.1)$ & $74(2.4)$ \\
\hline good & $100(39.5)$ & $71(38.0)$ & $1121(35.9)$ \\
\hline a little too salty & $74(29.2)$ & $60(32.1)$ & $935(29.9)$ \\
\hline much too salty & $70(27.7)$ & $50(26.7)$ & $673(21.5)$ \\
\hline \multicolumn{4}{|l|}{ Taste of restaurant food ${ }^{*}$} \\
\hline not salty enough & $13(5.5)$ & $10(5.8)$ & $173(5.5)$ \\
\hline good & $153(64.6)$ & $112(65.1)$ & $1801(57.7)$ \\
\hline a little too salty & $54(22.8)$ & $41(23.8)$ & $557(17.8)$ \\
\hline much too salty & $13(5.5)$ & $7(4.1)$ & $130(4.2)$ \\
\hline
\end{tabular}
"Because of missings values, the numbers do not add up to 282 or 208 cases and 3123 subcohortmembers
† Standard deviation

more cured meat than subjects without stomach disorders and subjects with a family history of 
TABLE 2: Mean intake (standard deviation (SD)) of dietary salt intake, salt added to the hot meal or to home-made soup, consumption of total cured meat and mean years (SD) of refrigerator use in the subcohort for several characteristics for men and women together: Netherlands Cohort Study 1986-1992.

\begin{tabular}{|c|c|c|c|c|c|}
\hline & $\begin{array}{l}\text { Dietary salt } \\
\text { intake }\end{array}$ & $\begin{array}{l}\text { Salt added to } \\
\text { the hot meal } \\
\text { during } \\
\text { cooking }\end{array}$ & $\begin{array}{l}\text { Salt added to } \\
\text { home-made } \\
\text { soup during } \\
\text { cooking }\end{array}$ & $\begin{array}{l}\text { Consumption } \\
\text { of total cured } \\
\text { meat }\end{array}$ & $\begin{array}{l}\text { Refrigerator } \\
\text { use }\end{array}$ \\
\hline Characteristios & g/day (SD) & $g /$ day $(S D)$ & g/day (SD) & g/day (SD) & years (SD) \\
\hline \multicolumn{6}{|l|}{ Age (years) } \\
\hline $55-59$ & $5.8(1.5)$ & $4.3(4.1)$ & $0.6(0.8)$ & $18.2(16.7)$ & $25.4(7.2)$ \\
\hline $60-64$ & $5.8(1.5)$ & $3.9(3.9)$ & $0.6(1.1)$ & $17.8(16.2)$ & $25.7(7.6)$ \\
\hline $65-69$ & $5.8(1.5)$ & $3.8(3.9)$ & $0.6(0.8)$ & $16.2(16.2)$ & $25.8(8.2)$ \\
\hline \multicolumn{6}{|l|}{ Sex } \\
\hline men & $6.6(1.5)$ & $4.3(4.3)$ & $0.7(1.1)$ & $20.7(18.8)$ & $26.2(7.4)$ \\
\hline women & $5.3(1.3)$ & $3.7(3.6)$ & $0.5(0.7)$ & $14.5(13.0)$ & $25.1(7.8)$ \\
\hline \multicolumn{6}{|l|}{ Cigarelte smoking status } \\
\hline never & $5.6(1.5)$ & $3.7(3.6)$ & $0.6(0.8)$ & $15.2(14.4)$ & $24.6(7.9)$ \\
\hline ex-smoker & $6.1(1.5)$ & $3.7(3.4)$ & $0.5(0.7)$ & $17.3(15.3)$ & $26.3(7.3)$ \\
\hline current smoker & $6.1(1.8)$ & $4.7(4.8)$ & $0.6(1.2)$ & $20.2(19.1)$ & $26.0(7.5)$ \\
\hline \multicolumn{6}{|l|}{ Education level } \\
\hline primary school /lower vocational & $6.1(1.5)$ & $4.3(4.2)$ & $0.7(1.1)$ & $18.5(17.5)$ & $24.5(7.7)$ \\
\hline secondary school/medium vocational & $5.8(1.5)$ & $3.8(3.9)$ & $0.5(0.7)$ & $16.2(14.9)$ & $26.8(7.7)$ \\
\hline university/higher vocational & $5.8(1.5)$ & $3.6(3.3)$ & $0.5(0.7)$ & $17.0(15.2)$ & $27.1(6.4)$ \\
\hline \multicolumn{6}{|l|}{ Stomach disorders } \\
\hline no & $5.8(1.5)$ & $4.0(4.0)$ & $0.6(0.9)$ & 17.4.(16.4) & $25.6(7.7)$ \\
\hline yes & $6.1(1.5)$ & $4.1(4.1)$ & $0.6(0.7)$ & $18.6(16.1)$ & $25.5(7.2)$ \\
\hline \multicolumn{6}{|l|}{ Family history of stomach cancer } \\
\hline no & $5.8(1.5)$ & $4.0(4.0)$ & $0.6(0.9)$ & $17.6(16.4)$ & $25.6(7.7)$ \\
\hline yes & $6.1(1.5)$ & $4.1(3.7)$ & $0.5(0.6)$ & $16.0(17.0)$ & $25.7(6.6)$ \\
\hline
\end{tabular}

stomach cancer consumed less cured meat than subjects without a family history of stomach cancer. There were no differences in years of refrigerator use between the categories of potential confounders, except that subjects of the lowest educational level reported to use the refrigerator less years than subjects of the higher educational levels.

Age- and sex-adjusted and multivariate adjusted $R R s$ and results of multivariate analyses in which first and second year cases were excluded for all variables are presented in table 3. Overall, ageand sex-adjusted and multivariate analyses RRs were quite similar. The results are described for multivariate analyses only. For dietary salt intake, the rate ratios were all higher than one, but without a linear trend. There was a significant inverse association between stomach cancer risk and salt added to the hot meal (trend $p=0.04$ ). Salt added to home-made soup and use of table salt showed no clear association with stomach cancer risk. Subjects who indicated that the taste of soup or restaurant food was much too salty appear to have an increased stomach cancer risk, and 
subjects who indicated that the taste of restaurant food was not salty enough appear to have a decreased risk. Use of a refrigerator and freezer was not associated with stomach cancer risk. High consumption of bacon as component of the hot meal and was associated with a significant increased stomach cancer risk ( $R R$ highest versus lowest consumption category $=1.33,95 \% \mathrm{CI}$ 1.03-1.71). No clear associations were observed between consumption of smoked sausage, total sliced cold meats, rashers/bacon, smoked beef/pork loin roll and stomach cancer. The RR of highest versus lowest category of boiled ham consumption was 0.77 (95\% CI 0.56-1.07) and for other sliced cold meat was 1.29 (95\% CI 0.96-1.72), but for both variables no significant trend in risk was observed. Additional adjustment for fruit and vegetable consumption in the multivariate model of all variables and additional adjustment for dietary salt intake in the model of the cured meat variables did not substantially change the risk estimates (data not shown).

Exclusion of cases diagnosed in the first or second year of follow-up did not substantially change the results much in table 3. For salt added to the hot meal, all RRs were below one, but the test for trend was no longer significant (trend $p=0.17$ ). The RR for often/very often used versus never use of table salt was now 0.85 (95\% Cl $0.50-1.43)$, but the test for trend did not reach significance $(p=0.07)$. For rashers/bacon, the RR became higher than one (RR high vs low consumption category $=1.08,95 \% \mathrm{CI} 0.80-1.46$ ) and for smoked beef/pork loin roll, the RR moved farther away from the null-value ( $R R$ high vs low consumption category $=0.83,95 \% \mathrm{Cl} 0.62-1.11$ ).

Analyses among subjects with and without stomach disorders revealed different associations (table 4). The rate ratios for dietary salt among subjects with stomach disorders were all higher than one, but there was no significan: trend in risk (trend $p=0.08$ ). For salt added to home-made soup, a significant positive trend in risk was found (trend $p=0.003$ ) while an inverse trend in risk was found (trend $p=0.04$ ) for subjects without stomach disorders. Rate ratios of bacon, smoked sausage, total sliced cold meats rashers/bacon and other sliced cold meat for people with stomach disorders were higher than one, although no RR was significant increased. High consumption of boiled ham and smoked beef/pork in loin roll was not associated with an increased stomach cancer risk in either subjects with or without stomach disorders.

\section{DISCUSSION}

In this prospective cohort study, energy-adjusted intake of dietary salt was associated with an increased stomach cancer risk but there was no clear trend with increasing risk. Salt added to food during cooking was inversely associated with risk. There was no association between salt added to home-made soup or use of table salt and stomach cancer risk. Results regarding salt preference questions were contrary to expectations. High intake of bacon and other sliced cold meat were associated with increased risks and high intake of boiled ham was associated with a decreased risk. There was no evidence that use of a refrigerator or freezer was related to stomach cancer. Before interpreting the results of this study, several features of this cohort study should be discussed. This is a large population-based prospective cohort study with a relatively large 
TABLE 3. Rate ratios (RRs) and $95 \%$ confidence intervals (95\% Cl) for stomach cancer according to salt intake, use of table salt, salt preference, use of refrigerator and freezer and consumption of cured meat: Netherlands Cohort Study 19861992.

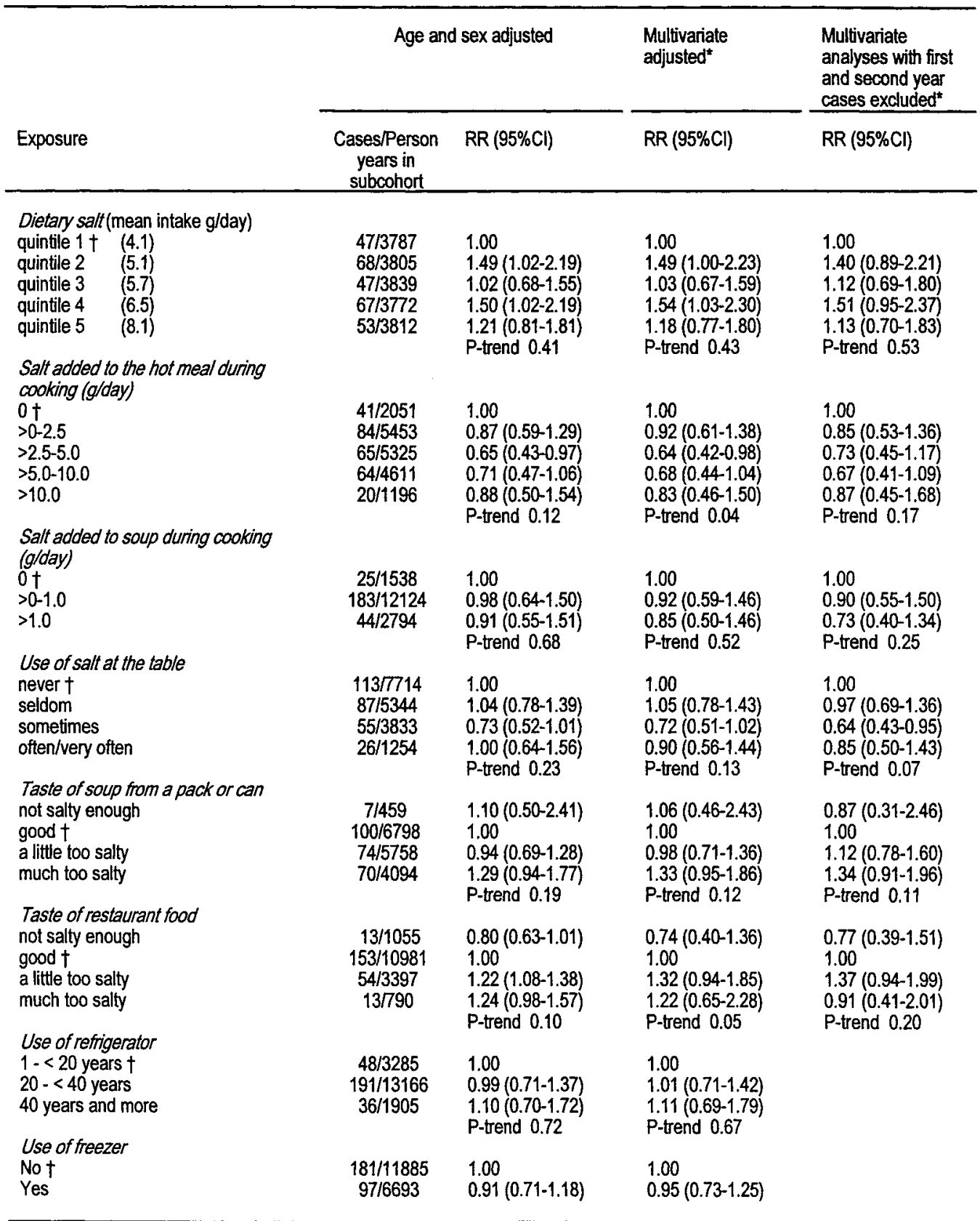




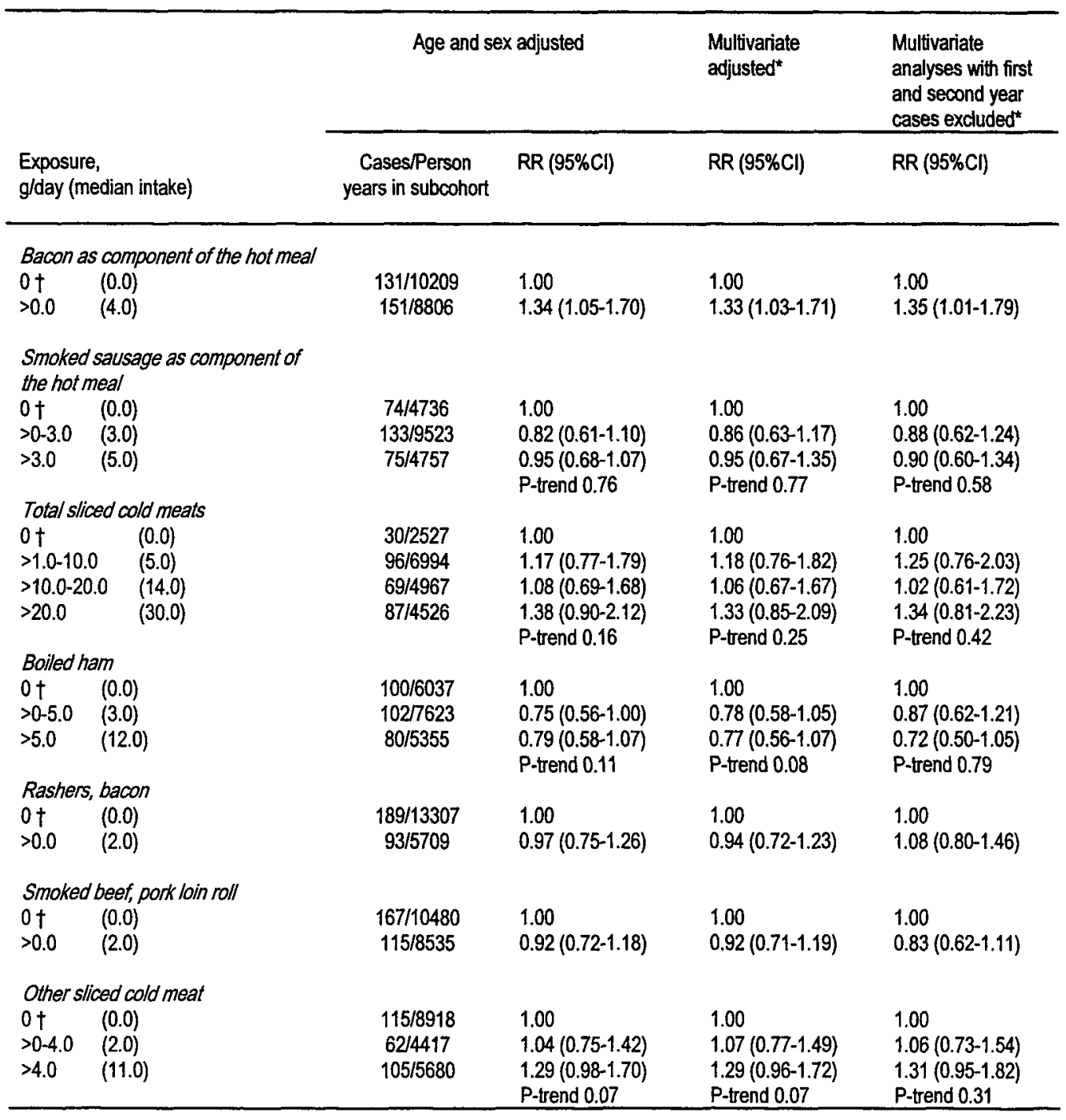

* RRs adjusted for age, sex, smoking status, level of education, stomach disorders and stomach cancer in the family treference category

number of cases $(n=310)$ after 6.3 years of follow-up. Selection bias due to loss-to follow-up is unlikely given the high completeness of follow-up of the cases and the subcohort person-years. It was possible to correct for several potential confounders because information about these factors was assessed in the extensive questionnaire. However, the associations may still be confounded by unknown and unmeasured factors. Information bias due to random misclassification may have resulted in bias towards the null value. We tried, however, to prevent substantial 
TABLE 4. Rate ratios (RRs) and $95 \%$ confidence intervals ( $95 \% \mathrm{Cl}$ ) for stomach cancer according to salt intake and consumption of cured for stomach cancer cases with and without stomach disorders: Netherlands Cohort Study 1986-1992.

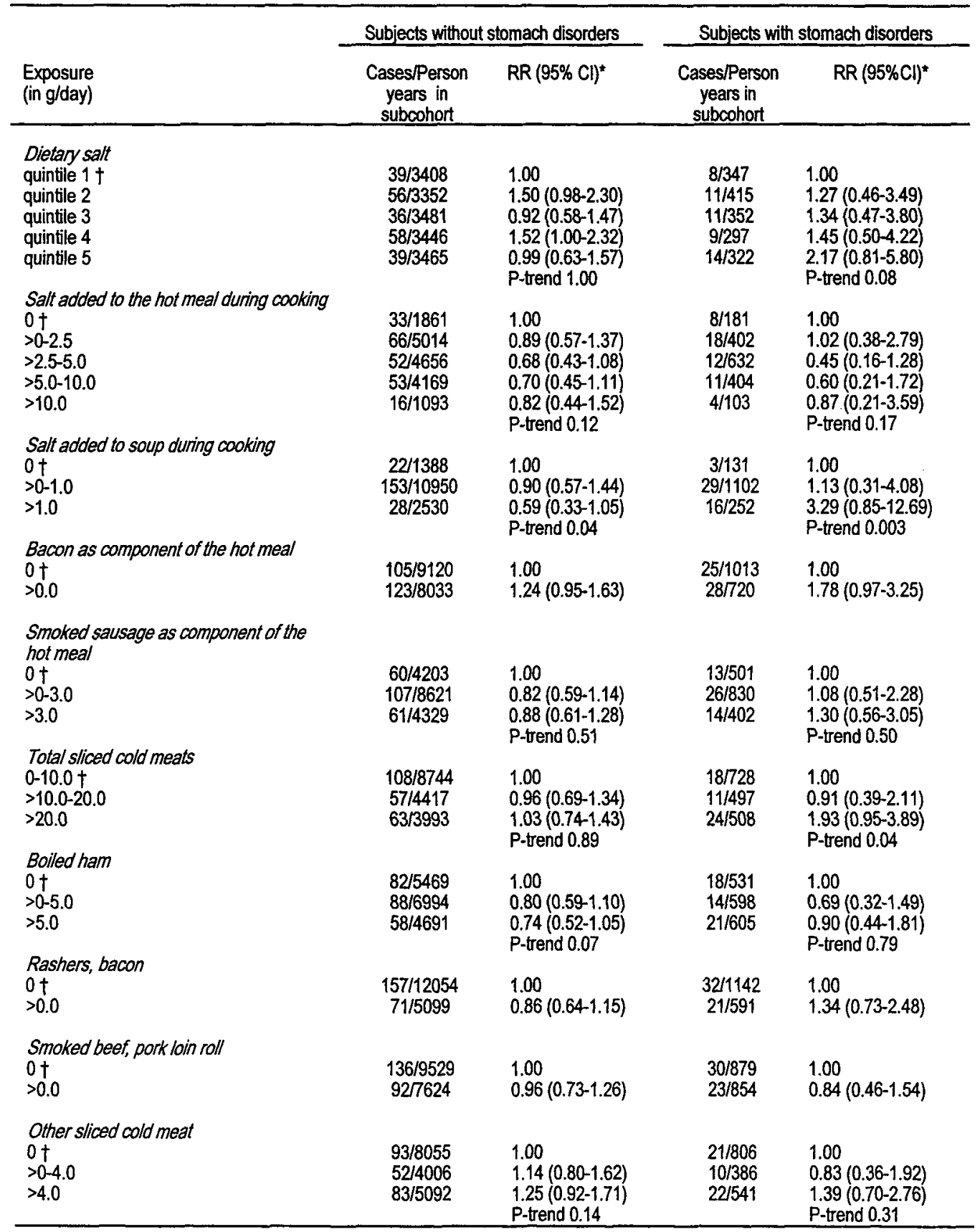

* RRs adjusted for age, sex, smoking status, level of education, stomach disorders and stomach cancer in the family † reference category 
misclassification of exposure by excluding subjects with incomplete and inconsistent data (23). It is rather difficult to quantify salt intake. In the present study, salt intake was measured by calculating mean daily sodium intake from the 150-item semi-quantitative food frequency questionnaire. Furthermore, specific questions focused on salt added during cooking and at table and salt preference. Sodium intake was validated and the Spearman correlation coefficient was 0.64 (23), which suggests that the questionnaire is able to rank subjects reasonably well according to sodium intake. This sodium variable (sodium naturally present in foods and sodium added in food processing) is estimated to represent two-thirds of the sodium ingested (32). The validity of the specific salt questions was not assessed and thus we cannot judge how valid these questions are.

We did not estimate the total salt intake by combining the information on dietary salt intake and salt added during cooking and at the table because we could not account for salt loss during cooking and we had no information about the amount salt added at the table. Nevertheless, when we added up dietary salt intake and salt added to the hot meal and home-made soup, the salt intake in the subcohort was $10.4 \mathrm{~g} /$ day. This corresponded relatively well with the estimated daily salt intake by adults in the Netherlands $(9 \mathrm{~g})(33)$ and the average daily salt intake reported in other European countries which varied from 7.6 to 11.4 gram $(3,32)$.

Overall, in the majority of case-control studies, positive associations were observed for (total) salt or sodium intake $(2,3,34,35)$, consumption of salted fish, salted meat, pickles and soup $(5,7,16,35-41)$, adding salt at food at dinner $(5,9,42)$, preference of salty foods $(4,5,11,41,43)$. The relative risks reported ranged from 1.5 to 6.7 for various measures of salt intake (14). In several other case-control studies no association was reported for (total) salt or sodium intake (44-46), salted foods $(11,13,44,47)$, for use of table salt $(10,48)$ or salt added to food $(8,13,15,16,48)$, preference of foods with a salty taste $(8,12,13,15)$.

The few cohort studies that reported results on salt and stomach cancer risk found no clear associations (49-54). Unlike our finding that dietary salt intake was associated with an increased stomach cancer risk, the only cohort study that reported on sodium intake found no difference in mean daily sodium intake between cases and non-cases (49). Two cohort studies reported a significantly increased risk for consumption of broiled fish $(R R=1.7)(53)$ and salted fish $(R R=$ 2.0)(51). The other three cohort studies found no association between stomach cancer incidence and the individual or total intake of several types of high-salted foods $(50,52,54)$. It is possible that the increased risks could be attributed to other compounds of the foods (possible carcinogens) developed during the preservation process but not to salt content of the foods (7). As in our study, use of table salt was not associated with stomach cancer risk in the only cohort study that reported on this association (50).

The reason why the other cohort studies failed to find clear associations between salt and stomach cancer risk may be the limited exposure information $(49-51,53)$, because they were initially not designed for evaluating stomach cancer $(50,51)$. In the Netherlands Cohort Study, sodium intake was measured more precisely with a 150-item food frequency questionnaire and possible the reason for detecting an slightly increased risk. Most other cohort studies who studied the 
relationship between stomach cancer and total salt intake were performed in Japan or with subjects of Japanese ancestry which makes comparison with our study population difficult.

Probable a more valid estimation of the individual sodium intake is to measure sodium excretion from 24 hour urine samples. However, there are no case-control or cohort studies that used these measures to estimate salt intake or to validate specific salt questions.

Case-control studies have reported positive associations between meat products and stomach cancer risk $(5,7,10,15-17,43,48,55,56)$, but not all $(9,13,34,57)$. A cohort study among Hawaiians of Japanese descent reported a non-significant positive association between stomach cancer risk and the consumption of processed meats $(49,50)$. In an American study, only a positive association was found for bacon (51), and in a third study with subjects of Japanese ancestry no association was found for processed meat (54).

In our study, high consumption of bacon and other sliced cold meat were positively associated with stomach cancer risk, but this did not seem to be related with a high salt or nitrite content of these products. Earlier analyses indicated that nitrite was not clearly related with stomach cancer risk (29). Additional adjustment for intake of salt or nitrite did not change the risk estimates. However, it is difficult to differentiate individual effects of salt and nitrite because of a high correlation between salt and total cured meat $(\mathrm{r}=0.47)$, and nitrite and total cured meat $(\mathrm{r}=0.91)$. Use of refrigerator or freezer was not associated with stomach cancer risk in the Netherlands Cohort Study, in contrast with the results of case-control studies performed in Europe or the USA which rather consistently reported a decreased stomach cancer risk with long-term use of a refrigerator $(2,5,9,16,18,39,55)$. Three of the case-control studies did not find an association $(15,45,48)$ and no other cohort study reported on this association.

In the Netherlands, the electric refrigerator was introduced in the household in the 1950s and after a period of 30 years, nearly all ( $98 \%$ ) of households had a refrigerator (58). Nearly $70 \%$ of cohort members reported to have had a refrigerator for 20-35 years at the start of the study. Therefore, the contrast in exposure is small and may be a reason for not finding an association. Moreover, refrigerator use is probably a rough indicator in this study population for storing conditions, certain food habits regarding preservation and preparation or availability of fresh food. In the Netherlands, almost everyone has had easy access to shops or supermarkets with fresh, well stored and preserved foods. It is possible that access to a refrigerator early in life is more important in relation to stomach cancer development. However, given the introduction of the electric refrigerator in the 1950 s in the Netherlands, we were not able to study this in the Netherlands Cohort Study.

We performed analyses with and without cases diagnosed in the first or second follow-up year in order to account for change in food habits in these 'early cases'. In contrast with earlier findings on vegetable consumption and stomach cancer risk (31), the results did not essentially change after exclusion of first and second cases. Probably preclinical symptoms of stomach cancer do not have an effect on salt intake or salt preference and cured meat consumption. It is known that (some) cancer patients have taste aberrations which contribute to the development of food aversion and avoidance $(59,60)$. The foods most commonly affected are (red) meat and coffee 
$(59,60)$. It is likely that this food aversion starts some time before cancer is diagnosed. In earlier reported Netherlands Cohort Study results a decreased consumption of vegetables, meat and potatoes was found in cases diagnosed in the first or second year after baseline compared to cases diagnosed in later years of follow-up (31), indicating that components of the hot meal were avoided. In this study, no convincing evidence was found for a decreased consumption of components of the cold meal, such as cured meat, cheese and bread.

Subgroup analyses on stomach cancer risk and intake of salt and cured meat among subjects with and without stomach disorders revealed stronger associations in subjects with stomach disorders. These people consumed more cured meat compared to people without stomach disorders, but it is not clear whether this is a result of stomach disorders symptoms. We did not observe a lower consumption of hot meal components and a higher consumption of cold meal components in people with stomach disorders like we found for people with possible preclinical symptoms of stomach cancer. An explanation for finding increased risks may be that subjects with stomach disorders (peptic ulcer or gastritis) may have a destroyed mucosal barrier caused by a high salt diet which may lead to an easy invasion of carcinogens, i.e. nitrosamines present in foods or formed out of nitrite in cured meat. This seems to support the hypothesis that salt and nitrite are involved in an early stage of gastric carcinogenesis $(1,61)$.

An interesting finding is the interaction between salt and H.pylori infection (62). The mucosal cell proliferation in the antrum was positively correlated with salt intake in H.pylori positive patients, while in patients without H.pylori no relationship was found (62). A part of the subjects with stomach disorders may be infected with $\mathrm{H}$. pylori. This finding suggests that it is important to have information on the percentage of infected people in the study population and that different results on salt and stomach cancer risk may be explained by different infection rates. Unfortunately, we did not have information on H.pylori infection in the Netherlands Cohort Study.

In summary, our data suggest that salt naturally present in foods and salt added in food processing is associated with an non-significantly increased risk for stomach cancer. No clear associations are found for other indicators of salt intake. Analyses of cured meat variables showed that bacon and other sliced cold meat are positively associated with stomach cancer risk, although this probable cannot be explained by the salt or nitrite content of these products. There was no association between duration of refigerator use and stomach cancer.

\section{ACKNOWLEDGEMENTS}

We gratefully acknowledge the regional cancer registries (IKA, IKL, IKMN, IKN, IKO, IKR, IKST, IKW, IKZ), the Dutch national database of Pathology (PALGA), and the National Health Care Information Center for providing incidence data; A. Volovics for statistical advice; E. Dorant, S. Van de Crommert, H. Brants, W. Van Dijk, P. Florax, M. Moll, J. Nelissen, A. Pisters and $C$. de Zwart for assistance; H. van Monfort, R. Schmeitz, T. van Monfort, and M. de Leeuw 
for programming and statistical assistance.

Furthermore, we thank Mr. van Vyfeyken from the Nederlandse Whirlpool Bedrijven B.V. for providing information on the history of refrigerator use in the Netherlands.

The Netherlands Cohort Study was financially supported by the Dutch Cancer Society.

\section{REFERENCES}

1. Correa P. Human gastric carcinogenesis: a multistep and multifactorial process--First American Cancer Society Award Lecture on Cancer Epidemiology and Prevention. Cancer Res 1992;52:6735-40.

2. Graham S, Haughey B, Marshall J, Brasure J, Zielezny M, Freudenheim J, et al. Diet in the epidemiology of gastric cancer. Nutr Cancer 1990;13:19-34.

3. Nazario CM, Szklo M, Diamond E, Roman-Franco A, Climent C, Suarez E, et al. Salt and gastric cancer: a case-control study in Puerto Rico. Int J Epidemiol 1993;22:790-7.

4. La Vecchia C, Negri E, Franceschi S, Decarli A. Case-control study on influence of methionine, nitrite, and salt on gastric carcinogenesis in northern Italy. Nutr Cancer 1997;27:65-8.

5. Buiatti E, Palli D, Decarli A, Amadori D, Avellini C, Bianchi S, et al. A case-control study of gastric cancer and diet in Italy. Int $\mathrm{J}$ Cancer 1989;44:611-6.

6. Ramon JM, Serra ML, Cerdo C, Oromi J. Nutrient intake and gastric cancer risk: a case-control study in Spain. Int J Epidemiol 1993;22:983-8.

7. Ward MH, Lopez Carrilio L. Dietary factors and the risk of gastric cancer in Mexico City. Am J Epidemiol 1999;149:925-32.

8. Tuyns AJ. Sodium chloride and cancer of the digestive tract. Nutr Cancer 1983;4:198-205.

9. Coggon D, Barker DJ, Cole RB, Nelson M. Stomach cancer and food storage. J Natl Cancer Inst 1989;81:1178-82.

10. Wu-Williams AH, Yu MC, Mack TM. Life-style, workplace, and stomach cancer by subsite in young men of Los Angeles County. Cancer Res 1990;50:2569-76.

11. You WC, Blot WJ, Chang YS, Ershow AG, Yang ZT, An Q, et al. Diet and high risk of stomach cancer in Shandong, China. Cancer Res 1988;48:3518-23.

12. Negri E, La VC, D'Avanzo B, Gentile A, Boyle P, Franceschi S. Salt preference and the risk of gastrointestinal cancers. Nutr Cancer 1990;14:227-32.

13. Hansson LE, Nyren O, Bergstrom R, Wolk A, Lindgren A, Baron J, et al. Diet and risk of gastric cancer. A population-based case-control study in Sweden. Int J Cancer 1993;55:181-9.

14. Kono S, Hirohata T. Nutrition and stomach cancer. Cancer Causes Control 1996;7:41-55.

15. Gonzalez CA, Sanz JM, Marcos G, Pita S, Brullet E, Saigi E, et al. Dietary factors and stomach cancer in Spain: a multi-centre case-control study. Int J Cancer 1991;49:513-9.

16. Boeing H, Frentzel BR, Berger M, Berndt V, Gores W, Korner M, et al. Case-control study on stomach cancer in Germany. Int J Cancer 1991;47:858-64.

17. Ward MH, Sinha R, Heineman EF, Rothman N, Markin R, Weisenburger DD, et al. Risk of adenocarcinoma of the stomach and esophagus with meat cooking method and doneness preference. Int J Cancer 1997;71:149.

18. La Vecchia C, Negri E, D'Avanzo B, Franceschi S. Electric refrigerator use and gastric cancer risk. Br J Cancer 1990;62:136-7.

19. Boeing H, Frentzel BR. Regional risk factors for stomach cancer in the FRG. Environ Health Perspect 1991;94:83-9.

20. van den Brandt PA, Goldbohm RA, van 't Veer P, Volovics A, Hermus RJ, Sturmans F. A large-scale prospective cohort study on diet and cancer in The Netherlands. J Clin Epidemiol 1990;43:285-95.

21. Self SG, Prentice RL. Asymptotic distribution theory and efficiency results for case-cohort studies. Ann Stat 1988;16:64-81.

22. van den Brandt PA, Schouten LJ, Goldbohm RA, Dorant E, Hunen PM. Development of a record linkage protocol for use in the Dutch Cancer Registry for Epidemiological Research. Int J Epidemiol 1990;19:553-8. 
23. Goldbohm RA, van den Brandt PA, Brants HA, van't Veer P, Al M, Sturmans F, et al. Validation of a dietary questionnaire used in a large-scale prospective cohort study on diet and cancer. Eur J Clin Nutr 1994;48:25365.

24. Nevo tabel. Dutch Food Composition table 1986-1987; Nederlands voedingsstoffenbestand 1986-1987. The Hague: Voorlichtingsbureau voor de Voeding, 1986.

25. Willett W, Stampfer MJ. Total energy intake: implications for epidemiologic analyses. Am J Epidemiol 1986;124:17-27.

26. van Loon AJM, Goldbohm RA, van den Brandt PA. Socioeconomic status and stomach cancer incidence in men: results from the Netherlands Cohort Study. J Epidemiol Community Health 1998;52:166-71.

27. Baker R. Glim 3.77 Reference manual. Oxford: Numerical Algorithms Group, 1985.

28. Volovics A, van den Brandt PA. Methods for the analyses of case-cohort studies. Biom J 1997;39:195-214.

29. van Loon AJM, Botterweck AAM, Goldbohm RA, Brants HAM, van Klaveren JD, van den Brandt PA. Intake of nitrate and nitrite and the risk of gastric cancer: a prospective cohort study. $\mathrm{Br} \mathrm{J}$ Cancer 1998;78:129-35.

30. van den Brandt PA, Goldbohm RA, van't Veer P, Bode P, Dorant E, Hermus RJ, et al. Toenail selenium levels and the risk of breast cancer. Am J Epidemiol 1994;140:20-6.

31. Botterweck AAM, van den Brandt PA, Goldbohm RA. A prospective cohort study on vegetable and fruit consumption and stomach cancer risk in the Netheriands. Am J Epidemiol 1998;148:842-853.

32. Hanneman RL, Moinier B. Dietary salt intake and epidemiological studies. Gut 1988;29:407-11.

33. Commissie Vermindering Gebruik Keukenzout. Vermindering gebruik keukenzout: Eindadvies. Den Haag: Voedingsraad, 1986.

34. La Vecchia C, Negri E, Decarli A, D'Avanzo B, Franceschi S. A case-control study of diet and gastric cancer in northern Italy. Int J Cancer 1987;40:484-9.

35. Ramon JM, Serra L, Cerdo C, Oromi J. Dietary factors and gastric cancer risk. A case-control study in Spain. Cancer 1993;71:1731-5.

36. Haenszel W, Kurihara M, Segi M, Lee RK. Stomach cancer among Japanese in Hawaii. J Natl Cancer Inst 1972;49:969-88.

37. Bjelke E. Epidemiologic studies of cancer of the stomach, colon, and rectum; with special emphasis on the role of diet. Scand J Gastroenterol Suppl 1974;31:1-235.

38. Kono S, Ikeda M, Tokudome S, Kuratsune M. A case-control study of gastric cancer and diet in northern Kyushu, Japan. Jpn J Cancer Res 1988;79:1067-74.

39. Demirer T, Icli F, Uzunalimoglu O, Kucuk O. Diet and stomach cancer incidence. A case-control study in Turkey. Cancer 1990;65:2344-8.

40. Palli D, Bianchi S, Decarli A, Cipriani F, Avellini C, Cocco P, et al. A case-control study of cancers of the gastric cardia in Italy. Br J Cancer 1992;65:263-6.

41. Lee JK, Park BJ, Yoo KY, Ahn YO. Dietary factors and stomach cancer: a case-control study in Korea. Int J Epidemiol 1995;24:33-41.

42. Tuyns AJ. Salt and gastrointestinal cancer. Nutr Cancer 1988;11:229-32.

43. Hoshiyama Y, Sasaba T. A case-control study of stomach cancer and its relation to diet, cigarettes, and alcohol consumption in Saitama Prefecture, Japan. Cancer Causes Control 1992;3:441-8.

44. Hu JF, Zhang SF, Jia EM, Wang QQ, Liu SD, Liu YY, et al. Diet and cancer of the stomach: a case-control study in China. Int J Cancer 1988;41:331-5.

45. Jedrychowski W, Boeing $H$, Popiela $T$, Wahrendorf J, Tobiasz AB, Kulig J. Dietary practices in households as risk factors for stomach cancer: a familial study in Poland. Eur J Cancer Prev 1992;1:297-304.

46. Harrison LE, Zhang ZF, Karpeh MS, Sun M, Kurtz RC. The role of dietary factors in the intestinal and diffuse histologic subtypes of gastric adenocarcinoma: a case-control study in the U.S. Cancer 1997;80:1021-8.

47. Acheson ED, Doll R. Dietary factors in carcinoma of the stomach: A study of 110 cases and 200 controls. Gut 1964;5:126-31.

48. Correa P, Fontham E, Pickle LW, Chen V, Lin YP, Haenszel W. Dietary determinants of gastric cancer in south Louisiana inhabitants. J Natl Cancer Inst 1985;75:645-54.

49. Chyou PH, Nomura AM, Hankin JH, Stemmermann GN. A case-cohort study of diet and stomach cancer. Cancer Res 1990;50:7501-4. 
50. Nomura A, Grove JS, Stemmermann GN, Severson RK. A prospective study of stomach cancer and its relation to diet, cigarettes, and alcohol consumption. Cancer Res 1990;50:627-31.

51. Kneller RW, McLaughlin JK, Bjelke E, Schuman LM, Blot WJ, Wacholder S, et al. A cohort study of stomach cancer in a high-risk American population. Cancer 1991;68:672-8.

52. Kato I, Tominaga S, Matsumoto K. A prospective study of stomach cancer among a rural Japanese population: a 6-year survey. Jpn J Cancer Res 1992;83:568-75.

53. Ikeda M, Yoshimoto $\mathrm{K}$, Yoshimura $\mathrm{T}$, Kono S, Kato H, Kuratsune M. A cohort study on the possible association between broiled fish intake and cancer. Gann 1983;74:640-8.

54. Galanis DJ, Kolonel LN, Lee J, Nomura A. Intakes of selected foods and beverages and the incidence of gastric cancer among the Japanese residents of Hawaii: a prospective study. Int J Epidemiol 1998;27:173-80.

55. Risch HA, Jain M, Choi NW, Fodor JG, Pfeiffer CJ, Howe GR, et al. Dietary factors and the incidence of cancer of the stomach. Am J Epidemiol 1985;122:947-59.

56. Sanchez-Diez A, Hernandez MR, Cueto EA. Study of the relation between diet and gastric cancer in a rural area of the Province of Leon, Spain. Eur J Epidemiol 1992;8:233-7.

57. Tuyns AJ, Kaaks R, Haelterman M, Riboli E. Diet and gastric cancer. A case-control study in Belgium. Int J Cancer 1992;51:1-6.

58. Berkel J, Tytgat GN. Epidemiologie van het maagcarcinoom. Ned Tijdschr Geneeskd 1982;126:1164-72.

59. Bernstein IL. Aversion conditioning in response to cancer and cancer treatment. Clinical Psychology Review 1991;11:185-191.

60. Boakes RA, Tarrier N, Barnes BW, Tattersall MH. Prevalence of anticipatory nausea and other side-effects in cancer patients receiving chemotherapy. Eur J Cancer 1993;29a:866-70.

61. Correa P, Haenszel W, Cuello C, Tannenbaum S, Archer M. A model for gastric cancer epidemiology. Lancet 1975;2:58-60.

62. De Koster E, Buset M, Fernandes E, Deltenre M. Helicobacter pylori: the link with gastric cancer. Eur J Cancer Prev 1994;3:247-57. 
APPENDIX: Questions about salt added when preparing a hot meal or home-made soup, the use of table salt, salt preference, and the use of a refrigerator and freezer from the baseline questionnaire: Netherlands Cohort Study 1986-1992.

Do you add salt during the preparation of the following dishes? if so, can you indicate how much salt is being added?

( 1 teaspoon of satt $=$ about 7 teaspoons of salt)

- potatoes, pasta, rice etc $\square$ no $\square$ yes if so, how much? ... teaspoons per person

- vegetables $\square$ no $\square$ yes if so, how much? ... teaspoons per person

- meat or fish $\square$ no $\square$ yes if so, how much? .... teaspoons per person

When you are at dinner, do you thén add salt to your food?

$\square$ never $\square$ seldom $\square$ sometimes $\square$ often $\square$ very often

How often do you eat home-made soup? ... times per month How many plates do you take? ... plates each time

When you prepare this soup, for how many plates is this usually? ... plates

How much of the following ingredients do you usually use to make the soup taste good?

$\square$ stock cubes ... pieces $\square$ dehydrated soup ... packs $\square$ salt ... teaspoons $\square$ only herbs

$\square$ maggi cubes ... pieces $\quad \square$ mixsoup ... boxes $\quad \square$ maggi ... drops

How do you think soup from a pack or can usually tastes?

$\square$ far from salty enough $\square$ not salty enough $\square$ good $\square$ a little too salty $\square$ much too salty

How do you think food in most of the restaurants and cafetarias usually tastes?

$\square$ far from salty enough $\square$ not salty enough $\square$ good $\square$ a little too salty $\square$ much too salty

Since when do you use a refigerator? Since $19 .$.

Do you use a freezer? $\square$ no $\square$ yes 
Chapter 5 


\section{6}

\section{Intake of butylated hydroxyanisole and butylated hydroxytoluene and stomach cancer risk: results from analyses in the Netherlands Cohort Study}

Anita A.M. Botterweck ${ }^{1}$

H. Verhagen ${ }^{2,5}$

R.A. Goldbohm ${ }^{3}$

J. Kleinjans ${ }^{4}$

P.A. van den Brandt ${ }^{1}$

${ }^{1}$ Department of Epidemiology, University Maastricht, Maastricht, The Netherlands

${ }^{2}$ Food Analysis Department, TNO Nutrition and Food Research Institute, Zeist, The Netherlands

${ }^{3}$ Department of Consumer Research and Epidemiology, TNO Nutrition and Food Research Institute, Zeist, The Netherlands

${ }^{4}$ Department of Health Risk Analysis and Toxicology, University Maastricht, Maastricht, The Netherlands

${ }^{5}$ Present address: Unilever Research Vlaardingen. Unilever Health Institute, P.O. Box 114, 3130 AC Vlaardingen, The Netherlands

Published in Food and Chemical Toxicology 2000; 38:599-605. 


\begin{abstract}
Both carcinogenic and anticarcinogenic properties have been reported for the synthetic antioxidants butylated hydroxyanisole (BHA) and butylated hydroxytoluene (BHT). The association between dietary intake of BHA and BHT and stomach cancer risk was investigated in the Netherlands Cohort Study (NLCS) that started in 1986 among 120,852 men and women aged 55 to 69 years. A semiquantitative food frequency questionnaire was used to assess food consumption. Information on BHA or BHT content of cooking fats, oils, mayonnaise and other creamy salad dressings and dried soups was obtained by chemical analysis, a Dutch database of food additives (ALBA) and the Dutch Compendium of Foods and Diet Products. After 6.3 years of follow-up, complete data on BHA and BHT intake of 192 incident stomach cancer cases and 2035 subcohort members were available for case-cohort analysis. Mean intake of BHA or BHT among subcohort members was 105 and 351 $\mu \mathrm{g} /$ day, respectively. For consumption of mayonnaise and other creamy salad dressings with BHA or BHT no association with stomach cancer risk was observed. A statistically non-significant decrease in stomach cancer risk was observed with increasing BHA and BHT intake (rate ratio (RR) highest/lowest intake of $\mathrm{BHA}=0.57$ (95\% confidence interval (CI) $0.25-1.30$ ) and $\mathrm{BHT}=0.74(95 \%$ CI 0.38-1.43). In this study, no significant association with stomach cancer risk was found for usual intake of low levels of BHA and BHT.
\end{abstract}




\section{INTRODUCTION}

Butylated hydroxyanisole (BHA) and butylated hydroxytoluene (BHT) are synthetic antioxidants which are applied in fat and fatty foods to prevent oxidative deterioration (1). Moreover, BHA and BHT are synthetic phenolic compounds, which are the two most widely applied synthetic antioxidants that have been used since the 1950s (2,3). BHA and BHT are present in small amounts in many commercial foods and thus constitute a small fraction of the diet of many people (4).

BHA and BHT were observed to act as anticarcinogen in various animal models (4-9). On the other hand, results have also been reported for the carcinogenicity of BHA and BHT in experimental animals $(4,8,10)$. Originally, BHA appeared to have initiating as well as promoting action (11). Recently, it was established that tumor formation appears to involve only tumor promotion (12). The target organ for BHA is the forestomach, an organ only present in rodents, whereas BHT has carcinogenic effects in the liver of rats and mice (13-15). Also esophagus proliferation stimulating effects of BHA have been reported in non-rodents (pigs, monkey) in response to BHA administration $(14,15)$. In a landmark publication in 1981 it was estimated that food additives accounted for less than $1 \%$ of all cancer deaths. The range of estimates for food additives varied from $+2 \%$ to $-5 \%$ suggesting that food additives may either have a positive or negative contribution to cancer development (16). However, effects of BHA and BHT on humans have been limited. A study by Verhagen et al. revealed no clinical effects (17). Because of the widespread use of BHA and BHT in food products and as a consequence long-term and widespread exposure of humans, it is important to investigate the potential health risks associated with their dietary intake. In the Netherlands Cohort Study (NLCS), a prospective cohort study in which various risk factors for stomach cancer have been investigated (18), we were also able to study the effect of usual BHA and BHT intake on stomach cancer risk. 


\section{METHODS}

\section{Subjects and study design}

The Netherlands Cohort Study on diet and cancer (NLCS) is a prospective cohort study which started in September 1986 among the general population in the Netherlands (19). The cohort included 62,573 women and 58,279 men aged 55 to 69 years in 1986. At baseline, the cohort members completed a mailed, self-administered questionnaire on dietary habits, smoking, occupation, medical history, personal and family history of cancer, and demographic data. Follow-up for incident cancer has been established by record linkage with cancer registries and a pathology register (20). For data analysis the case-cohort approach was used in which cases are derived from the entire cohort, while the person-years at risk of the entire cohort are estimated from a random sample of 3500 subjects (subcohort) (21). This subcohort of 1812 women and 1688 men has been followed up biennially for vital status information in order to estimate the accumulated person time in the cohort. No subcohort members were lost to follow-up. The present analysis is restricted to cancer incidence in the first 6.3 years of follow-up from September 1986 until December 1992. After the exclusion of subjects reporting prevalent stomach cancer at baseline $(n=33)$, cases with in situ stomach carcinoma $(n=2)$, and cases without microscopically confirmed stomach cancer $(n=2)$, there were 310 incident (242 men, 68 women) stomach carcinoma cases remaining. In the subcohort, 1630 men and 1716 women remained after the exclusion of prevalent cancer cases other than skin cancer.

\section{Exposure assessment}

For assessing $\mathrm{BHA}$ and $\mathrm{BHT}$ intake, both information on consumption of potential BHA- and/or BHT-containing foods and brand names of these foods were needed. Consumption of potential BHAand/or BHT-containing foods was assessed using the dietary section of the baseline questionnaire of the NLCS. The dietary section was a 150 -item semi-quantitative food frequency questionnaire concentrating on usual consumption of food and beverages during the year preceding the start of the study. The questionnaire was validated against a 9-day diet record (22). Among other questions, participants were asked to report their frequency of consumption of potential BHA- and/or BHTcontaining foods: cooking fats, oils, dried soups (from a pack), mayonnaise and other creamy salad dressings, potato products, cereals and cereal products, pastry, cake and biscuits, sugar, sweets and sweetspreads, nuts, seeds and snacks (23). They could choose one of six frequency categories, ranging from "never or less than once per month" to "6-7 times per week". Standard portion sizes were used to calculate daily intake. Participants were asked to specify type and brand for cooking fats (for preparing meat, fish and chips), oils, butter, mayonnaise and other creamy salad dressings and dried soups. Only these products with brand names could be used to obtain information on BHA and BHT content.

\section{Collection of information on BHA and BHT content of foods}

Information on BHA and/or BHT content was obtained by chemical analysis of selected potential BHA- and/or BHT-containing foods and by the use of two other information sources: a Dutch 
database of food additives for people with food intolerance and allergy (ALBA) and the Dutch Compendium of Foods and Diet Products (24).

\section{Chemical analysis}

The most frequently mentioned brand names of cooking fats, oils, mayonnaise and other creamy salad dressings and dried soups in the baseline questionnaire from a random sample of 400 cohort participants were selected in 1988. Because the fat content of dried soups is very low and as a consequence the BHA and/or BHT content, dried soups were not regarded as relevant for BHA and/or BHT intake. Dried soups were therefore excluded from chemical analysis. Although oils contain naturally occurring tocopherols and do not require the addition of BHA or BHT, a number of oils were still analysed. Finally, in 1990, 55 brand specific foods ( 30 mayonnaise and other creamy salad dressings, 11 oils and 14 cooking fats) were bought in local supermarkets and analysed by means of high-performance liquid chromatography (HPLC).

\section{Other data sources}

The ALBA database comprises data on the presence or absence of food additives in food products specified to type and brand for people with food intolerance and allergy. Regarding BHA and BHT, a list of food brand names containing BHA and/or BHT was obtained of the year 1989. Information before 1989 was not available.

The Compendium of Food and Diet Products contains information about the composition of a selection of (diet) foods by type and brand and is used by general practitioners and dieticians (24). Since 1989, information about the presence of food additives in food and diet products was added to the Compendium. Both ALBA and the Compendium obtained their information from food manufacturers. We assumed that the BHA and/or BHT content of foods in 1989/1990 was the same as in 1986.

Based on the information of these three sources, it could be concluded that in this study only mayonnaise and other creamy salad dressings contained BHA or BHT. There were no foods that contained both BHA and BHT.

\section{Calculation of BHA and BHT intake}

Foods were coded to contain BHA or BHT if at least one of the three sources (chemical analysis, ALBA or Compendium) showed that BHA or BHT was present. If, in addition, the amount of BHA and/or BHT was known by chemical analysis, this information was also used. Foods for which no information was available were coded as missing. Foods of which the presence of BHA or BHT was demonstrated but no amount of BHA or BHT was known, the average content of BHA or BHT in mayonnaise or other salad dressings from which the BHA or BHT concentration was known, was substituted. Mean daily intake was calculated by multiplying BHA or BHT content of foods (in $\mu \mathrm{g}$ per gram) and consumption of mayonnaise and other creamy salad dressings (in gram per day). 


\section{Covariates}

Other factors possibly relevant for the association between BHA and BHT and stomach cancer risk that were measured in the baseline questionnaire included age, sex, level of education (lower, medium and higher vocational school) (25), stomach disorders (yes or no), family history of stomach cancer (yes or no), smoking status (never/ex/current smoker), fruit and vegetable consumption (in gram/day)(18), monounsaturated fat and polyunsaturated fat consumption (in gram/day). In this study, stomach disorders were defined as having any stomach disease in the past which required medical attention (e.g., peptic ulcer, gastritis).

\section{Data analysis}

From an epidemiological point of view it is important to investigate the association between the consumption of mayonnaise and other creamy salad dressings per se and stomach cancer risk. All cases (282) and subcohortmembers (3123) could be classified as user or nonuser of mayonnaise and other creamy salad dressings. Then, the association between the use of mayonnaise and creamy salad dressings with BHA or BHT and intake of BHA or BHT and stomach cancer risk was examined. These analysis were based on 192 cases (68.1\%) and 2035 subcohort members (65.2\%) with complete data on BHA or BHT content of mayonnaise and other creamy salad dressings. These subjects were classified by the consumption of BHA- or BHT-containing foods (yes or no) and categorized into three categories of BHA $(0,>0-70,>70 \mu \mathrm{g} /$ day $)$ and BHT $(0,>0-225,>225 \mu \mathrm{g} /$ day $)$. For data analysis, the GLIM statistical package was used (26). Case-cohort analyses were performed based on the assumption that survival times were exponentially distributed in the follow-up period (21). Specific macros were developed to account for the additional variance introduced by using the subcohort instead of using the entire cohort (27). All analyses were conducted for men and women together. Multivariate rate ratios (RRs) of stomach cancer and their 95 percent confidence intervals (CI) were computed for all variables. Tests for trend in the rate ratios were based on likelihood ratio tests. The multivariate model included age, sex, level of education, stomach disorders, family history of stomach cancer and smoking status. Other multivariate models which included also monounsaturated fat or polyunsaturated fat or fruit and vegetable consumption were tested too. Because of potential influence of preclinical symptoms of stomach cancer on food consumption, all analyses were also conducted after excluding cases diagnosed in the first and second year of followup $(18,28)$.

\section{RESULTS}

Table 1 shows the consumption of mayonnaise and creamy salad dressings in cases and subcohort members. Of the subcohort members, $65.8 \%$ consumed mayonnaise and creamy salad dressings. For the subjects with complete data on the consumption of mayonnaise and creamy salad dressings with BHA or BHT, a slightly smaller percentage of cases used foods with BHA or BHT than the subcohort members. In table 2, the distribution of BHA or BHT intake in cases and subcohort members is 
TABLE 1. Users of mayonnaise and creamy salad dressings and consumption of mayonnaise and creamy salad dressings with BHA or BHT in stomach cancer cases and subcohort members with complete consumption data: Netherlands Cohort Study 1986-1992.

\begin{tabular}{lrr}
\hline & \multicolumn{1}{c}{$\begin{array}{c}\text { Cases } \\
n=282\end{array}$} & Subcohort $n=3123$ \\
& $n(\%)$ & $n(\%)$ \\
\hline $\begin{array}{l}\text { Users of mayonnaise and creamy salad dressings } \\
\text { Non-users }\end{array}$ & $180(63.8)$ & $2056(65.8)$ \\
Consumption of mayonnaise and creamy salad dressings*: & $102(36.2)$ & $1067(34.2)$ \\
$\quad$ with BHA & & \\
$\quad$ without BHA & $43(15.2)$ & $497(15.9)$ \\
$\quad$ with BHT & $149(52.8)$ & $1538(49.2)$ \\
without BHT & $43(15.2)$ & $499(16.0)$ \\
& $149(52.8)$ & $1536(49.2)$ \\
\hline
\end{tabular}

* There was no information on BHA and/or BHT content of foods in 90 cases (31.9\%) and 1088 subcohort members (34.8\%)

presented. Mean intake of BHA or BHT among subcohort members was 105 and $351 \mu \mathrm{g} / \mathrm{day}$, respectively. Intake of BHA or BHT was lower in cases at 89 and $330 \mu \mathrm{g} /$ day, respectively. There were small differences in distribution of BHA or BHT intake categories between cases and subcohort members. In the highest intake category of the two variables the percentage of cases was slightly lower compared to the subcohort members.

Rate ratios of stomach cancer according to the consumption of mayonnaise and creamy salad dressings, the use of mayonnaise and creamy salad dressings with BHA or BHT and intake of BHA or BHT are shown in table 3. Multivariate analyses of all stomach cancer cases and multivariate analyses after exclusion of cases diagnosed in the first and second year of follow-up are shown. For consumption of mayonnaise and creamy salad dressings and BHA- or BHT-containing foods no association with stomach cancer risk was observed. After exclusion of first and second year cases, the RRs of the consumption of mayonnaise and creamy salad dressings and BHT-containing foods did not change. However, the RR of BHA-containing foods decreased to 0.89 (95\% CI 0.58-1.37) after exclusion of first and second year cases. A decreasing stomach cancer risk was observed with increasing BHA or BHT intake. The RRs of high intake versus low intake of BHA and BHT were 0.84 (95\% CI 0.45-1.57) and 0.82 (95\% CI 0.46-1.43), respectively. However, the RRs for stomach cancer with each consumption category of the two variables, nor the tests for trend were statistically significant. After exclusion of cases diagnosed in the first or second follow-up year, the RRs of the highest intake of BHA and BHT compared to the lowest intake category decreased to 0.57 ( $95 \% \mathrm{CI}$ $0.25-1.30$ ) and 0.74 (95\% CI 0.38-1.43), respectively. Again, none of the RRs were statistically significant different from unity and none of the tests for trend were statistically significant. Inclusion of monounsaturated fat or polyunsaturated fat consumption or fruit and vegetable consumption in the model did not change the risk estimates. 
TABLE 2: Mean intake of BHA and BHT among users of mayonnaise and creamy salad dressings ( $\mu$ /day) and distribution of BHA and BHT intake in stomach cancer cases and subcohort members: Netherlands Cohort Study 1986-1992.

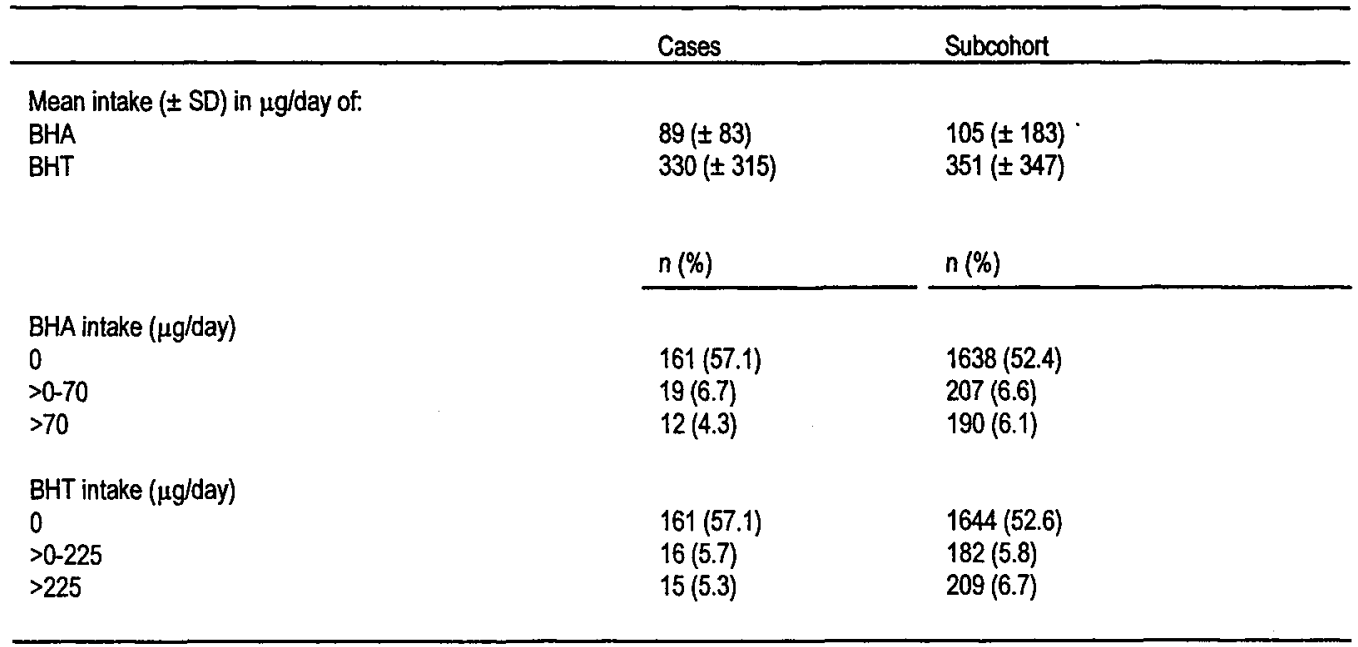

\section{DISCUSSION}

This prospective cohort study is the first epidemiologic study that evaluated the association between dietary intake of BHA and BHT and stomach cancer risk. We found no association between the consumption of foods containing BHA or BHT and stomach cancer risk. There seemed to be an indication for a decreased stomach cancer risk with increasing BHA and BHT intake.

\section{Methodological considerations}

The cohort study has been performed in a large sample of the general population aged 55-69 years at baseline. After 6.3 years of follow-up, 192 cases with complete dietary data on BHA or BHT were available for analysis. One of the strengths of this study is that the food consumption was measured before stomach cancer was diagnosed, thus avoiding the problem of biased recall of dietary habits. The follow-up of person-years was $100 \%$ complete and the completeness of cancer follow-up was also very high, indicating that selection bias due to loss of follow-up is unlikely. In multivariate analysis, adjustment was made for all measured variables that were associated with stomach cancer risk in this study. However, residual confounding is possible because some unidentified risk factors may be involved in the relation between BHA or BHT and stomach cancer risk. Because people with preclinical symptoms of stomach cancer are likely to change their dietary habits months or years before stomach cancer is diagnosed, all analyses were performed with and without cases diagnosed in the first and second follow-up year $(18,28)$. In this study, these analyses revealed slightly different rate ratios.

A fact that could have influenced the results is misclassification of exposure. The dietary questionnaire has been designed to assess an individual's long-term food consumption and not 
TABLE 3: Rate ratios (RRs) and $95 \%$ confidence interval (Cl) of stomach cancer according to use of mayonnaise and creamy salad dressings, consumption of BHA or BHT containing foods and intake of BHA or BHT ( $\mu \mathrm{g} /$ day): Netherlands Cohort Study 1986-1992.

\begin{tabular}{|c|c|c|c|c|}
\hline & $\operatorname{RR}(95 \% \mathrm{Cl})^{*}$ & P-trend & $\operatorname{RR}(95 \% \mathrm{Cl})^{* *}$ & P-trend \\
\hline \multicolumn{5}{|c|}{$\begin{array}{l}\text { Use of mayonnaise and creamy salad } \\
\text { dressings }\end{array}$} \\
\hline No & 1.00 & & 1.00 & \\
\hline Yes & $0.97(0.74-1.26)$ & - & $0.93(0.70-1.25)$ & - \\
\hline \multicolumn{5}{|c|}{$\begin{array}{l}\text { Use of mayonnaise and creamy salad } \\
\text { dressings: }\end{array}$} \\
\hline without BHA & 1.00 & & 1.00 & \\
\hline with $\mathrm{BHA}$ & $0.97(0.67-1.40)$ & - & $0.89(0.58-1.37)$ & - \\
\hline without BHT & 1.00 & & 1.00 & \\
\hline with $\mathrm{BHT}$ & $0.94(0.65-1.37)$ & - & $0.98(0.65-1.49)$ & - \\
\hline \multicolumn{5}{|c|}{ BHA intake ( $\mu \mathrm{g} /$ day) } \\
\hline 0 & 1.00 & & 1.00 & \\
\hline$>0-70$ & $0.96(0.57-1.61)$ & & $0.80(0.43-1.48)$ & \\
\hline$>70$ & $0.84(0.45-1.57)$ & 0.57 & $0.57(0.25-1.30)$ & 0.12 \\
\hline \multicolumn{5}{|c|}{ BHT intake ( $\mu /$ day) } \\
\hline 0 & 1.00 & & 1.00 & \\
\hline$>0-225$ & $1.00(0.58-1.76)$ & & $0.85(0.44-1.66)$ & \\
\hline$>225$ & $0.82(0.46-1.43)$ & 0.50 & $0.74(0.38-1.43)$ & 0.30 \\
\hline
\end{tabular}

- adjusted for age, sex, smoking status, level of education, stomach disorders and stomach cancer in the family

** analyses with first and second year cases excluded and adjusted for age, sex, smoking status, level of education, stomach disorders and stomach cancer in the family

specifically to assess the intake of BHA and BHT. Nevertheless, we did have brand specific information of cooking fats, oils, dried soups and mayonnaise and other creamy salad dressings which were potential sources of BHA and BHT. We did not have information on BHA or BHT content of all foods with brand names. In the baseline questionnaire, people reported unknown or foreign brand names. The chemical analysis on BHA and BHT content were performed in a selection of foods. These were the most frequently consumed foods reported by a sample of 400 people from the cohort. Although this was a large sample we could not exclude that rather frequently consumed food products were not mentioned. Both the ALBA database and The Compendium of Food and Diet Products obtained their information from food manufacturers, but not all food manufacturers provided information on food additives. Thus, we did not have $100 \%$ complete data on BHA or BHT content of foods. Despite that, we still could classify nearly $70 \%$ of cases and subcohort members as to whether or not they used BHA- or BHT-containing foods. Furthermore, there is no reason to think that the proportion of stomach cancer cases is different in the group with and without missing data, because information on food consumption was gathered before stomach cancer was diagnosed. 
However, if misclassification has occurred, this is to be expected non-differential and risk estimates are most likely biased towards the null value.

\section{Interpretation of findings}

In this study, the intake of BHA was 105 (range 2 - 3220) $\mu \mathrm{g} /$ day and BHT was 351 (range 19 2052) $\mu \mathrm{g} /$ day which is (approximately 10 times) lower than the intakes estimated in other studies $(23,29,30)$. In our study, intake values are only based on the consumption of mayonnaise and other creamy salad dressings. In a Dutch market-basket study, BHA and BHT content was obtained by chemical analyses in samples of five out of twelve food groups representing the basic two-week diet of 16 to 18 year-old male adolescents. The maximal BHA intake (BHT could not be detected) in this Dutch market-basket study was $4 \mathrm{mg} /$ person/day (29). In another Dutch study, the mean daily BHA and/or BHT intake was $4.51 \mathrm{mg}$ or $0.075 \mathrm{mg} / \mathrm{kg} /$ day for a $60-\mathrm{kg}$ individual. The daily dietary intake of BHA and/or BHT in this study was estimated using data obtained from a nationwide dietary record survey carried out in 1987/1988. The estimates were based on the fat content of seven out of twentythree selected food categories and their respective maximum permitted levels of BHA and/or BHT (23). The dietary intake of BHA in Canada was estimated using dietary recall data on food consumption and maximum permitted use levels for this antioxidant. The BHA intake ranged from $5.5-12.1 \mathrm{mg} / \mathrm{person} /$ day or $0.13-0.39 \mathrm{mg} / \mathrm{kg}$ bodyweight/day (30). In the latter studies, daily intake of BHA and BHT are probably overestimated. The estimates are based on maximum permitted levels of BHA and/or BHT. These estimates did not account for losses during storage and food processing, or for lower levels of BHA or BHT in foods, because of limited use of BHA or BHT in foods by the manufacturer, or even for the use of other antioxidants in combination with BHA or BHT.

In a limited experiment, the daily individual dietary intake of BHA was assessed using a biological monitoring approach which is based on the fact that $39 \%$ of a single oral dose of BHA is recovered from the urine as phase-II conjugates of BHA with glucuronic acid and sulphate (31). Six volunteers consumed foods that might contain BHA and subsequently collected their urine for $24 \mathrm{hr}$. Another 22 volunteers collected their urine for a 24-hour period without having consumed specific foods. Results of this experiment showed that the actual intake of BHA ranged from less than $1 \mu \mathrm{g}$ to 21.5 $\mu \mathrm{g} / \mathrm{kg}$ body weight (32).

Finding no association between BHA and BHT intake and stomach cancer risk incidence substantiates the hypothesis that low intake levels of BHA and BHT are not carcinogenic in humans. To our knowledge, no other relevant data on the evaluation of carcinogenic risk in humans are available. Therefore, the current study findings can only be compared with findings of experimental studies in animals on BHA and BHT. Data from animal experimental studies reported both carcinogenic and anticarcinogenic effects for both BHA and BHT $(2,3,6,11,12,33)$. BHA administered in the diet of rats, mice and hamsters induced dose depently benign and malignant tumours of the forestomach $(2,8,10,13,34,35)$. Not only the forestomach but also other organs of the digestive tract (oesophagus, small intestine and colon/rectum) seem to be potential target tissues for the carcinogenic action of BHA (36). When BHT was administered in the diet of mice and rats lung and liver tumours were induced, but there were also studies that reported no increase in tumour 
incidence were reported (3). When administered with known mutagens or carcinogens, BHA and BHT either enhanced, inhibited or had no effect on carcinogenity $(2-4,6-8,33)$. However, for both BHA and BHT anticarcinogenic effects were seen at low doses when given prior to and during exposure to carcinogens $(9,12)$. The International Agency for Research on Cancer (IARC) that evaluated BHA and BHT, concluded that there is sufficient evidence for carcinogenity of BHA in experimental animals (2), but for BHT there is limited evidence (3).

Results of experiments performed on animals are difficult to compare with human data and should be interpreted with caution. The amounts of BHA or BHT used in the diet of animals is much higher than the levels permitted in the human diet. Humans are exposed to low concentrations throughout life. Furthermore, humans do not posses a forestomach, and there are metabolic differences between humans and animals.

The finding of an apparent decreased risk with increasing BHA or BHT intake seem to be more in line with the hypothesis that synthetic antioxidants may be protective for cancer and support findings of studies suggesting that low doses of BHA and BHT inhibit carcinogenesis $(4,7,8,12)$. Antioxidants like BHA and BHT may have beneficial effects by protecting against toxic compounds that are derived from the destruction of nutrients and the oxidation of fatty acids in foods (37).

In conclusion, we found no clear evidence of an association between usual dietary intake of low leveis of BHA and BHT and the risk of stomach cancer in humans.

\section{ACKNOWLEDGEMENTS}

We gratefully acknowledge the regional cancer registries, the Dutch national database of Pathology (PALGA), and the National Health Care Information Center for providing incidence data; A. Volovics for statistical advice; E. Dorant, S. Van de Crommert, H. Brants, W. Van Dijk, P. Florax, M. Moll, J. Nelissen, A. Pisters and C. de Zwart for assistance; H. van Monfort, R. Schmeitz, T. van Monfort, and M. de Leeuw for programming and statistical assistance. The Netherlands Cohort Study was supported by the Dutch Cancer Society.

\section{REFERENCES}

1. Addis PB. Occurrence of lipid oxidation products in foods. Food Chem Toxicol 1986;24:1021-30.

2. IARC Monographs on the Evaluation Carcinogenic Risk to Humans. Vol 40. Some naturally occurring and synthetic Food Components, Furococemarins and Ultraviolet Radiation. Butylated hydroxyanisole (BHA). 1986;40:123-59. International Agency for Research on Cancer, Lyon.

3. IARC Monographs on the Evaluation Carcinogenic Risk to Humans. Vol 40. Butylated hydroxytoluene (BHT). 1986;40:161-206. International Agency for Research on Cancer, Lyon.

4. Hocman G. Chemoprevention of cancer: phenolic antioxidants (BHT, BHA). Int J Biochem 1988;20:639-51.

5. Wattenberg LW. Inhibition of carcinogenic and toxic effects of polycyclic hydrocarbons by phenolic antioxidants and ethoxyquin. J Natl Cancer Inst 1972;48:1425-30.

6. Wattenberg LW, Coccia JB, Lam LK. Inhibitory effects of phenolic compounds on benzo(a)pyrene-induced neoplasia. Cancer Res 1980;40:2820-3. 
7. Wattenberg LW. Protective effects of 2(3)-tert-butyl-4-hydroxyanisole on chemical carcinogenesis. Food Chem Toxicol 1986;24:1099-102.

8. Williams GM. Epigenetic promoting effects of butylated hydroxyanisole. Food Chem Toxicol 1986;24: $1163-6$.

9. Williams GM, Iatropoulos MJ. Inhibition of the hepatocarcinogenicity of aflatoxin B1 in rats by low levels of the phenolic antioxidants butylated hydroxyanisole and butylated hydroxytoluene. Cancer Lett 1996;104:49-53.

10. Ito N, Fukushima S, Hagiwara A, Shibata M, Ogiso T. Carcinogenicity of butylated hydroxyanisole in F344 rats. J Natl Cancer Inst 1983;70:343-52.

11. Ito $N$, Hirose $M$, Fukushima $S$, Tsuda $H$, Shirai $T$, Tatematsu $M$. Studies on antioxidants: their carcinogenic and modifying effects on chemical carcinogenesis. Food Chem Toxicol 1986;24:1071-82.

12. Williams GM, Iatropoulos MJ, Whysner J. Safety assessment of butylated hydroxyanisole and butylated hydroxytoluene as antioxidant food additives. Food Chem Toxicol 1999;37:1027-1938.

13. Clayson DB, Iverson F, Nera EA, Lok E. The importance of cellular proliferation induced by BHA and BHT. Toxicol Ind Health 1993;9:231-42.

14. Verhagen $\mathrm{H}$, Schilderman PA, Kleinjans JC. Butylated hydroxyanisole in perspective. Chem Biol Interact 1991;80:109-34.

15. Papas AM. Oil-soluble antioxidants in foods. Toxicol Ind Health 1993;9:123-49.

16. Doll R, Peto R. The causes of cancer: quantitative estimates of avoidable risks of cancer in the United States today. J Natl Cancer Inst 1981;66:1191-308.

17. Verhagen H, Maas LM, Beckers RH, et al. Effect of subacute oral intake of the food antioxidant butylated hydroxyanisole on clinical parameters and phase-I and -II biotransformation capacity in man. Hum Toxicol 1989;8:451-9.

18. Botterweck AAM, van den Brandt PA, Goldbohm RA. A prospective cohort study on vegetable and fruit consumption and stomach cancer risk in the Netherlands. Am J Epidemiol 1998;148:842-853.

19. van den Brandt PA, Goldbohm RA, van 't Veer P, Volovics A, Hermus RJ, Sturmans F. A large-scale prospective cohort study on diet and cancer in The Netherlands. J Clin Epidemiol 1990;43:285-95.

20. van den Brandt PA, Schouten LJ, Goldbohm RA, Dorant E, Hunen PM. Development of a record linkage protocol for use in the Dutch Cancer Registry for Epidemiological Research. Int J Epidemiol 1990;19:553-8.

21. Self SG, Prentice RL. Asymptotic distribution theory and efficiency results for case-cohort studies. Ann Stat 1988;16:64-81.

22. Goldbohm RA, van den Brandt PA, Brants HA, et al. Validation of a dietary questionnaire used in a large-scale prospective cohort study on diet and cancer. Eur J Clin Nutr 1994;48:253-65.

23. Verhagen H, Deerenberg I, Marx A, ten Hoor F, Henderson PT, Kleinjans JC. Estimate of the maximal daily dietary intake of butylated hydroxyanisole and butylated hydroxytoluene in The Netherlands. Food Chem Toxicol 1990;28:215-20.

24. Compendium of Food and Diet Products (17th edition). De Toorts: Haarlem 1989/1990.

25. van Loon AJM, Goldbohm RA, van den Brandt PA. Socioeconomic status and stomach cancer incidence in men: results from the Netherlands Cohort Study. J Epidemiol Community Health 1998;52:166-171.

26. Baker R. Glim 3.77 Reference manual. Oxford: Numerical Algorithms Group, 1985.

27. Volovics A, van den Brandt PA. Methods for the analyses of case-cohort studies. Biom J 1997;39:195-214.

28. van den Brandt PA, Goldbohm RA, van't Veer P, et al. Toenail selenium levels and the risk of breast cancer. Am J Epidemiol 1994;140:20-6.

29. Van Dokkum W, De Vos RH, Cloughley FA, Hulshof KF, Dukel F, Wijsman JA. Food additives and food components in total diets in the Netherlands. Br J Nutr 1982;48:223-31.

30. Kirkpatrick DC, Lauer BH. Intake of phenolic antioxidants from foods in Canada. Food Chem Toxicol 1986;24:1035-7.

31. Verhagen $\mathbf{H}$, Thijssen $\mathrm{HH}$, ten Hoor F, Kleinjans JC. Disposition of single oral doses of butylated hydroxyanisole in man and rat. Food Chem Toxicol 1989;27:151-8.

32. Verhagen $\mathrm{H}$, Kleinjans JCS. Some comments on the dietary intake of butylated hydroxytoluene. Food Chem Toxicol 1991;29:74-5.

33. Wattenberg LW. Chemoprevention of cancer. Cancer Res 1985;45:1-8.

34. Ito N, Fukushima S, Tamano S, Hirose M, Hagiwara A. Dose response in butylated hydroxyanisole induction of forestomach carcinogenesis in F344 rats. J Natl Cancer Inst 1986;77:1261-5. 
35. Masui T, Hirose M, Imaida K, Fukushima S, Tamano S, Ito N. Sequential changes of the forestomach of F344 rats, Syrian golden hamsters, and $\mathrm{B} 6 \mathrm{C} 3 \mathrm{~F} 1$ mice treated with butylated hydroxyanisole. Jpn J Cancer Res 1986;77:1083-90.

36. Verhagen H, Furnee C, Schutte B, et al. Dose-dependent effects of short-term dietary administration of the food additive butylated hydroxyanisole on cell kinetic parameters in rat gastro-intestinal tract. Carcinogenesis 1990;11:1461-8.

37. Grice HC, Clayson DB, Flamm WG, et al. Panel discussion: Possible mechanisms of BHA carcinogenicity from a consideration of its chemical and biological properties. Food Chem Toxicol 1986;24:1235-42. 
Chapter 6 


\section{7}

\section{Trends in incidence of adenocarcinoma of the}

oesophagus and gastric cardia in ten European countries

Anita A.M. Botterweck ${ }^{1}$

Leo J. Schouten ${ }^{2}$

Alexander Volovics ${ }^{3}$

Elisabeth Dorant ${ }^{1}$

Piet A. van den Brandt ${ }^{1}$

${ }^{1}$ Maastricht University, Department of Epidemiology, Maastricht, the Netherlands

${ }^{2}$ Comprehensive Cancer Centre Limburg (IKL), Maastricht Cancer Registry, Maastricht, the Netherlands

${ }^{3}$ Maastricht University, Department of Methodology and Statistics, Maastricht, the Netherlands

Published in International Journal of Epidemiology 2000; 29:645-54. 


\begin{abstract}
Background: In many western countries an increase in incidence of adenocarcinoma of the oesophagus and/or gastric cardia have been reported. The aim of this study was to describe and compare trends in incidence of adenocarcinoma of the oesophagus and gastric cardia in several areas of Europe, 1968 - 1995, using Eurocim data (a database of cancer incidence and mortality data from 95 European cancer registries).
\end{abstract}

Methods: Time-trends in age-standardized incidence rates of adenocarcinomas of the oesophagus and gastric cardia are described in 11 population-based cancer registries from 10 countries in North, South, East, West and Central Europe, 1968-1995. The statistical significance of the timetrends in incidence was assessed using Poisson regression analysis.

Results: An increase in incidence of adenocarcinomas of the oesophagus and gastric cardia was observed in Northern-Europe (Denmark), Southern-Europe (Italy,Varese), Eastern-Europe (Slovakia), Western-Europe (England and Wales, Scotland). In Central-Europe (Switzerland, Basel) and in the cancer registries of Iceland (Northern-Europe), France, Bas-Rhin and Calvados, Southern Ireland, and the Netherlands, Eindhoven (Western-Europe) no rise in incidence was observed. The increase in incidence of adenocarcinomas of the oesophagus and gastric cardia was accompanied by a decrease in incidence of both adenocarcinomas and non-adenocarcinomas of the non-cardia part of the stomach in almost all of the 11 cancer registries studied. Increased histological verification of tumours of the oesophagus and stomach and improvement in precision of histological diagnosis may partly explain the increase in incidence of adenocarcinomas in some registries.

Conclusions: This study, using Eurocim data, supports the findings from other time-trend studies of population-based cancer registries in western countries. 


\section{INTRODUCTION}

In the last decades, clinical-based case series studies in American (1), Canadian (2) and European centres (3) reported an increase in incidence of adenocarcinoma of the oesophagus and/or gastric cardia. These findings have been confirmed by many population-based studies in western countries like the US, Australia, New Zealand and several countries of Europe (4-21). This increase began around the 1970 s both in men and women $(9,12)$, but seemed to be most pronounced in (white) men $(6,14,16)$. This trend tends to affect all age groups. The highest rate of increase was nearly $10 \%$ per year and has been reported in the US $(10,22)$. However, in one small population-based study from the Swiss canton of Vaud no increase in incidence has been found for adenocarcinomas of the gastric cardia between 1976 and 1987 (23).

The increase in incidence of adenocarcinomas of the oesophagus and gastric cardia is different from trends observed in squamous cell carcinoma of the oesophagus and tumours in the noncardia part of the stomach. The incidence of squamous cell carcinoma of the oesophagus is quite stable in western countries $(19,20)$, while the incidence of tumours in the non-cardia part of the stomach (mainly adenocarcinomas) is decreasing (24).

There are also differences between adenocarcinomas of the oesophagus and gastric cardia, squamous cell carcinoma of the oesophagus and tumours in the non-cardia part of the stomach with respect to male-to-female-ratio (with a high $\mathrm{M} / \mathrm{F}$ ratio for adenocarcinomas of the oesophagus and gastric cardia (25)), ethnicity (with a higher incidence among American whites compared to American blacks (10)) and geographical distribution (16). This suggests that these three types of tumours are etiologically distinct (5). Recent epidemiological findings support this hypothesis $(26,27)$. In the same period in which the increase in incidence of adenocarcinomas of the oesophagus and gastric cardia has been reported, however, improvement in precision of histological diagnosis and improvement in diagnostic procedures for these tumours has been reported as well and may partly explain the increase in incidence (10). Several explanations of this increase will be discussed later.

The aim of this study is to describe and compare trends in incidence of adenocarcinoma of the oesophagus and gastric cardia in several areas of Europe, 1968 - 1995, using Eurocim data, a database of incidence and mortality data from 95 European cancer registries (28).

\section{MATERIALS AND METHODS}

\section{Eurocim database}

The Eurocim database is a computerized cancer incidence and mortality database developed by the European Network of Cancer Registries (ENCR). Cancer registries that are members of the ENCR are asked to make regular submissions of incidence, mortality and population data to a central Eurocim databank held at the International Agency for Research on Cancer in Lyon. The Eurocim database comprises detailed cancer data by topography and morphology from 95 European cancer registries over various years, 1960-1995. The Eurocim database also contains 
data-analysis software (28).

\section{Selection of cancer registries}

We selected cancer registries based on the criteria 'period' using version 1.1 (1993) of the Eurocim database. At least 10 years of continuous registration of a cancer registry had to be available in the database in the overall study period 1968-1995. Furthermore, we aimed at 'geographical variation', i.e., at least one cancer registry had to be available in each of the following regions of Europe: North, South, East, West, and Central Europe. This first selection yielded 24 cancer registries of the 95 . Because there were more potential cancer registries in some regions or countries, we used additional criteria. These criteria were: registries covering those populations that enlarged the contrast in incidence of oesophageal and stomach cancer between areas, registries covering a large population and registries with good data quality. The data quality of a cancer registry was measured with three indices of reliability (the percentage of cases histologically verified, the percentage of cases registered with a death certificate only and the ratio of mortality to incidence) as presented in Cancer Incidence of Five Continents (volume IV, V and VI) (29-31). The five regional cancer registries of Scotland were combined in the database to one cancer registry 'Scotland'. After this selection, 12 cancer registries were left. One cancer registry was excluded because no detailed data on morphology and topography were coded in the first six years of the available study period of this cancer registry. Finally, 11 cancer registries were included in the study (table 1). After version 2.1 of the Eurocim database was released (in 1997) we continued working with the 11 selected cancer registries, but now more years of registration (minimal 12 years) of each cancer registry were available.

\section{Selection of tumours}

All primary tumours of the oesophagus and stomach (International Classification of Diseases for Oncology (ICD-O) codes 150 and 151, respectively) were included in the analyses. Oesophageal tumours were classified into the following morphology categories: squamous cell carcinoma, adenocarcinoma and all other morphology codes (Appendix). Stomach tumours were classified into the following combined topography and morphology categories: adenocarcinoma of the cardia, non-adenocarcinoma of the cardia, adenocarcinoma of the non-cardia part of the stomach and non-adenocarcinoma of the non-cardia part of the stomach (Appendix). For the analyses, we combined adenocarcinomas of the oesophagus and gastric cardia (AEC) (ICD-O codes 150 and 151.0 and 8140-8473, 8480-8490, 8500-8550).

\section{Background information of cancer registries}

We contacted each selected cancer registry with a written questionnaire to get more information on classification and coding practice of AEC during the study period. We asked whether the cancer registry had specific coding rules regarding AEC, whether there had been changes in coding practice, diagnostic criteria or procedures for AEC in the period in which the cancer registry provided data, whether the cancer registry coded adenocarcinomas of the (lower) 
TABLE 1: Selected Eurocim cancer registries with 12 years of continuous registration or more in the Eurocim database (Eurocim version 2.1).

\begin{tabular}{|c|c|c|c|}
\hline Eurocim cancer registry & Available period $\dagger$ & $\begin{array}{l}\text { Number of AEC } \\
\text { cases } \ddagger\end{array}$ & Population size (x1000) in 1990 \\
\hline \multicolumn{4}{|l|}{ Northem Europe } \\
\hline Denmark & $1978-1992$ & 3064 & 5139.9 \\
\hline Iceland & $1970-1995$ & 184 & 254.8 \\
\hline \multicolumn{4}{|l|}{ Southem Europe } \\
\hline Italy, Varese & $1976-1992$ & 311 & 793.0 \\
\hline \multicolumn{4}{|l|}{ Eastem Europe } \\
\hline Slovakia & $1968-1992$ & 1300 & 5297.8 \\
\hline \multicolumn{4}{|l|}{ Westem Europe } \\
\hline England and Wales & $1971-1990$ & 32952 & 50718.8 \\
\hline France, Bas-Rhin & 1975-1992 & 366 & 954.5 \\
\hline France, Calvados & 1978-1992 & 242 & 617.6 \\
\hline Ireland, Southem & $1981-1992$ & 182 & 532.6 \\
\hline Netherlands, Eindhoven & $1978-1992$ & 433 & 935.7 \\
\hline Scotiand * & $1975-1995$ & 6484 & 5102.2 \\
\hline \multicolumn{4}{|l|}{ Central Europe } \\
\hline Switzerland, Basel & $1981-1992$ & 212 & 426.7 \\
\hline
\end{tabular}

\footnotetext{
* combined data for 5 regional registries

$\dagger$ period in which all registries have data: $1981-1990$

$\ddagger$ adenocarcinomas of the oesophagus and gastric cardia
}

oesophagus as cardia tumours, and if AEC was coded as 159.8 or 159.9 when it was difficult to distinguish tumours arising in the lower third of the oesophagus, the gastro-oesophageal junction and the gastric cardia. Seven of the 11 cancer registries responded.

\section{Presentation of the data}

In the EUROCIM database cases are classified into 5-year age-groups ( 0 to 4,5 to 9,10 to 14 etc..., and 85 and over). For comparison, age-standardized incidence rates for all age-groups together are calculated by the direct method using the standard European population and reported as number of incident cases per 100,000 person-years. Incidence rates of AEC and all oesophageal and stomach cancer together are calculated for each of the cancer registries by sex for the 5-year period 1986-1990 (in which all cancer registries provided data). Furthermore, incidence rates of AEC are calculated for each of the cancer registries by sex for 3-year periods (1969-1971, 1972-1974, etc., 1993-1995). To see whether an increase in incidence of one (morphology) type of tumour was accompanied by a decrease of another type of tumour of the oesophagus and/or stomach, we compared the trends in incidence of all types of tumours of the oesophagus and stomach simultaneously for each cancer registry. These rates are only graphically presented for two cancer registries with contrasting trends. 


\section{Statistical analysis}

The statistical significance of the time trend in the age-standardized incidence rates for each cancer registry was assessed using Poisson regression. The model included the variables period (3-year periods entered as dummies variables), age (numerical variable) and sex (dummy variable). For each 3-year period relative risks (RR) of AEC were computed using 1981-1983 as reference period. Interaction between sex and period was tested for each cancer registry. If there was a significant interaction, RRs of each 3-year period were presented for men and women separately, otherwise the RRs were presented for men and women combined. The test for trend was based on a likelihood ratio test. In this case period was entered as a continuous variable in the model. The statistical package STATA was used for Poisson regression modelling (32).

\section{RESULTS}

Table 1 presents each of the 11 selected cancer registries with the available period, the number of AEC cases, and population size. The available period of the cancer registries ranged from 12 to 26 years in the overall period 1968-1995. During the period 1968-1995, all 11 registries together recorded a total of 45730 incident cases of AEC ( 34267 men, 11463 women). For all cancers of the oesophagus and stomach these figures were 107503 (63 259 men, 44244 women) and 330 514 (197833 men, 132681 women), respectively.

\section{Incidence in 1986-1990}

Table 2 gives the age-standardized incidence rates for AEC, all cancers of the oesophagus and stomach for each cancer registry by sex, 1986-1990. The highest incidence rates of AEC were recorded in Scotland, both in men and women (9.7 and 2.9 per 100000 person-years, respectively). The lowest incidence rate for men was recorded in Slovakia (3.5 per 100000 ) and for women in France (Bas-Rhin) (0.4 per 100 000). The incidence of all cancers of the oesophagus was highest in France (Calvados) (34.2 per 100000 ) and lowest in the Netherlands (Eindhoven) (4.8 per 100000 ). For women, the oesophageal cancer rate was highest in Scotland (7.0 per 100000$)$ and lowest in Slovakia $(0.7$ per 100000$)$. The highest incidence rates of all cancers of the stomach for men and women were both recorded in Italy (Varese) (44.4 and 21.8 per 100000 person-years, respectively) and the lowest rates were 15.8 (males, Denmark) and 7.6 (females, France, Calvados). The male-to-female sex ratio of AEC varied from 2.8:1 (Netherlands, Eindhoven) to 12.0:1 (France, Bas-Rhin). The sex ratio of all cancers of the oesophagus varied more than the sex ratio of AEC between the cancer registries (1.9 - 16.3), but the sex ratio for all cancers of the stomach was rather constant (about $2.0-2.5$ ) across the countries.

\section{Trends in incidence}

Figure $1(a, b, c$ and d) shows trends in incidence rates of AEC by sex in each of the 11 cancer 


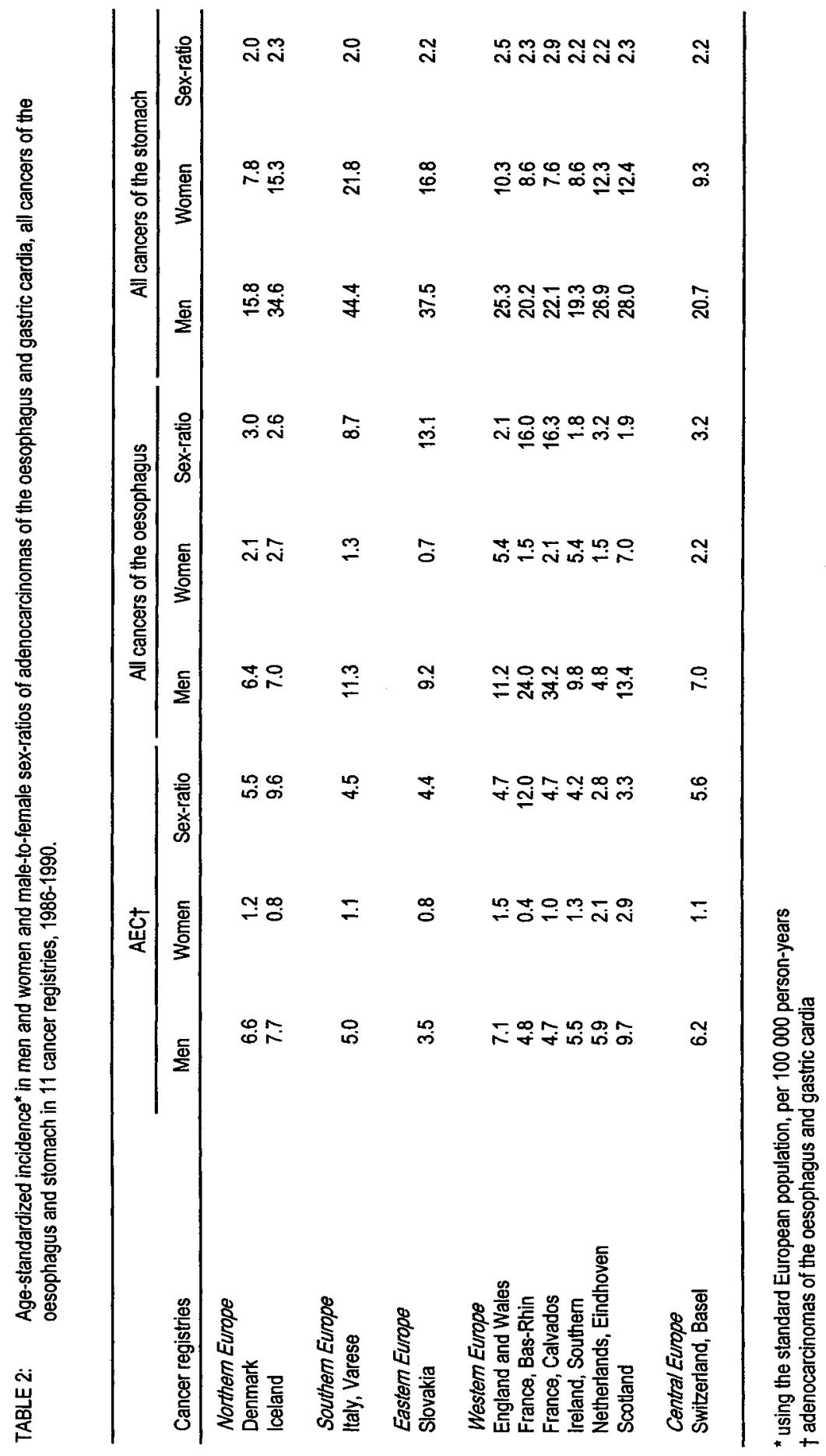




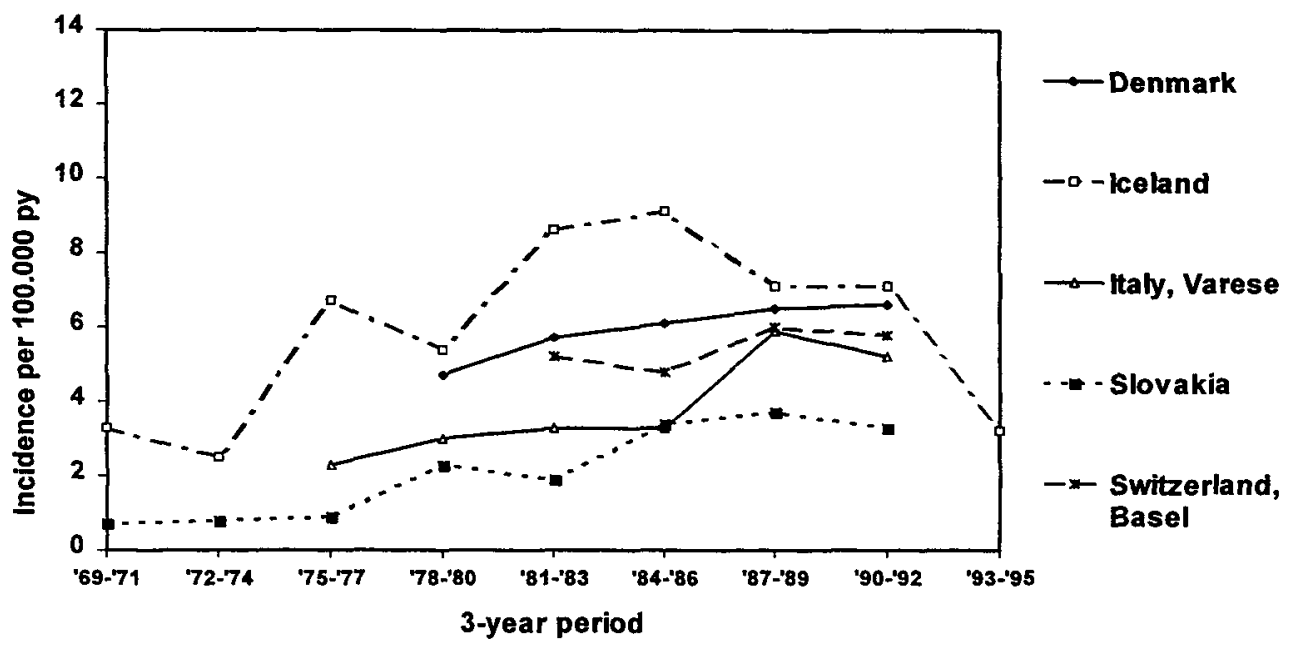

FIGURE 1a: Age-standardized incidence rates of adenocarcinomas of the oesophagus and gastric cardia by 3-year period in cancer registries of Northem, Southern, Eastern and Central Europe, men.

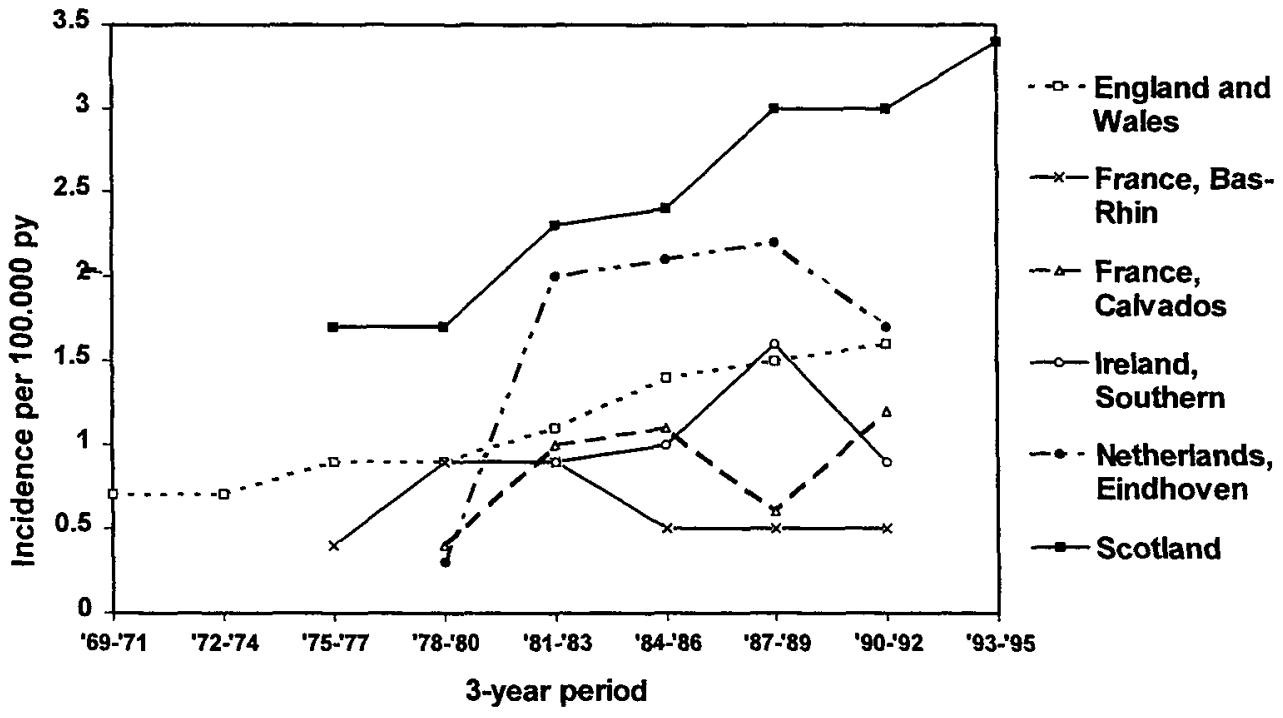

FIGURE 1b: Age-standardized incidence rates of adenocarcinomas of the oesophagus and gastic cardia by 3-year period in cancer registries of Western Europe, men. 


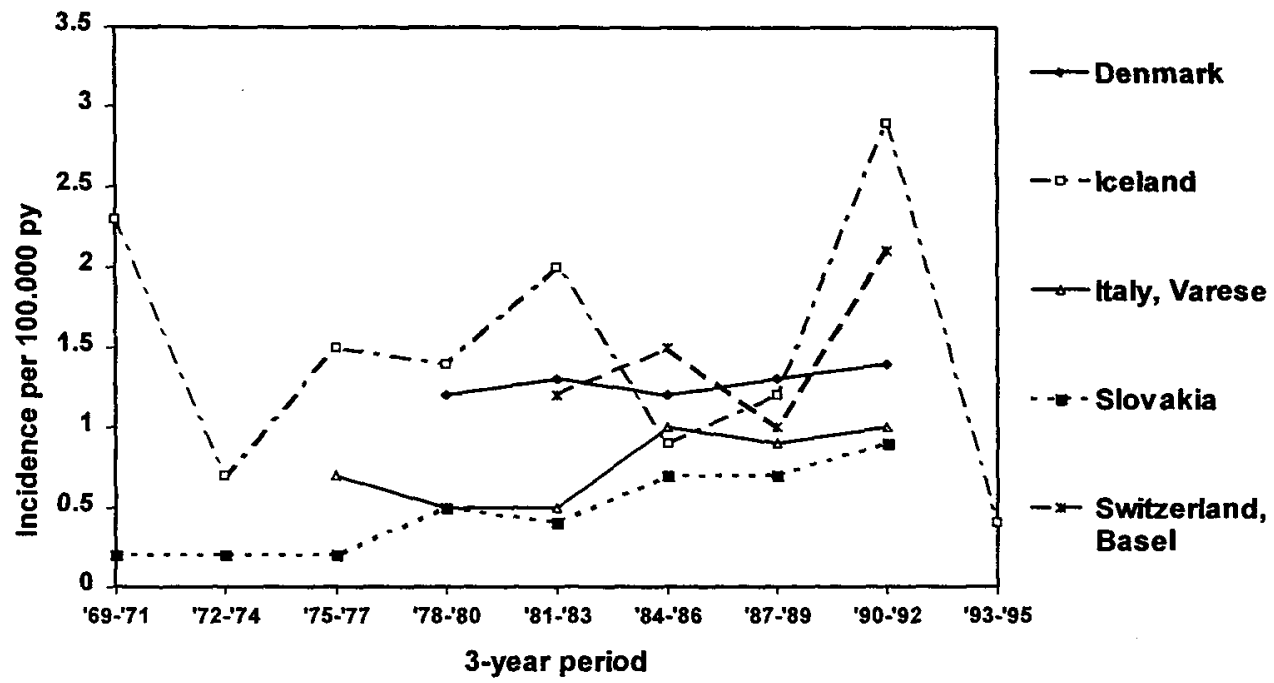

FIGURE 1c: Age-standardized incidence rates of adenocarcinomas of the oesophagus and gastric cardia by 3-year period in cancer registries of Northem, Southem, Eastern and Central Europe, women.

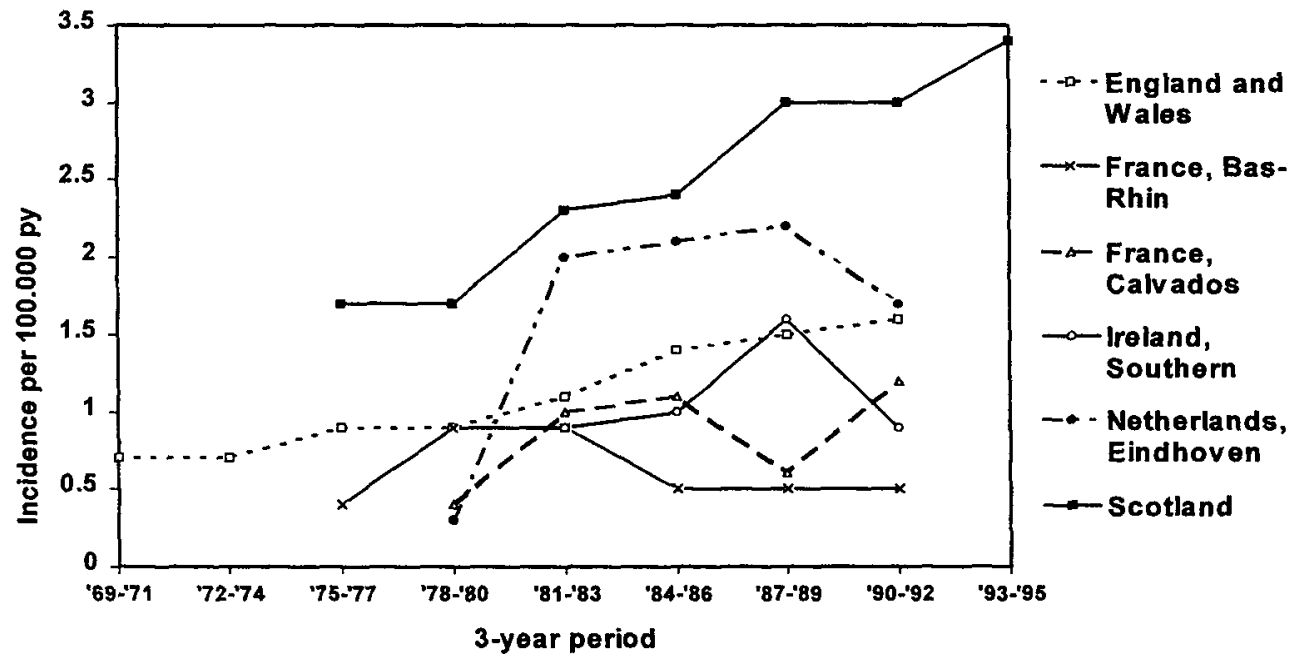

FIGURE 1d: Age-standardized incidence rates of adenocarcinomas of the oesophagus and gastric cardia by 3-year period in cancer registries of Western Europe, women. 
registries. The corresponding age-standardized incidence rates of each cancer registry for men and women separately are shown in tables $3 a$ and $3 b$, respectively. In England and Wales, Scotland and Slovakia the incidence of AEC increased in both men and women. A slight increase in incidence was seen in Denmark in men but not in women. After a slight increase in incidence during 1975-1986 in Italy (Varese) among men and a rather stable incidence during 1978-1983 among women, the incidence rates doubled. In Iceland the incidence rate in men reached a peak in the mid 1980s and decreased again. The incidence rates seemed rather stable in France (Bas-Rhin) and the Netherlands (Eindhoven) among men and in Denmark among women. The incidence rates in the cancer registries of Iceland (women), France (Bas-Rhin, women), France Calvados (men and women), the Netherlands (Eindhoven, women), Southern Ireland (men and women) and Switzerland (Basel, men and women), fluctuated during the study period without an apparent trend. In these cancer registries relatively few incident cases were registered in each 3-year period.

\section{Trends in subtypes of oesophageal and stomach cancer}

The trends in incidence of all subtypes of oesophageal and stomach cancer are shown for Danish and Slovakian men (figure 2a and b); two examples for the main trends in subtypes.

In Denmark, England and Wales, Scotland, Slovakia and Italy, Varese (men) the rise in incidence of AEC was accompanied by a decrease in incidence of non-adenocarcinomas of the non-cardia site of the stomach (including unspecified tumours and tumours with no morphology) and in Denmark and Scotland also by a decrease incidence of the adenocarcinomas of the non-cardia site of the stomach. The incidence rate of squamous cell carcinoma of the oesophagus increased in Denmark (men), Italy (Varese), Scotland and Slovakia or remained stable in England and Wales. For 'other cancers of the oesophagus', the incidence rate remained stable or decreased a little in these cancer registries. However, in some cancer registries the rise in incidence of the AEC was much smaller than the decrease in incidence of the other cancers of the oesophagus and stomach. In all cancer registries without a rise in incidence of AEC the incidence of the nonadenocarcinomas of the non-cardia site of the stomach decreased. In Iceland, France (Bas-Rhin and Calvados), the Netherlands (Eindhoven) and Switzerland (Basel) also a decrease of the adenocarcinomas of the non-cardia site of the stomach was observed. The incidence of squamous cell carcinoma of the oesophagus and 'other cancers of the oesophagus' was rather stable in these cancer registries.

\section{Poisson analysis}

Results of the Poisson analysis are presented in table 4. The model with age, sex and period gave a reasonably good fit to the data. In Denmark, England and Wales, Italy (Varese), Scotland and Slovakia the relative risk of developing AEC increased in the study period. In these countries the test for trend was also significant. In England and Wales, Italy (Varese), Scotland and Slovakia a relatively strong increase in risk (46 to $81 \%$ ) was observed in the 12-year period 1981-1983 to 1990-1992 compared to the $15 \%$ increase in Denmark in the same period. The RRs were slightly 


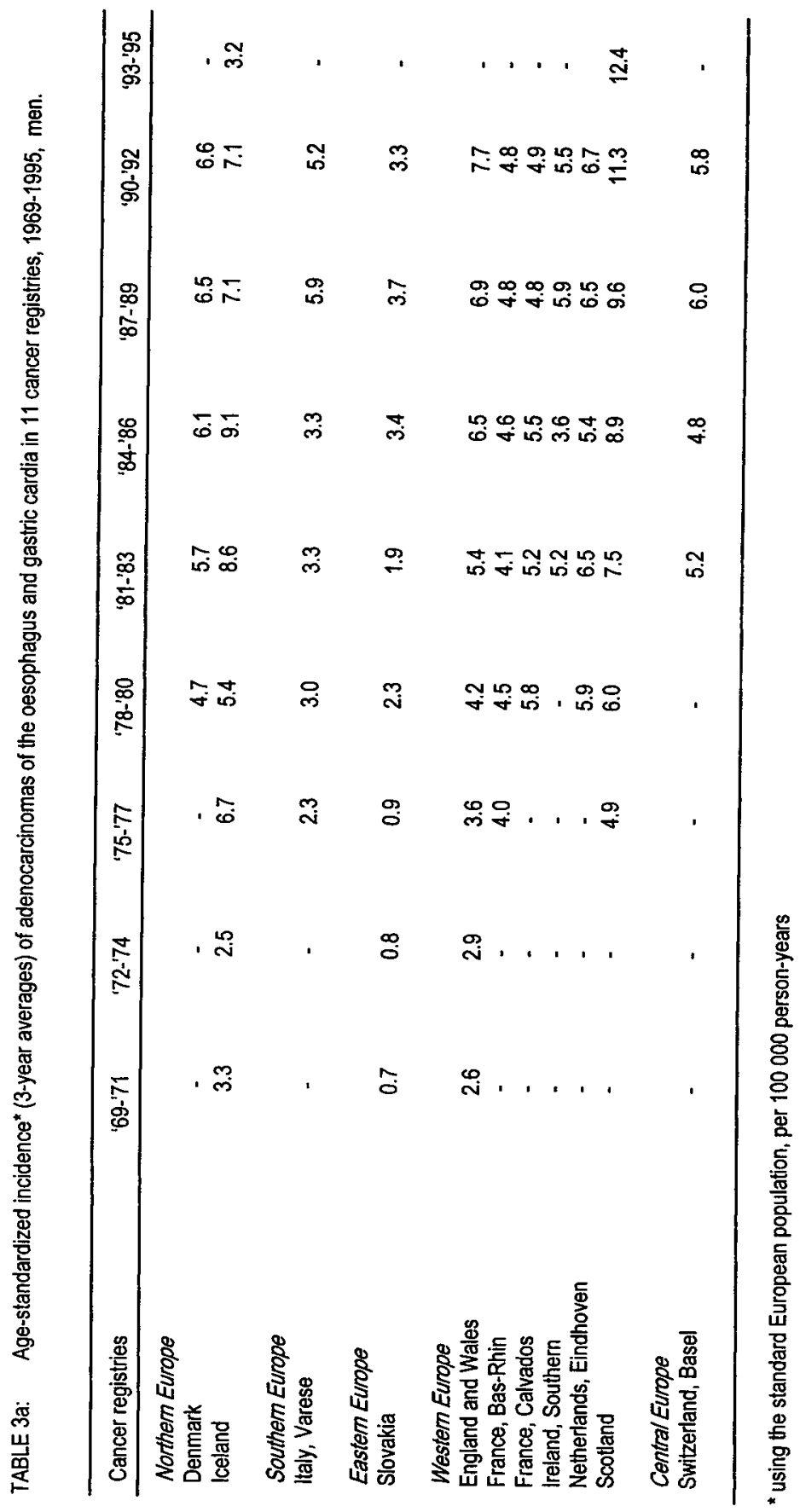




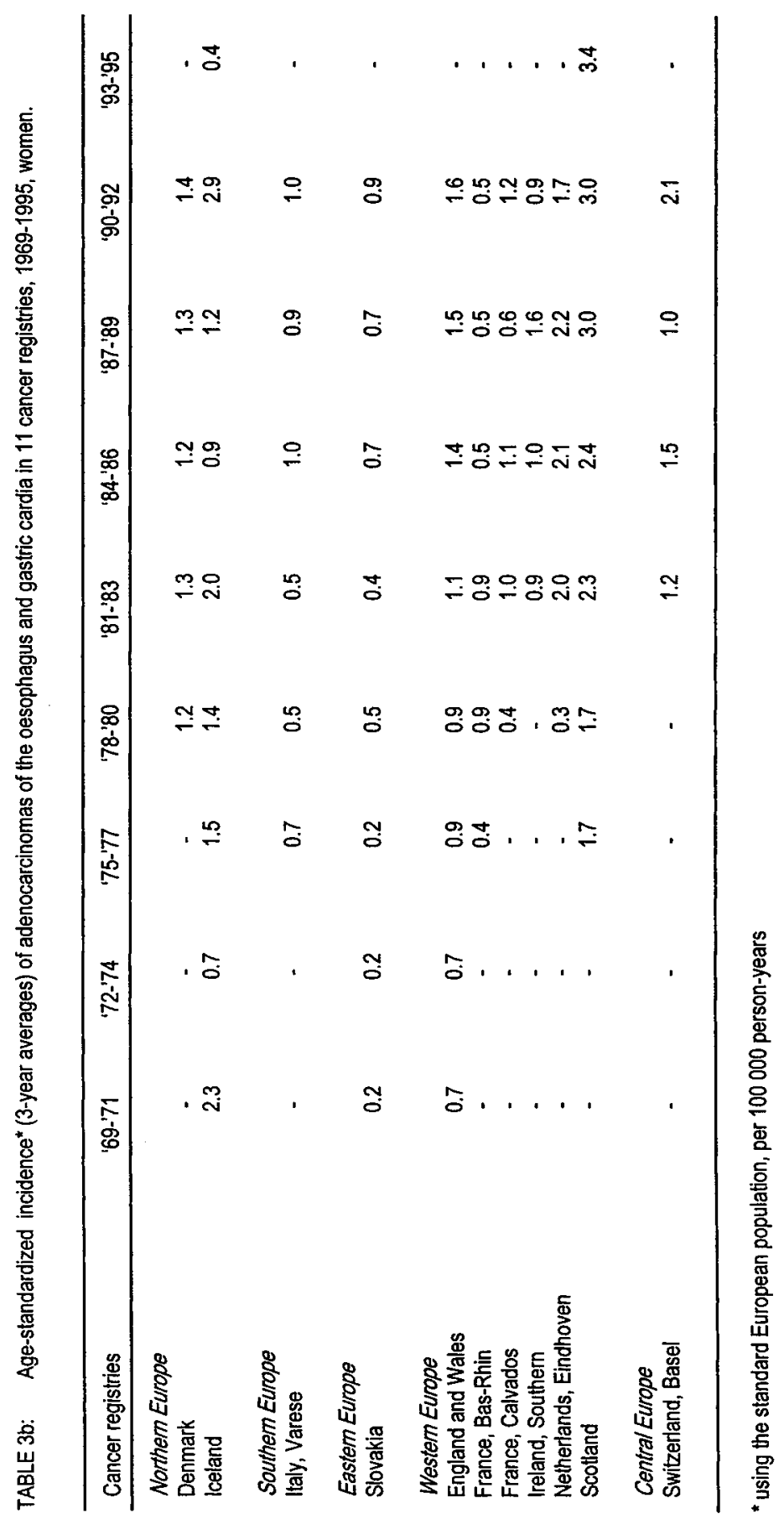




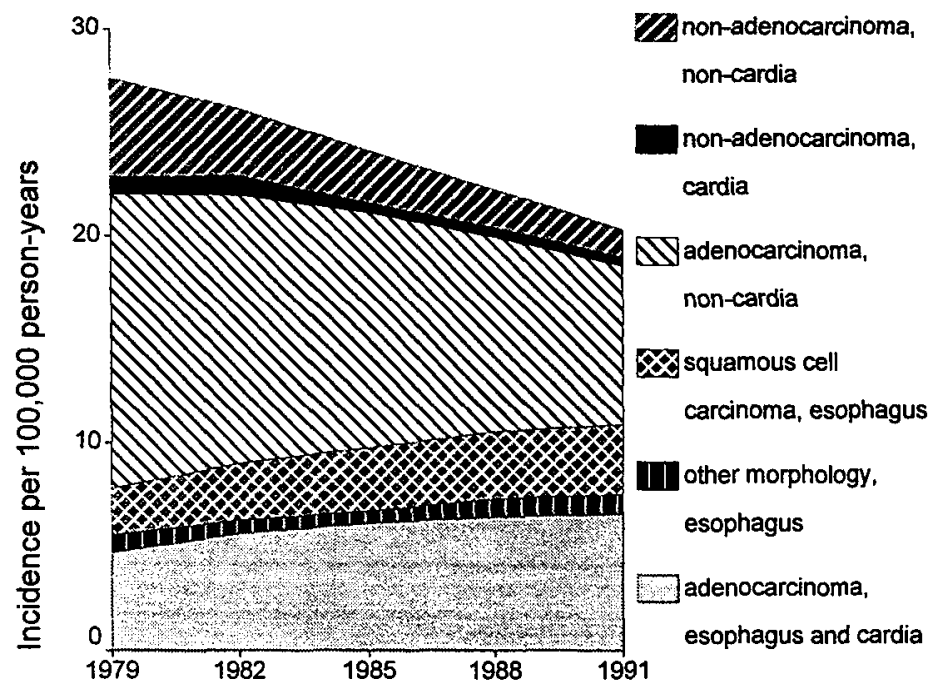

3-year period (mid-year)

FIGURE 2a: age-standardized incidence of morphological subtypes of the esophagus and stomach, Denmark, men

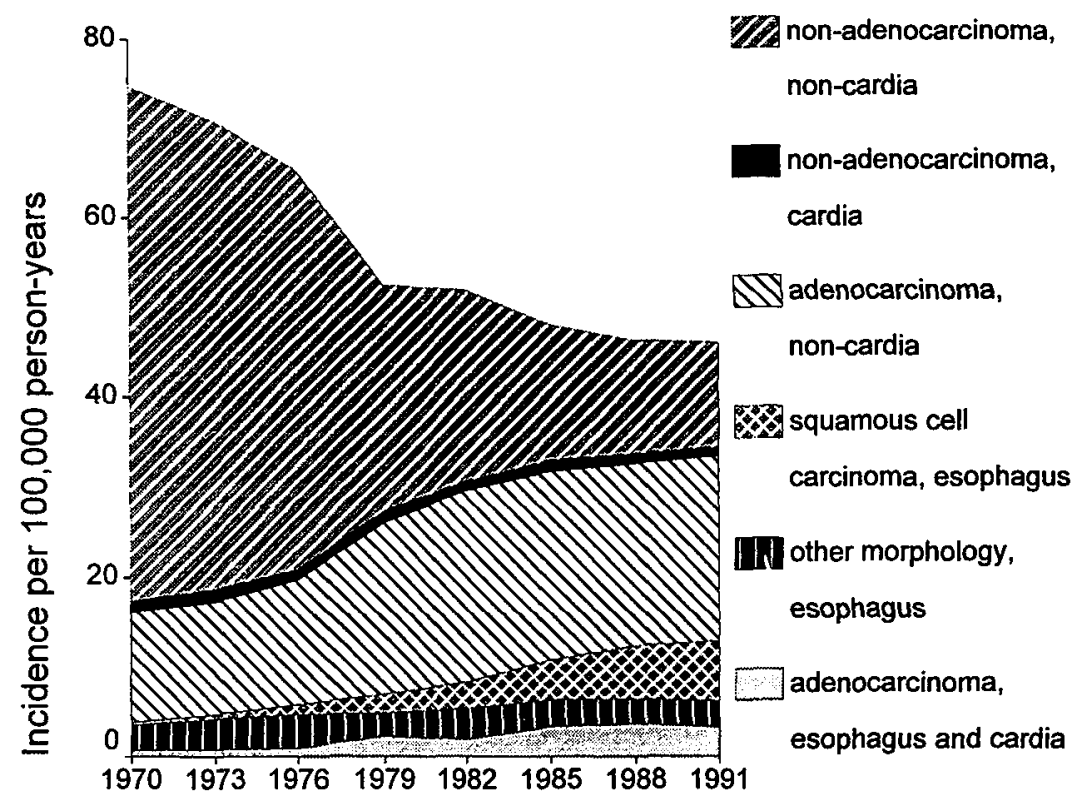

3-year period (mid-year)

FIGURE 2b: age-standardized incidence of morphological subtypes of the esophagus and stomach, Slovakia, men 
different in each 3-year period between men and women in England and Wales. In Italy (Varese), only the RRs for 1987-1989 and 1990-1992 were significantly increased. In the Netherlands (Eindhoven, women), the relative risk for 1978-1980 was significantly different from one (RR = 0.13 ) compared to the reference period (1981-1983), resulting in a significant test for linear trend. The RRs in the 3-year periods did not differ significantly from the RR of the reference period in France (Bas-Rhin), France (Calvados), Ireland (Southern), Netherlands (Eindhoven, males) and Switzerland (Basel). In Iceland, no clear linear trend was shown; the RRs of 1972-1974 and 19931995 were significantly decreased.

\section{DISCUSSION}

In this time-trend study of AEC using Eurocim data, we found an increase in incidence of AEC in Northern-Europe (Denmark), Southern-Europe (Italy, Varese), Eastern-Europe (Slovakia), Western-Europe (England and Wales, Scotland) during 1968-1995. A relatively strong increase in risk varying from 46 to $81 \%$ was observed in Italy (Varese), Slovakia, England and Wales and Scotland in the 12-year period 1981-1992. No particular trend was shown in Central-Europe (Switzerland, Basel) and in the cancer registries of Iceland (Northern-Europe), France, Bas-Rhin and Calvados, Southern Ireland, and the Netherlands, Eindhoven (Western-Europe).

Our primary focus was to describe the overall direction of the trends in incidence of AEC for each region of Europe, not to separate effects of age, birth cohort and time period as determinants of the observed trend. Therefore, we used a relatively simple model with the variables period, age and sex.

This is one of the first studies that used Eurocim data to investigate time trends in incidence rates, in this case, of AEC in ten European countries spread over 5 regions. The Eurocim database is very useful for all kinds of descriptive studies because detailed data are available from many European cancer registries. The data-quality of the Eurocim database is dependent on the quality of the provided data of the contributing cancer registries. The contributing cancer registries make regular submissions of incidence, mortality and population data to the central Eurocim data bank. The data of each cancer registry are subjected to validity checks and, if needed, returned to the cancer registry for verification. However, the collection and coding of data of the cancer registries are not uniform, e.g., due to different coding rules, differences in coding precision between cancer registries, which hampers comparison of the data.

Several features of the data quality and coding practice of the cancer registries in our study are discussed which may be of importance in interpreting the observed trends in incidence. We used information of three indices of reliability for oesophageal and stomach cancer as presented in Cancer Incidence in Five Continents (volume IV, V and VI) (29-31) as rough indicators of data quality. Regarding the percentage of histologically verified diagnoses (\%HV) of tumours of the oesophagus and stomach, this percentage increased from 40-50 \% (1973-1977) to 70-85\% (19831987 ) in the cancer registries of Italy (Varese) and Slovakia. This large increase in \% $\mathrm{HV}$ may have affected the incidence rates of AEC and in particular the incidence of tumours with 


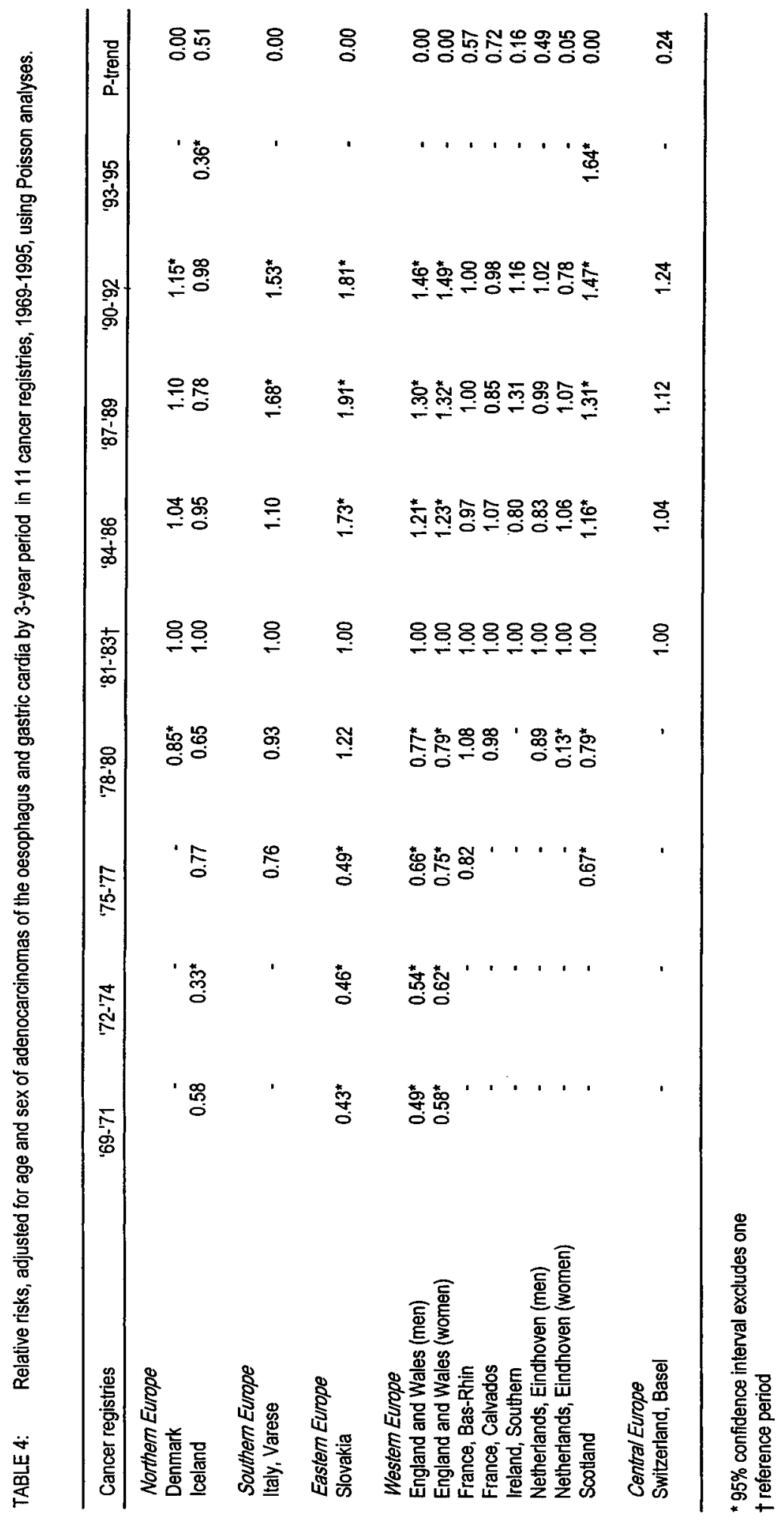


unspecified morphology. In our study, the increase in \%HV in Italy (Varese) and Slovakia may partly account for the decrease in incidence of non-adenocarcinomas of the non-cardia part of the stomach. The \%HV was high in the other cancer registries. However, we did not have information on histological verification rates of topographical subsites of oesophageal and stomach cancer. Furthermore, the proportion of 'cases known from a death certificate only' varied over time and varied between men and women in the cancer registries but was nearly always less than $15 \%$ which is considered to be acceptable (33).

Improvement of precision of histological diagnosis and improvement in diagnostic procedures (such as increased use of endoscopy) may have affected the incidence rates of AEC as well (7). In our study, the rise in incidence of AEC was accompanied by a much greater fall in rates of tumours with 'unspecified morphology' and 'no morphology'. It is unknown which proportion of tumours coded in early years of the study period as 'unspecified morphology' or 'no morphology' are being coded as AEC in later years of the study period.

In order to circumvent the potential problem of difficulties to distinguish tumours arising in the lower third of the oesophagus, the gastro oesophageal junction and the gastric cardia (Dr R. Otter, personal communication) and changes in classification or coding practice regarding these tumours in the study period we decided to combine adenocarcinomas of the oesophagus and gastric cardia for analyses. We knew from the background information that certain cancer registries used to classify adenocarcinomas of the lower oesophagus as cardia tumours in the study period. Some cancer registries coded tumours to 151.0 in case of doubt about localization of an adenocarcinoma in the lower oesophagus or cardia.

Besides changes in histological verification of tumours of the oesophagus and stomach over time, improvement of precision of histological diagnosis and improvement of diagnostic procedures over time, the increase in incidence in adenocarcinomas of the oesophagus and cardia might be explained by the introduction of a 'new' environmental risk factor in the etiologic relevant period. At present, little is known about risk factors of AEC, except for the link with Barrett's oesophagus, a condition associated with gastro oesophageal reflux (22).

Recently, obesity has been implicated as risk factor of AEC $(26,27)$. Obesity is associated with increased intra-abdominal pressure which may promote gastro-oesophageal reflux and the development of Barrett's oesophagus. The prevalence of obesity is growing in a number of western countries (34).

It has also been debated that long term use of peptic ulcer drugs (e.g. cimetidine) could lead to an increased risk of AEC. The drug suppresses acid production and creates hypochlohydric conditions in the stomach. Reflux of the alkaline stomach juice causes irritation and oesophagitis, and may lead to development of Barrett's oesophagus which is believed to be a precursor of adenocarcinoma of the oesophagus (35). However, these peptic ulcer drugs were introduced in the late 1970s, coinciding with the start of the increase in incidence of AEC. Given the latency period of AEC, the relation between peptic ulcer drugs and development of AEC is not likely.

In this study, in which an increasing trend of AEC was found in Denmark and England and Wales with Eurocim data confirms previous observations in other studies of population-based cancer 
registries in the same countries $(4,7-9,11,12)$. We could not reproduce the rise in incidence of adenocarcinomas of the oesophagus which was reported by Liabeuf et al. (20) in Burgundy, France in the two other French regions Bas-Rhin and Calvados that were investigated in this study. The rise in incidence of cardia tumours in women in the Netherlands (Eindhoven) reported by Van der Sanden et al. (15) was interpreted as a monotonic increase in our study, because the incidence rate of the first 3-year period 1978-1980 was low compared to the rates of the subsequent four 3-year periods. Another recent Dutch study reported stable gastric cardia cancer mortality rates between 1969 and 1994 (36). Nearly all other time-trend studies conducted in European countries (e.g 9,19), the United States (e.g. 10,14), Australia (18) and New Zealand (17) reported an increase in incidence, either in adenocarcinomas of the oesophagus or adenocarcinomas of the gastric cardia or a combination of two sites of the oesophagus and cardia. Exceptions were a study in Switzerland, Vaud (23) which reported a stable incidence of adenocarcinomas of the cardia during the period 1976-1987 in both men and women and a study in France, Côte d'Or and Calvados which reported no significant change in incidence of adenocarcinomas of the oesophagus during the period 1978-1987 (37). In this study no increasing trend was found in another part of Switzerland (i.e., Basel) as well. Some studies reported an increase in incidence of adenocarcinomas of the oesophagus or cardia in males, but not in females $(6,11,19)$. In our study, only the cancer registries of Slovakia, England and Wales and Scotland showed a clear increase in women. To our knowledge no time trend studies have been performed in a non-western countries.

In conclusion, we could reproduce the rise in incidence of AEC using the Eurocim database in nearly all regions of Europe. We did not observe an increase in incidence in those cancer registries which covered smaller populations. Due to small number of cases probably unstable rates were calculated.

In the future, time trends of AEC should be monitored more closely to confirm the trend. In particular, small cancer registries may have more data for calculating stable rates. Furthermore, more attention should be paid to the bias that can occur in diagnosing and coding of these tumours. In addition, analytic epidemiologic studies are needed to investigate etiologic factors that are involved in the development of these specific tumours.

\section{ACKNOWLEDGEMENTS}

The data used in this publication were taken from the EUROCIM database of the European Network of Cancer Registries. The contributions of the National Cancer Registry of Ireland, Registre Bas-Rhinois des Tumeurs, Registre Spécialisé des Tumeurs Digestives du Calvados, National Cancer Registry of England and Wales, Scotland Cancer Registry, Basel Cancer Registry, Danish Cancer Registry, Eindhoven Cancer Registry, Registro Tumori LombardiaProvenicia di Varese, Iceland Cancer Registry and National Cancer Registry of Slovakia are gratefully acknowledged. 


\section{REFERENCES}

1. Antonioli DA, Goldman H. Changes in the location and type of gastric adenocarcinoma. Cancer 1982;50:775-81.

2. MacDonald WC, MacDonald JB. Adenocarcinoma of the esophagus and/or gastric cardia. Cancer 1987;60:1094-8.

3. Rios-Castellanos E, Sitas F, Shepherd NA, Jewell DP. Changing pattern of gastric cancer in Oxfordshire. Gut 1992;33:1312-7.

4. Storm HH. Sammenligning of udvikling i lunge-, larynx-, esophagus- og ventrikelcancer 1943-1977 i Danmark. [Comparison of pulmonary, laryngeal, esophageal and stomach cancer in Denmark, 1943-1977]. Ugeskr Laeger 1983;145:1178-83.

5. Yang PC, Davis S. Epidemiological characteristics of adenocarcinoma of the gastric cardia and distal stomach in the United States, 1973-1982. Int J Epidemiol 1988;17:293-7.

6. Yang PC, Davis S. Incidence of cancer of the esophagus in the US by histologic type. Cancer 1988;61:612-7.

7. Allum WH, Powell DJ, McConkey CC, Fielding JW. Gastric cancer: a 25-year review. Br J Surg 1989;76:535-40.

8. Powell J, McConkey CC. Increasing incidence of adenocarcinoma of the gastric cardia and adjacent sites. $\mathrm{Br}$ J Cancer 1990;62:440-3.

9. Powell J, McConkey CC. The rising trend in oesophageal adenocarcinoma and gastric cardia. Eur J Cancer Prev 1992;1:265-9.

10. Blot WJ, Devesa SS, Kneller RW, Fraumeni JF, Jr. Rising incidence of adenocarcinoma of the esophagus and gastric cardia. Jama 1991;265:1287-9.

11. Moller $\mathrm{H}$. Incidence of cancer of oesophagus, cardia and stomach in Denmark. Eur J Cancer Prev 1992;1:159-64.

12. Harrison SL, Goldacre MJ, Seagroatt V. Trends in registered incidence of oesophageal and stomach cancer in the Oxford region, 1974-88. Eur J Cancer Prev 1992;1:271-4.

13. Zheng T, Mayne ST, Holford TR, Boyle P, Liu W, Chen Y, et al. Time trend and age-period-cohort effects on incidence of esophageal cancer in Connecticut, 1935-89. Cancer Causes Control 1992;3:481-92.

14. Zheng T, Mayne ST, Holford TR, Boyle P, Liu W, Chen Y, et al. The time trend and age-period-cohort effects on incidence of adenocarcinoma of the stomach in Connecticut from 1955-1989. Cancer 1993;72:330-40.

15. Van der Sanden GAC, Coebergh JWW, van der Heijden LH, Verhagen TMT. Trends in incidentie van maag-darmkanker in Zuidoost-Nederland, 1975-1989 [Trends in incidence of gastrointestinal cancer in the Southeastern Netherlands, 1975-1989]. Tijdschr Soc Gezondheidsz 1993;71:326-32.

16. Hansson LE, Sparen $P$, Nyren $O$. Increasing incidence of carcinoma of the gastric cardia in Sweden from 1970 to 1985. Br J Surg 1993;80:374-7.

17. Armstrong RW, Borman B. Trends in incidence rates of adenocarcinoma of the oesophagus and gastric cardia in New Zealand, 1978-1992. Int J Epidemiol 1996;25:941-7.

18. Thomas RJ, Lade S, Giles GG, Thursfield V. Incidence trends in oesophageal and proximal gastric carcinoma in Victoria. Aust N Z J Surg 1996;66:271-5.

19. Hansen S, Wiig JN, Giercksky KE, Tretli S. Esophageal and gastric carcinoma in Norway 1958-1992: incidence time trend variability according to morphological subtypes and organ subsites. Int J Cancer 1997;71:340-4.

20. Liabeuf A, Faivre J. Time trends in oesophageal cancer incidence in Cote d'Or (France), 1976-93. Eur J Cancer Prev 1997;6:24-30.

21. Macfarlane GJ, Plesko I, Kramarova E, Obsitnikova A, Boyle P. Epidemiological features of gastric and oesophageal cancers in Slovakia. Br J Cancer 1994;70:177-9.

22. Kim R, Weissfeld J, Reynolds JC, Kuller LH. Etiology of Barrett's metaplasia and esophageal adenocarcinoma. Cancer Epidemiol Biomarkers Prev 1997;6:369-77.

23. Levi F, La Vecchia C, Te VC. Descriptive epidemiology of adenocarcinomas of the cardia and distal stomach in the Swiss Canton of Vaud. Tumori 1990;76:167-71. 
24. Hansson LE, Bergstrom R, Sparen $P$, Adami HO. The decline in the incidence of stomach cancer in Sweden 1960-1984: a birth cohort phenomenon. Int J Cancer 1991;47:499-503.

25. Schouten LJ, Kiemeney LA. Remarkable age-dependent sex differences in the incidence of adenocarcinoma of the gastric cardia and oesophagus in The Netherlands [letter]. Eur J Cancer 1997;33:1519.

26. Brown LM, Swanson CA, Gridley G, Swanson GM, Schoenberg JB, Greenberg RS, et al. Adenocarcinoma of the oesophagus: role of obesity and diet. J Natl Cancer Inst 1995;87:104-9.

27. Vaughan TL, Davis S, Kristal A, Thomas DB. Obesity, alcohol, and tobacco as risk factors for cancers of the oesophagus and gastric cardia: adenocarcinoma versus squamous cell carcinoma. Cancer Epidemiol Biomarkers Prev 1995;4:85-92.

28. European Network of Cancer Registries. Eurocim database version 2.1. Lyon: International Agency for Research on Cancer, 1997.

29. Waterhouse J, Muir C, Shanmugaratnam K, Powell J. Cancer Incidence in Five Continents, Volume IV. Lyon, 1982.

30. Muir C, Waterhouse J, Mack T, Powell J, Whelan S. Cancer Incidence in Five Continents, Volume V. Lyon, 1987.

31. Parkin DM, Muir CS, Whelan SL, Gao YT, Ferlay J, Powell J. Cancer Incidence in Five Continents, Volume VI. Lyon, 1992.

32. Stata Corp. Stata Statistical Software: Release 5.0. College Station: TX: Stata Corporation, 1997.

33. Jensen OM, Storm HH. Reporting of results. Cancer registration: Principles and methods. Lyon: IARC, Scientific Publications Series, 1991:108-125.

34. Kuczmarski RI, Flegal KM, Campbell SM, Johnson CL. Increasing prevalence of overweight among US adults. The National Health and Nutrition Examination Surveys, 1960 to 1991. Jama 1994;272:205-11.

35. Watson A. Oesophageal cancer [letter]. Lancet 1991;338:819-20.

36. Laheij RJ, Straatman H, Verbeek AL, Jansen JB. Mortality trend from cancer of the gastric cardia in The Netherlands, 1969-1994. Int J Epidemiol 1999;28:391-5.

37. Launoy G, Faivre J, Pienkowski P, Milan C, Gignoux M, Pottier D. Changing pattern of oesophageal cancer incidence in France. Int J Epidemiol 1994;23:246-51.

38. World Health Organization. International Classification of Diseases for Oncology. Geneva, Switzerland: World Health Organization, 1976. 


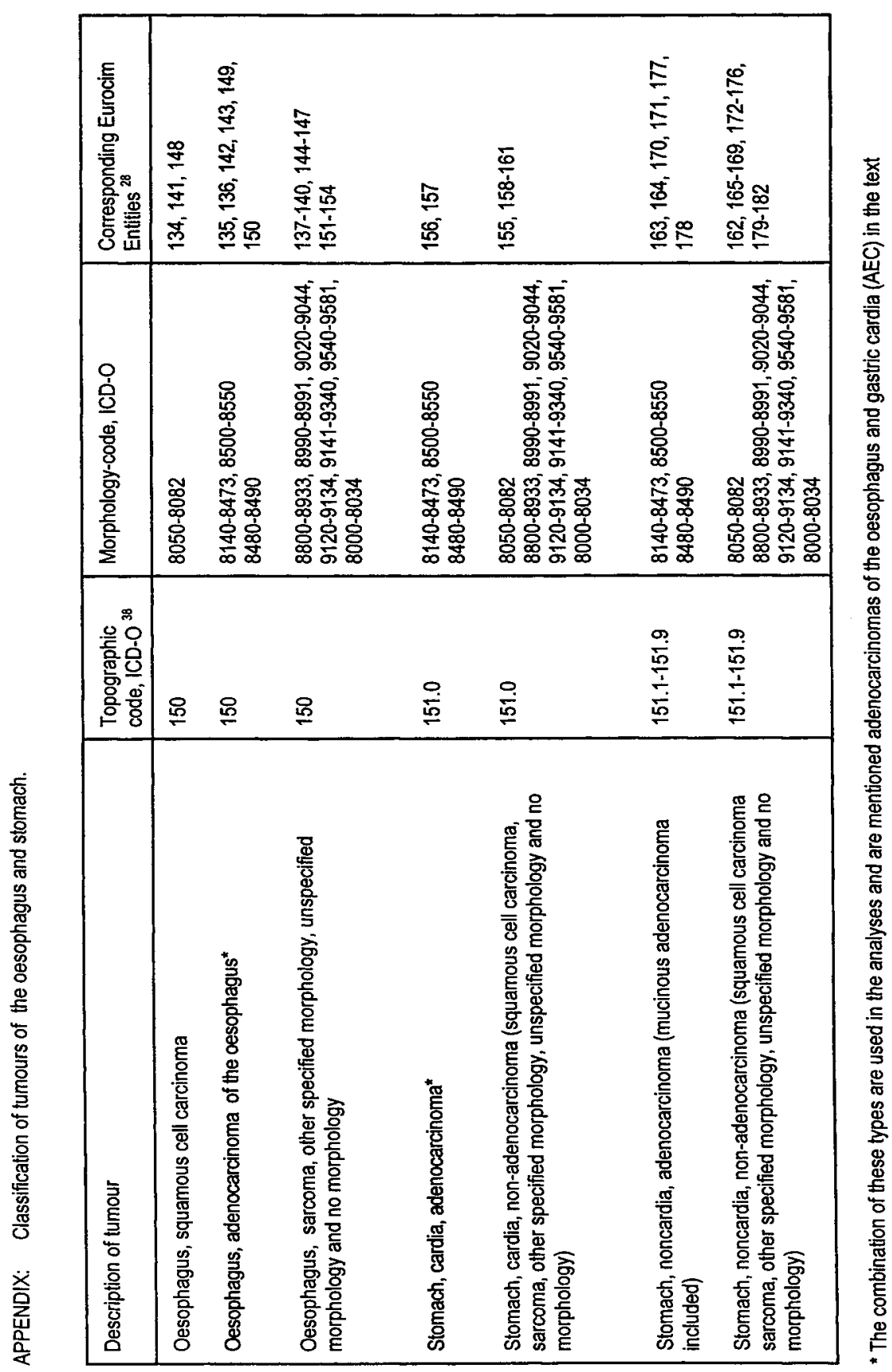




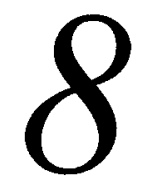

General Discussion 


\section{General discussion}

In this thesis, a prospective cohort study on the association between several dietary factors and stomach cancer risk has been described. In this chapter, the major results of the separate studies of this thesis are summarized and compared with results of other cohort studies and case-control studies on dietary factors and stomach cancer risk. In contrast with the other cohort studies and the case-control studies, in the NLCS it was possible to study the effects of possible change of dietary habits due to preclinical undiagnosed stomach cancer and the influence of stomach disorders on the association between dietary factors and stomach cancer risk.

Dietary factors did not seem to be strongly associated with stomach cancer risk in this study. A possible explanation is that the measurement of dietary intake does not refer to the etiologically relevant time period. Moreover, the effects of dietary factors may vary for different subtypes of stomach cancer (e.g., the cardia and the non-cardia subsite).

Furthermore attention is paid to a newly proposed risk factor in stomach cancer etiology: the bacterium Helicobacter pylori. Finally, recommendations for future investigations will be made.

\section{Major results}

The major results of this study are summarized in table 1 . Overall, the consumption of total fruit and vegetables, vitamin $\mathrm{C}$, vitamin $\mathrm{E}$, dietary nitrate, butylated hydroxyanisole (BHA) and butylated hydroxytoluene (BHT) was inversely associated and the intake of retinol, $\beta$-carotene, nitrite and cured meat was positively associated with stomach cancer risk, although there were no strong associations and only a few statistically significant results observed. For dietary salt, all rate ratios were higher than one, but without a linear trend. Folate intake did not seem to be associated with stomach cancer risk. Exclusion of cases diagnosed in the first or second year of follow-up from the analyses changed the risk estimates substantially in nearly all analyses, indicating that cases diagnosed shortly after the start of the cohort study had food habits different from cases diagnosed in later years of the follow-up.

\section{Comparison with results from other cohort studies}

Results of the NLCS are partly in line with results of eleven other cohort studies that have investigated the relation between diet and stomach cancer (1-12). An inverse association between stomach cancer and consumption of several types of fruit and vegetables was reported by the majority of the other studies, although not all associations were significantly inverse. They did not show a clear association with salt consumption, except that in some studies high consumption of specific salted foods (broiled fish, salted fish) was associated with a significantly increased stomach cancer risk $(1,5)$. Most studies found a (slightly) positive association between 
TABLE 1: Summary of main results of dietary risk factors for stomach cancer in the NLCS, 1986-1992.

\begin{tabular}{|c|c|c|c|}
\hline \multirow[t]{2}{*}{$\begin{array}{l}\text { Dietary factor } \\
\text { (highest vs. lowest mean daily } \\
\text { intake) }\end{array}$} & $\begin{array}{l}\text { Age and sex-adjusted } \\
\text { analyses }\end{array}$ & Multivariate analyses * & $\begin{array}{l}\text { Multivariate analyses with } \\
\text { first and second year } \\
\text { cases excluded * }\end{array}$ \\
\hline & \multicolumn{3}{|c|}{$\mathrm{RR}(95 \% \mathrm{Cl}), p$ trend over 5 quintiles or 3 categories } \\
\hline $\begin{array}{l}\text { Total vegetable consumption } \\
\text { ( } 286 \text { vs. } 103 \mathrm{~g} \text { ) }\end{array}$ & $0.8(0.6-1.1), 0.10$ & $0.9(0.6-1.3), 0.25 \dagger$ & $1.2(0.8-1.8), 0.40 \dagger$ \\
\hline $\begin{array}{l}\text { Total fruit consumption } \\
\text { ( } 325 \text { vs. } 46 \mathrm{~g})\end{array}$ & $0.8(0.6-1.2), 0.14$ & $1.0(0.6-1.5), 0.51 \ddagger$ & $0.8(0.5-1.3), 0.28 \ddagger$ \\
\hline $\begin{array}{l}\text { Retinol intake } \\
\text { (0.86 vs. } 0.26 \mathrm{mg})\end{array}$ & $1.1(0.8-1.7), 0.13$ & $1.2(0.8-1.7), 0.12$ & $1.6(1.0-2.5), 0.02$ \\
\hline $\begin{array}{l}\text { Vitamin C intake } \\
\text { (135 vs. } 55 \mathrm{mg} \text { ) }\end{array}$ & $0.7(0.5-0.9), 0.01$ & $0.7(0.5-1.0), 0.06$ & $0.9(0.6-1.2), 0.44$ \\
\hline $\begin{array}{l}\text { Vitamine E intake } \\
\text { ( } 21.7 \text { vs. } 6.6 \mathrm{mg} \text { ) }\end{array}$ & $0.8(0.5-1.2), 0.46$ & $0.8(0.5-1.2), 0.62$ & $0.9(0.6-1.4), 0.83$ \\
\hline $\begin{array}{l}\text { Folate intake } \\
\text { (0.38 vs. } 0.20 \mathrm{mg} \text { ) }\end{array}$ & $0.9(0.6-1.3), 0.39$ & $1.0(0.6-1.4), 0.71$ & $1.3(0.8-2.1), 0.40$ \\
\hline $\begin{array}{l}\text { B-carolene intake } \\
\text { ( } 4.77 \text { vs. } 1.43 \mathrm{mg} \text { ) }\end{array}$ & $1.2(0.8-1.7), 0.83$ & $1.2(0.8-1.8) .061$ & $1.6(1.0-2.6), 0.13$ \\
\hline $\begin{array}{l}\text { Dietary nitrate intake } \\
(172 \text { vs. } 56 \mathrm{mg})\end{array}$ & $0.8(0.6-1.2), 0.11$ & $0.9(0.6-1.3), 0.25$ & $1.2(0.8-1.9), 0.66$ \\
\hline $\begin{array}{l}\text { Dietary nitrite intake } \\
\text { (0.35 vs. } 0.01 \mathrm{mg})\end{array}$ & $1.5(1.0-2.2), 0.14$ & $1.5(1.0-2.2), 0.20$ & $1.4(0.9-2.2), 0.50$ \\
\hline $\begin{array}{l}\text { Dietary salt intake (salt naturally } \\
\text { present in foods and added by } \\
\text { food manufacturers } \\
\text { (8.1 vs. } 4.1 \mathrm{~g} \text { ) }\end{array}$ & $1.2(0.8-1.8), 0.41$ & $1.2(0.8-1.8), 0.43$ & $1.1(0.7-1.8), 0.53$ \\
\hline $\begin{array}{l}\text { Cured meat consumption } \\
\text { ( } 35.5 \text { vs. } 0 \mathrm{~g})\end{array}$ & $1.4(0.9-2.1), 0.16$ & $1.3(0.9-2.1), 0.25$ & $1.3(0.8-2.2), 0.42$ \\
\hline $\begin{array}{l}\text { Butylated hydroxyanisole (BHA) } \\
\text { intake, }(128 \text { vs. } 0 \mu \mathrm{g})\end{array}$ & $0.8(0.4-1.5), 0.60$ & $0.8(0.5-1.6), 0.57$ & $0.6(0.3-1.3), 0.12$ \\
\hline $\begin{array}{l}\text { Butylated hydroxytoluene (BHT) } \\
\text { intake, }(456 \text { vs. } 0 \mu \mathrm{g})\end{array}$ & $0.8(0.5-1.4), 0.50$ & $0.8(0.5-1.4), 0.50$ & $0.7(0.4-1.4), 0.30$ \\
\hline
\end{tabular}

* The model included age, sex, smoking, education, stomach disorders, family history of stomach cancer

† The model included age, sex, smoking, education, stomach disorders, family history of stomach cancer and total fruit consumption (g/day)

$\ddagger$ The model included age, sex, smoking, education, stomach disorders, family history of stomach cancer and total vegetable consumption (g/day)

consumption of cured meat or processed meat and stomach cancer risk (4-6). Other cohort studies 
reported stronger inverse associations between dietary intake or plasma levels of vitamins $A, C$ and $E$, and $\beta$-carotene and stomach cancer risk than our study $(6,12)$. However, these associations were not statistically significant. Intake of folate, nitrate, nitrite, BHA and BHT in relation with stomach cancer risk has not been studied in other cohort studies, thus the NLCS is the first cohort study that reported on these associations. None of the other cohort studies performed analyses in which cases diagnosed shortly after the baseline measurement of the study were excluded.

The reasons for not finding very consistent results between the various cohort studies may be explained by the variable quality of the studies, especially in terms of the measurement of dietary intake and control for possible confounding factors and the precision (statistical power: the number of cases studied). Furthermore, the failure to take into account the possibility that dietary habits may have been changed due to preclinical symptoms of stomach cancer of cases diagnosed shortly after the start of the study may have biased the findings.

The NLCS is worldwide the second largest cohort study with a population size of 120,000 persons and 310 incident stomach cancer cases diagnosed after 6.3 years of follow-up. The NLCS has used a detailed questionnaire in which the usual food consumption was measured with a 150 items food frequency questionnaire and other information on possible confounding factors was gathered. The largest cohort study is a Japanese cohort study of Hirayama with a population size of 265,000 and, because of the high stomach cancer incidence rate in Japan, 5247 deaths from stomach cancer occurred during 17 years of follow-up (2). Other cohort studies have a small number of cases (23-150 cases) which may have led to chance findings $(1,3,4-7)$. One of the major limitations of the other cohort studies was the inadequate measurement of exposure. In both the Japanese cohort studies of Hirayama (2) and Ikeda (1) the dietary measures were based on a very short self-administered questionnaire (9 items (2) and 6 items (1), respectively) which did not provide very detailed information. In the Hawaiian cohort study $(3,4)$ the dietary questionnaire was designed for evaluation of cardiovascular diseases instead of stomach cancer. Therefore, the questionnaire did not cover sufficient relevant food items important for studying the relation between food and stomach cancer. Moreover, in one publication of this study the dietary intake only was based on a 24-hour recall only, so the usual diet of an individual was not measured (3). Random misclassification arising from these imprecise diet measures is clearly a possibility and may have resulted in attenuation of associations.

Due to the limited exposure measurement, also no accurate measurement of confounders was performed in these studies which resulted in insufficient correction for potential confounders.

In the NLCS, inverse associations observed with vegetables, fruit and nitrate consumption in ageand sex-adjusted analyses became weaker after further adjustment for other possible confounders. Some of the discrepancies in the findings of separate cohort studies also could be due to intercountry differences in foods consumed, the form in which foods are consumed (raw or cooked, different ways of food preservation) or the variety in foods available within a population. 


\section{Comparison with results from case-control studies}

At the moment, most evidence on dietary risk factors is based on findings of case-control studies. These studies have consistently demonstrated that high intake of salt and salt-preserved food has been associated with an increased risk of stomach cancer and a high consumption of fruit and vegetables has been found to reduce the risk of stomach cancer $(13,14)$. Generally, associations found in case-control studies were stronger than the associations found in cohort studies. However, it is possible that associations demonstrated in case-control studies are an under- or overestimation of the true association due to inherent limitations of case-control studies. Major potential shortcomings of case-control studies include bias in selecting cases and controls and recall bias due to knowledge of disease status.

\section{Effects of preclinical stomach cancer on food habits}

A specific methodological shortcoming of case-control studies is that patients with stomach cancer may have changed their food habits as a consequence of preclinical stomach cancer or even precursors of stomach cancer which may have resulted in biased odds ratio estimates.

Patients with preclinical stomach cancer are often unaware of their disease, have vague, nonspecific diagnostic symptoms such as epigastric uneasiness, mild anemia, fatigue, ulcer history, weight loss (15) and also anorexia often with slight nausea are quite common (16). A high percentage of patients with early stomach carcinoma had already complaints for a year or longer before diagnosis (17). It is also known that (some) cancer patients have taste aberrations which contribute to the development of food aversion and avoidance $(18,19)$. On the whole, this may cause a decreased food intake or avoidance of specific foods.

In case-control studies, information on food habits is obtained after the diagnosis of stomach cancer and usually refers to one year before diagnosis or the period before the onset of symptoms. It is conceivable that in the year preceding the diagnosis of stomach cancer patients already may have changed their food intake and thus report a changed food intake. The period before the onset of symptoms is probably not clearly defined and patients may have difficulties in recalling the food intake. Moreover, recall of food habits may be influenced by present food habits (20-22).

The foods most commonly reported as avoided by cancer patients are (red) meat and coffee (1819). In the NLCS, we demonstrated that cases diagnosed in the first or second year after the start of the study had a lower consumption of vegetables, meat, potatoes and coffee compared to cases diagnosed in later years of follow-up (23), indicating that, in particular, components of the hot meal were avoided. Furthermore, when we conducted analyses limited to first and second year cases, thus resembling a case-control study, we found a strong inverse association between vegetable consumption and stomach cancer risk similar to the findings in many case-control studies (23). This phenomenon may explain (some of) the discrepancies between results of cohort and case-control studies. 


\section{Influence of stomach disorders}

Subjects with certain pathological conditions of the stomach mucosa, e.g., atrophic gastritis and intestinal metaplasia are at higher risk for stomach cancer. In a prospective study, atrophic gastritis was associated with a fivefold increase in stomach cancer risk (24). Gastric ulcers, on the other hand, are not associated with an increased stomach cancer risk (16). The presence of a stomach disorder, whether or not an early manifestation of stomach cancer, may lead to an altered food intake or a change in food habits. As a consequence, this may influence the risk of getting stomach cancer. For example, a patient with a stomach disorder may avoid certain foods that have anticarcinogenic properties. This implies that stomach disorders should be regarded as a confounding factor or an effect modifier in the relationship between food intake and stomach cancer.

On the other hand, certain dietary factors (e.g., salt) may play a role in the causation of stomach disorders (25). In a changed stomach environment the action of endogenously formed carcinogens or carcinogens from foods will be enhanced (26). For example, hypochlorhydria as a result of atrophic gastritis may facilitate the growth of nitrate reducing bacteria, which may result in increased formation of $\mathrm{N}$-nitroso compounds (formed out of nitrite and amides/amines), potential carcinogens for the stomach (27). Moreover, precancerous lesions of the stomach would seem to be especially susceptible to the promoting or antineoplastic effects of compounds in foods (26). In this respect, a stomach disorder should be regarded as an intermediate risk factor in the etiologic sequence between diet and stomach cancer. At present, it is not very clear how stomach disorders are related to either diet or stomach cancer risk.

In the NLCS, the only indication for altered stomach conditions was self-reported prevalence of stomach disorders. The participants were asked to report any stomach disorder requiring medical attention in the past. Because of the potential influence of stomach disorders on dietary habits and the potential role of stomach disorders in stomach cancer etiology, analyses were performed for subjects with and without stomach disorders (partly reported in earlier chapters). In table 2, multivariate rate ratios of several dietary variables for subjects with and without stomach disorders are presented.

The associations with total vegetable and fruit consumption, intake of retinol, vitamins $\mathrm{C}$ and $\mathrm{E}$, folate, dietary nitrate, and BHT were similar among subjects with and without stomach disorders. Among subjects with stomach disorders, positive associations with statistically significant trends were observed for nitrite, cured meat and BHA. Among subjects without stomach disorders nitrite and cured meat were not associated and BHA was inversely associated with stomach cancer risk. For $\beta$-carotene and dietary salt, a positive association with stomach cancer risk without a significant trend in subjects with stomach disorders was observed, but not in subjects without stomach disorders.

The positive association observed for salt and nitrite seems to support the theory that changes in the stomach mucosa render the tissue more susceptible to the damaging action of genotoxic 
TABLE 2: Rate ratios (RRs) and 95\% confidence intervals (95\% Cl) of stomach cancer for subjects with and without stomach disorders according to several dietary factors in the NLCS, 1986-1992.

\begin{tabular}{|c|c|c|}
\hline \multirow[t]{2}{*}{ Dietary factor } & $\begin{array}{l}\text { Subjects with stomach } \\
\text { disorders, } \\
\text { Multivariate analyses* } \\
n=54\end{array}$ & $\begin{array}{l}\text { Subjects without stomach } \\
\text { disorders, } \\
\text { Multivariate analyses } \\
n=228\end{array}$ \\
\hline & \multicolumn{2}{|c|}{$\mathrm{RR}(95 \% \mathrm{Cl}), p$ trend over 5 quintiles or 3 categories } \\
\hline Total vegetable consumption & $0.7(0.3-1.7), 0.35 t$ & $0.9\langle 0.6-1.3), 0.40 \dagger$ \\
\hline Total fruit consumption & $1.0(0.4-2.9), 0.42 \ddagger$ & $1.0(0.6-1.6), 0.78 \ddagger$ \\
\hline Retinol intake & $1.6(0.6-4.2), 0.49$ & $1.1(0.7-1.7), 0.15$ \\
\hline Vitamin C intake & $0.8(0.4-1.8), 0.58$ & $0.7(0.5-1.0), 0.09$ \\
\hline Vitamine $E$ intake & $0.9(0.4-2.6), 0.35$ & $0.8(0.5-1.2), 0.32$ \\
\hline Folate intake & $1.3(0.5-3.5), 0.71$ & $0.9(0.6-1.4), 0.61$ \\
\hline B-carotene intake & $2.0(0.8-5.2), 0.10$ & $1.1(0.7-1.7) \cdot 0.86$ \\
\hline Dietary nitrate intake & $0.7(0.3-1.7), 0.48$ & $1.0(0.6-1.4), 0.36$ \\
\hline Dietary nitrite intake & $3.5(1.2-10.5), 0.02$ & $1.2(0.8-1.8), 0.76$ \\
\hline $\begin{array}{l}\text { Dielary salt intake (salt naturally } \\
\text { present in foods and added by } \\
\text { food manufacturers }\end{array}$ & $2.2(0.8-5.8), 0.08$ & $1.0(0.6-1.6), 1.00$ \\
\hline Cured meat consumption & $1.9(1.0-3.9), 0.04 \S$ & $1.0(0.7-1.4), 0.89 \S$ \\
\hline $\begin{array}{l}\text { Butylated hydroxyanisole (BHA) } \\
\text { intake ๆ }\end{array}$ & $3.7(1.0-14.2), 0.02$ & $0.6(0.3-1.3), 0.10$ \\
\hline $\begin{array}{l}\text { Butylated hydroxytoluene (BHT) } \\
\text { intake } 7\end{array}$ & $0.9(0.3-3.5), 0.81$ & $0.8(0.4-1.5), 0.40$ \\
\hline
\end{tabular}

* The model included age, sex, smoking, education, family history of stomach cancer

† The model included age, sex, smoking, education, family history of stomach cancer, and total fruit consumption (g/day)

¥ The model included age, sex, smoking, education, family history of stomach cancer, and total vegetable consumption ( $g /$ day)

$\S$ intake categories 1 and 2 are combined due to few cases

II cardia cases, $n=37$; non-cardia cases $n=155$, because of missing values

agents and irritants in foods (26). However, stomach disorders were self-reported and both overand underreporting is a possibility which may bias the results. Despite the possibility of bias, the differences in risk estimates between the two groups warrants further research. 


\section{Etiologically relevant time window}

Taking together all results of cohort studies on diet and stomach cancer, dietary factors do not seem to be strongly related to the risk of stomach cancer. A possible explanation may be that dietary intake was not measured in the etiologically relevant time window.

In theory, there is an etiologically relevant time window during which an exposure of interest is causally related to the disease (28) (see figure 1).

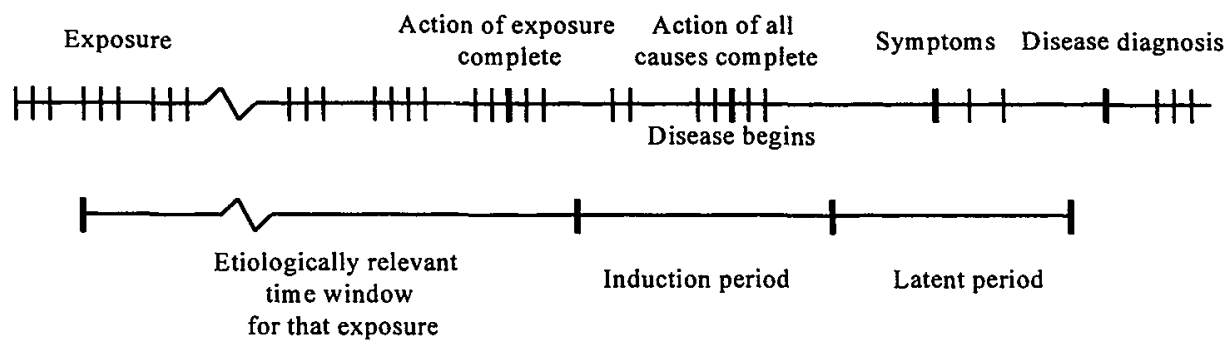

FIGURE 1: Causal sequence for a specific exposure and disease (28).

After the action of a specific exposure is complete, the remaining component causes for that disease occur in the induction period. The latency period begins when the disease irreversibly begins and ends when the disease is diagnosed (figure 1). The exposure should be measured in the etiologically relevant time window.

A human model of carcinogenesis for the intestinal type of stomach cancer was proposed by Correa with the following stages: superficial gastritis, atrophic gastritis, intestinal metaplasia and dysplasia $(25,29)$. The progress from superficial gastritis to gastric carcinoma is thought to take from 16-24 years on the basis of cell kinetic studies (30). Assuming that the sequential stages of carcinogenesis all occur during the latency period and that the action of all causes (including dietary factors) are complete before the start of the latency period, the measurement of dietary intake should refer to the period approximately 20 years before the start of a cohort study.

In the NLCS, the measurement of dietary intake referred to the usual consumption of food during the year preceding the start of the study. In this case the measurement of dietary intake has been performed after the etiologically relevant time window, and may lead to exposure measurement error. However, the relatively old study population (55-69 years at the start of the study) of the NLCS was thought to have reasonably stable dietary habits over a longer period, and thus the current diet was expected to be a good measure of past exposure. Support from this assumption came from the reproducibility study of the NLCS in which the 5-year reproducibility of the 150item food frequency questionnaire was determined. From the results it was concluded that the single measurement of the diet (baseline measurement) can characterize dietary habits for a period of at least five years (31). In this case, the measurement of dietary intake could reflect dietary exposure in the etiologically relevant time window. 
Moreover, it has been also suggested that dietary factors may play a role during progress from gastritis to carcinoma (25), thus during the latency period according to the theory. The best period for the measurement of dietary intake may range from 20 years to some years before the start of the study.

This issue is very complex since it is largely unknown which factors are involved in stomach carcinogenesis, factors may act at different points in time and dietary factors may interact with each other or with non-dietary factors.

Furthermore, the Correa model applies to the intestinal type of cancer, not to cancers of the diffuse or mixed type (25). Stomach cancer is probably not a single disease entity but consists of several types, which may all have different epidemiologic and etiologic characteristics. The identification of different types of stomach cancer is important and, in addition, the role of (dietary) factors in the development of the subtypes of stomach cancer deserves further study.

\section{Subtypes of stomach cancer}

The markedly different male-to-female ratios, difference in time-trends and the ethnic differences suggest that cancers of the cardia and the distal part of the stomach (non-cardia) are specific entities $(32,33)$. The most common cell type of both cardia and non-cardia tumors are adenocarcinomas (95\%)(15).

In the NLCS we were able to determine the association between dietary factors and the risk of cardia (ICD-O topography code 151.0) and non-cardia cancer (ICD-O topography code 151.19)(34). In table 3, results from multivariate analyses are presented for cases with cardia cancer $(n=65)$ and non-cardia cancer $(n=217)$.

Total vegetable and fruit consumption, folate and dietary nitrate intake were not associated with the risk of cardia cancers and non-cardia cancers. For retinol, cured meat, nitrite, BHA and BHT, the association was similar in the subgroup of cardia and non-cardia cancers. Inverse associations were observed in the subgroup of cardia cancers for the intake of vitamins $\mathrm{C}$ and $\mathrm{E}$ and $\beta$ carotene. Only vitamin $C$ showed a statistically significant inverse association with cardia cancer risk. For non-cardia cancers no clear association was observed for vitamins $C$ and $E$, but for $\beta$ carotene a statistically significant positive association was found. For the highest vs. lowest intake category of dietary salt a RR of $3.2(95 \% \mathrm{CI}=1.8-5.7$, trend $p=0.03)$ was found in the subgroup of cardia cancers, while no assocation was observed in the subgroup of non-cardia cancers. At present, only case-control studies have analyzed the effect of dietary factors for cardia and non-cardia cancer (35-38). In general, inconsistent results were reported. Some case-control studies found differences in the strength of associations with dietary factors (fruits, barbequed/smoked foods (37); salty foods (38); vitamins A and C (35) by subsites of stomach cancer. High intake of barbecued/smoked foods (37) and salty food (38) was positively associated 
TABLE 3: Rate ratios (RRs) and $95 \%$ confidence intervals ( $95 \% \mathrm{Ci}$ ) of cardia and non-cardia cancer according to several dietary factors in the NLCS, 1986-1992.

\begin{tabular}{|c|c|c|}
\hline \multirow[t]{2}{*}{ Dietary factor } & $\begin{array}{c}\text { Cardia cases, Multivariate } \\
\text { analyses } \\
n=65\end{array}$ & $\begin{array}{l}\text { Non-cardia cases, } \\
\text { Multivariate analyses* } \\
n=217\end{array}$ \\
\hline & \multicolumn{2}{|c|}{ RR ( $95 \% \mathrm{Cl}), \rho$ trend over 5 quintiles or 3 categories } \\
\hline Total vegetable consumption & $1.0(0.4-2.4), 0.92 \dagger$ & $0.8(0.5-1.3), 0.26 \dagger$ \\
\hline Total fruit consumption & $0.9(0.4-2.0), 0.39 \ddagger$ & $1.0(0.7-1.6), 0.81 \ddagger$ \\
\hline Retinol intake & $1.1(0.5-2.5), 0.35$ & $1.2(0.8-1.8), 0.20$ \\
\hline Vitamin C intake & $0.4(0.2-0.9), 0.01$ & $0.9(0.6-1.2), 0.47$ \\
\hline Vitamine $\mathrm{E}$ intake & $0.5(0.3-1.1), 0.14$ & $1.0(0.6-1.5), 0.79$ \\
\hline Folate intake & $0.8(0.4-1.8), 0.65$ & $1.0(0.7-1.6), 0.87$ \\
\hline B-carotene intake & $0.6(0.3-1.4), 0.15$ & $1.5(1.0-2.3), 0.16$ \\
\hline Dietary nitrate intake & $0.8(0.4-1.8), 0.55$ & $0.9(0.6-1.4), 0.33$ \\
\hline Dietary nitrite intake & $1.7(0.8-3.9), 0.45$ & $1.4(0.9-2.1), 0.29$ \\
\hline $\begin{array}{l}\text { Dietary salt intake (salt naturally } \\
\text { present in foods and added by food } \\
\text { manufacturers }\end{array}$ & $3.2(1.8-5.7), 0.03$ & $0.9(0.6-1.5), 0.78$ \\
\hline Cured meat consumption & $1.4(0.6-3.6), 0.73$ & $1.3(0.8-2.1), 0.25$ \\
\hline $\begin{array}{l}\text { Butylated hydroxyanisole (BHA) } \\
\text { intake } \S\end{array}$ & $0.8(0.3-2.8), 0.72$ & $0.8(0.4-1.7), 0.64$ \\
\hline $\begin{array}{l}\text { Butylated hydroxytoluene (BHT) } \\
\text { intake } \S\end{array}$ & $0.9(0.3-2.6), 0.92$ & $0.8(0.4-1.5), 0.48$ \\
\hline
\end{tabular}

* The model included age, sex, smoking, education, stomach disorders, family history of stomach cancer

† The model included age, sex, smoking, education, stomach disorders, family history of stomach cancer, nitrite intake and total fruit consumption (g/day).

¥ The model included age, sex, smoking, education, stomach disorders, family history of stomach cancer, and total vegetable consumption ( $g /$ day).

$\S$ cardia cases, $n=45$; non-cardia cases $n=147$, because of missing values

with cardia cancer risk, but unrelated to the risk of non-cardia cancer. Cardia cancer was not associated with fruit consumption while non-cardia cancer was non-significantly associated with fruit consumption (37). Both vitamins $\mathrm{A}$ and $\mathrm{C}$ were unrelated to cardia cancer risk, but vitamin $\mathrm{A}$ was associated with a non-significantly increased and vitamin $\mathrm{C}$ with a non-significantly decreased risk of non-cardia cancer (35). In the same study, retinol was only positively associated with cardia cancer risk (35). Other studies found similar risks for cardia and non-cardia cancer regarding vegetables, fruit $(36,38)$ or cold cuts $(36)$. 
The relatively small number of cardia cases may be a reason for not finding consistent results between studies. In future analyses, adenocarcinomas of the gastric cardia and the esophagus could be investigated together because both adenocarcinomas of the gastric cardia and the esophagus share epidemiologic and probably etiologic characteristics (39).

At the moment little is known about risk factors of adenocarcinomas of the gastric cardia and the esophagus. Possibly, other factors than dietary factors may play a major role in the development of gastric cardia cancer. Barrett's oesophagus, a condition associated with gastro-oesophageal reflux is linked with adenocarcinomas of the gastric cardia and the esophagus (40), and more recently, obesity has been implicated as risk factor of adenocarcinomas of the gastric cardia and the esophagus $(41,42)$.

\section{Intestinal and the diffuse type of stomach cancer}

Neoplasms of the stomach can be classified according to Laurén which divides adenocarcinomas of the stomach into two main types: the intestinal and diffuse type (43). This classification has histological and prognostic relevance, and etiological difference have been suggested as well. It has been hypothesized that the intestinal cancers are more closely related to environmental and dietary factors and that diffuse cancers are more influenced by genetic factors (29). Although many reports have suggested that the intestinal and diffuse type are etiologically distinct, only a few epidemiologic studies have actually examined (dietary) risk factors according to the two histologic types of stomach cancer $(4,44-49)$. However, the majority of studies have failed to show differences in risk factors for diffuse and intestinal cancer $(4,45,47,48)$. Data supporting the above mentioned hypothesis were not convincing and therefore, evaluation of dietary factors in relation to diffuse and intestinal type of stomach cancer was not considered in the NLCS. Furthermore, the coding of stomach cancers into the intestinal and the diffuse type is not performed routinely in the Netherlands Cancer Registry which provided our tumor data.

\section{Helicobacter pylori}

Another relevant non-dietary factor which has been proposed in stomach cancer etiology is H.pylori (50). H.pylori associated gastritis may progress towards gastric mucosal atrophy and intestinal metaplasia which are probably precancerous lesions, especially for the intestinal type of stomach cancer. H.pylori is probably mainly involved in the first phase of the histopathological sequence in the stomach carcinogenesis by causing chronic gastritis (25). H.pylori infection is associated with a two- to threefold increased risk of stomach cancer, established in both casecontrol and cohort studies $(51,52)$. The proportion of stomach cancers attributable to H.pylori infection is $35 \%$ to $60 \%$, based on evidence from nested case-control studies (53-55). 
Much is uncertain, however. Only a small proportion of H.pylori-positive subjects will develop stomach carcinoma. Moreover, stomach cancer is twice as common in men as in women, whereas H.pylori infection occurs equally in both sexes. It is largely unknown which factors, besides H.pylori infection, determine the development to stomach carcinoma. Probably, a combination of host factors, bacterial virulence and environmental factors interact and lead to a different disease outcome in individuals. For example, host factors such as blood group $\mathrm{A}$ and $\mathrm{O}$ have been shown to be positively associated with risk of infection, while blood group $B$ may be protective against H.pylori infection (51). Some studies have suggested that specific strains of H.pylori, (e.g., strains that contain the cytotoxin associated gene (cagA)) are more likely to progress to gastric atrophy, metaplasia and dysplasia (51). However, evidence suggests that H.pylori, in particular the cagApositive type, may protect against cancer of the cardia (56). Also, interactions are proposed between H.pylori infection and dietary factors, such as vitamin $\mathrm{C}$ and salt $(57,58)$. Furthermore, the mechanism through which H.pylori is supposed to induce stomach cancer needs to be elucidated.

In the NLCS, we were not able to study the effect of H.pylori infection on stomach cancer risk, because we did not have blood samples or other material to determine infection with H.pylori in the study population. Moreover, the start of the NLCS was just a few years after the discovery of H.pylori (59).

\section{Future research}

The continuous decline of stomach cancer incidence rates over the last decades, large differences in incidence rates between geographic areas and results of migrant studies suggest a predominant role of environmental, and specifically dietary factors in the development of stomach cancer. However, the role of the most important risk factors remains to be established and the specific mechanisms by which (dietary) risk factors affect the cancer process are essentially unknown. Therefore, more work is needed to clarify the role of dietary factors in the development of stomach cancer. Future epidemiologic studies should have preferably a prospective design, an adequate number of cases and a detailed exposure measurement. The case-control study design, which has been to date the most often used design for studying risk factors of stomach cancer, is subject to (recall) bias which may have resulted in less objective evidence. Specifically for stomach cancer, (recall) of dietary habits may be influenced by symptoms of preclinical stomach cancer. Nutrition intervention trials will be useful to clarify the benefits of certain food compounds as well. Despite the major advantages of the design, a long follow-up (because of the long latency period of stomach cancer) and a large size is needed to detect significant benefits. Thus, the identification of predisposing lesions or intermediate stages of stomach cancer is important. In this respect, nutrition intervention trials could be useful for studying the association between compounds in foods and progression or regression of precancerous lesions of the 
stomach.

As suggested by studies on descriptive epidemiologic and histopathological characteristics stomach cancer is no single disease entity, but should be considered as a disease in which several subtypes can be distinguished. The precise identification of these subtypes is important and detailed analysis focusing on topographic sites and histologic subtypes may be informative with respect to the role of risk factors.

Measurement of stomach disorders is also an important issue to consider in order to identify subgroups and to study risks factors of stomach cancer within these subgroups.

The interaction between different exposures, and interactions between environmental exposures and genetic susceptibility needs to be examined further.

Future research should consider the role of H.pylori in stomach cancer carcinogenesis. It is therefore recommended that H.pylori infection status is determined in future studies and that possible interaction with dietary and other factors is evaluated. In addition, genotypic variation in H.pylori strain is a source of heterogeneity which may explain the diversity in outcome in H.pylori infection and remains to be determined.

\section{REFERENCES}

1. Ikeda M, Yoshimoto K, Yoshimura T, Kono S, Kato H, Kuratsune M. A cohort study on the possible association between broiled fish intake and cancer. Gann 1983;74:640-8.

2. Hirayama T. Life-style and mortality. A large-scale census-based Cohort Study in Japan. Karger, Basel: 1990.

3. Chyou PH, Nomura AM, Hankin JH, Stemmermann GN. A case-cohort study of diet and stomach cancer. Cancer Res 1990;50:7501-4.

4. Nomura A, Grove JS, Stemmermann GN, Severson RK. A prospective study of stomach cancer and its relation to diet, cigarettes, and alcohol consumption. Cancer Res 1990;50:627-31.

5. Kneller RW, McLaughlin JK, Bjelke E, et al. A cohort study of stomach cancer in a high-risk American population. Cancer 1991;68:672-8.

6. Zheng W, Sellers TA, Doyle TJ, Kushi LH, Potter JD, Folsom AR. Retinol, antioxidant vitamins, and cancers of the upper digestive tract in a prospective cohort study of postmenopausal women. Am J Epidemiol 1995;142:955-60.

7. Kato I, Tominaga S, Matsumoto K. A prospective study of stomach cancer among a rural Japanese population: a 6-year survey. Jpn J Cancer Res 1992;83:568-75.

8. Galanis DJ, Kolonel LN, Lee J, Nomura A. Intakes of selected foods and beverages and the incidence of gastric cancer among the Japanese residents of Hawaii: a prospective study. Int J Epidemiol 1998;27:173-80.

9. Terry P, Nyren $O$, Yuen J. Protective effect of fruits and vegetables on stomach cancer in a cohort of Swedish twins. Int J Cancer 1998;76:35-7.

10. Stahelin HB, Rosel F, Buess E, Brubacher G. Cancer, vitamins, and plasma lipids: prospective Basel study. J Natl Cancer Inst 1984;73:1463-8.

11. Nomura AM, Stemmermann GN, Heilbrun LK, Salkeld RM, Vuilleumier JP. Serum vitamin levels and the risk of cancer of specific sites in men of Japanese ancestry in Hawaii. Cancer Res 1985;45:2369-72.

12. Knekt P, Aromaa A, Maatela J, et al. Serum vitamin E and risk of cancer among Finnish men during a 10year follow-up. Am J Epidemiol 1988;127:28-41.

13. Doll R. The lessons of life: keynote address to the nutrition and cancer conference. Cancer Res 1992;52(7 Suppl):2024s-2029s.

14. Doll R. Nature and nurture: possibilities for cancer control. Carcinogenesis 1996;17:177-84. 
15. Devita VT, Hellman S, Rosenberg SA. Principles \& Practice of Oncology. Philadelphia: J.B. Lippincott Company, 1989.

16. Fuchs CS, Mayer RJ. Gastric carcinoma. N Engl J Med 1995;333:32-41.

17. Griffioen G. Vroeg carcinoom van de maag. Ned Tijdschr Geneeskd1982;126:1862-5.

18. Bernstein IL. Aversion conditioning in response to cancer and cancer treatment. Clinical Psychology Review 1991;11:185-191.

19. Boakes RA, Tarrier N, Barnes BW, Tattersall MH. Prevalence of anticipatory nausea and other side-effects in cancer patients receiving chemotherapy. Eur J Cancer 1993;29a:866-70.

20. Jensen OM, Wahrendorf J, Rosenqvist A, Geser A. The reliability of questionnaire-derived historical dietary information and temporal stability of food habits in individuals. Am J Epidemiol 1984;120:281-90.

21. Thompson FE, Lamphiear DE, Metzner HL, Hawthome VM, Oh MS. Reproducibility of reports of frequency of food use in the Tecumseh Diet Methodology Study. Am J Epidemiol 1987;125:658-71. Wu ML, Whittemore AS, Jung DL. Errors in reported dietary intakes. II. Long-term recall. Am J Epidemiol 1988;128:1137-45.

23. Botterweck AAM, van den Brandt PA, Goldbohm RA. A prospective cohort study on vegetable and fruit consumption and stomach cancer risk in the Netherlands. Am J Epidemiol 1998;148:842-853.

24. Kato I, Tominaga S, Ito Y, et al. A prospective study of atrophic gastritis and stomach cancer risk. Jpn J Cancer Res 1992;83:1137-42.

25. Correa P. Human gastric carcinogenesis: a multistep and multifactorial process--First American Cancer Society Award Lecture on Cancer Epidemiology and Prevention. Cancer Res 1992;52:6735-40.

26. Singh VN, Gaby SK. Premalignant lesions: role of antioxidant vitamins and beta-carotene in risk reduction and prevention of malignant transformation. Am J Clin Nutr 1991;53(1 Suppl):386s-390s.

27. Mirvish SS. The etiology of gastric cancer. Intragastric nitrosamide formation and other theories. J Natl Cancer Inst 1983;71:629-47.

28. White E, Hunt JR, Casso D. Exposure measurement in cohort studies: the challenges of prospective data collection. Epidemiol Rev 1998;20:43-56.

29. Correa P, Haenszel W, Cuello C, Tannenbaum S, Archer M. A model for gastric cancer epidemiology. Lancet 1975;2:58-60.

30. Howson CP, Hiyama T, Wynder EL. The decline in gastric cancer: epidemiology of an unplanned triumph. Epidemiol Rev 1986;8:1-27.

31. Goldbohm RA, van 't Veer P, van den Brandt PA, et al. Reproducibility of a food frequency questionnaire and stability of dietary habits determined from five annually repeated measurements. Eur $\mathrm{J}$ Clin Nutr 1995;49:420-9.

32. Wang HH, Antonioli DA, Goldman H. Comparative features of esophageal and gastric adenocarcinomas: recent changes in type and frequency. Hum Pathol 1986;17:482-7.

33. MacDonald WC, MacDonald JB. Adenocarcinoma of the esophagus and/or gastric cardia. Cancer 1987;60:1094-8.

34. Organization WH. International Classification of Diseases for Oncology. Geneva, Switzerland: World Health Organization, 1976.

35. Kabat GC, Ng SK, Wynder EL. Tobacco, alcohol intake, and diet in relation to adenocarcinoma of the esophagus and gastric cardia. Cancer Causes Control 1993;4:123-32.

36. Palli D, Bianchi S, Decarli A, et al. A case-control study of cancers of the gastric cardia in Italy. $\mathrm{Br} \mathrm{J}$ Cancer 1992;65:263-6.

37. Wu-Williams AH, Yu MC, Mack TM. Life-style, workplace, and stomach cancer by subsite in young men of Los Angeles County. Cancer Res 1990;50:2569-76.

38. Inoue $M$, Tajima $\mathrm{K}$, Hirose $\mathrm{K}$, Kuroishi $\mathrm{T}$, Gao $\mathrm{CM}$, Kitoh $\mathrm{T}$. Life-style and subsite of gastric cancer--joint effect of smoking and drinking habits. Int J Cancer 1994;56:494-9.

39. Blot WJ, Devesa SS, Kneller RW, Fraumeni JF, Jr. Rising incidence of adenocarcinoma of the esophagus and gastric cardia. Jama 1991;265:1287-9.

40. Kim R, Weissfeld JL, Reynolds JC, Kuller LH. Etiology of Barrett's metaplasia and esophageal adenocarcinoma. Cancer Epidemiol Biomarkers Prev 1997;6:369-77.

41. Vaughan TL, Davis S, Kristal A, Thomas DB. Obesity, alcohol, and tobacco as risk factors for cancers of the esophagus and gastric cardia: adenocarcinoma versus squamous cell carcinoma. Cancer Epidemiol Biomarkers Prev 1995;4:85-92. 
42. Brown LM, Swanson CA, Gridley G, et al. Adenocarcinoma of the esophagus: role of obesity and diet. J Natl Cancer Inst 1995;87:104-9.

43. Lauren P. The two histological main types of gastric carcinoma: diffuse and so-called intestinal-type carcinoma. Acta Path Microbiol Scandinav 1965;64:31-49.

44. Haenszel W, Kurihara M, Segi M, Lee RK. Stomach cancer among Japanese in Hawaii. J Natl Cancer Inst 1972;49:969-88.

45. Haenszel W, Kurihara M, Locke FB, Shimuzu K, Segi M. Stomach cancer in Japan. J Natl Cancer Inst 1976;56:265-74.

46. Kato I, Tominaga S, Ito Y, et al. A comparative case-control analysis of stomach cancer and atrophic gastritis. Cancer Res 1990;50:6559-64.

47. Boeing $H$, Jedrychowski W, Wahrendorf J, Popiela $T$, Tobiasz AB, Kulig A. Dietary risk factors in intestinal and diffuse types of stomach cancer: a multicenter case-control study in Poland. Cancer Causes Control 1991;2:227-33.

48. Buiatti E, Palli D, Bianchi S, et al. A case-control study of gastric cancer and diet in Italy. III. Risk patterns by histologic type. Int J Cancer 1991;48:369-74.

49. Harrison LE, Zhang ZF, Karpeh MS, Sun M, Kurtz RC. The role of dietary factors in the intestinal and diffuse histologic subtypes of gastric adenocarcinoma: a case-control study in the U.S. Cancer 1997;80:1021-8.

50. Munoz N. Is Helicobacter pylori a cause of gastric cancer? An appraisal of the seroepidemiological evidence. Cancer Epidemiol Biomarkers Prev 1994;3:445-51.

51. Eslick GD, Lim LL, Byles JE, Xia HH, Talley NJ. Association of Helicobacter pylori infection with gastric carcinoma: a meta-analysis. Am J Gastroenterol 1999;94:2373-9.

52. Danesh J. Helicobacter pylori infection and gastric cancer: systematic review of the epidemiological studies. Aliment Pharmacol Ther 1999;13:851-6.

53. Forman D, Newell DG, Fullerton F, et al. Association between infection with Helicobacter pylori and risk of gastric cancer: evidence from a prospective investigation. Bmj 1991;302:1302-5.

54. Parsonnet J, Friedman GD, Vandersteen DP, et al. Helicobacter pylori infection and the risk of gastric carcinoma. N Engl J Med 1991;325:1127-31.

55. Veldhuyzen vZSJ, Sherman PM. Helicobacter pylori infection as a cause of gastritis, duodenal ulcer, gastric cancer and nonulcer dyspepsia: a systematic overview. Can Med Assoc J 1994;150:177-85.

56. Kuipers EJ. Review article: exploring the link between Helicobacter pylori and gastric cancer. Aliment Pharmacol Ther 1999;13 Suppl 1:3-11.

57. Zhang HM, Wakisaka N, Maeda O, Yamamoto T. Vitamin $C$ inhibits the growth of a bacterial risk factor for gastric carcinoma: Helicobacter pylori. Cancer 1997;80:1897-903.

58. De Koster E, Buset M, Fernandes E, Deltenre M. Helicobacter pylori: the link with gastric cancer. Eur J Cancer Prev 1994;3:247-57.

59. Warren JR, Marshall B. Unidentified curved bacilli on gastric epithelium in active chronic gastritis. Lancet $1983 ; 1: 1273-5$. 
Chapter 8 


\section{Summary}

In this thesis the association between dietary factors and the risk of stomach cancer is investigated in a large-scale prospective cohort study: the Netherlands Cohort Study (NLCS). The NLCS was started in 1986 among 120,852 people aged 55-69 years. At the start of the study baseline information was collected on usual consumption of foods and beverages, smoking habits, education, occupation, family history of cancer and medical history with a questionnaire. Cancer incidence in the cohort has been measured by record linkage with all Dutch regional cancer registries and a national pathology register (PALGA). A case-cohort approach was chosen; the cases were enumerated for the entire cohort, while the person-years at risk accumulated in the cohort were estimated from a randomly selected subcohort. The subcohort consisted of 3500 people (1688 men and 1812 women). Analyses in this thesis are based on stomach carcinoma cases diagnosed in the first 6.3 years of follow-up. People with prevalent cancer (other than skin cancer) and people with incomplete or inconsistent dietary data were excluded, leaving 282 stomach cancer cases ( 219 men, 63 women) and 3123 subcohort members (1525 men, 1598 women) for the analyses.

In Chapter 1, an extensive overview of the literature is given on characteristics of stomach cancer (worldwide variation in incidence rates, time-trends in incidence, classification of stomach tumors) and major risk factors of stomach cancer. Stomach cancer is the second most frequent cancer in the world (after lung cancer), with an estimated 798,300 new cases per year (data from 1990). The fast decline in incidence rates of stomach cancer over the past decades and the large differences between countries suggest that environmental factors, especially nutritional factors, are etiologically important. Factors that have been suggested to increase risk include salt, nitrate, nitrite, smoked meat and fish, alcohol, infection with Helicobacter pylori and smoking. Vegetables, fruit, vitamins $\mathrm{C}, \mathrm{A}$ and $\mathrm{E}$ and refrigerator use have been suggested to decrease stomach cancer risk. These factors are briefly decribed in this chapter on the basis of results of two types of epidemiological studies (case-control and cohort studies.)

The results of the analyses from the NLCS regarding the various dietary factors and the association with stomach cancer risk are described in chapters two to six.

We found a weak inverse association between stomach cancer risk and consumption of fruit and vegetables combined, total vegetable consumption, prepared vegetables, pulses, citrus fruit and apples and pears (Chapter 2). For total fruit consumption, raw vegetables, Brassicas, raw and prepared leafy vegetables no protective effect was observed. We looked more closely at the total vegetable or fruit consumption of cases diagnosed in the first or second year of follow-up, because these cases might have changed their dietary intake due to preclinical symptoms of stomach cancer. We found that cases diagnosed in the first or second year of follow-up consumed significantly less vegetables than cases diagnosed in the third to seventh year of follow-up. For fruit, we found no differences in consumption between the 'early' and 'late' diagnosed cases. When we included only cases diagnosed in the first two years of follow-up in the analyses, we found a strong inverse association between vegetable consumption and stomach cancer risk, but not for fruit consumption. With these analyses we imitated 
the typical case-control study, obtaining information about food habits of stomach cancer patients (less than) a year before the time of diagnosis of stomach cancer. We concluded that results of case-control studies might be biased by the changed dietary habits of the stomach cancer patients. This was the reason to repeat all analyses in this thesis with exclusion of first and second year cases.

In Chapter 3, for the intake of folate, vitamin E, alpha-carotene, lutein + zeaxanthin, beta-cryptoxanthin, lycopene and dietary fiber, no association with stomach cancer risk was observed. Only for vitamin $\mathrm{C}$ a weak inverse association with stomach cancer risk was found. After exclusion of first and second year cases: the association became weaker. Intake of retinol and beta-carotene was positively associated with stomach cancer risk. Users of vitamin A containing supplements had a significantly lower stomach cancer risk than non-users.

Nitrate is found in leafy vegetables, potatoes and drinking water. Both nitrate and nitrite are used as food additives in cheese and cured meat. Metabolites of nitrate and nitrite are known carcinogens. In this study, we did not find a higher risk for stomach cancer for persons with a higher nitrate intake from foods or drinking water or a higher intake of nitrite (Chapter 4).

In Chapter 5 several methods of food preservation (salting, curing and use of a refrigerator) were investigated in relation to stomach cancer. Our study did not support the positive association between salt intake and stomach cancer risk found in many case-control studies. High intake of bacon and other types of other sliced cold meat was associated with an increased stomach cancer risk. There was no association between use of refrigerator or freezer and stomach cancer risk.

Butylated Hydroxyanisole (BHA) and Butylated Hydroxytoluene (BHT) are synthetic antioxidants applied in fat and fatty foods to prevent oxidative deterioration. Small amounts of BHA and BHT are used in many foods. So far, evidence concerning anticarcinogenic or carcinognic properties came from animal experiments. A slight but not significant decrease in stomach cancer risk with increasing intake of BHA and BHT was found in our study (Chapter 6). We concluded that no significant association with stomach cancer risk was found for the intake of small amounts of BHA and BHT.

In Chapter 7, time-trends in age-standardized incidence rates of adenocarcinomas of the esophagus and gastric cardia were described in 11 cancer registries from 10 countries in North-, South-, East-, Westand Central-Europe over the period 1968-1995. The data were from the Eurocim database, a database with incidence and mortality data from 95 European cancer registries. An increase in incidence of adenocarcinomas of the esophagus and gastric cardia was observed in Northern Europe (Denmark), Southern Europe (Italy,Varese), Eastern Europe (Slovakia), Western Europe (England and Wales, Scotland). In Central-Europe (Switzerland, Basel) and in the cancer registries of Iceland (Northern Europe), France, Bas-Rhin and Calvados, Southern Ireland, and the Netherlands, Eindhoven (Western Europe) no rise in incidence was observed. The rising incidence of adenocarcinomas of the esophagus and gastric cardia was accompanied by a falling incidence of both adenocarcinomas and non- 
adenocarcinomas of the non-cardia part of the stomach in nearly all cancer registries studied. Increased histological verification of tumors of the esophagus and stomach, improved precision of histological diagnosis, improved diagnostic procedures (e.g. endoscopy) may partly explain the increase in incidence of adenocarcinomas of the esophagus and gastric cardia in some registries.

In Chapter 8, the results of our study are discussed in relation to the results of other cohort and casecontrol studies on dietary factors and stomach cancer. Our results were partly in line with other cohort studies. Variable quality of the cohort studies in terms of measurement of dietary intake, control for confounding factors and the number of case studied made comparison of results difficult, however. Our results were not in line with results of case-control studies. Generally, associations found in case-control studies were stronger than those found in our study. A possible explanation is that some stomach cancer patients changed their food habits as a consequence of preclinical symptoms of stomach cancer months or years before diagnosis of stomach cancer. In case-control studies, information on food habits is obtained after the diagnosis of stomach cancer is made and usually refers to one year before diagnosis or the period before the onset of symptoms. In this period they may already have changed their dietary habits and report a changed food intake. This may have resulted in biased odds ratio estimates. Other explanations for not finding strong associations between dietary factors and stomach cancer in our study are that the measurement of dietary intake does not refer to the etiologically relevant time period, and that stomach cancer is not a single disease entity, that is; the effects of dietary factors may vary for different subtypes of stomach cancer. In this chapter, attention is paid to the bacterium Helicobacter pylori which is proposed to be an important risk factor of stomach cancer. Finally suggestions for future research are made. 


\section{Samenvatting}

In dit proefschrift is de samenhang tussen voedingsfactoren en het risico op maagkanker onderzocht in een grootschalige prospectieve cohortstudie: de Nederlandse Cohort Studie (NLCS). De NLCS is in 1986 gestart onder 120.852 mensen van 55-69 jaar. Bij de start van de studie werd via een vragenlijst informatie verzameld over de gewoonlijke voedselconsumptie, rookgewoonten, opleiding, beroep en het voorkomen van kanker in de familie. De incidentie van kanker in het cohort wordt gemeten door middel van een koppeling met alle Nederlandse regionale kankerregistraties en met het Pathologisch Anatomisch Landelijk Geautomatiseerd Archief (PALGA).

Er is gekozen voor een case-cohort benadering; de patiënten (cases) komen uit het gehele cohort terwijl de persoonsjaren 'at risk' opgebouwd in dit cohort geschat worden aan de hand van gegevens van een aselect getrokken subcohort. Het subcohort bestaat uit 3500 mensen (1688 mannen en 1812 vrouwen). De in dit proefschrift gepresenteerde resultaten zijn gebaseerd op maagkanker cases die in de eerste 6,3 jaren van de follow-up gediagnostiseerd werden. Mensen die al kanker hadden (anders dan huidkanker) bij de start van het onderzoek en waarvan de vragenlijstinformatie incompleet of inconsistent was, werden uitgesloten, waardoor 282 maagkanker cases (219 mannen, 63 vrouwen) en 3123 subcohortleden (1525 mannen, 1598 vrouwen) overbleven voor de analyses.

In hoofdstuk 1 wordt een uitgebreid literatuuroverzicht gegeven over de kenmerken van maagkanker (wereldwijde variatie in incidentie, tijdtrends in incidentie, klassificatie van maagtumoren) en de belangrijkste risicofactoren van maagkanker. Maagkanker is na longkanker de meest voorkomende vorm van kanker in de wereld, met een geschat aantal van 798.300 nieuwe patiënten per jaar (gegevens van 1990). De snelle daling van de incidentie in de afgelopen decennia en de grote verschillen in incidentie tussen landen suggereren dat omgevingsfactoren, en met name voedingsfactoren een belangrijke rol spelen in de etiologie van maagkanker. Factoren die het risico op maagkanker lijken te verhogen zijn zout, nitraat, nitriet, gerookt vlees en vis, alcohol, infectie met Helicobacter pylori en roken. Groenten, fruit, vitamine $\mathrm{A}, \mathrm{C}$ en $\mathrm{E}$ en gebruik van een koelkast hebben mogelijk een beschermende werking. Deze factoren worden kort besproken aan de hand van resultaten van twee belangrijkste typen epidemiologische studies (patiënt-controle en cohort studies).

De resultaten van de analyses van de NLCS worden beschreven in de hoofdstukken twee tot en met zes. We vonden een zwak invers verband tussen de consumptie van fruit en groenten samen, totale groentenconsumptie, gekookte groer:ten, peulgroenten, citrus fruit en appels en peren en het risico op maagkanker (hoofdstuk 2). Geen beschermend effect is gevonden voor totale fruitconsumptie, rauwe groenten, koolsoorten, rauwe en gekookte bladgroenten. We hebben nauwkeuriger gekeken naar de consumptie van groenten en fruit van de cases die in het eerste of tweede jaar van follow-up gediagnostiseerd werden, omdat voedingsgewoonten van deze cases mogelijk veranderd zijn door de eerste symptomen van maagkanker. De cases die in het eerste of tweede jaar van follow-up gediagnostiseerd werden aten significant minder groenten dan de cases die gediagnostiseerd werden in het derde tot en met het zevende jaar van follow-up. We vonden geen verschil in fruitconsumptie 
tussen de 'vroege' en 'late' cases. Als we alleen keken naar de cases die in het eerste of tweede jaar van follow-up gediagnostiseerd werden, vonden we een beschermend effect van groentenconsumptie en het risico op maagkanker, maar geen effect voor fruit. Met deze analyses imiteerden we het typische patiënt-controle onderzoek, waarin maagkankerpatiënten informatie geven over hun voedingsgewoonten (minder dan) een jaar voordat de diagnose gesteld wordt. We concluderen dat de resultaten van patiënt-controle onderzoeken mogelijk vertekend zijn door veranderingen in de voedingsgewoonten van maagkankerpatiënten. Dit was de reden om alle analyses in dit proefschrift te herhalen met uitsluiting van de eerste- en tweedejaars cases.

In hoofdstuk 3 werd geen verband gevonden tussen de inneming van foliumzuur, vitamine $\mathrm{E}$, carotenoïden (alpha-caroteen, luteïne + zeaxanthine, beta-cryptoxanthine en lycopeen) en voedingsvezel en het risico op maagkanker. Alleen voor vitamine $\mathrm{C}$ werd een zwak beschermend effect gevonden. $\mathrm{Na}$ uitsluiting van de eerste- en tweedejaars cases werd het verband nog zwakker. De inneming van retinol en beta-caroteen was positief geassocieerd met het maagkankerrisico. Gebruikers van supplementen met vitamine $A$ hadden een significant verlaagd maagkankerrisico ten opzichte van niet-gebruikers.

Nitraat komt voor in bladgroenten, aardappelen en drinkwater. Zowel nitraat als nitriet worden gebruikt als additieven in kaas en vleeswaren. Metabolieten van nitraat en nitriet zijn bekende carcinogenen. In onze studie vonden we echter geen verhoogd maagkankerrisicio voor die personen met een hogere inneming van nitraat uit voedsel of drinkwater of nitriet (hoofdstuk 4).

In hoofdstuk 5 worden verschillende methoden van voedselconservering (zouten, verduurzamen van vlees en vleeswaren en het gebruik van de koelkast) onderzocht op hun samenhang met maagkanker. Onze studie kon geen positieve associatie aantonen tussen de zoutinneming en maagkankerrisico zoals gevonden werd in veel patiënt-controle studies. Een hoge consumptie van bacon en andere soorten vleeswaren was geassocieerd met een verhoogd maagkankerrisico. Er was geen associatie tussen gebruik van een koelkast of diepvries en het maagkankerrisico.

Butylhydroxyanisol (BHA) en butylhydroxytolueen (BHT) zijn synthetische antioxidanten die worden toegevoegd aan voedingsvetten en vetbevattende voedingsmiddelen in kleine hoeveelheden om bederf te voorkomen. Tot nu toe was bewijs over anticarcinogene of carcinogene werking van BHA en BHT afkomstig uit dierexperimenteel onderzoek. Er was een kleine, niet-significante verlaging van het maagkankerrisico met een toenemende inneming van BHA of BHT in onze studie (hoofdstuk 6). We concludeerden dat er geen significante associatie was tussen het maagkankerrisico en de inneming van kleine hoeveelheden BHA en BHT.

In hoofdstuk 7 worden de tijdstrend beschreven van de leeftijd-gestandaardiseerde incidentiecijfers van adenocarcinomen van de slokdarm en cardia van de maag van 11 kankerregistraties uit 10 landen uit Noord-, Zuid-, Oost-, West- en Centraal-Europa in de periode 1968-1995. De gegevens waren afkomstig van de Eurocim database, een database met incidentie- en mortaliteitscijfers van 95 Europese 
kankerregistraties. De incidentie van adenocarcinomen van de slokdarm en de cardia van de maag nam toe in Noord-Europa (Denemarken), Zuid-Europa (Italië, Varese), Oost-Europa (Slowakije), WestEuropa (Engeland en Wales, Schotland). In Centraal-Europa (Zwitserland, Basel) en in de kankerregistraties van IJsland (Noord-Europa), Frankrijk, Bas-Rhin en Calvados, Zuid-Ierland, en Nederland, Eindhoven (West-Europa) werd geen stijging gevonden. De stijgende incidentie van de adenocarcinomen van de slokdarm en cardia van de maag ging samen met een dalende incidentie van zowel adenocarcinomen als niet-adenocarcinomen van het distale (niet-cardia) deel van de maag in bijna alle bestudeerde kankerregistraties. Toegenomen histologische verificatie van tumoren van de slokdarm en de maag, verbeterde precisie van histologische diagnose en verbeterde diagnostische procedures (bijvoorbeeld endoscopie) kunnen de toename in de incidentie van adenocarcinomen van de slokdarm en de cardia van de maag verklaren in sommige kankerregistraties.

In hoofdstuk 8 worden de resultaten van onze studie besproken in het licht van resultaten van andere cohort en patiënt-controle studies op het gebied van voeding en maagkanker. Onze resultaten komen ten dele overeen met die van andere cohortstudies. Variabele kwaliteit van de cohortstudies met betrekking tot de meting van de voedselconsumptie, de controle voor confounders en het aantal bestudeerde cases bemoeilijkte de vergelijking. Onze resultaten verschilden met de resultaten van patiënt-controle studies. In het algemeen zijn in patiënt-controle studies sterkere verbanden gevonden dan in onze studie. Een mogelijke verklaring hiervoor is dat sommige maagkankerpatiënten hun voedingsgewoonten veranderen als gevolg van preklinische verschijnselen van maagkanker maanden of jaren voordat de diagnose maagkanker gesteld wordt. In patiënt-controle studies wordt de informatie over voedingsgewoonten verzameld nadat de diagnose van maagkanker is gesteld. Deze informatie gaat gewoonlijk over de periode een jaar vóór de diagnose of naar de periode vóór het begin van klachten. Patiënten kunnen voedingsgewoonten op dat moment al veranderd hebben en een veranderde voedselconsumptie rapporteren. Dit kan geresulteerd hebben in vertekende odds ratio's. Andere verklaringen voor het niet vinden van sterke associaties tussen voedingsfactoren en maagkanker in onze studie zijn dat mogelijk de meting van de voedselconsumptie niet slaat op de etiologisch relevante tijdsperiode, en dat maagkanker wellicht niet één ziekte is, maar bestaat uit een aantal subtypen met elk hun eigen risicofactoren. In dit hoofdstuk is ook aandacht besteed aan de bacterie Helicobacter pylori die wordt gezien als een belangrijke risicofactor voor maagkanker. Als afsluiting worden suggesties gegeven voor toekomstig onderzoek. 


\section{Dankwoord}

Het dankwoord schrijven. Beginnen met een leeg vel. Meteen schieten allerlei gedachten door mijn hoofd en ik begin te schrijven. De gedachten gaan sneller dan ik kan schrijven (of typen). Later maak ik de halve zinnen wel af en verander de volgorde van de alinea's. Hier en daar voeg ik nog gedachten bij.

Misschien ongebruikelijk, maar om niet te eindigen met de verschrikkelijke woorden "last but not least", noem ik Piet(ie) het eerste van een hele reeks mensen die op een of andere manier inhoudelijk of niet direct inhoudelijk, steunend, sturend enz. aanwezig waren in de tijd dat ik aan mijn proefschrift heb gewerkt.

Piet, heel wat avonden hebben we tegenover elkaar gezeten aan tafel, jij met jouw artikelen en ik met de mijne. Gezellig!?, maar misschien heeft het bijgedragen aan enige discipline om onze proefschriften te voltooien. Tegenover elkaar aan tafel zitten doen we allang niet meer, simpelweg omdat ik de tafel in beslag heb genomen met stapels proefschriftpapieren.

"Dreutel" Iris. Je wist mij gelukkig heel goed te claimen voor je activiteiten. "Mama nou leesse", en met een handzwaai vlogen mijn papieren op de grond waarna meteen met de andere hand een leesboekje op schoot belandde.

Een heleboel vrienden hebben voor de nodige tussentijdse ontspanning gezorgd en mijn 'gezeur' over het nooit afkomende proefschrift aangehoord: Sandra van Eck, Antoine Zorenc, Miranda Dik, Lidewij Henneman, Chris Wissels, Sharmila Rambaran, Maurice Zijlstra. Miranda en Lidewij, jullie heb ik niet kunnen behoeden om AIO te worden. Gelukkig maar, want betere paranimfen met het juiste invoelende vermogen kan ik me niet voorstellen.

Sandra en Piet, als mijn begeleiders hebben jullie mij (bijge)gestuurd, beoordeeld en commentaar geleverd op mijn stukken. Verder hebben jullie gediscussieerd met mij over voeding, maagkanker en epidemiologie, maar ook over de ömdoorgrondelijke wetenschapswereld, over wie er thuis kookt en over bestuurlijke perikelen in de tennisclub. Met andere woorden, in de loop van de vijf jaar dat ik aan het projekt gewerkt heb zijn er heel wat meer zaken ter tafel gekomen dan 'hoe schrijf ik een artikel'. Bedankt voor een heleboel positieve ervaringen.

Alle NLCS-collega's en ex-NLCS-ers Henny Brants, Mirian Brink, Carin de Brouwer, Sacha van den Crommert, Willy van Dijk, Miranda Dirx, Elisabeth Dorant, Patricia Florax, Anne-marie Korsten, Jeanne van Loon, Cobie Martens, Ton van Moergastel, Marijke Moll, Harry van Monfort, Jolanda Nelissen, Agnes Schuurman, Dorette Verhoeven, Laura Voorrips, Matty Weijenberg, Maurice Zeegers, Conny de Zwart horen thuis in het dankwoord. Allerlei cohort- en andere belangrijke levensvragen werden besproken in de wandelgangen, op de kamer, op kraamvisite, per e-mail, telefoon, tussen de apen in het tropisch regenwoud en aan de restauranttafel. Het was heel plezierig om bij 'het cohort' te 
horen.

Daarnaast hoorde ik ook bij Epidemiologie, en hoewel de NLCS-verjaardagsfeestjes altijd met een scheef oog bekeken werden door de niet-cohortmedewerkers hoefde ik niet te klagen aan tekort aan belangstelling. Zij die van tijd tot tijd peilden "hoe het ging" wil ik hier noemen en met name Sandra Beurskens, Christel van Gool, Nicole Jansen, Mariëlle Kroese, Daniëlle Mohren, Ute Bültmann, Rik Bogers, Erik van Rossum, Fons Kessels en Gerben ter Riet.

Ria verdient een aparte paragraaf. Ria, die eindeloos alle hoofdstukken verbeterde, al mijn verschrikkelijke tabellen in het gareel kreeg en steeds weer nieuwe inconsistenties ontdekte in mijn voorgestelde lay-out. Bedankt!

De Epiladies Agnes Schuurman, Monique de Kok, Cecile Ronckers, Peggy van den Hoogen, Loes van Herten en Helen Klip zijn onlosmakelijk verbonden met dit proefschrift. De epiladies (in het begin als studiegenoten en later als epidemiologie-collega's) zijn inmiddels een begrip geworden. Het was en is heel plezierig met "lotgenoten" werk-, loopbaan-ervaringen en nog veel meer dan dat uit te wisselen. Er komen nog heel wat epiladie-promoties.

Agnes wil ik graag apart noemen als 'eeuwige kamergenoot' gedurende mijn AIO-periode. Wij hebben heel wat uren samen doorgebracht, ups and downs gekend, discussies gevoerd en altijd kwamen we uit bij het artikel dat maar niet af leek te komen. Bedankt voor jouw interesse en hulpvaardigheid. 


\section{About the author}

Anita Aldegonda Mathea Botterweck was born on September 15, 1966 in Heerlen, the Netherlands. In 1984 she completed secondary school (Atheneum- $\beta$ ) at the Bernardinus College in Heerlen. From 1984 to 1988 she studied Nutrition and Dietetics at the Wachtendonck in Heerlen. After graduating she worked for almost two years as a dietician at the University Hospital in Groningen. In 1990 she started to study Biological Health Sciences with a major in Epidemiology at the Maastricht University. She graduated in September 1994. In the same month she started the PhD-project 'risk factors of stomach cancer' at the Department of Epidemiology. She attended the Annual New England Epidemiology Summer Program in Boston, U.S.A. in the summer of 1996.

She is living with Piet Portegijs and their two year old daughter Iris. 